\title{
Assessment of Energy Production Potential from Tidal Streams in the United States
}

\author{
Final Project Report
}

\author{
June 29, 2011
}

Georgia Tech Research Corporation

Award Number: DE-FG36-08G018174 
Project Title: Assessment of Energy Production Potential from Tidal Streams in the United States

Recipient: Georgia Tech Research Corporation

Award Number: DE-FG36-08GO18174

Working Partners:

PI: Dr. Kevin A. Haas - Georgia Tech Savannah, School of Civil and Environmental Engineering, khaas@gatech.edu

Co-PI: Dr. Hermann M. Fritz - Georgia Tech Savannah, School of Civil and

Environmental Engineering, fritz@gatech.edu

Co-PI: Dr. Steven P. French - Georgia Tech Atlanta, Center for Geographic

Information Systems, steven.french@coa.gatech.edu

Co-PI: Dr. Brennan T. Smith - Oak Ridge National Laboratory, Environmental

Sciences Division, smithbt@ornl.gov

Co-PI: Dr. Vincent Neary - Oak Ridge National Laboratory, Environmental Sciences

Division, nearyvs@ornl.gov

\section{Acknowledgments:}

Georgia Tech's contributions to this report were funded by the Wind \& Water Power Program, Office of Energy Efficiency and Renewable Energy of the U.S. Department of Energy under Contract No. DE- FG36-08GO18174. The authors are solely responsible for any omissions or errors contained herein.

This report was prepared as an account of work sponsored by an agency of the United States government. Neither the United States government nor any agency thereof, nor any of their employees, makes any warranty, express or implied, or assumes any legal liability or responsibility for the accuracy, completeness, or usefulness of any information, apparatus, product, or process disclosed, or represents that its use would not infringe privately owned rights. Reference herein to any specific commercial product, process, or service by trade name, trademark, manufacturer, or otherwise does not necessarily constitute or imply its endorsement, recommendation, or favoring by the United States government or any agency thereof. The views and opinions of authors expressed herein do not necessarily state or reflect those of the United States government or any agency thereof. 


\section{Executive Summary}

Tidal stream energy is one of the alternative energy sources that are renewable and clean. With the constantly increasing effort in promoting alternative energy, tidal streams have become one of the more promising energy sources due to their continuous, predictable and spatially-concentrated characteristics. However, the present lack of a full spatial-temporal assessment of tidal currents for the U.S. coastline down to the scale of individual devices is a barrier to the comprehensive development of tidal current energy technology. This project created a national database of tidal stream energy potential, as well as a GIS tool usable by industry in order to accelerate the market for tidal energy conversion technology.

Tidal currents are numerically modeled with the Regional Ocean Modeling System and calibrated with the available measurements of tidal current speed and water level surface. The performance of the model in predicting the tidal currents and water levels is assessed with an independent validation. The geodatabase is published at a public domain via a spatial database engine and interactive tools to select, query and download the data are provided. Regions with the maximum of the average kinetic power density larger than $500 \mathrm{~W} / \mathrm{m}^{2}$ (corresponding to a current speed of $\sim 1 \mathrm{~m} / \mathrm{s}$ ), surface area larger than $0.5 \mathrm{~km}^{2}$ and depth larger than $5 \mathrm{~m}$ are defined as hotspots and list of hotspots along the USA coast is documented. The results of the regional assessment show that the state of Alaska (AK) contains the largest number of locations with considerably high kinetic power density, and is followed by, Maine (ME), Washington (WA), Oregon (OR), California (CA), New Hampshire (NH), Massachusetts (MA), New York (NY), New Jersey (NJ), North and South Carolina (NC, SC), Georgia (GA), and Florida (FL). The average tidal stream power density at some of these locations can be larger than 8 $\mathrm{kW} / \mathrm{m}^{2}$ with surface areas on the order of few hundred kilometers squared, and depths larger than 100 meters. The Cook Inlet in AK is found to have a substantially large tidal stream power density sustained over a very large area. 


\section{Background}

Tidal streams are high velocity sea currents created by periodic horizontal movement of the tides, often magnified by local topographical features such as headlands, inlets to inland lagoons, and straits. As tides ebb and flow, currents are often generated in coastal waters. In many places the shape of the seabed forces water to flow through narrow channels, or around headlands. Tidal stream energy extraction is derived from the kinetic energy of the moving flow; analogous to the way a wind turbine operates in air, and as such differs from tidal barrages, which create a head of water for energy extraction. A tidal stream energy converter extracts and converts the mechanical energy in the current into a transmittable energy form. A variety of conversion devices are currently being proposed or are under active development, from a water turbine similar to a scaled wind turbine, driving a generator via a gearbox, to an oscillating hydrofoil which drives a hydraulic motor.

Tidal energy is one of the fastest growing emerging technologies in the renewable sector and is set to make a major contribution to carbon free energy generation.. The key advantage of tidal streams is the deterministic and precise energy production forecast governed by astronomy. In addition, the predictable slack water facilitates deployment and maintenance. In 2005, EPRI was first to study representative sites (Knik Arm, AK; Tacoma Narrows, WA; Golden Gate, CA; Muskeget Channel, MA; Western Passage, ME) without mapping the resources (EPRI, 2006g). Additional favorable sites exist in Puget Sound, New York, Connecticut, Cook Inlet, Southeast Alaska, and the Aleutian Islands among others. Besides large scale power production, tidal streams may serve as local and reliable energy sources for remote and dispersed coastal communities and islands. The extractable resource is not completely known; assuming 15\% level of extraction, EPRI has documented $16 \mathrm{TWh} / \mathrm{yr}$ in Alaska, 0.6 TWh/yr in Puget Sound, and 0.4 TWh/yr in CA, MA, and ME (EPRI 2006b-f). The selection of location for a tidal stream energy converter farm is made upon assessment of a number of criteria:

- Tidal current velocity and flow rate: the direction, speed and volume of water passing through the site in space and time.

- Other site characteristics: bathymetry, water depth, geology of the seabed and environmental impacts will determine the deployment method needed and the cost of installation.

- Electrical grid connection and local cost of electricity: the seafloor cable distance from the proposed site to a grid access point and the cost of competing sources of electricity will also help determine the viability of an installation.

Following the guidelines in the EPRI report for estimating tidal current energy resources (EPRI 2006a), preliminary investigations of the tidal currents can be conducted based on the tidal current predictions provided by NOAA tidal current stations (NOAA, 2008b). There are over 2700 of these stations which are sparsely distributed in inlets, rivers, channels and bays. The gauge stations are concentrated along navigation channels, harbors and rivers but widely absent elsewhere along the coast. As an example, the maximum powers at some of these locations around the Savannah River on the coast of Georgia are shown in Figure 1. The kinetic tidal power per unit area, power density, given in this figure were calculated using the equation 


$$
P_{\text {tide }}=\frac{1}{2} \cdot \rho \cdot V^{3}
$$

where $\rho$ is the density of water and $V$ is the magnitude of the depth averaged maximum velocity.

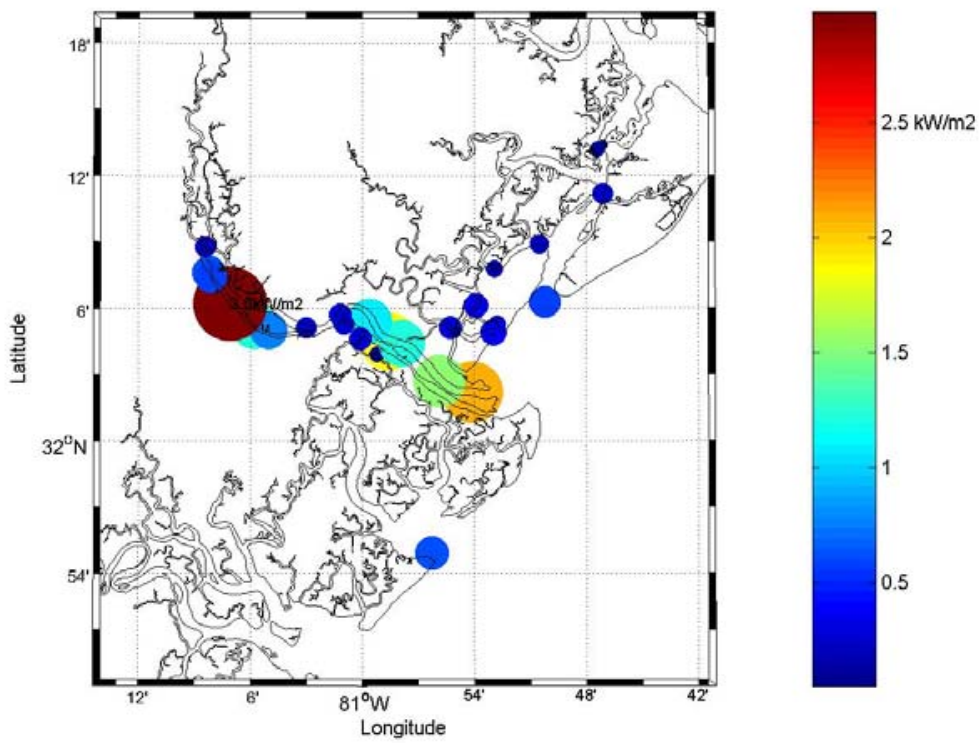

Figure 1. Maximum available power per unit area (power density) based on NOAA tidal current predictions in the vicinity of the Savannah River. The diameters of the circles are proportional to the power density.

These tidal currents and therefore the available power per unit area can have significant spatial variability (Figure 1); therefore, measurements (or predictions) of currents at one location are generally a poor indicator of conditions at another location, even nearby. It is clear that the majority of the data is available along the navigation channel in the Savannah River, with sparse data within the rest of the tidal area. EPRI (2006a) suggest a methodology using continuity and the Bernoulli equation for determining the flow in different sections of a channel. This is a reasonable approach for flow along a geometrically simple channel, but is not applicable for the flow in the complex network of rivers and creeks along much of the US coastline. Thus we have applied a state-ofthe-art numerical model for simulating the tidal flows along the coast of the entire United States.

\section{Project Objectives}

The original project objectives are as follows:

1. Utilize an advanced ocean circulation numerical model (ROMS) to predict tidal currents.

2. Compute the tidal harmonic constituents for the tidal velocities and water levels.

3. Validate the velocities and water levels predicted by the model with available data.

4. Build a GIS database of the tidal constituents.

5. Develop GIS tools for dissemination of the data 
a. A filter based on depth requirements.

b. Compute current velocity histograms based on the tidal constituents.

c. Compute the available power density $\left(\mathrm{W} / \mathrm{m}^{2}\right)$ based on the velocity histograms.

d. Use turbine efficiencies to determine the effective power density.

e. Compute the total available power within arrays based on turbine parameters.

f. Compute the velocity histogram at specified elevations.

6. Develop a web based interface for accessing the GIS database and using the GIS tools

\section{Task 1.0 Application of ROMS for simulation of tidal currents}

The Regional Ocean Modeling System (ROMS) has been configured to simulate the tidal flows along the coast of the United States. More details about the model setup and application can be found in the next section and under the model documentation in the website help menu.

\section{Task 2.0 Compute harmonic constituents}

The model output time series at 1-hr intervals, from which the T_TIDE harmonic analysis toolbox for MATLAB was used to extract the harmonic constituents. The program was run for each grid point, and the constituents extracted included $Q_{1}, O_{1}, K_{1}$, $\mathrm{S}_{2}, \mathrm{M}_{2}, \mathrm{~N}_{2}, \mathrm{~K}_{2}, \mathrm{M}_{4}$ and $\mathrm{M}_{6}$. $\mathrm{K}_{2}$ constituent was not extracted on the West coast and Alaska domains since it was not included in the tidal forcing. Nodal correction was also used by providing the start time of the simulation and the latitude of the location.

\section{Task 3.0 Validate the model output}

ORNL performed a verification of the tidal energy resource database and tools. Comparisons were made with approximately 25 primary NOAA tidal data stations. Selection of tidal stations for verification focused on stations near high-energy sites as indicated by the model results. Multiple statistics and parameters to compare tidal station data to the model database, including tidal constituents (magnitude and phase of harmonics), velocity histograms, and a limited number of tidal elevation and current time series comparisons were used.

\section{Task 4.0 Build GIS database}

The GIS model consists of a database containing results from the tidal model and several computational tools which extract useful information for the user. The database consists of the tidal constituents for the water level, depth-averaged currents, and the MLLW depths at a high resolution (10-500m spacing). These tidal constituents are used to derive velocity, power density and other parameters of interest as requested by the user in near real time.

\section{Task 5.0 Develop GIS tools}

The GIS tools allow the user to view the full spatial distribution of the pre-calculated available power density and then to enter bathymetric constraints and energy converter specific parameters to tailor the output for particular regions. 


\section{Subtask 5.a Depth filter}

Tidal stream energy converters are currently limited in their variety and are primarily classified as vertical and horizontal axis devices with open or shrouded rotors. Independent of their design, all the devices have depth requirements based on their dimensions. The first step for assisting in site selection is to determine which locations will meet the minimum depth requirements. Generally these requirements are based on minimum height of the prototype above the bed $\left(\mathrm{h}_{\mathrm{b}}\right)$, the minimum clearance of the prototype below the surface $\left(\mathrm{h}_{\mathrm{s}}\right)$ and the device dimensions $\left(\mathrm{d}_{\mathrm{p}}\right)$. The minimum depth $\left(\mathrm{h}_{\min }\right)$ would then be given as $h_{\min }=h_{b}+h_{s}+d_{p}$.

\section{Subtask 5.b Velocity histograms}

The model runs produce time series of the velocity which are 32 days. The first 2 days are neglected for the computations of the tidal constituents. These constituents are then used to create a new time series of the velocity for an entire year. The one year of hourly data is then used to create a probability histogram of the velocity magnitude. The tool computes the histograms for sections of the coast as specified by the user. The user can also view or extract the resulting histograms or other statistics at any particular location.

\section{Subtask 5.c Compute available power densities}

The histograms of distributions of annual tidal current velocity are used to compute a histogram of total available power density. These histograms can be used to compute the annual average available power at all locations. Similar to the velocity histograms, the user is able to view or extract the histograms and statistics of the available power density. In addition, the spatial distribution of the average annual available power will be computed and displayed as the precalculated available power for the webpage. This can be filtered by the depth constraint previously specified.

\section{Subtask 5.d Compute effective power densities}

Turbines are incapable of extracting all available power from the flow field. Because this efficiency is a function of the flow speed, an efficiency curve is frequently used for computing the expected turbine output power. However, after discussions with DOE project managers, this tool is not included in the final webpage order to encourage users to not use the database as a site characterization tool.

\section{Subtask 5.e Compute total available power}

Based on the feedback from a project workshop in Atlanta with outside experts, the Garrett and Cummins (2005) method for calculating the tidal stream energy potential has been applied with a gamma value of 0.22 . The results are not publicly available via the webpage but are contained in the next section of this report.

Subtask 5.f Compute the velocity histogram at specified elevations.

The depth variations of the currents predicted by the model have been deemed to have too much uncertainty. In order to accurately reproduce the vertical 
variations of the currents, much more extensive calibration would be required on a site by site basis. In addition, baroclinic forcing would be required at many locations. Therefore, after discussions with the DOE project managers, this task was deemed to be beyond the scope of the project and was not completed.

\section{Task 6.0 Web based interface}

Results from this study have been made available via an internet web site (www.tidalstreampower.gatech.edu) that can be linked to other similar ongoing projects. An interactive, web-based GIS system has been developed to facilitate dissemination of the tidal data to interested users. The presentation of the data and results has been designed in a manner equally accessible and useful to both specialists and a lay audience.

\section{Project Description}

\subsection{Numerical modeling of tidal streams}

Details of the numerical modeling system used for the simulations of the tidal flows are discussed in this section.

\subsubsection{System Requirements}

The numerical simulations are run on the Georgia Tech Savannah Beowulf-class cluster 'Minerva', which includes 22 dual-core $3.2 \mathrm{GHz}$ Intel Xeon processors, for a total of 44 cores across 11 computers in a distributed-memory architecture. Each computer in the cluster has 4 GB of memory and an 80 GB hard drive. In addition, the cluster features a separate 1 TB RAID array for data storage. A dedicated, high-speed Infiniband switch controls the interconnects between the computers on the cluster. The Portland Group compiler suite and MPICH libraries enable parallel programming for the user.

\subsubsection{Regional Ocean Modeling System (ROMS)}

The numerical model the Regional Ocean Modeling System (ROMS) is a member of a general class of three-dimensional, free surface, terrain following numerical models that solve three dimensional Reynolds-averaged Navier-Stokes equations (RANS) using the hydrostatic and Boussinesq assumptions (Haidvogel et al., 2008). ROMS uses finitedifference approximations on a horizontal curvilinear Arakawa $\mathrm{C}$ grid and vertical stretched terrain-following coordinates. Momentum and scalar advection and diffusive processes are solved using transport equations and an equation of state computes the density field that accounts for temperature, salinity, and suspended-sediment concentrations. The modeling system provides a flexible framework that allows multiple choices for many of the model components such as several options for advection schemes (second order, third order, fourth order, and positive definite), turbulence models, lateral boundary conditions, bottom- and surface-boundary layer submodels, air-sea fluxes, surface drifters, a nutrient-phytoplankton-zooplankton model, and a fully developed adjoint model for computing model inverses and data assimilation. The model also includes a wetting and drying boundary condition which is essential for tidal flow simulations. The code is written in Fortran90 and runs in serial 
mode or on multiple processors using either shared- or distributed-memory architectures. The computational grids were set up and the results were calibrated following the outlines of tidal stream modeling efforts for a regional study (Defne et al., 2011b).

ROMS uses NetCDF (Network Common Data Form) files to handle the input and output interface. NetCDF is a set of software libraries and machine-independent data formats that support the creation, access, and sharing of array-oriented scientific data (UNIDATA, 2007). The NetCDF inputs for ROMS and the output data streams from ROMS can be accessed with Matlab for pre-processing and post-processing of the results using the NetCDF toolbox for Matlab.

For computational economy, the hydrostatic primitive equations for momentum are solved using a split-explicit time-stepping scheme which requires special treatment and coupling between barotropic (fast) and baroclinic (slow) modes. A finite number of barotropic time steps, within each baroclinic step, are carried out to evolve the freesurface and vertically integrated momentum equations. In order to avoid the errors associated with the aliasing of frequencies resolved by the barotropic steps but unresolved by the baroclinic step, the barotropic fields are time averaged before they replace those values obtained with a longer baroclinic step. A cosine-shape time filter, centered at the new time level, is used for the averaging of the barotropic fields (Shchepetkin and McWilliams, 2005). Currently, all 2D and 3D equations are timediscretized using a third-order accurate predictor (Leap-Frog) and corrector (AdamsMolton) time-stepping algorithm which is very robust and stable. The enhanced stability of the scheme allows larger time steps, by a factor of about four, which more than offsets the increased cost of the predictor-corrector algorithm.

The computational grids are generated using the SeaGrid toolbox developed for Matlab to prepare an orthogonal grid within a curved perimeter, suitable for oceanographic modeling (Denham, 2008). The bathymetric data, which is measured positive downwards from the MSL, is used to generate depths for each grid point. Grid points within the computational domain which remain permanently "dry" are determined by masking the land cells using the coastline data. The boundary between land and water is a solid wall boundary with free slip condition. An example of ROMS Arakawa C type computational grid and boundary conditions are given in Figure 2. The scalar values such as density, tracers and free surface are calculated at rho points located at the center of the computational cells. The horizontal velocities ( $u$ and $v$ ) are computed on staggered grids that correspond to the interface of the computational cells. The derivatives are calculated at psi points. Therefore for a rectangular grid of $\mathrm{M}+1$ by $\mathrm{L}+1$ dimensions, $\mathrm{u}, \mathrm{v}$ and psi has dimensions of $\mathrm{M}+1$ by $\mathrm{L}, \mathrm{M}$ by $\mathrm{L}+1$ and $\mathrm{M}$ by $\mathrm{L}$, respectively.

ROMS uses a stretched, terrain-following vertical coordinate system to conform to variable topography. Therefore, each vertical layer may have a different thickness. The total height of the computational grid in the vertical is N+Nbed layers (Figure 2). In the present study sediment transport is not considered and therefore there is only one bed layer (Nbed=1) and it is fixed. However, the free-surface evolves in time. The vertical discretization is also staggered so that the variables in the horizontal plane are 
calculated at the mid-plane in between bottom and top faces of each computational cell. Vertical velocity $(\mathrm{u})$ and vertical mixing variables are given at the bottom and top faces as shown in Figure 3. For tidal modeling the model is run in 3D barotropic mode. More information on ROMS modeling and the underlying mathematics can be found at the WikiROMS Documentation Portal (WikiROMS).

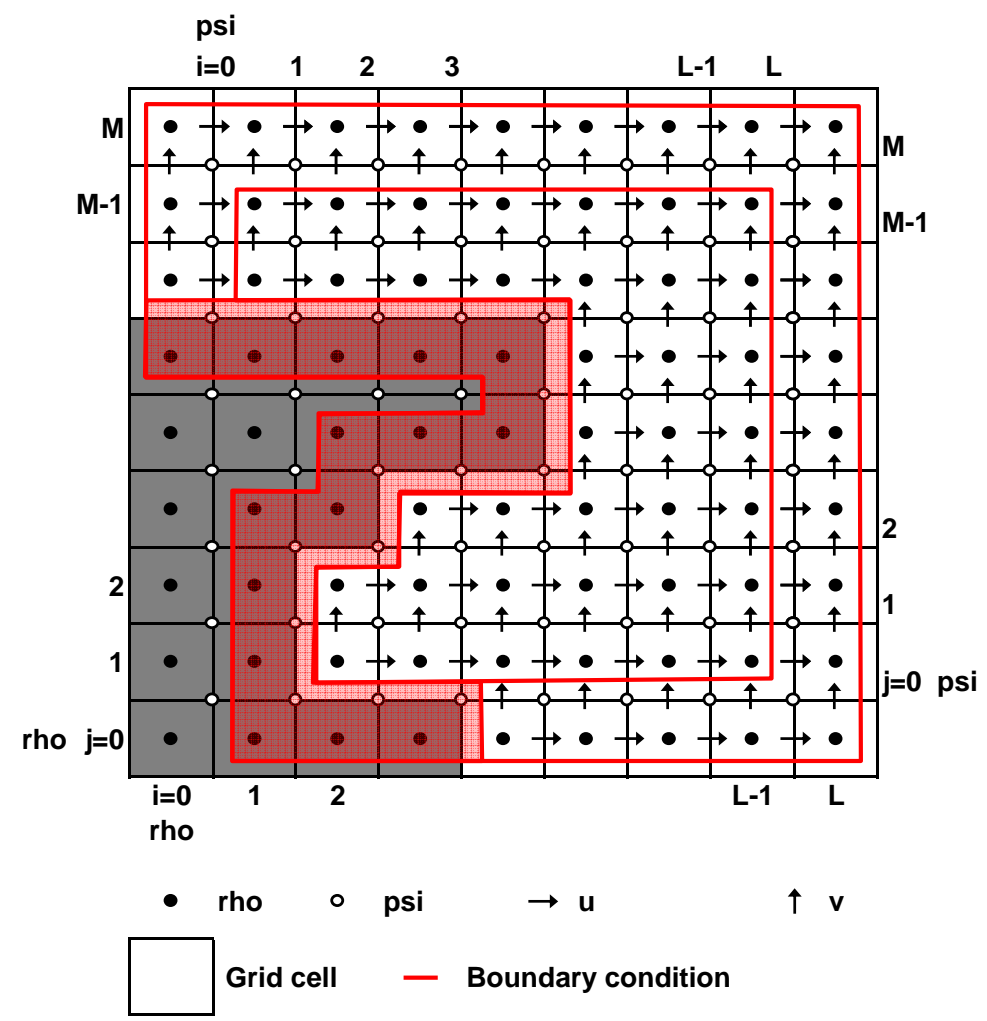

Figure 2. An example of ROMS Arakawa $C$ type computational grid and boundary conditions. Gray boxes are dry points.

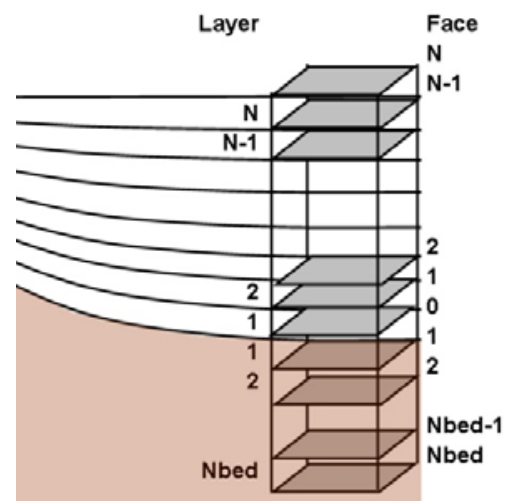

(a)

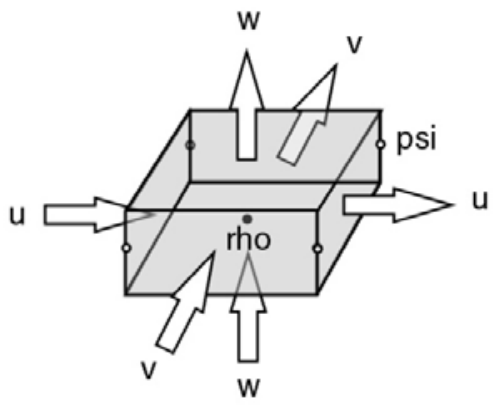

(b)

Figure 3. Example of (a) vertical discretization of computational domain and (b) an example computational cell in ROMS. 


\subsubsection{Grid Generation}

In order to simulate the tidal flows inside the estuaries, rivers, inlets and bays more accurately numerical grid resolution needs to be kept small enough to resolve these features. For this reason the USA coast is broken up into subgrids for separate simulations while keeping the computational domain at a manageable size. Wherever possible, natural barriers will be selected as boundaries between the different grids; estuaries or bays are contained in their entirety within a single computational domain. The neighboring grids contain overlaps of several kilometers to ensure seamless coverage.

The United States coastline was divided into 52 subdomains with an average grid spacing of $350 \mathrm{~m}$ as shown in Figure 4. The only exception was the Puget Sound grid for which the results from an earlier study were used (Sutherland et al.). The coastline data, used for masking the land nodes, was obtained from National Ocean Service (NOS) Medium Resolution Coastline via the Coastline Extractor (NGDC, 2008a) and processed in MATLAB to remove the gaps. Raw bathymetry was obtained from NOS Hydrographic Surveys Database (NOS, 2008a). The bathymetry data from the database are generally referenced to mean low low water (MLLW) while ROMS bathymetry is defined with respect to mean water level (MWL) or mean tidal level (MTL). A conversion from MLLW to MTL referenced values was performed based on the data from the present Epoch's datum data provided by National Oceanic and Atmospheric Administration (NOAA). Tides \& Currents at the tidal stations (NOAA, 2008b) or NOAA Vertical Datum Transformation software (VDatum) (NOS, 2008b). Supplementary data to replace missing bathymetry points were acquired from NOAA Electronic Navigational Charts (NOAA, 2008a) and National Geophysical Data Center Geophysical Data System database (GEODAS) (NGDC).

The bathymetric data is interpolated onto the model grid. Even with the relatively high resolution of the grid $(\sim 350 \mathrm{~m})$, the spatial variability of the bathymetry is not always fully resolved. As pointed out in the validation report (Steward and Neary, 2011), the bathymetric difference between the model and ADCP measurements are sometimes observed to be as large as 30\%. This may be a result of bathymetric variations on spatial scales shorter than the grid scale. For a more detailed site characterization study, higher spatial resolution for the model would alleviate these differences. 

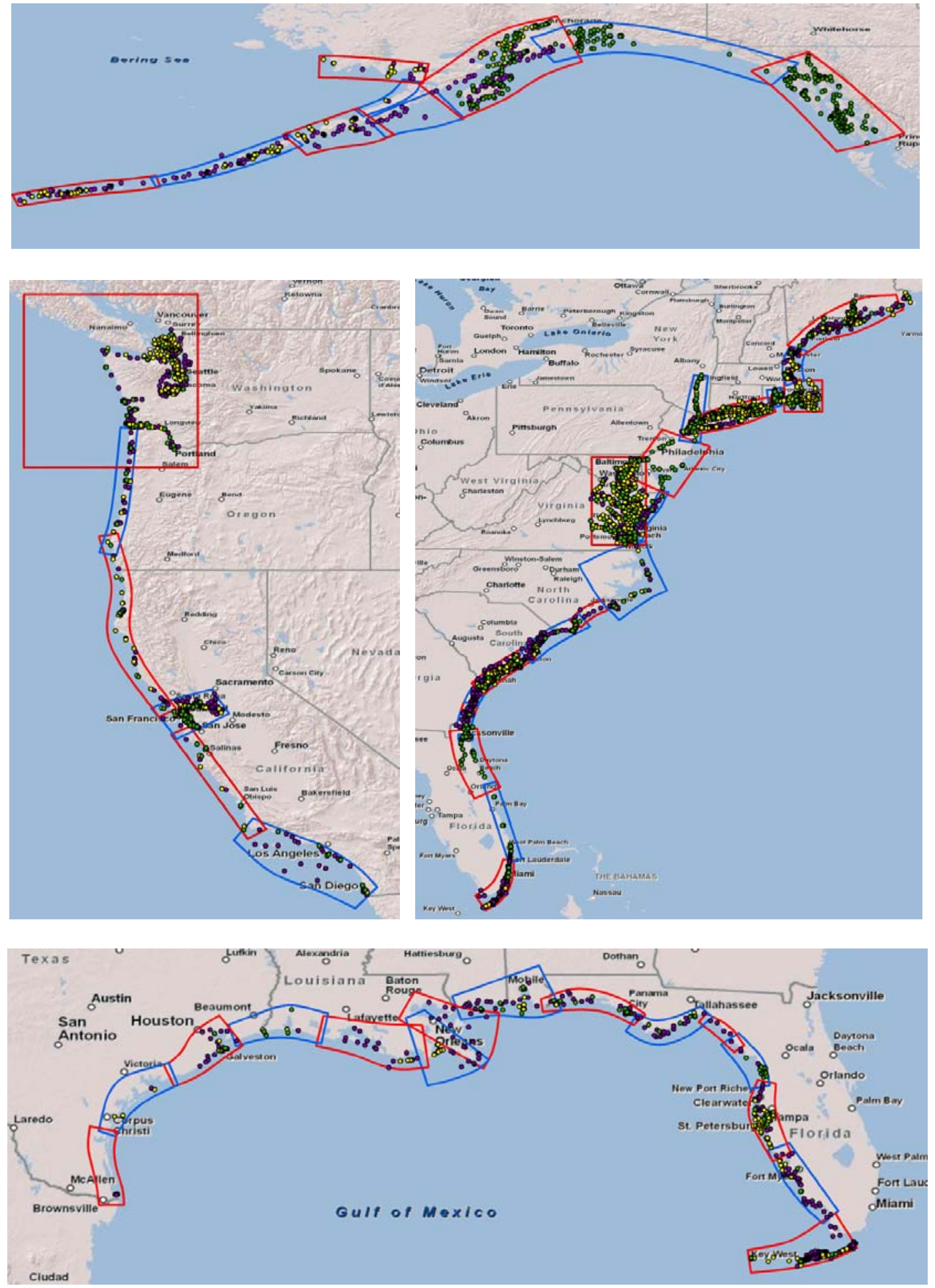

Figure 4. Map of computational grids and the calibration data sources. Harmonic constituents for tidal currents (green) and water levels (black), and prediction for maximum current (yellow) and high/low tide elevations (purple). 
The additional volume of water provided by the wetlands was implemented in the computational model through the wet-dry module in ROMS, which allows for computational nodes to be defined as land or sea nodes dynamically with respect to the water content. Wetland boundaries were acquired from National Wetland Inventory of US Fish \& Wildlife Services (USFWS). Elevation data for wetlands is cropped from the 1 arc second topography data downloaded from USGS Seamless Server (USGS). The topography data is referred to NAVD88. The data is converted to MTL reference via interpolating from NOAA tidal stations datum in the model domain or VDatum where available. After conversion the sea bathymetry and the wetland topography are merged into a single set of points before constructing the computational grids. A quadratic bottom stress formulation with a spatially uniform friction factor is used for each grid.

Tidal constituents are periodic oscillations driven by the celestial forces computed with the mathematical approximation of the astronomical tides is given as

$$
H=a_{0}+\sum_{i=1}^{N} a_{i} \cdot \cos \left(\sigma_{i} \cdot t+\delta_{i}\right)
$$

where $H$ is the astronomical tide at time $t$ since the start of the tidal epoch, $a_{0}$ is the vertical offset, $a_{i}, \sigma_{i}, \delta_{i}$ are the amplitude, angular frequency and phase angle of the $i^{\text {th }}$ tidal constituent (Zevenbergen et al., 2004). For the US East coast and the Gulf of Mexico, the ROMS tidal forcing file was generated by interpolating the ADCIRC (ADCIRC) tidal database at the open boundary nodes of the ROMS grid. The harmonic constituents used for the forcing included Q1, O1, K1, S2, M2, N2, K2, M4 and M6. For the West coast and Alaska domains, TPXO data (ESR), with the constituents Q1, $\mathrm{O} 1, \mathrm{~K} 1, \mathrm{~S} 2, \mathrm{M} 2, \mathrm{~N} 2$ and M4 is used. The M6 constituent is not included in the TPXO data and therefore cannot be included in the forcing. For this dataset it was also found that more accurate results for S2 were obtained when not including K2 because they have such similar frequencies it is difficult to separate them for 30 day simulations.

Stream flow data is obtained from USGS National Water Information System (USGS, 2008b) when needed and yearly average discharges are applied as a point source at the major river boundaries. Open boundary conditions were defined identically in all of the grids as free-surface Chapman condition (Chapman, 1985) for the tidal elevation, Flather condition (Carter and Merrifield, 2007) for barotropic velocity (2D momentum), and gradient (aka Neumann) condition for baroclinic velocity (3D momentum)

(WikiROMS). The results from 30-day simulations were used in the analyses after running the model for 32-day simulations with 2 days for the spin-up.

\subsection{Model calibration}

The calibration data includes the in-situ measurements collected from various sources, harmonic constituents and as well as the high/low tide or maximum/minimum current predictions from NOAA Tides \& Currents. If measurements with duration longer than a month are available, harmonic constituents are extracted from both model and data to be compared. For the calibration data that contain only high/low tides or maximum/minimum currents, the extreme values are extracted from the model for calibration. Harmonic constituent calibrations are preferred over extreme value calibrations, since the harmonic constituents are obtained from measurement sites and 
may be more reliable than the predicted extreme values. Therefore, extreme value calibrations are only used when there are few or no measurements sites in the region.

The calibration procedure begins with a full 32 day model run which is then compared with the data. Due to the quantity and size of the different domains used in this study, a holistic approach about the general trend of over versus under predictions for the constituents at all the various stations in the domain was used to develop a target overall relative error in currents. To achieve the necessary relative change in currents, the friction factor was modified uniformly for the entire grid and a shorter model run consisting of 7 days was completed. In general, a larger friction factor produces more drag thereby decreasing the currents. For a more localized study, a more quantitative approach may be utilized with spatially varying friction factors along with tuning of other model parameters such as turbulence parameters. For the shorter model runs, the relative changes in time series of the magnitude of the currents were evaluated, and this process was repeated until the desired relative change was obtained. Finally another 32 day model run was completed with the selected parameter values for the creation of the final harmonic constituents.

The calibration parameters regarding the harmonic constituents of tidal elevations, harmonic constituents of tidal currents and predicted maximum/minimum tidal currents and predicted high/low tides are explained below.

\subsubsection{Harmonic Constituents for Tidal Currents}

\section{Amplitude Difference (amd):}

This parameter shows how much the model underpredicts $(a m d<0)$ or overpredicts (amd $>0$ ) the amplitude of the $\mathrm{k}^{\text {th }}$ harmonic constituent.

$$
\operatorname{amd}_{\mathrm{k}}=\left(\mathrm{amp}_{\mathrm{m}}\right)_{\mathrm{k}}-\left(\mathrm{amp}_{\mathrm{x}}\right)_{\mathrm{k}}
$$

where $\left(a m p_{m}\right)_{k}$ and $\left(a m p_{x}\right)_{k}$ are the combined amplitudes of the $k^{\text {th }}$ harmonic constituent computed by the model output and given in data, respectively. The combined amplitude for each harmonic constituent is calculated as the square root of the squares of major and minor axes of the tidal ellipse.

$$
\mathrm{amp}=\sqrt{\mathrm{a}_{\mathrm{maj}}{ }^{2}+\mathrm{a}_{\min }{ }^{2}}
$$

where $\mathrm{a}_{\text {maj }}$ and $\mathrm{a}_{\mathrm{min}}$ are the major and the minor axis amplitudes of the tidal ellipse.

\section{Percentage Amplitude Difference (amdp):}

A dimensionless parameter that gives the percent underprediction $(a m d p<0)$ or overprediction $(a m d p>0)$ of the amplitude of the $\mathrm{k}^{\text {th }}$ harmonic constituent.

$$
\operatorname{amdp}_{\mathrm{k}}=\frac{\left(\mathrm{amp}_{\mathrm{m}}\right)_{\mathrm{k}}-\left(\mathrm{amp}_{\mathrm{x}}\right)_{\mathrm{k}}}{\left(\mathrm{amp}_{\mathrm{x}}\right)_{\mathrm{k}}} \cdot 100
$$


Tidal Ellipse Inclination Difference (incd):

The difference between the inclination of the tidal ellipses ( \pm 180 degrees) calculated by the model and given with the measurements.

$$
\operatorname{incd}_{\mathrm{k}}=\left(\text { inc }_{\mathrm{m}}\right)_{\mathrm{k}}-\left(\mathrm{inc}_{\mathrm{x}}\right)_{\mathrm{k}}
$$

where $\left(\text { inc }_{\mathrm{m}}\right)_{\mathrm{k}}$ and $\left(\mathrm{inc}_{\mathrm{x}}\right)_{\mathrm{k}}$ are the orientation of the tidal ellipse (measured in degrees, clockwise from North) of the kth harmonic constituent computed by the model output and given in data, respectively.

\section{Phase Difference (phd):}

This parameter indicates how much the model output lags (phd $>0$ ) or leads (phd $<0$ ) the given data for each of the modeled harmonic constituent for water surface level.

$$
\operatorname{phd}_{\mathrm{k}}=\left(\mathrm{pha}_{\mathrm{m}}\right)_{\mathrm{k}}-\left(\mathrm{pha}_{\mathrm{x}}\right)_{\mathrm{k}}
$$

where $\left(\mathrm{pha}_{\mathrm{m}}\right)_{\mathrm{k}}$ and $\left(\mathrm{pha}_{\mathrm{x}}\right)_{\mathrm{k}}$ are the phases of the $\mathrm{k}^{\text {th }}$ harmonic constituent computed by the model output and given in data, respectively, in minutes.

\subsubsection{Harmonic Constituents for Water Level}

The calibration parameters for the harmonic constituents for water levels include amplitude difference ( $a m d$ ), percentage amplitude difference ( $a m d p$ ) and phase difference $(p h d)$ and are defined in the same manner with the calibration parameters for the harmonic constituents for tidal currents.

Statistics of final results from two points at Cook Inlet after calibration are given here as an example. The comparison of the tidal current constituents derived from measurement data and model results on the east of Kalgin Island is shown in Table 1. According to the model the combined amplitude $\left(a m p_{m}\right)$ for major constituent M2 at this location is $1.66 \mathrm{~m} / \mathrm{s}$, which is $11 \%$ less than the combined amplitude derived from the measurements ( $0.18 \mathrm{~m} / \mathrm{s}$ smaller). The percentage amplitude difference is larger for S2 and K1 than M2 although they translate to a much smaller amplitude difference between the measurements and the model results. The calibration process involves overall evaluation of results from every measurement point in a given computational grid. The results for combined magnitude of M2 tidal current constituent for Cook Inlet, AK are shown in Figure 5. It is seen that the model can be overpredicting or underpredicting given that the results are within an acceptable range. The average absolute difference between the model and the measurements in Cook Inlet for the combined amplitude and the tidal ellipse inclination are $19 \%$ and $13 \%$, respectively. The phase differences are found to be under an hour for the first five major constituents, which is reasonable since the model output is recorded hourly. It is also seen that as the amplitude of the constituent starts to diminish the error in phase can increase significantly (e.g. 530 minutes for Q1). However, this does not impose a major problem when the amplitude is negligible. 
Table 1. Comparison of the tidal current constituents derived from measurement data and model results on the east of Kalgin Island at Cook Inlet, AK (151.6732 ${ }^{\circ}$

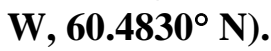

\begin{tabular}{llllllll}
\hline Constituent & $\begin{array}{l}\text { Period } \\
(\mathrm{hrs})\end{array}$ & $\begin{array}{l}\mathrm{amp}_{\mathrm{m}} \\
(\mathrm{m} / \mathrm{s})\end{array}$ & $\begin{array}{l}\text { amd } \\
(\mathrm{m} / \mathrm{s})\end{array}$ & $\begin{array}{l}\text { amdp } \\
(\%)\end{array}$ & $\begin{array}{l}\text { inc }_{\mathrm{m}} \\
(\mathrm{deg})\end{array}$ & $\begin{array}{l}\text { incd } \\
(\mathrm{deg})\end{array}$ & $\begin{array}{l}\text { phd } \\
(\mathrm{min})\end{array}$ \\
\hline M2 & 12.4206 & 1.66 & -0.18 & -11 & 70 & -34 & -43 \\
S2 & 12 & 0.38 & 0.1 & 27 & 75 & -38 & 12 \\
K1 & 23.9345 & 0.32 & -0.08 & -26 & 72 & -35 & 54 \\
N2 & 12.6583 & 0.31 & -0.02 & -6 & 76 & -40 & -39 \\
O1 & 25.8193 & 0.14 & 0.01 & 8 & 84 & -47 & 45 \\
M4 & 6.2103 & 0.12 & -0.07 & -56 & 54 & -25 & -120 \\
M6 & 4.1402 & 0.1 & -0.08 & -82 & 103 & -56 & 94 \\
Q1 & 26.8684 & 0.01 & 0.01 & 164 & 113 & -76 & 530 \\
\hline
\end{tabular}

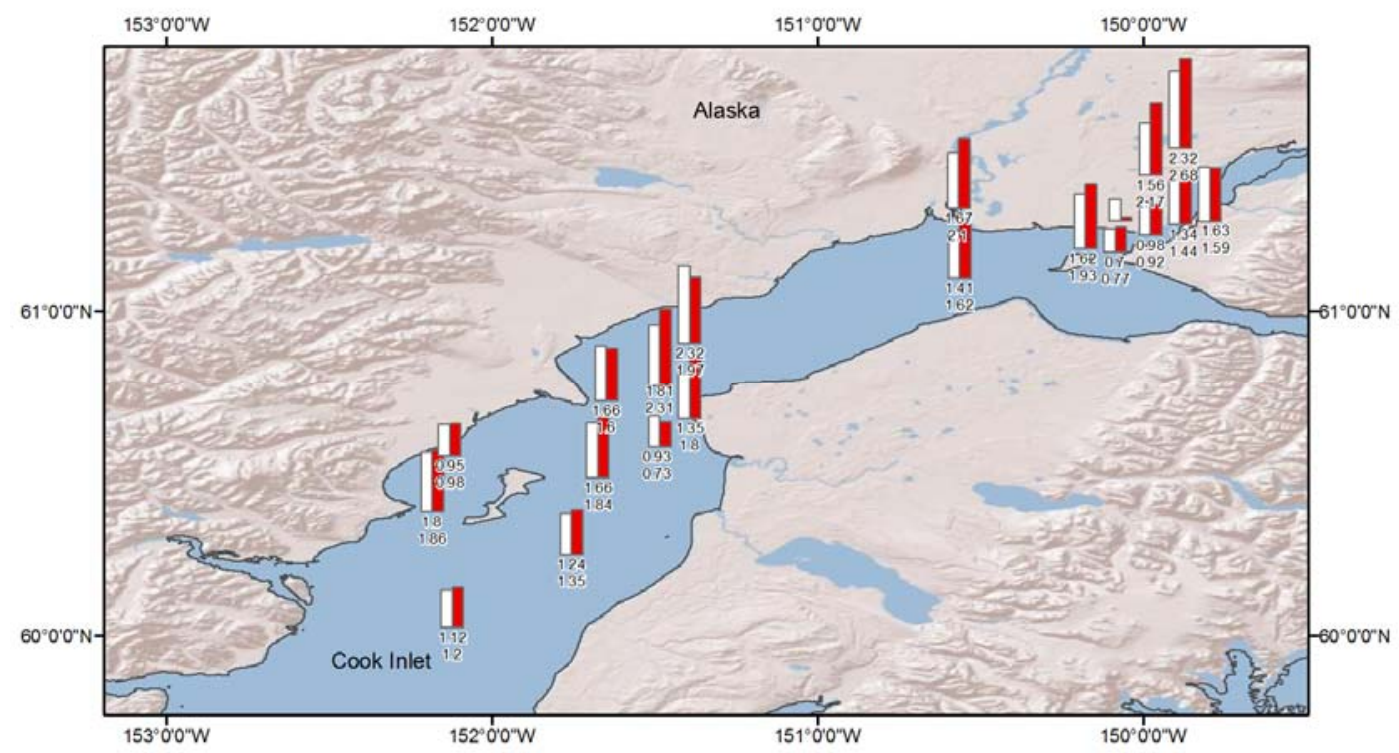

Figure 5. Comparison of combined amplitude $(\mathrm{m} / \mathrm{s})$ of $\mathrm{M} 2$ tidal current constituent calculated from the model (white) and measurements (red) for the Cook Inlet, AK. The model (top) and the measurement (bottom) values are marked at every point.

The final calibration statistics for the water level constituent near Nikiski, AK are displayed in Table 2. Here, the model prediction for the amplitude of the major constituent is $2.5 \mathrm{~m}$, which is $7 \%$ less than the measured amplitude ( $0.17 \mathrm{~m}$ less). The percentage amplitude difference is also below $10 \%$ for all other constituents with the exception of M4. Additionally, the larger percent difference in M4 amplitude corresponds to a few centimeters since the amplitude of M4 is considerably small. The modeled and measured magnitude of M2 tidal constituent for Cook Inlet are shown in Figure 6. The model overpredicts the measured M2 amplitudes slightly for this grid, with an average of $10 \%$. This is considered acceptable within the purpose of a regional assessment. The differences in terms of phase are less than 30 minutes, slightly better than the results for tidal currents. Overall, the water level calibration statistics are better than tidal current calibration statistics, which is a general trend observed throughout the entire data set. The tidal water levels generally have a much smaller spatial variation 
than tidal currents, allowing them to be modeled with higher accuracy. For the computation of the kinetic power density, the tidal water levels are not directly utilized. However, the computation of the total available power is directly a function of the tidal water level amplitude; therefore accuracy of theses constituents is still important.

Table 2. Comparison of the water level constituents derived from measurement data and model results at near Nikiski at Cook Inlet $\mathrm{AK}\left(151.4053^{\circ} \mathrm{W}, 60.6810^{\circ} \mathrm{N}\right)$

\begin{tabular}{llllll}
\hline Constituent & Period $(\mathrm{hrs})$ & $\mathrm{amp}_{\mathrm{m}}(\mathrm{m})$ & $\mathrm{amd}(\mathrm{m})$ & $\mathrm{amdp}(\%)$ & phd $(\mathrm{min})$ \\
\hline M2 & 12.4206 & 2.5 & -0.17 & -7 & -25 \\
S2 & 12 & 0.86 & -0.04 & -5 & -4 \\
K1 & 23.9345 & 0.64 & -0.05 & -8 & 11 \\
N2 & 12.6583 & 0.5 & -0.01 & -2 & -6 \\
O1 & 25.8193 & 0.38 & 0.01 & 2 & 25 \\
M4 & 6.2103 & 0.09 & 0.03 & 35 & -9 \\
M6 & 4.1402 & 0.07 & 0 & -2 & -12 \\
Q1 & 26.8684 & 0.06 & 0 & 4 & -8 \\
\hline
\end{tabular}

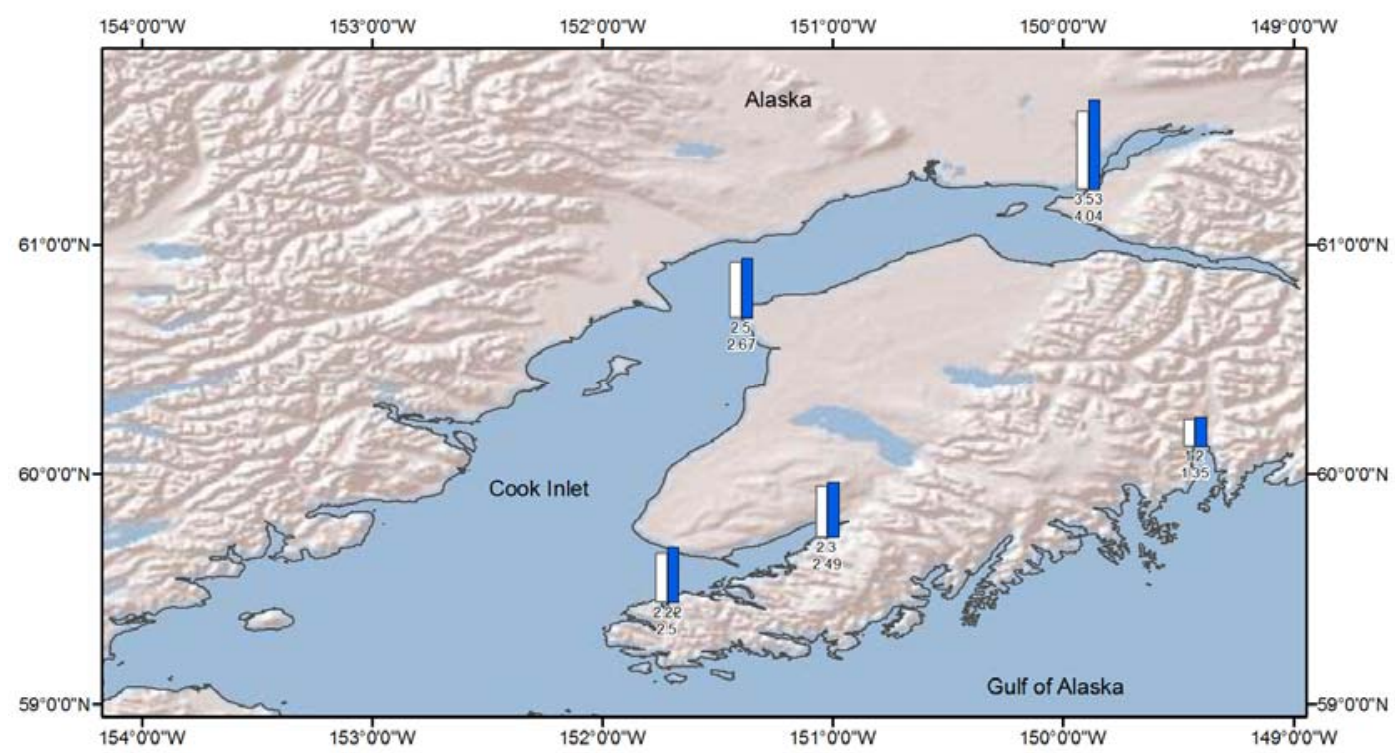

Figure 6. Comparison of amplitude of water level constituent (m) for M2 tidal constituent calculated from the model (white) and measurements (blue) for the Cook Inlet, AK. The model (top) and the measurement (bottom) values are marked at every point. 


\subsubsection{Predicted Maximum Currents}

\section{Mean current magnitude ratio of maximum currents (cmgrt):}

The average ratio of the maximum current magnitudes from the model to the magnitudes of the corresponding maximum current values from the calibration data, are given by

$$
\text { cmgrt }=\frac{\sum_{i=1}^{N} \frac{\mid\left(\text { cur }_{m}\right)_{i} \mid}{\mid\left(\text { cur }_{c}\right)_{i} \mid}}{N}
$$

where $c u r_{m}$ is the maximum current magnitude from the model and $c u r_{v}$ is the maximum current value from the calibration data. $i$ and $N$ are the $i^{\text {th }}$ occurrence and total number of occurrences of maximum and minimum during the simulation duration, respectively.

Root-mean-square difference of maximum currents (crms, fcrms, ecrm):

This parameter is the root-mean-square of the difference between the maximum current values output by the model and maximum current values from the data and is an estimate for the error in predicting maximum current magnitude

$$
\text { crms }=\sqrt{\frac{\sum_{i=1}^{N}\left\{\left(\text { cur }_{m}\right)_{i}-\left(\text { cur }_{v}\right)_{i}\right\}^{2}}{N}}
$$

Current root-mean-square differences for maximum flood and ebb currents (fcrms and ecrms) are calculated using the same equation but only the maximum of the flood (or ebb) tides are used to compare.

\section{Mean difference in maximum flood (or ebb) currents (fcmd and ecmd):}

The mean difference in maximum flood current between the model output and the calibration data shows whether the model produced larger flood current ( $f c m d>0$ ) or smaller flood current $(f c m d<0)$ than the calibration data. It is given by

$$
f c m d=\frac{\sum_{i=1}^{N}\left\{\left(\operatorname{cur}_{m}^{f}\right)_{i}-\left(\operatorname{cur}_{v}^{f}\right)_{i}\right\}}{N}
$$

where $c u r_{m}^{f}$ and $c u r_{v}^{f}$ are maximum flood currents from the model and from data, respectively. Similarly, the difference in maximum ebb current between the model output and the calibration data is computed by

$$
\text { ecmd }=\frac{\sum_{i=1}^{N}\left\{\left(\text { cur }_{m}^{e}\right)_{i}-\left(\text { cur }_{v}^{e}\right)_{i}\right\}}{N}
$$

where $\mathrm{cur}_{m}^{e}$ and $\mathrm{cur}_{v}^{e}$ are maximum flood currents from the model and from data, respectively. fcmd and ecmd are used to evaluate ability of the model to simulate the flood or ebb dominant tidal regimes.

Phase Difference between Maximum Currents (cpd, fcpd and ecpd):

The mean phase difference for maximum currents and the mean phase difference for maximum flood and ebb currents are given by

$$
c p d=\frac{\sum_{i=1}^{N}\left\{\left(t_{m}\right)_{i}-\left(t_{v}\right)_{i}\right\}}{N}
$$




$$
\begin{aligned}
& f c p d=\frac{\sum_{i=1}^{N}\left\{\left(t_{m}^{f}\right)_{i}-\left(t_{v}^{f}\right)_{i}\right\}}{N} \\
& \text { ecpd }=\frac{\sum_{i=1}^{N}\left\{\left(t_{m}^{e}\right)_{i}-\left(t_{v}^{e}\right)_{i}\right\}}{N}
\end{aligned}
$$

where $t_{m}$ and $t_{v}$ are the times that correspond to the maximum tidal current occurrences in the model output and the calibration data, respectively. The superscripts $f$ and $e$ denote flood and ebb. Current phase difference is an estimate of how much the model phase lags (cpd, fcpd, ecpd $>0$ ) or precedes $(c p d, f c p d$, ecpd $<0)$ the calibration data.

\subsubsection{Predicted High/Low Tides}

\section{Standard Deviation Ratio of High/Low Tides (stdrt):}

The ratio between standard deviation of the high/low tide computed with the model and given in the data. It is an estimate of how much the model underpredicts $(s t d r t<1)$ or overpredicts (stdrt $>1$ ) the tidal range.

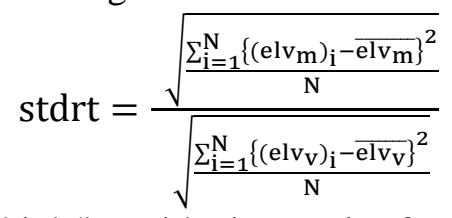

where elvm and elvv are the high/low tide time series from the model and the data.

\section{Root-Mean-Square Difference of High/Low Tides (rms, hirms and lorms):}

The root mean square difference between the model output and the data for high/low tides is an estimate for the error of the model prediction in predicting the tidal elevation. It is given by

$$
r m s=\sqrt{\frac{\sum_{i=1}^{N}\left\{\left(e l v_{m}\right)_{i}-\left(e l v_{v}\right)_{i}\right\}^{2}}{N}}
$$

\section{Phase Difference between High/Low Tide (phd, hiphd and lophd):}

These terms show the phase difference between the NOAA predictions and the model for high/low tides regarding only high tides only (hiphd), or low itdes only (lophd) or both (phd). They measure how much the model output lags (phd, hiphd, lophd $>0$ ) or leads ( $p h d$, hiphd, lophd $<0$ ) the change in the water surface level. It is calculated with the same equations for currents by substituting the high and low tide times into the equation.

Calibration statistics of model results with NOAA predictions for maximum currents is demonstrated with examples from St Catherines Sound in Georgia in Table 3. This location has moderate tidal currents with average magnitude for maximum currents $\left(\mathrm{cmg}_{\mathrm{m}}\right)$ less than $1 \mathrm{~m} / \mathrm{s}$. It is seen that the model usually overpredicts the magnitude of maximum tidal current for this particular location. However, the data shown here covers only a small part of the computational grid that includes several sounds for which the results also include underpredictions. For this specific example, depending on the location the mean current magnitude ratio ( $\mathrm{cmgrt}$ ) can be as high as 1.32, although 
much higher values are common for the complete set of data. The large differences for the maximum current predictions can be attributed to many reasons. In addition to correct prediction of the currents being more challenging than water levels, comparing the results with predictions rather than directly to measurements introduces some ambiguity. Having only the maximum predicted values to compare against can contribute to larger differences. On the other hand, although the magnitude differences can vary largely, the phase differences for the maximum current speed are generally on the order of an hour for the entire data set. For the locations considered in the St Catherines Sound, the time differences are calculated to be slightly larger than half an hour.

\section{Table 3. Maximum current predictions at St. Catherines Sound and Newport River, GA.}

\begin{tabular}{lllllll}
\hline Station Name & $\begin{array}{l}\text { Longitude } \\
(\mathrm{deg})\end{array}$ & $\begin{array}{l}\text { Latitude } \\
(\mathrm{deg})\end{array}$ & $\begin{array}{c}\mathrm{cmgm} \\
(\mathrm{m} / \mathrm{s})\end{array}$ & $\begin{array}{c}\mathrm{cmgrt} \\
(-)\end{array}$ & $\begin{array}{c}\mathrm{crms} \\
(\mathrm{m} / \mathrm{s})\end{array}$ & $\begin{array}{c}\mathrm{cpd} \\
(\mathrm{min})\end{array}$ \\
\hline St. Catherines Sound Entrance & -81.1405 & 31.7150 & 0.94 & 1.32 & 0.39 & 33 \\
Medway River, northwest of Cedar Point & -81.1908 & 31.7145 & 0.82 & 1.36 & 0.44 & -52 \\
N. Newport River, NE of Vandyke Creek & -81.1870 & 31.6912 & 0.82 & 1.29 & 0.42 & 52 \\
N. Newport River, above Walburg Creek & -81.1953 & 31.6738 & 0.75 & 1.00 & 0.25 & -49 \\
N. Newport River, NW of Johnson Creek & -81.2105 & 31.6630 & 0.74 & 1.17 & 0.32 & -23 \\
N. Newport River, ESE of S. Newport Cut & -81.2645 & 31.6653 & 0.64 & 1.41 & 0.35 & 10 \\
\hline
\end{tabular}

The tidal range in St. Catherine Sound, GA is predicted to be slightly larger than $2 \mathrm{~m}$ based on the high/low water calibrations statistics of the locations displayed in Table 4. The root-mean-square difference in high/low tides is approximately $0.14 \mathrm{~m} / \mathrm{s}$, which is satisfactory for the given tidal range. The standard deviation ratio of high/low water levels (stdrt) is slightly less than 1 at all of the locations, indicating that the modeled tidal range is slightly smaller than the NOAA predictions. The modeled high/low tides are found to lead the predictions nearly by half an hour.

\section{Table 4. High/low water elevation predictions at St. Catherines Sound and Newport River, GA.}

\begin{tabular}{|c|c|c|c|c|c|c|c|}
\hline Station Name & $\begin{array}{l}\text { Longitude } \\
\text { (deg) }\end{array}$ & $\begin{array}{l}\text { Latitude } \\
\text { (deg) }\end{array}$ & $\begin{array}{l}\text { Mean of } \\
\text { High } \\
\text { Water }(\mathrm{m})\end{array}$ & $\begin{array}{l}\text { Mean of } \\
\text { Low Water } \\
(\mathrm{m})\end{array}$ & strdt (-) & $\begin{array}{l}\mathrm{rms} \\
(\mathrm{m})\end{array}$ & $\begin{array}{l}\text { phd } \\
\text { (min) }\end{array}$ \\
\hline Walburg Creek entrance & -81.3667 & 31.5500 & 1.10 & -0.97 & 0.93 & 0.15 & -28 \\
\hline Bear River Entrance & -81.3167 & 31.4833 & 1.10 & -0.95 & 0.92 & 0.16 & -27 \\
\hline North Newport River & -81.4667 & 31.3333 & 1.20 & -1.01 & 0.95 & 0.13 & -32 \\
\hline South Newport Cut, N. Newport River & -81.4000 & 31.3000 & 1.15 & -1.02 & 0.97 & 0.11 & -43 \\
\hline
\end{tabular}

Like the maximum current predictions, high/low water predictions are also based on numerical modeling. The predictions are less reliable sources than the actual measurements and are only used for calibration when there is no measured data available. Nevertheless, when both sources are available, the final calibration statistics for them are published together with the measurement data even if they are not used in calibration. 


\subsection{Validation of model results}

An independent validation of the model performance in predicting tidal elevation and depth-averaged velocity was done by the Oak Ridge National Laboratory (ORNL) at locations where true values were taken as point measurements from tidal monitoring stations (Stewart and Neary, 2011). Two classes of point measurements were defined for the purpose of validation: Class 1 validation is a split sample validation commonly used to evaluate the performance of a calibrated model with measurements independent of those used for calibration, whereas Class 2 validation is an assessment of the model calibration procedure using different performance metrics (Stewart and Neary, 2011) than those described here. More than fifty measurement stations are selected for validation based on 1) Various levels of power densities; 2) Vicinity to larger population and cities; and 3) Representative of several different areas along the U.S. Correlation statistics, including phase shift, amplitude ratio, and coefficient of determination $\left(\mathrm{R}^{2}\right)$ value are calculated along with model performance metrics that include the root mean square error, Nash-Sutcliffe efficiency coefficient, and mean absolute error. Predicted and measured depth-averaged current speed frequency and cumulative frequency histograms, means, standard deviation and maximum and minimum value are compared. Further information about the validation procedure and detailed results is available in the original source (Stewart and Neary, 2011).

Following the EMEC guidelines for a regional assessment, model predictions are considered adequate when predicted maximum current speeds are within $30 \%$ of those estimated from tidal monitoring station measurements. The validation results indicate a fair model performance for predicting currents speeds and tidal elevation with $\mathrm{R}^{2}$ values ranging values ranging from 0.76 to 0.80 and from 0.79 to 0.85 , respectively. The model has a slight tendency to over predict mean and max current speeds for medium to high power density regions and a tendency to under predict speeds in low power density regions. Based on the comparison of measured and predicted current speeds, for both classes of stations located in the medium to high power density regions the model over predicts mean and maximum current speeds by $24 \%$ and $21 \%$ on average, respectively. Similarly, for those stations that are under predicted, it is done so by $-18 \%$ on average for the mean current speeds and $-13 \%$ on average for the max current speed. The model performance for the prediction of tidal elevations is found to be better than the tidal currents.

The validation methodology focuses on comparing the time-series of the current speeds and elevations as opposed to comparing tidal constituents. The time series for model are constructed from the final constituent database and compared to the measured time series. Hence, any effects related to wind driven flow and fresh water intrusion and even localized effects caused by flooding in tidal rivers can influence the validation results. In addition, the validation procedure recognizes the limitations of regional assessment models with coarse grid resolution to predict local variations in current speed and tidal elevation within $300 \mathrm{~m}$ to $500 \mathrm{~m}$ parcels. Model performance evaluations are therefore restricted because model predicted values that are spatially averaged over a $300 \mathrm{~m}$ to $500 \mathrm{~m}$ grid cell cannot be expected to correspond with tidal monitoring station measurements taken at a point at a given latitude and longitude. Tidal currents at places like Admiralty Inlet have been shown to vary greatly over scales less than $500 \mathrm{~m}$ (Epler, 
2010). Overall, the model predictions are found to be satisfactory for purposes of regional assessment of tidal stream power potential.

\subsection{Assessment of tidal stream resource}

The tidal database includes the harmonic constituents for both the water level and the depth-averaged currents. These constituents may be used to compute time series of the currents for any time period and to find the kinetic power density $\left(\mathrm{kW} / \mathrm{m}^{2}\right)$. This is the theoretical available kinetic power density for a particular location which does not include any assumptions about technology, nor does it account for any flow field effects from energy extraction.

At the request of DOE, we have also estimated the total theoretical available power which has units of power (ie gigawatts). This needs to be estimated on the scale of individual estuaries and involves the total power and not just the kinetic power of the tides. This estimate also requires incorporating the cumulative effects of energy dissipation to determine the maximum amount of energy which may be dissipated. However, this estimate also does not involve assumptions about particular technologies.

\subsubsection{Theoretical available kinetic power density}

The tidal stream power is evaluated by computing the kinetic power density from the tidal current speeds using

$$
P=\frac{1}{2} \cdot \rho \cdot V^{3}
$$

where $P$ is the tidal stream power per unit area of flow, i.e. tidal stream power density, $\rho$ is the density of seawater and $V$ is the current speed. Because of the desire towards the use of open turbines rather than tidal barrages, and the fact that existing tidal stream power conversion technologies have minimum current speed requirements for power take-off, there is a tendency for the identification of hotspots based on the kinetic power of the tides rather than their tidal head. Stronger tidal streams mean faster currents, which corresponds to a cubical increase in power density. The overall power that can be converted from tidal streams is a function of both the kinetic and potential energy, with other parameters such as the site characteristics, device characteristics and environmental impacts also influencing the calculation of the practical resource potential (defined as the amount of power which can actually be extracted under all such constraints). Calculating the practical resource of a hotspot will require much more detailed site characterization.

On the other hand, a regional assessment is well suited for the purpose of site screening. Additionally, minimum current speed and minimum depth requirements can be imposed in order to narrow down the number of hotspots. Generally, tidal stream power converters require a minimum flow speed (cut-in speed) to start operating, which ranges from $0.5 \mathrm{~m} / \mathrm{s}$ to $1 \mathrm{~m} / \mathrm{s}$ depending on their design. Although some studies that simulate power extraction acknowledge cut-in speed values for the horizontal axis turbines as large as $1 \mathrm{~m} / \mathrm{s}$ (Lim and Koh, 2010; Myers and Bahaj, 2005), there are many examples with cut-in speeds around $0.7 \mathrm{~m} / \mathrm{s}$ and a vertical axis turbine with $0.5 \mathrm{~m} / \mathrm{s}$ (Bedard et al., 2006; Fraenkel, 2007; Lee et al., 2009). In this study, the minimum for the power density is selected as $500 \mathrm{~W} / \mathrm{m}^{2}$ which corresponds to a flow speed of $\sim 1 \mathrm{~m} / \mathrm{s}$. If the 
maximum of the mean kinetic power does not exceed $500 \mathrm{~W} / \mathrm{m}^{2}$ within the boundaries of the hotspot area the hotspot is excluded from the list. Regardless of their design, the tidal stream power converters also require a minimum depth that allows for allocating the device with enough top and bottom clearance. The dimensions of tidal stream power devices change from several meters to tens of meters (Bedard et al., 2006; Froberg, 2006), and since the analysis in this study does not depend on a specific device the minimum depth is chosen to be $5 \mathrm{~m}$, large enough to accommodate a small size conversion device with the existing technology. Finally, the list of hotspots is filtered with a minimum surface area requirement of $0.5 \mathrm{~km}^{2}$. The surface area does not contribute to power density, is expected to accommodate larger space for development. This final filter also reduces the number hotspots to a two-page list by removing more than two thirds of the initial list. Based on these criteria, the geospatial data along the USA coast has been filtered to define the hotspots with notable tidal stream power densities, which are listed in Table 5. The coordinates of each hotspot location, maximum and average depth with respect to Mean Lower Low Water (MLLW), and surface area of these regions are given together with the largest mean power density within each location. For brevity, the listed locations mark the general vicinity of the hotspots and do not necessarily pinpoint the exact location of each hotspot individually. For further analysis the reader is suggested to visit the original geodatabase (GT, 2011).

Table 5. Locations and characteristics of the theoretical available tidal stream density hotspots along the coast of USA.

\begin{tabular}{|c|c|c|c|c|c|c|}
\hline State & Hotspot & $\begin{array}{l}\text { Location } \\
\text { (degrees } \mathrm{N} \text {, degrees } \mathrm{W} \text { ) }\end{array}$ & $\begin{array}{l}\text { Surface } \\
\text { Area } \\
\text { (sqkm) }\end{array}$ & $\begin{array}{l}\text { Maximum } \\
\text { Depth } \\
\text { (m) }\end{array}$ & $\begin{array}{l}\text { Mean } \\
\text { Depth } \\
\text { (m) }\end{array}$ & $\begin{array}{l}\text { Kinetic Power } \\
\text { Density } \\
\text { (W/sqm) }\end{array}$ \\
\hline $\mathrm{ME}$ & Coobscook Bay & $(44.891,67.107)$ & $<1$ & 17 & 14 & 574 \\
\hline ME & Lubec Channel & $(44.853,66.977)$ & $<1$ & 8 & 7 & 891 \\
\hline ME & Grand Manan Channel & $(44.8,66.892)$ & 21 & 101 & 79 & 768 \\
\hline ME & Western Paasage & $(44.911,66.977)$ & 7 & 106 & 43 & 7366 \\
\hline ME & Knubble bay & $(43.882,69.731)$ & $<1$ & 14 & 11 & 730 \\
\hline ME & Hockmock Bay & $(43.902,69.737),(43.912,69.718)$ & $<1,<1$ & 12,7 & 7,6 & 1747,567 \\
\hline ME & Kennebeck River & $(43.93,69.81),(43.969,69.825)$ & $<1,<1$ & 7,8 & 7,8 & 552,528 \\
\hline $\mathrm{ME} / \mathrm{NH}$ & Piscataqua River & $\begin{array}{l}(43.073,70.728),(43.092,70.775), \\
(43.113,70.807)\end{array}$ & $\begin{array}{l}2,1 \\
<1\end{array}$ & $\begin{array}{l}20,17 \\
13\end{array}$ & $\begin{array}{l}13,12 \\
9\end{array}$ & $\begin{array}{l}2823,2633 \\
1239\end{array}$ \\
\hline MA & Nantucket Sound & $(41.197,69.902),(41.345,70.396)$ & $\begin{array}{l}398 \\
202\end{array}$ & 38,39 & 16,10 & 7328,4844 \\
\hline MA & Vineyard Sound & $(41.499,70.647),(41.362,70.854)$ & 137,2 & 33,24 & 19,15 & 3344,603 \\
\hline NY & Block Island Sound & $\begin{array}{l}(41.229,72.061),(41.167,72.21), \\
(41.075,71.845)\end{array}$ & $\begin{array}{l}7,2 \\
4\end{array}$ & $\begin{array}{l}85,49 \\
15\end{array}$ & $\begin{array}{l}38,21 \\
12\end{array}$ & $\begin{array}{l}740,610 \\
530\end{array}$ \\
\hline NY & East Rive & $\begin{array}{l}(40.79,73.935),(40.775,73.937), \\
(40.706,73.979)\end{array}$ & $\begin{array}{l}<1,< \\
1, \\
<1\end{array}$ & $\begin{array}{l}5,1 \\
11\end{array}$ & $\begin{array}{l}5,6 \\
11\end{array}$ & $\begin{array}{l}547,1546 \\
768\end{array}$ \\
\hline NJ & Delaware Bay & $(38.921,74.963)$ & 11 & 13 & 9 & 913 \\
\hline NC & Cape Hatteras & $(35.185,75.762)$ & $<1$ & 9 & 8 & 1378 \\
\hline NC & Portsmouth Island & $(35.068,76.016)$ & 3 & 10 & 7 & 911 \\
\hline SC & Cooper River & $(32.88,79.961)$ & $<1$ & 8 & 7 & 830 \\
\hline SC & North Edisto River & $(32.576,80.2)$ & 7 & 19 & 12 & 1008 \\
\hline SC & Coosaw River & $(32.492,80.49)$ & 12 & 17 & 10 & 566 \\
\hline GA & Ogeechee River & $(31.856,81.118)$ & 1 & 8 & 7 & 834 \\
\hline GA & Altamaha River & $(31.319,81.309)$ & 1 & 8 & 6 & 511 \\
\hline GA & Satilla River & $(30.97,81.505)$ & $<1$ & 8 & 7 & 606 \\
\hline $\mathrm{GA} / \mathrm{FL}$ & St Marys River & $(30.707,81.445),(30.721,81.508)$ & $5,<1$ & 20,8 & 12,6 & 798,705 \\
\hline $\mathrm{FL}$ & Florida Keys & $\begin{array}{l}(24.692,81.143),(24.681,81.168), \\
(24.574,81.839),(24.556,82.056)\end{array}$ & $\begin{array}{l}3,1 \\
10,29\end{array}$ & $\begin{array}{l}10,7 \\
11,10\end{array}$ & $\begin{array}{l}6,6 \\
7,6\end{array}$ & $\begin{array}{l}992,643 \\
904,538\end{array}$ \\
\hline
\end{tabular}




\begin{tabular}{|c|c|c|c|c|c|c|}
\hline $\mathrm{FL}$ & Port Boca Grande & $(26.716,82.251)$ & $<1$ & 20 & 10 & 1140 \\
\hline FL & St Vincrnt island & $(29.625,85.101)$ & $<1$ & 11 & 8 & 625 \\
\hline CA & Golden Gate & $(37.822,122.471)$ & $<1$ & 111 & 50 & 750 \\
\hline CA & Carquinez Strait & $(38.036,122.158)$ & 12 & 36 & 19 & 914 \\
\hline CA & Humbolt Bay Entrance & $(40.757,124.231)$ & $<1$ & 11 & 9 & 941 \\
\hline OR & Coos Bay Entrance & $(43.353,124.339)$ & 1 & 13 & 8 & 2480 \\
\hline WA & Columbia River & $(46.254,124.026),(46.253,123.563)$ & 35,2 & 14,11 & 11,10 & 1751,689 \\
\hline WA & Grays Harbor & $(46.917,124.117)$ & 11 & 9 & 8 & 576 \\
\hline WA & Haro Strait & $(48.495,123.154),(48.587,123.218)$ & 15,15 & 276,271 & 232,199 & 625,503 \\
\hline WA & Spieden Channel & $(48.63,123.126)$ & 5 & 60 & 43 & 1893 \\
\hline WA & President Channel & $(48.656,123.139),(48.679,122.999)$ & 4,4 & 54,155 & 39,129 & 1227,528 \\
\hline WA & San Juan Channel & $(48.547,122.978)$ & 7 & 93 & 62 & 1030 \\
\hline WA & Middle Channel & $(48.459,122.949)$ & 8 & 93 & 60 & 2380 \\
\hline WA & Boundary Pass & $(48.735,123.061)$ & 8 & 308 & 163 & 620 \\
\hline WA & Rosario Strait & $(48.594,122.755)$ & 45 & 92 & 53 & 3349 \\
\hline WA & Bellingham Channel & $(48.556,122.658)$ & 17 & 45 & 27 & 3077 \\
\hline WA & Guemes Channel & $(48.523,122.621)$ & 2 & 8 & 7 & 1777 \\
\hline WA & Deception Pass & $(48.407,122.627)$ & 2 & 6 & 6 & 1058 \\
\hline WA & Admiralty Inlet & $(48.162,122.737)$ & 54 & 141 & 62 & 907 \\
\hline WA & Puget Sound & $(47.591,122.559)$ & 2 & 22 & 11 & 2568 \\
\hline WA & Tacoma Narrows & $(47.268,122.544)$ & 13 & 64 & 39 & 5602 \\
\hline WA & Dana Paasage & $(47.164,122.862)$ & 3 & 18 & 13 & 1851 \\
\hline AK & Bristol Bay & $\begin{array}{l}(58.604,162.268),(58.532,160.923) \\
(58.442,158.693)\end{array}$ & $\begin{array}{l}160 \\
11 \\
304\end{array}$ & $\begin{array}{l}48,13 \\
19.9\end{array}$ & $\begin{array}{l}28,11 \\
12\end{array}$ & $\begin{array}{l}5000,654, \\
957\end{array}$ \\
\hline AK & Nushagak Bay & $(58.975,158.519)$ & 122 & 14 & 8 & 2811 \\
\hline AK & Hague Channel & $(55.908,160.574)$ & 1 & 24 & 17 & 564 \\
\hline $\mathrm{AK}$ & Herendeen Bay Entrance & $(55.892,160.793)$ & 10 & 38 & 19 & 1564 \\
\hline AK & Moffet Lagoon Inlet & $(55.446,162.587)$ & 1 & 7 & 7 & 845 \\
\hline AK & Izembek Lagoon & $(55.328,162.896),(55.248,162.981)$ & $<1,1$ & 8,6 & 7,6 & 539,1606 \\
\hline AK & Bechevin Bay & $(55.048,163.45)$ & 4 & 7 & 6 & 2252 \\
\hline AK & False Pass & $(54.827,163.384)$ & 5 & 60 & 35 & 1619 \\
\hline AK & Unimak Pass & $(54.333,164.824)$ & 132 & 82 & 57 & 830 \\
\hline AK & Ugamak Strait & $(54.168,164.914)$ & 63 & 88 & 48 & 1341 \\
\hline AK & Derbin Strait & $(54.092,165.235)$ & 23 & 97 & 54 & 2348 \\
\hline AK & Avatanak Strait & $(54.108,165.478)$ & 73 & 136 & 73 & 911 \\
\hline AK & Akutan Bay & $(54.129,165.649)$ & 4 & 44 & 26 & 3365 \\
\hline AK & Akutan Pass & $(54.025,166.074)$ & 50 & 83 & 49 & 2870 \\
\hline AK & Unalga Pass & $(53.948,166.21)$ & 25 & 117 & 64 & 3751 \\
\hline AK & Umnk Pass & $(53.322,167.893)$ & 97 & 138 & 56 & 2144 \\
\hline AK & Samalga Pass & $\begin{array}{l}(52.808,169.122),(52.765,169.346) \\
(52.757,169.686)\end{array}$ & $\begin{array}{l}8,138 \\
66\end{array}$ & $\begin{array}{l}30,277 \\
195\end{array}$ & $\begin{array}{l}13,103 \\
140\end{array}$ & $\begin{array}{l}4102,1718, \\
794\end{array}$ \\
\hline AK & Islands of Four Mountains & $(52.862,169.998)$ & 7 & 147 & 53 & 2505 \\
\hline AK & Seguam Pass & $(52.247,172.673),(52.132,172.826)$ & 52,128 & 190, 151 & 129,85 & 800,538 \\
\hline AK & Atka Island & $(52.121,174.065)$ & 41 & 70 & 36 & 3444 \\
\hline AK & Fenimore Pass & $(51.998,175.388),(51.979,175.477)$ & 4,28 & 95,30 & 52,16 & 2147,1554 \\
\hline AK & Fenimore Pass & $(51.974,175.532),(51.961,175.649)$ & 3,1 & 97,25 & 50,20 & 2410,1304 \\
\hline AK & Chugul Island & $(51.937,175.755),(51.961,175.866)$ & 9,9 & 100,81 & 47,48 & 1677,1600 \\
\hline AK & Igitkin Island & $(51.968,175.974)$ & 9 & 93 & 59 & 1110 \\
\hline AK & Unmak Island & $(51.857,176.066)$ & 1 & 26 & 22 & 1155 \\
\hline AK & Little Tanaga Strait & $(51.818,176.254)$ & 6 & 68 & 43 & 2276 \\
\hline AK & Kagalaska Strait & $(51.79,176.414)$ & 1 & 20 & 18 & 758 \\
\hline AK & Adak Strait & $(51.816,176.982)$ & 63 & 93 & 63 & 807 \\
\hline AK & Kanaga Pass & $(51.723,177.748)$ & 36 & 55 & 29 & 889 \\
\hline AK & Delar of Islands & $\begin{array}{l}(51.677,178.19),(51.55,178.467) \\
(51.564,178.716),(51.586,178.928)\end{array}$ & $\begin{array}{l}83,54 \\
8,31\end{array}$ & $\begin{array}{l}217,102 \\
19,126\end{array}$ & $\begin{array}{l}78,64 \\
11,66\end{array}$ & $\begin{array}{l}764,649 \\
537,1053\end{array}$ \\
\hline AK & Chirikof island & $(55.964,155.45)$ & 198 & 44 & 31 & 597 \\
\hline AK & Tugidak Island & $(56.294,154.872)$ & 284 & 51 & 26 & 681 \\
\hline AK & Sitkinak Island & $(56.512,154.383)$ & 13 & 40 & 8 & 3104 \\
\hline
\end{tabular}




\begin{tabular}{|c|c|c|c|c|c|c|}
\hline AK & Aiaktalik Island & $(56.639,154.072),(56.738,154.053)$ & 79,23 & 69,33 & 28,16 & 2497,2038 \\
\hline AK & Moser Bay & $(57.038,154.115)$ & 3 & 10 & 7 & 1874 \\
\hline AK & Kopreanof Strait & (57.934, 152.84), $(57.987,152.795)$ & 17,10 & 59,21 & 29,14 & 5454,4636 \\
\hline AK & Shuyak Strait & $(58.466,152.496)$ & 2 & 23 & 15 & 1007 \\
\hline AK & Stevenson Entrance & $(58.647,152.292),(58.663,152.525)$ & 33,7 & 157,75 & 102,39 & 895,779 \\
\hline AK & Barren Islands & $(58.939,152.127),(58.855,152.345)$ & 15,9 & 115,127 & 73,78 & 686,571 \\
\hline AK & Chugach Island & $\begin{array}{l}(59.091,151.777),(59.12,151.875) \\
(59.148,151.74),(59.163,151.531) \\
(59.082,151.433)\end{array}$ & $\begin{array}{l}34,19 \\
15,13 \\
20\end{array}$ & $\begin{array}{l}116,96 \\
90,58 \\
64\end{array}$ & $\begin{array}{l}54,64 \\
26,34 \\
47\end{array}$ & $\begin{array}{l}587,528 \\
1466,916 \\
852\end{array}$ \\
\hline AK & Cook Inlet & $(60.676,151.58)$ & 5285 & 140 & 34 & 5344 \\
\hline AK & Turnagain Arm & $\begin{array}{l}(60.978,149.825),(60.982,149.702) \\
(60.998,149.729)\end{array}$ & $\begin{array}{l}8,5 \\
2\end{array}$ & $\begin{array}{l}13,6 \\
5\end{array}$ & $\begin{array}{l}9,5 \\
5\end{array}$ & $\begin{array}{l}3199,657 \\
558\end{array}$ \\
\hline AK & Knik Arm & $\begin{array}{l}(61.385,149.809),(61.396,149.77) \\
(61.41,149.734),(61.428,149.709) \\
(61.371,149.726)\end{array}$ & $\begin{array}{l}4,2 \\
2,3 \\
3\end{array}$ & $\begin{array}{l}6,5 \\
5,7 \\
6\end{array}$ & $\begin{array}{l}6,5 \\
5,6 \\
6\end{array}$ & $\begin{array}{l}1993,742 \\
749,597 \\
1048\end{array}$ \\
\hline AK & Shelikof Strait & $(58.239,151.752)$ & 15 & 31 & 24 & 524 \\
\hline AK & Montague Strait & $(59.767,147.966)$ & 29 & 36 & 26 & 691 \\
\hline AK & Icy Strait & $(58.353,135.994)$ & 274 & 287 & 94 & 8781 \\
\hline AK & Cross Sound & $\begin{array}{l}(58.223,136.356),(58.225,136.302) \\
(58.256,136.372),(58.288,135.819)\end{array}$ & $\begin{array}{l}3,3 \\
1,9\end{array}$ & $\begin{array}{l}79,139 \\
55,124\end{array}$ & $\begin{array}{l}72,79 \\
46,84\end{array}$ & $\begin{array}{l}976,503 \\
945,513\end{array}$ \\
\hline AK & Adams Inlet & $(58.863,135.979)$ & 4 & 16 & 9 & 1426 \\
\hline AK & Peril Strait & $(57.455,135.549),(57.371,135.695)$ & 1,2 & 7,43 & 7,24 & 3285,892 \\
\hline AK & Taku inlet & $(58.384,134.032)$ & 4 & 14 & 10 & 864 \\
\hline AK & Seymour Canal & $(57.922,134.156),(57.93,134.276)$ & $\begin{array}{l}<1,< \\
1\end{array}$ & 14,5 & 14,5 & 770,976 \\
\hline AK & Summer Strait & $\begin{array}{l}(56.369,133.658),(56.437,133.19) \\
(56.441,133.028)\end{array}$ & $\begin{array}{l}11,6 \\
4\end{array}$ & $\begin{array}{l}185,45 \\
184\end{array}$ & $\begin{array}{l}67,15 \\
101\end{array}$ & $\begin{array}{l}1474,801 \\
529\end{array}$ \\
\hline AK & Duncan Canal & $(56.54,133.088)$ & $<1$ & 37 & 37 & 604 \\
\hline AK & Kashevarof Passage & $(56.233,133.043),(56.269,132.948)$ & 6,7 & 37,109 & 27,80 & 1039,744 \\
\hline AK & Meares Passage & $(55.259,133.109)$ & 1 & 17 & 14 & 1692 \\
\hline
\end{tabular}

The list of hotspots in table 5 shows that Alaska (AK) has the largest number of hotspots, including some of the largest kinetic power density in the USA. With a surface area that is an order of magnitude larger than the rest of the hotspots and a substantially large kinetic power density, Cook Inlet is one of the best resources of tidal stream power. The largest kinetic power density locations include Bristol Bay, Akutan, Unalga and Samalga Passes, Sikitnak Island, Turnagain Arm; and Kopreanof, Icy and Peril Straits. Maine (ME), Washington (WA), Oregon (OR), California (CA), New Hampshire (NH), Massachusetts (MA), New York (NY), New Jersey (NJ) North and South Carolina (NC, SC) , Georgia (GA), and Florida (FL) follow Alaska. Tacoma Narrows, Rosario Strait, Bellingham Channel, Nantucket Sound and Western Passage are some of the hotspots with largest kinetic power density. The list given with this study includes the top tier tidal stream power density hotspots at a national resource assessment scale based on numerical modeling of the tidal currents and after certain filtering. There are many locations that are excluded as a result of applied filters, however, they can be found in the original geodatabase. Some of the filtered locations with tidal power density greater than $250 \mathrm{~W} / \mathrm{m}^{2}$ include, but not limited to Cape Cod Canal in MA; Hudson River in NY; Great Egg Harbor Bay in NJ; Cape Fear in NC; Charleston Harbor, Port Royal Sound, Cooper and Beaufort Rivers in SC; St Johns River in FL; Carquinez Strait, Eel and Siltcoos Rivers in CA, Mud Bay Entrance and Cooper River Delta in AK. There may also be additional locations that are viable for tidal stream power conversion, but which are not resolved by the numerical model. These are probably local resources that can only be detected through finer modeling at smaller scales or with field measurements such as the Kootznahoo Inlet in AK; Willapa 
Bay in WA; Sheepscot Bay in ME; Shelter Island Sound in NY; Manasquan River in NJ.

\subsubsection{Total theoretical available power estimates}

The published maps and the database provide the distribution of the existing kinetic power density of tidal streams in the undisturbed flow conditions. These results do not include any technology assumptions or flow field effects as in the case of device arrays. In order to calculate a theoretical upper bound based on physics only, a simplified method that considers both the kinetic and potential power with the exclusion of any technology specific assumptions is applied. The details of the method is outlined in a recent paper (Garrett and Cummins, 2005). The power calculated with this method is used in estimating the tidal power potential for the entire country with a specific value for each state. The method uses undisturbed flow field from the model with simple analytical methods, accounts for the cumulative effect of dissipating energy and provides information on an estuary scale.

Considering a constricted channel connecting two large bodies of water in which the tides at both ends are assumed to be unaffected by the currents through the channel, a general formula gives the maximum average power as between 20 and $24 \%$ of the peak tidal pressure head times the peak of the undisturbed mass flux through the channel. This maximum average power is independent of the location of the turbine fences along the channel. Maximum average tidal stream power, $P_{\max }$, is given as

$$
P_{\max }=\gamma \cdot \rho \cdot g \cdot a \cdot Q_{\max }
$$

where $\gamma$ is a parameter, $\rho$ is the density of seawater, $a$ is the amplitude of the tidal water level constituent and $Q_{\max }$ is the maximum corresponding tidal flow rate. For a background friction dominated, nonsinusoidal (i.e. considering more than one tidal constituent) case, if data for the head and flux in the natural state are available, the maximum average power may be estimated with an accuracy of $10 \%$ using $\gamma=0.22$, without any need to understand the basic dynamical balance (Garrett and Cummins, 2005). . A multiplying factor is used to account for additional constituents $\left(a_{1}, a_{2}, \ldots\right)$ given as

where $r_{1}=\frac{a_{1}}{a}, r_{2}=\frac{a_{2}}{a} \ldots$

$$
1+\left(\frac{9}{16}\right)\left(r_{1}^{2}+r_{2}^{2}+\cdots\right)
$$

This upper bound on the available power ignores losses associated with turbine operation and assumes that turbines are deployed in uniform fences, with all the water passing through the turbines at each fence.

This method is applied to the locations bounded between two land masses and has locally increased tidal current speed along the United States coast. A list of these locations grouped by state is given in Table 6 . The list displays the coordinates and the name of each location (i.e. the midpoint) together with the width, mean/maximum of the constriction and the total theoretical available power. The totals are given for each state and for the entire country. Once again, Alaska with a total of 47GW constitutes the largest piece of the national total of $50 \mathrm{GW}$. Cook Inlet has the largest average maximum available power of 18 GW (Figure A22) closely followed by Chatham Strait with $12 \mathrm{GW}$ (Figure A20). Alaska is stands out as an abundant resource of tidal stream 
power with eighty different promising locations. The top ten of these locations include, in addition to Cook Inlet and Chatham Strait: north of Inian Islands (2.5 GW) in Figure A20, Summer Strait (2.7 GW), northeast of Warren Island (535 MW), Clarence Strait $(4.1 \mathrm{GW})$ in Figure A19, between Sundstrom and Sitkinak Islands (628 MW) in Figure A21, between Seguam and Amlia Islands (1.2 GW) in Figure A26, Kagalaska and Adak Islands (424 MW) in Figure A28., and between Unalga and Kavalga Islands (435 MW) in Figure A29.

On a state by state basis Alaska is followed by Washington and Maine with 683 and 675 MW, respectively. The other states with considerable average maximum power available from tidal streams include South Carolina (388 MW), New York (280 MW), Georgia (219 MW), California (204 MW), New Jersey (192 MW), Florida (166 MW), Delaware (165 MW) and Virginia (133MW). In addition, Massachusetts (66 MW), North Carolina (66 MW), Oregon (48 MW), Maryland (35 MW) include other possible energetic locations with Rhode Island (16 MW) and Texas (6 MW) having somewhat limited overall tidal stream power. Some of the sites with considerably larger power than their other alternatives in these states include: Admiralty Inlet Entrance, WA (456 MW) in Figure A18; east of Cross Island (269 MW) and south of Eastport, ME (106 MW) in Figure A2; St Helena (102 MW) and Port Royal Sounds, SC (109 MW) in Figure A9; Fisher Island Sound Entrance ( 186 MW), St Catherine (44 MW) and Sapelo Sounds , GA (47 MW) in Figure A10; San Francisco Bay , CA (178 MW) in Figure A17; Delaware Bay (331 MW) in Figure A5; Chesapeake Bay Entrance (130 MW) in Figure A6 and the Florida Keys in Figure A12.

\section{Table 6. Locations and characteristics of the total theoretical available power along the coast of USA.}

\begin{tabular}{|c|c|c|c|c|c|c|c|}
\hline $\begin{array}{l}\text { Latitude } \\
\text { (deg) }\end{array}$ & $\begin{array}{l}\text { Longitude } \\
\text { (deg) }\end{array}$ & $\begin{array}{l}\text { Width } \\
\text { (m) }\end{array}$ & $\begin{array}{l}\text { Mean } \\
\text { depth } \\
(\mathrm{m})\end{array}$ & $\begin{array}{l}\text { Max } \\
\text { depth } \\
\text { (m) }\end{array}$ & Name & State & $\begin{array}{l}\text { Maximum } \\
\text { Power } \\
\text { (MW) }\end{array}$ \\
\hline 44.8889 & -66.9908 & 1499 & 15.8 & 26.3 & S of Eastport & ME & 106 \\
\hline 44.9364 & -67.0465 & 374 & 1.2 & 1.4 & Bar Harbor & ME & 4 \\
\hline 44.6198 & -67.2786 & 765 & 6.5 & 7.6 & $\mathrm{~N}$ of Cross Island & ME & 26 \\
\hline 44.5940 & -67.5486 & 1362 & 6.6 & 15.3 & NE of Roque Island & ME & 32 \\
\hline 44.5915 & -67.3949 & 943 & 4.0 & 7.3 & Btwn Starboard and Foster Islands & ME & 21 \\
\hline 44.5905 & -67.3551 & 7008 & 29.1 & 56.6 & E of Cross Island & ME & 269 \\
\hline 44.5249 & -67.6161 & 582 & 8.3 & 10.5 & S of Jonesport & ME & 22 \\
\hline 44.5148 & -67.5655 & 813 & 3.6 & 5.5 & Btwn Sheep and Head Harbor Islands & ME & 15 \\
\hline 44.5688 & -67.7583 & 628 & 2.8 & 3.1 & Channel Rock & ME & 9 \\
\hline 44.3851 & -67.8845 & 2826 & 6.3 & 8.4 & Btwn Southwest Breaker and Green Islands & ME & 68 \\
\hline 44.1332 & -68.3631 & 2036 & 10.5 & 15.1 & Btwn East Sister and Crow Islands & ME & 61 \\
\hline 44.2756 & -68.6756 & 459 & 1.4 & 1.4 & Deer Isle & ME & 3 \\
\hline 44.5517 & -68.8007 & 470 & 4.0 & 4.0 & E of Verona Island & ME & 10 \\
\hline 43.8503 & -69.7152 & 627 & 17.3 & 19.8 & NE of Mac Mahan Island & ME & 10 \\
\hline 43.7909 & -69.7857 & 619 & 12.5 & 12.8 & $\mathrm{~N}$ of Perkins Island & ME & 19 \\
\hline State Total & & & & & & ME & 675 \\
\hline 43.0730 & -70.7075 & 656 & 12.7 & 18.0 & New Castle & $\mathrm{MA}$ & 21 \\
\hline 42.8198 & -70.8176 & 428 & 6.3 & 6.5 & Badgers Rock & MA & 11 \\
\hline 42.6960 & -70.7756 & 1049 & 2.9 & 5.0 & Bass Rock & MA & 15 \\
\hline 42.2997 & -70.9245 & 525 & 9.1 & 12.0 & Hull Gut & MA & 13 \\
\hline
\end{tabular}




\begin{tabular}{|c|c|c|c|c|c|c|c|}
\hline 42.6647 & -70.7214 & 340 & 5.1 & 6.3 & Essex Bay Entrance & $\mathrm{MA}$ & 6 \\
\hline State Total & & & & & & MA & 66 \\
\hline 41.6254 & -71.2160 & 468 & 6.8 & 11.8 & Stone Bridge & RI & 2 \\
\hline 41.3845 & -71.5136 & 787 & 1.1 & 1.5 & Point Judith Pond & RI & 1 \\
\hline 41.4708 & -71.3652 & 1446 & 28.2 & 45.4 & Newport & RI & 12 \\
\hline 41.3591 & -71.6399 & 254 & 2.0 & 2.0 & Charlestown Breachway & $\mathrm{RI}$ & 1 \\
\hline State Total & & & & & & $\mathbf{R} \mathbf{I}$ & 16 \\
\hline 41.2985 & -71.9061 & 4419 & 8.3 & 22.6 & Fishers Island Sound Entrance N (Closed) & NY & 21 \\
\hline 41.2234 & -72.0758 & 7887 & 25.4 & 84.3 & Fishers Island Sound Centeral Entrance & NY & 186 \\
\hline 41.1647 & -72.2234 & 2438 & 10.6 & 23.5 & Fishers Island SoundEntrance S & NY & 28 \\
\hline 41.1090 & -72.3388 & 908 & 13.3 & 17.1 & $\mathrm{~N}$ of Shelter Island & NY & 7 \\
\hline 41.0415 & -72.3175 & 602 & 6.7 & 9.7 & Btwn Shelter Island and North Haven & NY & 4 \\
\hline 40.8443 & -72.4763 & 241 & 2.5 & 2.5 & Shinnecock Bay Entrance & NY & 1 \\
\hline 40.5831 & -73.5768 & 518 & 2.8 & 3.2 & Point Lookout & NY & 3 \\
\hline 40.5758 & -73.8764 & 951 & 8.0 & 9.8 & Martine Parkway Bridge & NY & 9 \\
\hline 40.7885 & -73.9357 & 263 & 4.6 & 4.6 & Wards Island Bridge & NY & 6 \\
\hline 40.8085 & -73.9769 & 794 & 13.2 & 17.8 & Hudson River & NY & 15 \\
\hline State Total & & & & & & NY & 280 \\
\hline 39.7659 & -74.1002 & 354 & 2.2 & 2.2 & Barnegat & NJ & 1 \\
\hline 39.5110 & -74.2991 & 662 & 2.5 & 3.3 & Point Creek & NJ & 4 \\
\hline 39.5031 & -74.3264 & 884 & 4.3 & 5.4 & Little Egg Inlet & NJ & 5 \\
\hline 39.4477 & -74.3280 & 689 & 4.0 & 5.3 & Steelman Bay & NJ & 3 \\
\hline 39.3738 & -74.4101 & 686 & 5.1 & 9.2 & Absecon Inlet & NJ & 2 \\
\hline 39.3003 & -74.5534 & 1322 & 4.0 & 7.6 & Great Egg Harbor Inlet & NJ & 6 \\
\hline 39.2047 & -74.6473 & 1022 & 1.2 & 1.5 & Corson Inlet & NJ & 2 \\
\hline 39.0163 & -74.7879 & 895 & 1.1 & 1.6 & Hereford Inlet & NJ & 1 \\
\hline 38.9487 & -74.8739 & 683 & 2.3 & 3.0 & Cape May Inlet & NJ & 2 \\
\hline State Total & & & & & & NJ & 191.5 \\
\hline 38.8664 & -75.0262 & 18729 & 14.7 & 39.3 & Delaware Bay & NJ-DE & 331 \\
\hline State Total & & & & & & $\mathrm{DE}$ & 165.5 \\
\hline 38.3246 & -75.0962 & 330 & 1.1 & 2.3 & Ocean City Inlet & MD & 2 \\
\hline 37.8798 & -75.4122 & 12558 & 1.2 & 1.8 & Toms Cove & $\mathrm{MD}$ & 33 \\
\hline State Total & & & & & & MD & 35 \\
\hline 37.0072 & -75.9869 & 17521 & 11.6 & 26.2 & Chesapeake Bay Entrance & VA & 130 \\
\hline 37.1075 & -75.9314 & 1708 & 1.2 & 1.5 & Magothy Bay Entrance & VA & 3 \\
\hline State Total & & & & & & VA & 133 \\
\hline 35.7822 & -75.5302 & 2735 & 2.9 & 6.0 & Oregon Inlet & NC & 9 \\
\hline 35.1930 & -75.7626 & 843 & 4.4 & 7.3 & Cape Hatteras & NC & 4 \\
\hline 35.0682 & -76.0149 & 2367 & 4.2 & 6.5 & Portsmouth & NC & 10 \\
\hline 34.8559 & -76.3205 & 1561 & 1.0 & 1.2 & Core Sound & NC & 1 \\
\hline 34.6930 & -76.6738 & 1160 & 3.3 & 4.4 & Beaufort Inlet & NC & 6 \\
\hline 34.6536 & -76.5547 & 578 & 0.7 & 0.7 & Lookout Bight & $\mathrm{NC}$ & 1 \\
\hline 34.6455 & -77.1066 & 1549 & 1.7 & 1.7 & Hammocks Beach & NC & 4 \\
\hline 34.6250 & -77.1764 & 419 & 1.7 & 1.8 & Bear Inlet & NC & 1 \\
\hline 34.5956 & -77.2312 & 408 & 2.4 & 2.4 & S of Browns Island & NC & 1 \\
\hline 34.5328 & -77.3376 & 208 & 2.0 & 2.0 & New River Inlet & NC & 1 \\
\hline 34.3486 & -77.6571 & 219 & 4.1 & 4.1 & S of Topsail Island & NC & 1 \\
\hline 33.9037 & -78.3807 & 272 & 2.1 & 2.1 & Long Beach S & NC & 1 \\
\hline 33.9166 & -78.2348 & 761 & 2.9 & 4.0 & Long Beach N & NC & 3 \\
\hline 33.8828 & -78.0096 & 1870 & 6.4 & 13.7 & Cape fear River Inlet & NC & 16 \\
\hline 33.9197 & -77.9436 & 856 & 2.8 & 4.6 & $\mathrm{~N}$ of Bald Head Island & NC & 2 \\
\hline State Total & & & & & & NC & 61 \\
\hline
\end{tabular}




\begin{tabular}{|c|c|c|c|c|c|c|c|}
\hline 33.0795 & -79.3407 & 1591 & 2.3 & 2.8 & Cape Romain Harbor & SC & 5 \\
\hline 32.8808 & -79.6555 & 535 & 2.8 & 3.1 & Price Inlet & SC & 2 \\
\hline 32.7535 & -79.8683 & 1867 & 9.7 & 18.1 & Charleston harbor & SC & 27 \\
\hline 32.6896 & -79.8895 & 265 & 1.6 & 1.6 & Light House Inlet & SC & 1 \\
\hline 32.5705 & -80.1944 & 1022 & 8.7 & 17.2 & S of Seabrook Island & SC & 22 \\
\hline 32.4449 & -80.3867 & 11818 & 5.7 & 11.6 & Saint Helena Sound & SC & 102 \\
\hline 32.3369 & -80.4600 & 501 & 7.1 & 7.4 & $\mathrm{~S}$ of Hunting island & SC & 6 \\
\hline 32.2491 & -80.6599 & 3685 & 12.9 & 16.4 & Port Royal Sound & SC & 109 \\
\hline 32.1198 & -80.8333 & 854 & 14.3 & 16.7 & Calibogue Sound & SC & 25 \\
\hline 32.0796 & -80.8798 & 534 & 4.7 & 8.3 & $\mathrm{~N}$ of Turtle island & SC & 6 \\
\hline State Total & & & & & & SC & 388 \\
\hline 32.0354 & -80.8882 & 483 & 9.7 & 12.5 & $\mathrm{~N}$ of Fort Pulski & SC and GA & 10 \\
\hline 32.0205 & -80.8884 & 481 & 4.4 & 4.9 & S of Fort Pulaski & GA & 5 \\
\hline 31.8682 & -81.0688 & 1891 & 5.6 & 11.0 & Btwn Green Island and Racoon Key & GA & 16 \\
\hline 31.8478 & -81.0792 & 1178 & 6.0 & 7.6 & Btwn Racoon Key and Egg Islands & GA & 15 \\
\hline 31.7117 & -81.1388 & 2542 & 9.1 & 14.6 & St Catherines Sound & GA & 44 \\
\hline 31.5459 & -81.1862 & 2734 & 7.9 & 14.8 & Sapelo Sound & $\mathrm{GA}$ & 47 \\
\hline 31.3185 & -81.3057 & 929 & 4.7 & 6.5 & Altamaha Sound & GA & 12 \\
\hline 31.3075 & -81.3254 & 754 & 1.2 & 2.0 & Buttermilk Sound & $\mathrm{GA}$ & 3 \\
\hline 31.0238 & -81.4451 & 1694 & 4.7 & 6.7 & Jekyll Sound & GA & 18 \\
\hline 30.9681 & -81.5017 & 1482 & 4.8 & 7.0 & $\mathrm{~N}$ of Pompey Island & GA & 18 \\
\hline 30.7110 & -81.4526 & 1132 & 11.6 & 18.2 & Cumberland Sound Entrance & $\mathrm{GA}$ and $\mathrm{FL}$ & 31 \\
\hline State Total & & & & & & GA & 219 \\
\hline 30.5080 & -81.4407 & 1548 & 4.0 & 7.9 & Nassau Sound & $\mathrm{FL}$ & 10 \\
\hline 30.4030 & -81.4153 & 664 & 9.1 & 11.9 & Fort George & $\mathrm{FL}$ & 10 \\
\hline 29.9099 & -81.2898 & 845 & 2.1 & 2.3 & $\mathrm{~N}$ of Anastasia State Park & $\mathrm{FL}$ & 4 \\
\hline 29.8740 & -81.2755 & 291 & 4.8 & 4.8 & Anastasia State Park & $\mathrm{FL}$ & 2 \\
\hline 29.7058 & -81.2275 & 280 & 2.2 & 2.2 & Matanzas Inlet & $\mathrm{FL}$ & 1 \\
\hline 29.0744 & -80.9204 & 635 & 2.0 & 2.4 & Ponce Inlet & $\mathrm{FL}$ & 2 \\
\hline 27.8588 & -80.4481 & 370 & 1.2 & 1.2 & Sebastian Inlet & $\mathrm{FL}$ & 1 \\
\hline 27.4714 & -80.2948 & 371 & 5.2 & 5.2 & Fort Pierce Inlet & $\mathrm{FL}$ & 2 \\
\hline 27.1637 & -80.1652 & 1262 & 1.8 & 3.4 & Saint Lucie Inlet & $\mathrm{FL}$ & 3 \\
\hline 26.9464 & -80.0742 & 373 & 2.3 & 2.3 & Jupiter Inlet & $\mathrm{FL}$ & 1 \\
\hline 26.7740 & -80.0380 & 374 & 2.7 & 2.7 & Palm Beach Shores & $\mathrm{FL}$ & 1 \\
\hline 25.8997 & -80.1253 & 244 & 4.5 & 4.5 & Bay Harbor Inlet & $\mathrm{FL}$ & 1 \\
\hline 25.7656 & -80.1356 & 303 & 2.5 & 2.5 & Miami Harbor Entrance & $\mathrm{FL}$ & 1 \\
\hline 25.7301 & -80.1573 & 373 & 5.8 & 5.8 & Btwn Vigini Key and Key Biscane & $\mathrm{FL}$ & 2 \\
\hline 25.6623 & -80.1583 & 536 & 5.3 & 5.3 & Bill Baggs Cape & $\mathrm{FL}$ & 2 \\
\hline 25.5200 & -80.1737 & 288 & 1.5 & 1.5 & Lewis Cut & $\mathrm{FL}$ & 1 \\
\hline 25.2854 & -80.3739 & 1442 & 1.2 & 1.4 & Little Card Sound & $\mathrm{FL}$ & 1 \\
\hline 24.8401 & -80.7658 & 4490 & 2.4 & 4.3 & Fiesta Key & $\mathrm{FL}$ & 6 \\
\hline 24.7978 & -80.8690 & 4308 & 2.5 & 3.5 & Btwn Long Key and Conch Keys & $\mathrm{FL}$ & 8 \\
\hline 24.7749 & -80.8992 & 1037 & 2.0 & 2.6 & NE of Duck Key & $\mathrm{FL}$ & 2 \\
\hline 24.6976 & -81.1546 & 6395 & 3.1 & 4.7 & W of Piegon Key & $\mathrm{FL}$ & 16 \\
\hline 24.6898 & -81.2019 & 1885 & 2.4 & 3.4 & E of Money Key & $\mathrm{FL}$ & 3 \\
\hline 24.5547 & -81.8231 & 2636 & 6.6 & 10.4 & E of Key West & $\mathrm{FL}$ & 12 \\
\hline 24.5489 & -82.0534 & 9869 & 4.6 & 7.6 & Btwn Boca Grande and Gull Keys & $\mathrm{FL}$ & 28 \\
\hline 25.8262 & -81.4383 & 355 & 0.8 & 0.8 & Jenkins Key & $\mathrm{FL}$ & 1 \\
\hline 26.5305 & -81.9980 & 468 & 1.6 & 1.6 & Little Shell Island & $\mathrm{FL}$ & 1 \\
\hline 26.6088 & -82.2231 & 355 & 6.4 & 6.4 & $\mathrm{~N}$ of North Captiva Island & $\mathrm{FL}$ & 2 \\
\hline 26.5576 & -82.1969 & 955 & 1.6 & 2.7 & Btwn Captiva and North Captiva Islands & $\mathrm{FL}$ & 1 \\
\hline 26.7120 & -82.2562 & 1070 & 8.8 & 13.1 & Boca Grande & $\mathrm{FL}$ & 9 \\
\hline
\end{tabular}




\begin{tabular}{|c|c|c|c|c|c|c|c|}
\hline 27.5472 & -82.7436 & 1399 & 2.6 & 4.6 & Passage Key Inlet & $\mathrm{FL}$ & 3 \\
\hline 27.5685 & -82.7548 & 2468 & 5.7 & 8.9 & Tanpa Bay Entrance & $\mathrm{FL}$ & 9 \\
\hline 27.6070 & -82.7487 & 2331 & 14.2 & 26.6 & $\mathrm{~N}$ of Egmont Key & $\mathrm{FL}$ & 13 \\
\hline 27.6945 & -82.7205 & 408 & 3.7 & 3.7 & Tierra Verde & $\mathrm{FL}$ & 2 \\
\hline 29.9603 & -84.3423 & 2317 & 0.9 & 2.0 & Ochlockonee Bay & $\mathrm{FL}$ & 2 \\
\hline 29.6336 & -85.0971 & 496 & 15.0 & 15.0 & Apalachicola Bay & $\mathrm{FL}$ & 2 \\
\hline 30.3871 & -86.5135 & 1218 & 2.5 & 4.9 & Destin Beach & $\mathrm{FL}$ & 1 \\
\hline State Total & & & & & & $\mathrm{FL}$ & 166 \\
\hline 30.2349 & -88.0521 & 5188 & 5.3 & 16.3 & Pelican Bay & $\mathrm{AL}$ & 7 \\
\hline State Total & & & & & & $A L$ & 7 \\
\hline 29.2646 & -89.9444 & 1329 & 4.7 & 7.4 & Btwn Grand Isle and Isle Grande Terre & LA & 2 \\
\hline State Total & & & & & & LA & 2 \\
\hline 29.3723 & -94.7976 & 2699 & 4.0 & 8.0 & Galveston Bay & $\mathrm{TX}$ & 3 \\
\hline 28.3870 & -96.3821 & 1042 & 1.9 & 2.3 & Matagorda Bay & TX & 1 \\
\hline 27.8835 & -97.0468 & 350 & 5.4 & 5.4 & Middle Pass & $\mathrm{TX}$ & 1 \\
\hline 26.0694 & -97.1746 & 2111 & 1.2 & 2.0 & S of S Padre Island & TX & 1 \\
\hline State Total & & & & & & TX & 6 \\
\hline 32.7204 & -117.1875 & 1124 & 3.0 & 3.9 & San Diego Bay & CA & 3 \\
\hline 38.2166 & -122.9589 & 673 & 1.5 & 1.6 & Tomales Bay & CA & 3 \\
\hline 40.6390 & -124.3147 & 439 & 3.9 & 3.9 & Heckman Island & $\mathrm{CA}$ & 6 \\
\hline 40.7599 & -124.2353 & 663 & 7.8 & 7.9 & Humboldt Bay & $\mathrm{CA}$ & 14 \\
\hline 37.8037 & -122.5186 & 3943 & 30.7 & 51.3 & San Francisco Bay Entrance & CA & 178 \\
\hline State Total & & & & & & CA & 204 \\
\hline 43.1227 & -124.4221 & 267 & 6.3 & 6.3 & Bandon & OR & 5 \\
\hline 43.3537 & -124.3405 & 642 & 7.6 & 8.5 & Coos Bay Entrance & OR & 20 \\
\hline 43.6695 & -124.2007 & 310 & 2.7 & 2.7 & Winchester Bay Entrance & OR & 4 \\
\hline 43.8835 & -124.1171 & 262 & 4.0 & 4.0 & Dunes City & OR & 4 \\
\hline 44.6179 & -124.0656 & 509 & 4.4 & 7.1 & Yaquina Bay Entrance & OR & 5 \\
\hline 44.9255 & -124.0269 & 252 & 4.9 & 4.9 & Siletz Bay Entrance & OR & 3 \\
\hline 45.5669 & -123.9530 & 587 & 3.6 & 3.7 & tillamook Bay entrance & OR & 7 \\
\hline State Total & & & & & & OR & 48 \\
\hline 46.2517 & -124.0159 & 1234 & 13.7 & 14.1 & Columbia River & WA & 70 \\
\hline 46.6847 & -124.0477 & 7371 & 5.6 & 7.4 & Willapa Bay & WA & 91 \\
\hline 46.9275 & -124.1030 & 2939 & 7.1 & 7.9 & Grays Harbor & WA & 61 \\
\hline 48.1775 & -122.7556 & 6743 & 56.2 & 68.6 & Admiralty Inlet Entrance & WA & 461 \\
\hline State Total & & & & & & WA & 683 \\
\hline 55.2291 & 131.9197 & 10170 & 301.2 & 415.2 & Clarence Strait & AK & 4105 \\
\hline 55.9494 & 133.8482 & 3352 & 86.6 & 119.6 & NE of Warren Island & AK & 535 \\
\hline 55.9832 & 134.0028 & 19838 & 132.2 & 251.5 & Summer Strait & AK & 2667 \\
\hline 56.7374 & 134.5198 & 16686 & 503.1 & 736.2 & Chatham Strait & AK & 12038 \\
\hline 57.4463 & 135.5538 & 1752 & 5.4 & 6.4 & Peril Strait & AK & 104 \\
\hline 58.2233 & -136.3034 & 1715 & 41.6 & 61.2 & S of Ininan Islands & AK & 273 \\
\hline 58.2561 & -136.3736 & 816 & 39.7 & 39.7 & Inian Islands & AK & 168 \\
\hline 58.2898 & -136.4156 & 5123 & 133.3 & 232.6 & $\mathrm{~N}$ of Inian Islands & AK & 2564 \\
\hline 60.0690 & -144.3737 & 4567 & 5.8 & 11.7 & Btwn Wingham and Kanak Isklands & AK & 74 \\
\hline 60.2167 & -144.7335 & 2287 & 3.9 & 4.0 & E of Strawberry Reef & AK & 52 \\
\hline 60.2305 & -144.8915 & 2161 & 3.3 & 3.4 & W of Strawberry Reef & AK & 47 \\
\hline 60.2483 & -145.0702 & 3248 & 1.8 & 3.1 & Copper & AK & 48 \\
\hline 60.3100 & -145.4525 & 2398 & 6.0 & 6.8 & E of Copper Sands & AK & 43 \\
\hline 60.3760 & -145.5980 & 1635 & 8.2 & 8.6 & $\mathrm{~N}$ of Copper Sands & AK & 33 \\
\hline 60.4137 & -145.9888 & 530 & 1.2 & 1.2 & W of Egg Islands & $A K$ & 3 \\
\hline 60.4000 & -146.0485 & 1944 & 4.1 & 9.4 & E Hinchinbrook Island & AK & 28 \\
\hline
\end{tabular}




\begin{tabular}{|c|c|c|c|c|c|c|c|}
\hline 60.3856 & -146.0790 & 521 & 2.7 & 2.7 & SE of Boswell Bay & AK & 5 \\
\hline 59.0927 & -152.6733 & 93780 & 127.9 & 160.5 & Cook Inlet & AK & 18239 \\
\hline 57.9858 & -152.7952 & 679 & 14.5 & 14.5 & $\mathrm{~N}$ of Whale Island & AK & 85 \\
\hline 57.9358 & -152.8482 & 1040 & 24.9 & 32.7 & S of Whale Island & AK & 220 \\
\hline 57.0492 & -154.1195 & 521 & 5.8 & 5.8 & Moser Bay & AK & 8 \\
\hline 56.7391 & -154.0325 & 2188 & 20.6 & 32.6 & Russian Harbor & AK & 164 \\
\hline 56.6576 & -154.1069 & 7447 & 20.4 & 45.5 & Btwn Sundstrom and Sitkinak Islands & AK & 628 \\
\hline 56.5281 & -154.4119 & 6141 & 4.2 & 6.7 & Btwn Sitkinak and Tugidak Islands & AK & 326 \\
\hline 55.0480 & -163.4439 & 1870 & 4.8 & 6.4 & Bechevin Bay & AK & 2 \\
\hline 55.2558 & -162.9946 & 1111 & 4.9 & 7.2 & Izembek Lagoon & AK & 3 \\
\hline 56.0017 & -161.0578 & 1007 & 1.4 & 1.8 & Nelson Lagoon & AK & 2 \\
\hline 54.0888 & -165.5386 & 5834 & 54.4 & 94.5 & Avatanak Strait & AK & 251 \\
\hline 54.1637 & -164.9067 & 6800 & 41.5 & 69.9 & Ugamak Strait & AK & 188 \\
\hline 54.0825 & -165.2323 & 3014 & 40.3 & 80.7 & Derbin Strait & AK & 99 \\
\hline 54.0692 & -165.5014 & 2401 & 36.5 & 65.4 & Btwn Rootok and Avatanak Islands & AK & 50 \\
\hline 54.1320 & -165.6542 & 1194 & 13.6 & 15.6 & Btwn Akutan and Akun Islands & AK & 14 \\
\hline 54.0225 & -166.0595 & 3737 & 37.6 & 46.6 & Akutan Pass & AK & 114 \\
\hline 53.9993 & -166.0877 & 2385 & 22.3 & 31.1 & Baby Pass & AK & 26 \\
\hline 53.9470 & -166.2060 & 2992 & 34.8 & 49.5 & Unalga Pass & AK & 75 \\
\hline 53.3351 & -167.8847 & 5937 & 48.8 & 63.7 & Umnak Pass & AK & 275 \\
\hline 52.8104 & -169.1365 & 3602 & 6.4 & 8.7 & Btwn Samalga and Breadloaf Islands & AK & 21 \\
\hline 53.0383 & -169.7457 & 2374 & 21.5 & 29.2 & Btwn Chuginadak and Kagamil Islands & AK & 26 \\
\hline 52.9168 & -169.7292 & 5892 & 54.2 & 69.1 & Btwn Uliaga and Kagamil Islands & AK & 202 \\
\hline 52.8633 & -169.9996 & 2342 & 31.9 & 52.1 & Btwn Carlisle and Chuginadak Islands & AK & 82 \\
\hline 52.1778 & -172.7808 & 26785 & 94.6 & 175.6 & Btwn Seguam and Amlia Islands & AK & 1169 \\
\hline 52.1261 & -174.0696 & 2242 & 22.6 & 32.1 & Btwn Atka And Amlia Islands & AK & 49 \\
\hline 51.9969 & -175.3859 & 7033 & 32.6 & 43.9 & Btwn Oglodak and Atka Islands & AK & 271 \\
\hline 51.9762 & -175.5189 & 7407 & 30.2 & 44.3 & Btwn Fenimore and Ikiginak Islands & AK & 246 \\
\hline 51.9618 & -175.5945 & 1139 & 17.1 & 17.7 & Btwn Tagalak and Fenimore Islands & AK & 18 \\
\hline 51.9640 & -175.6502 & 568 & 15.4 & 15.4 & NW of Tagalak Island & AK & 9 \\
\hline 51.9434 & -175.7700 & 2843 & 29.6 & 40.5 & Btwn Chugul and Tagalak Islands & AK & 67 \\
\hline 51.9598 & -175.8772 & 2075 & 32.4 & 45.0 & Btwn Igitkin and Chugul Islands & AK & 75 \\
\hline 51.9742 & -175.9797 & 2577 & 55.2 & 76.3 & Btwn Igitkin and Great Sitkin Islands & AK & 119 \\
\hline 51.8620 & -176.0660 & 1292 & 18.7 & 21.4 & Btwn Unmak and Little Tanaga Islands & AK & 15 \\
\hline 51.8184 & -176.2519 & 2261 & 36.0 & 45.2 & Btwn Little Tanaga and Kagalaska Islands & AK & 65 \\
\hline 51.7946 & -176.4153 & 563 & 13.4 & 13.4 & Btwn Kagalaska and Adak Islands & AK & 6 \\
\hline 51.8323 & -176.9941 & 8667 & 57.1 & 71.0 & Btwn Kagalaska and Adak Islands & AK & 424 \\
\hline 51.7138 & -177.7614 & 7579 & 24.8 & 43.3 & Btwn Tanaga and Kanaga Islands & AK & 138 \\
\hline 51.6014 & -178.6124 & 562 & 8.9 & 8.9 & Btwn Ogliuga and Skagul Islands & AK & 2 \\
\hline 51.5760 & -178.7110 & 5177 & 10.7 & 13.3 & Btwn Obliuga and Kavalga Islands & AK & 29 \\
\hline 51.5810 & -178.9460 & 11782 & 48.0 & 69.6 & Btwn Unalga and Kavalga Islands & AK & 435 \\
\hline 56.6651 & -159.4462 & 490 & 1.0 & 1.0 & Seal Islands W & AK & 2 \\
\hline 56.6871 & -159.3766 & 487 & 1.0 & 1.0 & Seal Islands M & AK & 2 \\
\hline 56.7158 & -159.2917 & 999 & 1.2 & 1.3 & Seal Islands E & AK & 3 \\
\hline 57.5943 & -157.6936 & 4947 & 1.0 & 1.0 & Ugashik Bay Entrance & AK & 13 \\
\hline 58.2197 & -157.5019 & 4056 & 3.1 & 4.6 & Egegik Bay Entrance & AK & 58 \\
\hline 58.8052 & -157.1269 & 9225 & 2.8 & 4.5 & Upper Kvichack Bay & AK & 198 \\
\hline 58.9905 & -158.5124 & 1855 & 6.9 & 8.9 & S of Dillingham & AK & 137 \\
\hline State Total & & & & & & AK & 47437 \\
\hline National Total & & & & & & USA & 50783 \\
\hline
\end{tabular}




\subsection{Dissemination of data}

The final results at each grid point are stored in a database with 67 fields that display geographical coordinates, the modeled depth, computed water level constituents and tidal current constituents, and one-month mean/ maximum for tidal current speed and tidal stream power density. The information regarding the constituents includes the constituent name, amplitude and phase (with respect to Greenwich) for water level; a major and a minor axis amplitude, phase and inclination angle for the tidal current. The final data is published on the internet over an interactive map.

\subsubsection{Web Server Deployment}

Originally it was planned to use ArcIMS to develop an interactive, web-based GIS system to facilitate the dissemination of the tidal data and deliver the information of energy production potential from tidal streams to interested users. This project has three main functions. One is to build a map GUI in ArcIMS to allow users to identify the location on the map to extract the tidal constituents of a given location, or the nearest survey point. The second is to derive the information about the tidal current magnitude and power density as the histogram and time series graphics generated by MATLAB server. MATLAB functions are invoked in ArcIMS by passing the tidal constituents to MATLAB server via a REST Web service call. To enable the dissemination of the tidal data, the third function allows users to extract the tidal data of a given spatial extent. The users can either use the map extent of ArcIMS or draw a box to define a specific spatial extent. Data extraction can be refined by a combination of three constituents, including water depth, power density, and mean current.

Since ArcIMS is the old technology for Web mapping applications, ESRI will no longer support ArcIMS in releases after ArcGIS 10.0. With the adoption of ArcGIS Server and the move to 64-bit servers, ArcIMS is no longer the recommended product for producing web maps. ArcGIS server offers three APIs (javascript API, Flex API, and Silverlight API) for Web mapping development. In contrast to frame-based ArcIMS, the new APIs support the so-called rich internet applications (RIAs) development.

Both Javascript API and Flex API were fully developed but eventually Flex API is recommended for this project for several reasons. By using the Flash plug-in, its crossplatform, cross-browser feature help to simplify the GUI design and implementation. Particularly the Flex viewer offers much user-friendly and interactive GUI in mapping and arranging the search query results. One disadvantage for Flex development is its ActionScript is not standardized but a proprietary script language and has a limited debugging environment.

\subsubsection{Design and Highlights of Data Dissemination}

The entire suite of data is stored in a geodatabase and made public via the ArcGIS spatial database engine server. All of the edits are transferred and synchronized with the data on the production geodatabase, which is accessible by multiple editors and then copied to a publication geodatabase for dissemination (Figure 7). The web page interface is a rich internet application (RIA) that facilitates easy navigation over the map with the option for alternative views (GT, 2011). 


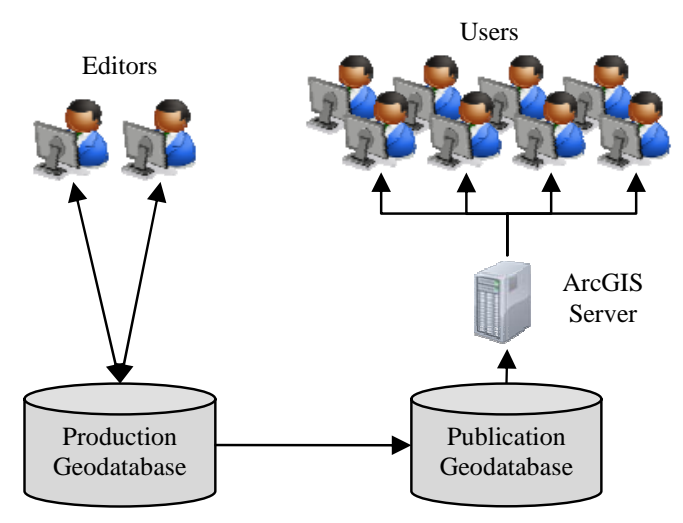

Figure 7. A production and publication geodatabase approach is used in management of the distributed data for the tidal stream power assessment.

Both the database and the web server are hosted in the same workstation with a DualCore AMD Optheron Processor, $2.20 \mathrm{GHz}, 4$ GB RAM, that runs on Microsoft Windows Server 2003SE SP2 platform. The software requirements include the ArcGIS Server for publishing data, Matlab Microsoft Visual Studio 2008 for interactive operations, and Microsoft Internet Information Services for hosting the website.

Assessment of Energy Production Potential from Tidal Streams in United States web page can be accessed at http://www.tidalstreampower.gatech.edu/ address. A screenshot of the web page and its main functions is shown in Figure 8. Users can interact with the map using the pull down menus or widgets on the right of the screen. Overview map, data layers and the legend widgets are displayed on the right of the screen by default. It is possible to switch between the satellite and street views via the Map menu while zooming and panning are facilitated with the Navigation menu. The web page consists of multiple layers that can be turned on and off through the data layers widget. The data layers and interactive tools that can be used for detailed analysis are explained below.

\section{Data Layers}

The data layers widget is shown together with the overview map and the legends widget in Figure 9. The transparency of each layer can be adjusted with a slider in the data layers widget. The color mapped raster layers include the water depth, the mean current speed (one month average of depth integrated tidal current speed) and the mean kinetic power density (one month average of kinetic power density based on depth integrated tidal current speed). These layers are generated by interpolating the model results from computational grids onto an ArcGIS raster grid with $0.003^{\circ}$ resolution and are useful for a quick visual examination. On the other hand, the data points layer contains more detailed information that corresponds to actual model grid points and can be queried through the interactive tools, and therefore is more suited for in-depth analyses.

\section{Identify tool}

This tool is used to identify a single data point either by clicking on the map or by a given longitude and latitude. The identify tool returns the model water depth, mean/maximum tidal current magnitude, mean/maximum available kinetic power density and the exact longitude, latitude at the selected point. Detailed information 
about the related computational grid can also be accessed via the grid documentation link provided with this tool (Figure 10). The grid documentation includes a map showing the extent of the computational domain, and information on the model settings (boundary conditions, advection scheme, time step, bottom friction etc.). The calibration statistics are also given in the grid documentation. Histograms for tidal current and tidal power density at a selected point can be plotted for any specific year using the identify tool. These histograms facilitate an overview of the nature of the tidal stream resource at a location as they display the total hours of availability for different ranges of specific current magnitude (or tidal power density) in a year. Similarly, time series for water surface elevation and tidal current speed plots and the associated data can be downloaded with the identify tool. An example for the year 2011 from a location at San Francisco Bay, CA, where the model predicts relatively larger currents is shown in Figure 11. The identify tool shows that the one-month mean tidal current magnitude is predicted to be $0.66 \mathrm{~m} / \mathrm{s}$ at this location, while the time series show the range of variation in a year with a mean and maximum of 0.86 and $2.03 \mathrm{~m} / \mathrm{s}$. The histogram indicates that more than 5450 hours ( 227 days) a year the current speed is larger than $0.5 \mathrm{~m} / \mathrm{s}$ whereas only 3113 hours ( 129 days) a year larger than $0.8 \mathrm{~m} / \mathrm{s}$.

\section{Select/Export data tool}

The select/export data tool is used to download data at selected grid points. A single point or multiple points can be selected using the select data tool via the selecting by dragging a window or selecting by the current view extent. The selected data can be filtered based on the water depth, mean current magnitude or mean power density or a combination of them prior to downloading (Figure 12). This provides users the option to exclude the areas that do not meet certain criteria, such as a minimum depth or a minimum speed. The selected data is exported to a spreadsheet and for each point it includes 67 columns that display the entire information at regarding geographical coordinates, the modeled depth, computed water level constituents and tidal current constituents, and one-month mean/ maximum for tidal current speed and tidal stream power density (constituent name, amplitude and phase for water level; a major and a minor axis amplitude, phase and inclination angle for the tidal current).

Once the results are displayed in the identify or select/export widget, the user can switch between the results and selection display using the buttons at the top of each widget. Instructions on how to use the web page can be accessed through the Help menu. , Detailed project information, model documentation and contact information are also found under this menu (Figure 13). The project information contains the background information, objectives and methodology. The computational model, generation of the grids and tidal forcing, calibration and constituent extraction are explained under the model documentation.

For further investigations of tidal stream power resources additional geographical information can be integrated to the analysis. The choice of location for a tidal stream power converter farm depends on assessment of a number of criteria including the available power, site characteristics, and environmental, economic and social impacts of the planned project. These include available power and the site characteristics such as bathymetry, water depth and the geology of the seabed, changes in the flow patterns, water quality, sediment transport climates and related ecological impacts on the aquatic 
and terrestrial life, economic and social impacts based on the increased energy supply for the region and alterations to the marine and land use. Although it is not possible to quantify all of these criteria and there are no set rules on how to determine acceptable limits for many of them, certain functionalities of GIS can be used to build a decision support system to select suitable locations for tidal stream power conversion (Defne et al., 2011a). A list of most suitable areas can be determined based on the level of power density, ease of accessibility and the number of environmental conflicts. 


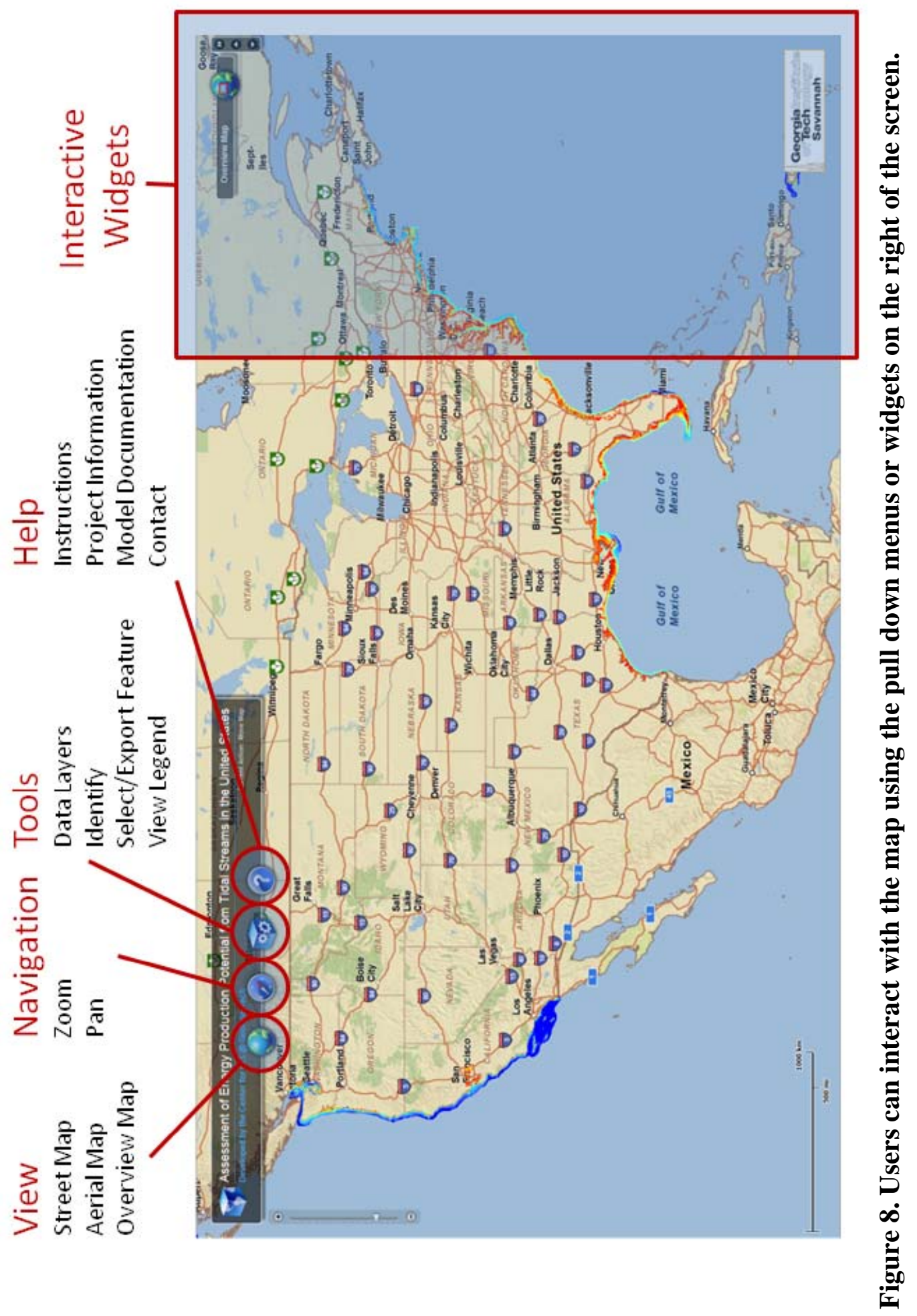




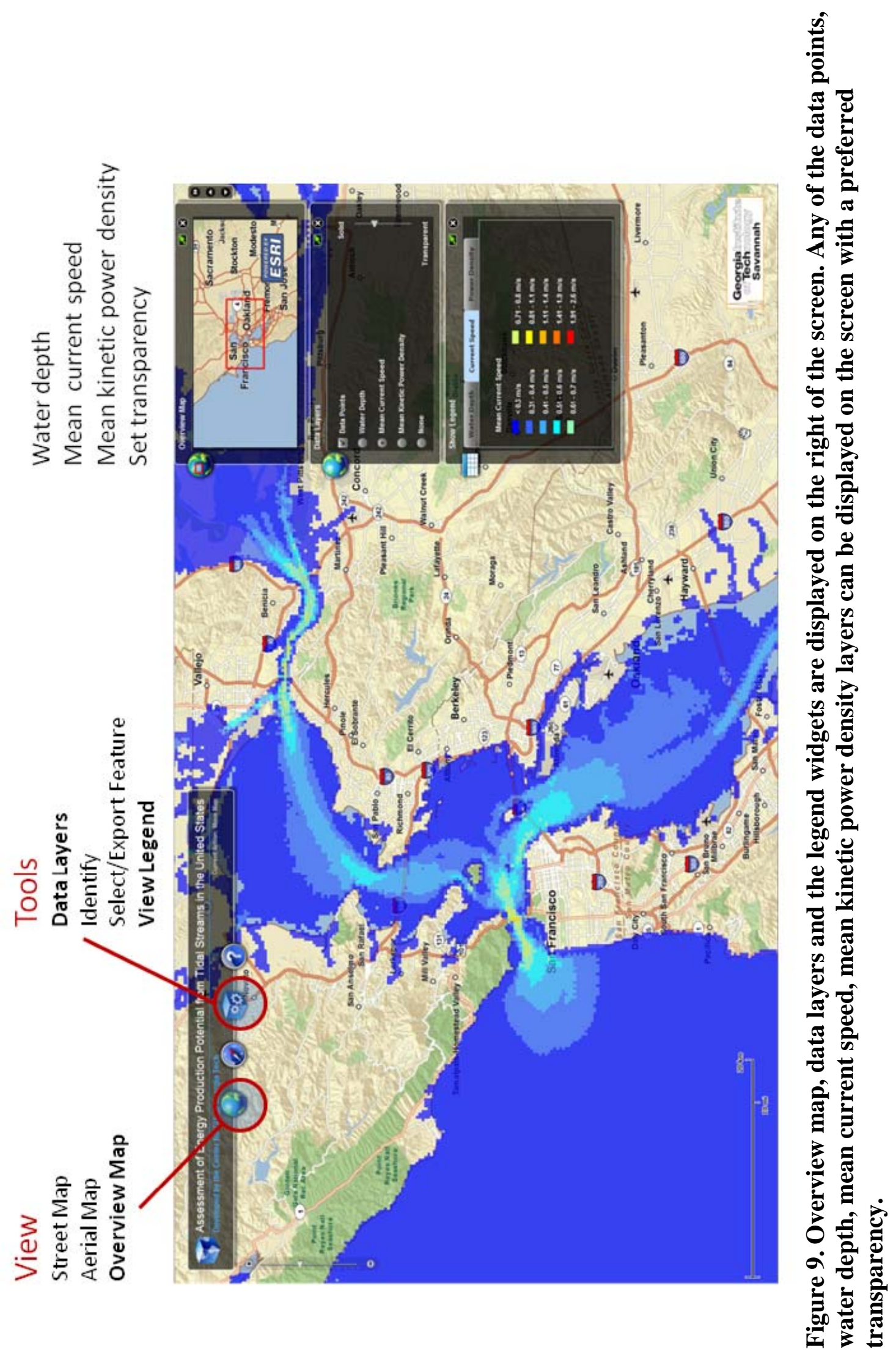




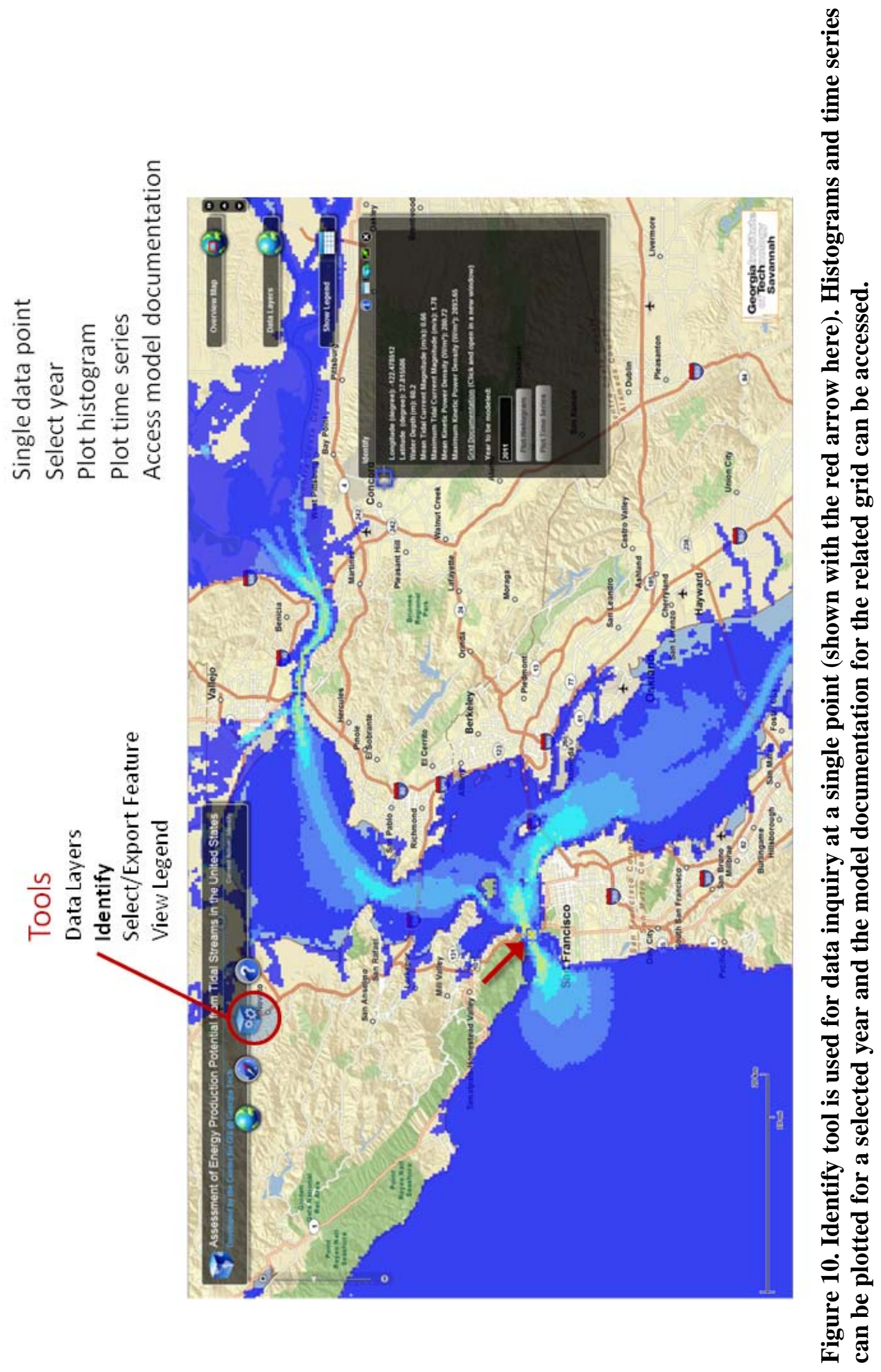




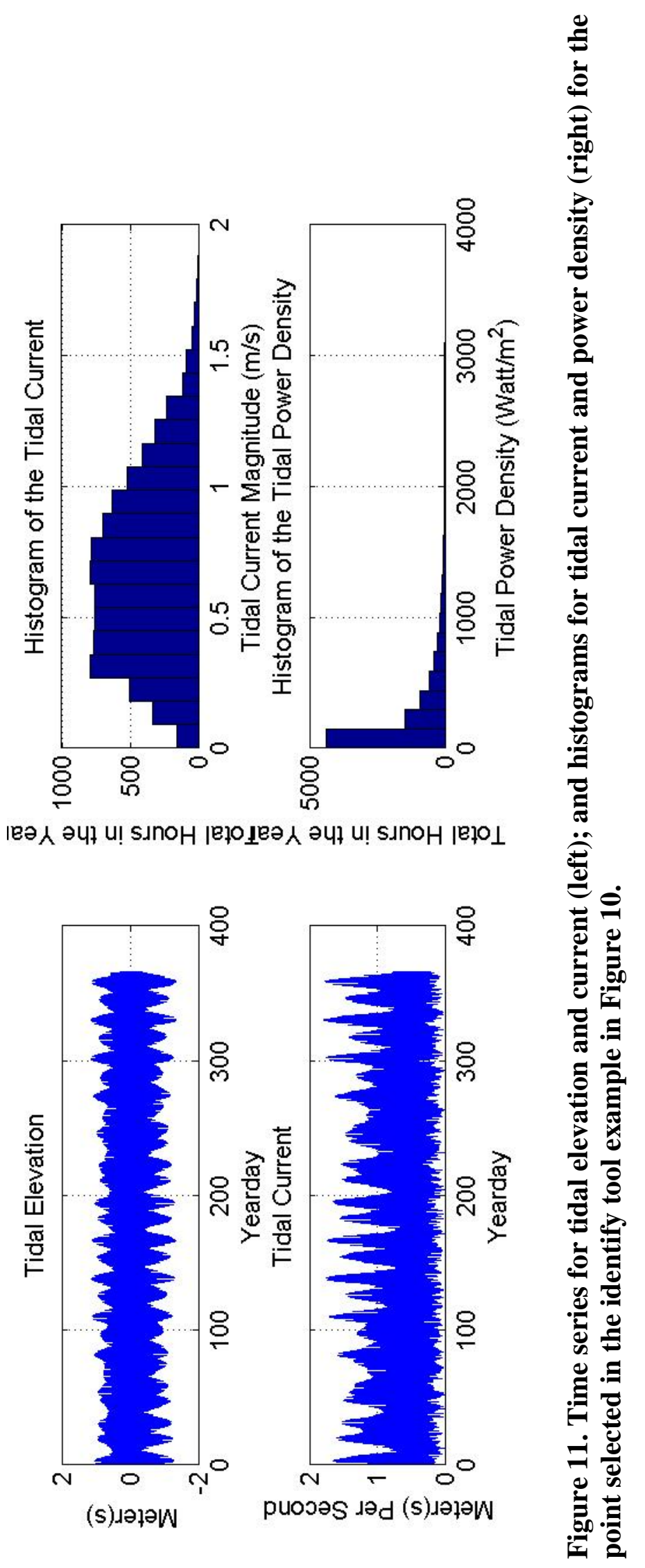




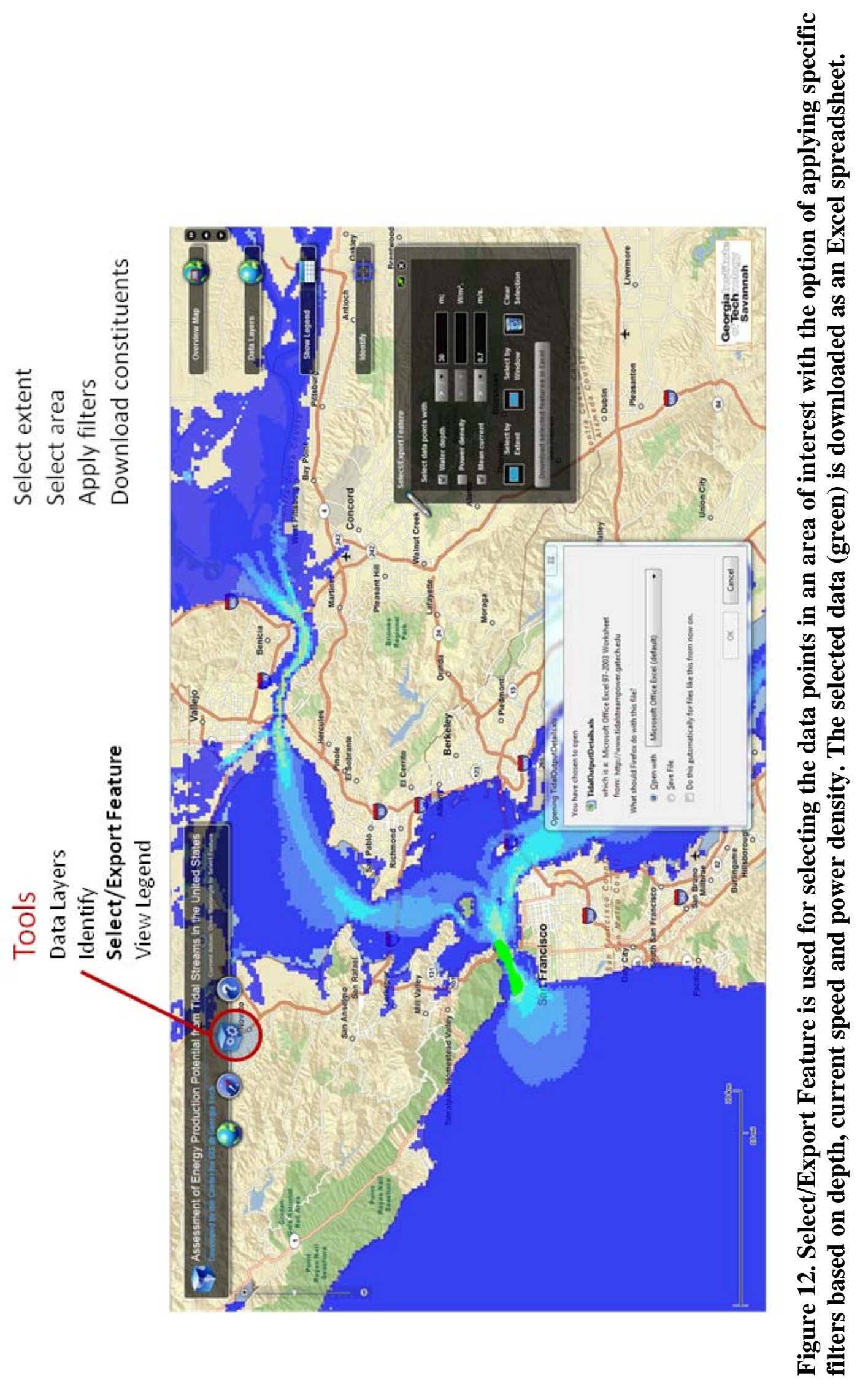




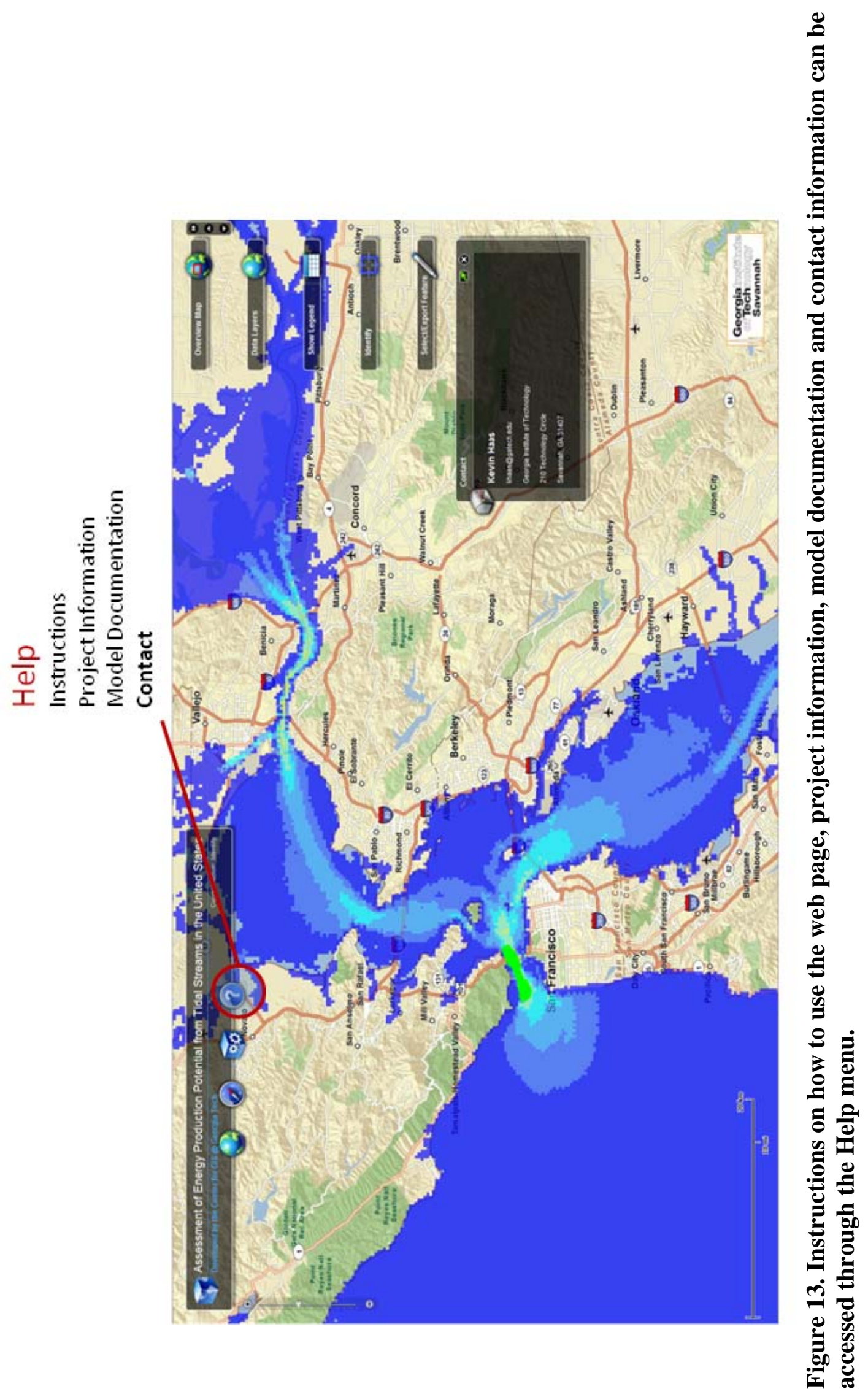




\section{Products}

\section{Publications}

Defne Z., Haas K. A., Fritz H. M. (2011) GIS based multi-criteria assessment of tidal stream power potential: A case study for Georgia, USA. Renewable and Sustainable Energy Reviews. Volume 15, Issue 5, June 2011, Pages 2310-2321.

Defne Z., Haas K. A., Fritz H. M. (2011) Numerical modeling of tidal currents and the effects of power extraction on estuarine hydrodynamics along the Georgia Coast, USA. Renewable Energy, in press.

Defne, Z., Haas, K. and Fritz, H. (2011) Multi-criteria assessment of tidal stream power potential using ArcGIS. Submitted to ArcNews, March 2011.

Defne, Z., Haas, K. and Fritz, H. (2008) Assessment of Tidal Currents along the Atlantic Coast of the Southeast USA for Energy Conversion: Case Study for Georgia. 2nd International Conference on Ocean Energy, Brest, France.

\section{Presentations}

Haas, K., Defne, Z., Fritz, H., Jiang, L., French, S., Shi, X., Neary, V., Stewart, K. and Smith, B. (2011) A Database of the U.S. Tidal Stream Power Potential. Invited presentation at the 4th Annual Global Marine Renewable Energy Conference, Washington, DC.

Haas, K., Defne, Z., Jiang, L. and Fritz, H. (2010) Assessment of Tidal Stream Energy Potential for the United States. AGU Fall Meeting, San Francisco, California.

Jiang, L., Haas, K., Fritz, H., Defne, Z., French, S., Shi, X. and Smith, B. (2010) Numerical Modeling of Tidal Streams for Energy Assessment Along the US Coast. Presented at the 2010 Ocean Sciences Meeting, Portland, OR.

Haas, K., Fritz, H., Defne, Z., Jiang, L., French, S., Shi, X. and Smith, B. (2009) Assessment of Power Production Potential from Tidal Streams in the United States. Invited presentation at the 2nd Annual Global Marine Renewable Energy Conference, Washington, DC.

Haas, K. (2010) Invited speaker for Standards and Resource Assessment panel in the Ocean/Tidal/Stream Power track at the 2010 Hydro Vision International Conference, Aug. 2010.

Haas, K. (2010) Invited speaker, Texas A\&M coastal engineering seminar series, "Assessment of Tidal Stream Energy Production for the United States” Sept. 2010.

\section{Website/Databases}

The data is stored in a GIS database accessible via the website http://www.tidalstreampower.gatech.edu 


\section{Collaborations/Networks}

Kevin Haas is an expert member of the U.S. Technical Advisory Group for IEC TC-114 working on the specification WG-1“Tidal Energy Resource Characterization and Assessment.”

Kevin Haas was an invited participant in the Symposium on Renewable Ocean Energy for North Carolina, March 2011.

\section{Student Education}

Ph.D. Student

Zafer Defne

Advisers: Kevin Haas and Hermann Fritz

Graduation: Spring 2010

Topic: Assessment of Wave and Tidal Power Potential Along the Atlantic Coast of the Southeast USA for Energy Conversion

Post Doctoral Fellow

Lide Jiang, Ph.D.

Advisers: Kevin Haas and Hermann Fritz

February 2009 - June 2010

Topic: Assessment of Tidal Stream Power Potential for the United States

Post Doctoral Fellow

Zafer Defne Ph.D.

Advisers: Kevin Haas and Hermann Fritz

February 2010 - June 2011

Topic: Assessment of Ocean Energy for the United States 


\section{References}

ADCIRC. (2011) ADCIRC Coastal Circulation and Storm Surge Model. $<$ http://www.unc.edu/ims/ccats/tides/tides.htm> (Accessed 2011).

Bedard, R, Previsic, M, Siddiqui, O, Hagerman, G, and Robinson, M. (2006). North American Tidal In Stream Energy Conversion Feasibility Demostration Project. EPRI TP-04-NA. Electric Power Research Institute.

Carter, GS, and Merrifield, MA. (2007). "Open boundary conditions for regional tidal simulations". Ocean Modelling. 18(3-4), 194-209.

Chapman, DC. (1985). "Numerical Treatment of Cross-Shelf Open Boundaries in a Barotropic Coastal Ocean Model". Journal of Physical Oceanography. 15(8), 1060-1075.

Defne, Z, Haas, KA, and Fritz, HM. (2011a). "GIS based multi-criteria assessment of tidal stream power potential: A case study for Georgia, USA". Renewable and Sustainable Energy Reviews. 15(5), 2310-2321.

Defne, Z, Haas, KA, and Fritz, HM. (2011b). "Numerical Modeling of Tidal Currents and the Effects of Power Extraction on Estuarine Hydrodynamics along the Georgia Coast, USA". Renewable Energy. in press, doi:10.1016/j.renene.2011.05.027.

Denham, CR. (2008) SeaGrid Orthogonal Grid Maker for Matlab. U.S. Geological Survey, $<$ http://woodshole.er.usgs.gov/staffpages/cdenham/public html/seagrid/seagrid.html $>$ (Accessed 2008).

Epler, J. (2010). Tidal Resource Characterization from Acoustic Doppler Current Profilers. University of Washington, Seattle.

EPRI, 2006a. Methodology for Estimating Tidal Current Energy Resources and Power Production by Tidal In-Stream Energy (TISEC) Devices. EPRI-TP-001-NA-Rev-3

EPRI, 2006b. Tidal In-Stream Energy Resource Assessment for Southeast Alaska. EPRI-TP003-AK

EPRI, 2006c. Maine Tidal In-Stream Energy Conversion (TISEC): Survey and Characterization of Potential Project Sites. EPRI-TP-003-ME

EPRI, 2006d. Massachusetts Tidal In-Stream Energy Conversion (TISEC): Survey and Characterization of Potential Project Sites. EPRI-TP-003-MA 
EPRI, 2006e. New Brunswick Tidal In-Stream Energy Conversion (TISEC): Survey and Characterization of Potential Project Sites. EPRI-TP-003-NB

EPRI, 2006f. Nova Scotia Tidal In-Stream Energy Conversion (TISEC): Survey and Characterization of Potential Project Sites. EPRI-TP-003-NS

EPRI, 2006g. North America Tidal In-Stream Energy Conversion Feasibility Study. $\quad$ EPRITP-008-NA

ESR. (2011) TPXO. Earth \& Space Research,

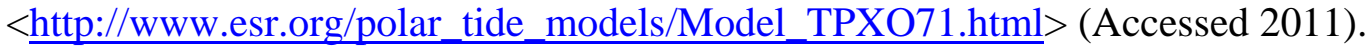

Fraenkel, P. (2007). "Marine current turbines: pioneering the development of marine kinetic energy converters". Proceedings of the Institution of Mechanical Engineers, Part A: Journal of Power and Energy. 221(2), 159-169.

Froberg, E. (2006). Current Power Resource Assessment. Uppsala University, Uppsala.

Garrett, C, and Cummins, P. (2005). "The power potential of tidal currents in channels". Proceedings of the Royal Society a-Mathematical Physical and Engineering Sciences. 461(2060), 2563-2572.

GT. (2011) Assessment of Energy Production Potential from Tidal Streams in the United Sates. Georgia Institute of Technology, <http://www.tidalstreampower.gatech.edu/> (Accessed 2011).

Haidvogel, DB, Arango, H, Budgell, WP, Cornuelle, BD, Curchitser, E, Di Lorenzo, E, Fennel, K, Geyer, WR, Hermann, AJ, Lanerolle, L, Levin, J, McWilliams, JC, Miller, AJ, Moore, AM, Powell, TM, Shchepetkin, AF, Sherwood, CR, Signell, RP, Warner, JC, and Wilkin, J. (2008). "Ocean forecasting in terrain-following coordinates: Formulation and skill assessment of the Regional Ocean Modeling System". Journal of Computational Physics. 227(7), 3595-3624.

Lee, MQ, Lu, CN, and Huang, HS. (2009). "Reliability and cost analyses of electricity collection systems of a marine current farm--A Taiwanese case study". Renewable and Sustainable Energy Reviews. 13(8), 2012-2021.

Lim, YS, and Koh, SL. (2010). "Analytical assessments on the potential of harnessing tidal currents for electricity generation in Malaysia". Renewable Energy. 35(5), 1024-1032.

Myers, L, and Bahaj, AS. (2005). "Simulated electrical power potential harnessed by marine current turbine arrays in the Alderney Race". Renewable Energy. 30(11), 1713-1731. 
NGDC. (2008a) Coast Line Extractor. National Oceanic and Atmospheric Administration,

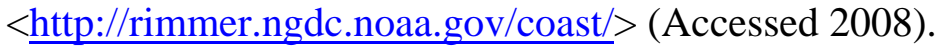

NGDC. (2008b) Geodas Grid Translator. National Geophysical Data Center,

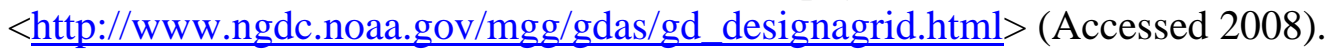

NOAA. (2008a) Electronic Navigational Charts (ENC). Office of Coast Survey , National Oceanic and Atmospheric Administration, $<$ http://nauticalcharts.noaa.gov/mcd/enc/download.htm> (Accessed 2008).

NOAA. (2008b) Tides and Currents. National Oceanic and Atmospheric Administration,

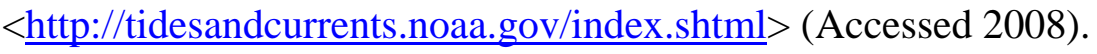

NOS. (2008a) US Bathymetric \& Fishing Maps. Office of Coast Survey, National Ocean Service, NOAA, <http://map.ngdc.noaa.gov/website/mgg/fishmap/> (Accessed 2008).

NOS. (2008b) VDatum Vertical Datum Translator. NOAA's National Geodetic Survey (NGS), Office of Coast Survey (OCS), and Center for Operational Oceanographic Products and Services (CO-OPS), <http://vdatum.noaa.gov/> (Accessed 2008).

Stewart, K, and Neary, V. (2011). Validation of the Georgia Tech Regional Tidal CurrentResource Assessment Model and GIS-web Tool. Oak Ridge National Laboratory.

Sutherland, DA, MacCready, P, Banas, NS, and Smedstad, LF. (In Press). "A Model Study of the Salish Sea Estuarine Circulation". Journal of Physical Oceanography. in press, doi:10.1175/2011JPO4540.1(0).

USFWS. (2008) National Wetlands Inventory. U.S. Fish \& Wildlife Service, $<$ http://www.fws.gov/wetlands/> (Accessed 2008).

USGS. (2008a) Seamless Server. U. S. Geological Survey, <http://seamless.usgs.gov/> (Accessed 2008).

USGS. (2008b) Water Data for the Nation: National Water Information System. U.S. Geological

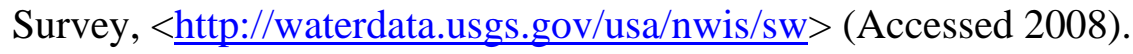

WikiROMS. (2011) Horizontal Boundary Conditions. WikiROMS, $<$ https://www.myroms.org/wiki/index.php/Boundary_Conditions\#Horizontal_Boundary Conditions $>$ (Accessed 2011).

Zevenbergen, LW, Lagasse, PF, and Edge, BL. (2004). Tidal Hydrology, Hydraulics, and Scour at Bridges. FHWA NHI-05-077. Ayres Associates. 


\section{APPENDIX A}

\section{TOTAL THEORETICAL AVAILABLE POWER FROM TIDAL STREAMS}

This appendix includes the maps of locations with considerable tidal stream power based on the simplified analytical calculations of the maximum average power from a tidal stream along a channel following the Garret and Cummins (2005) formulation. 


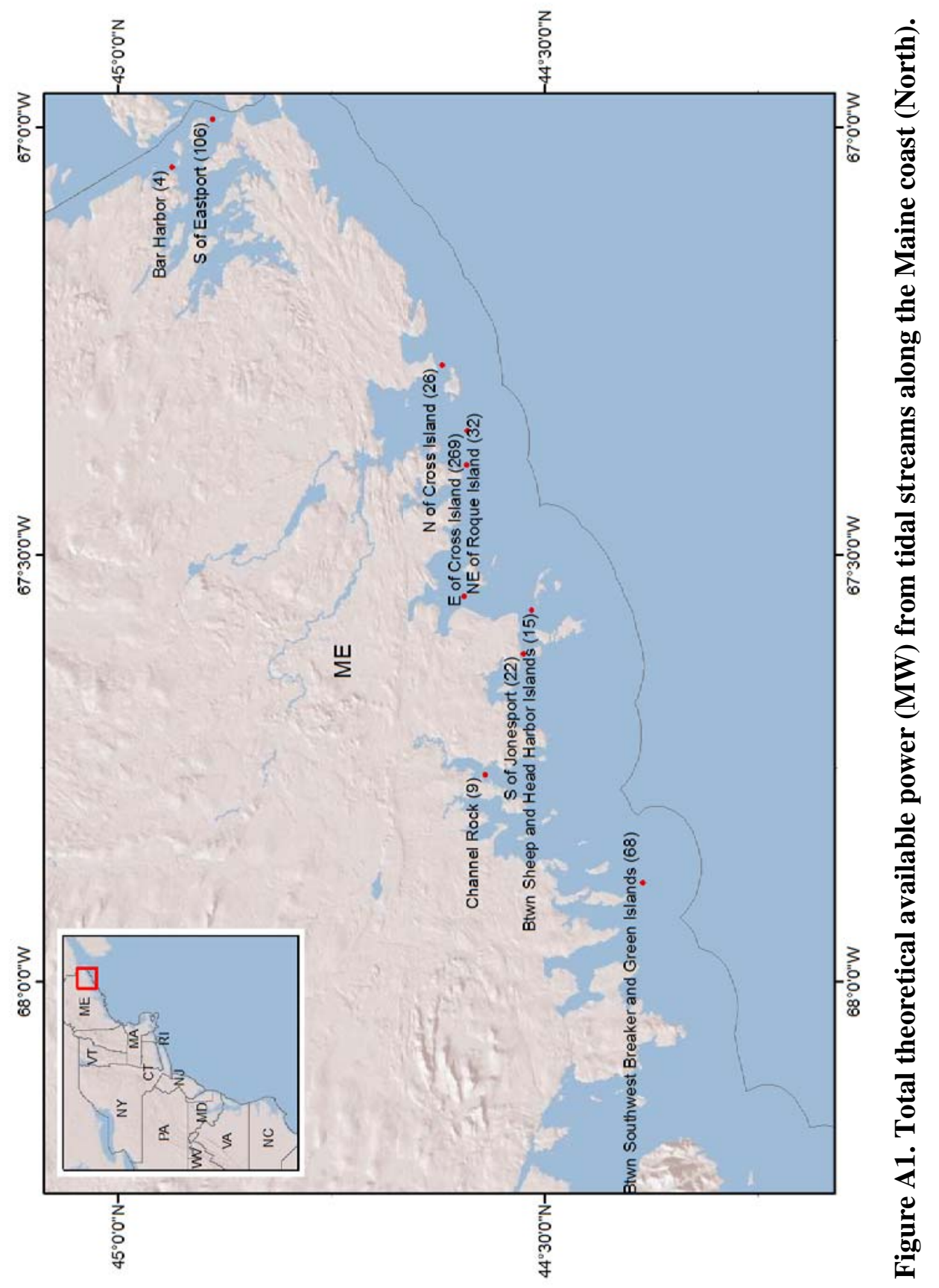




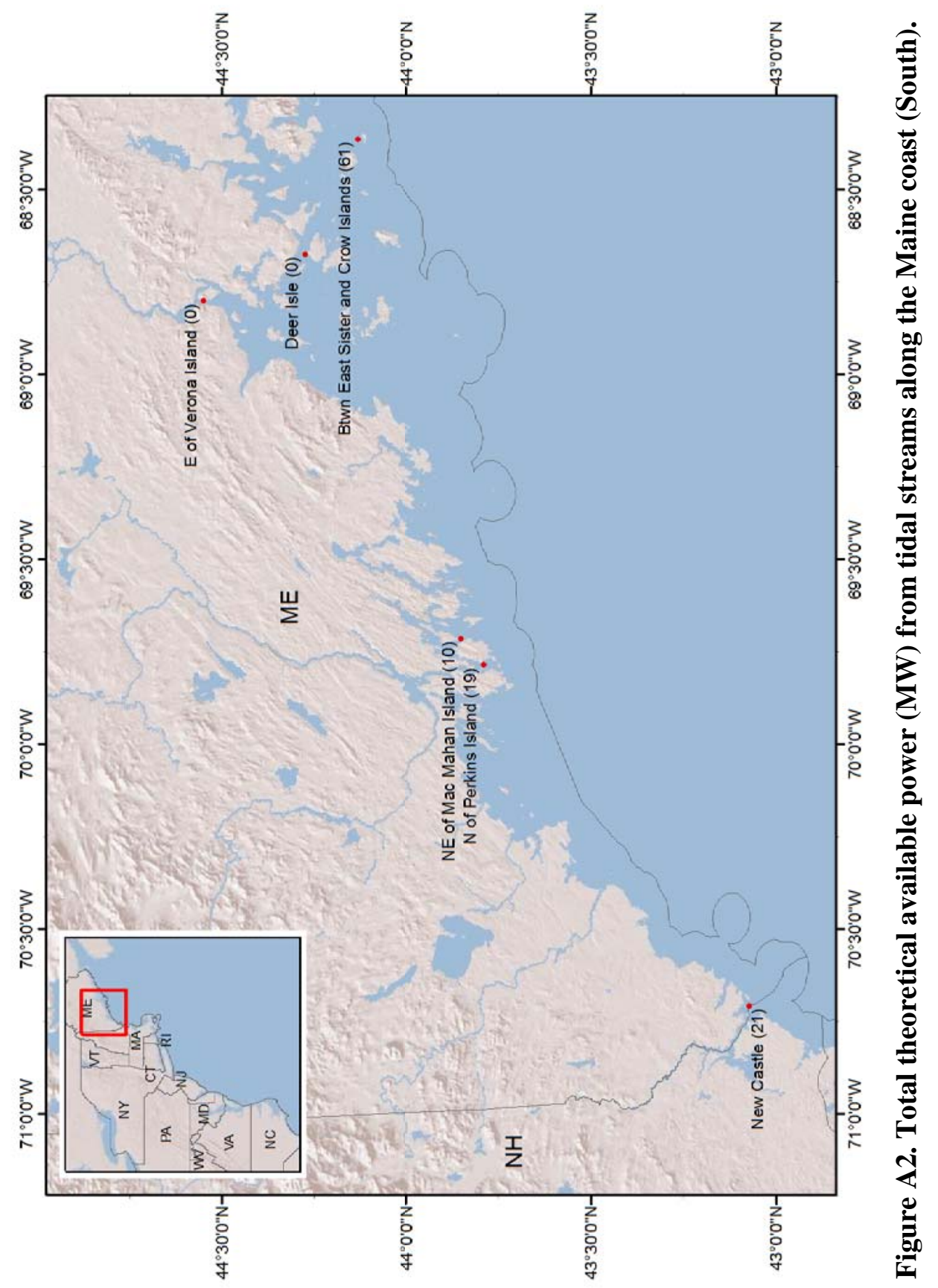




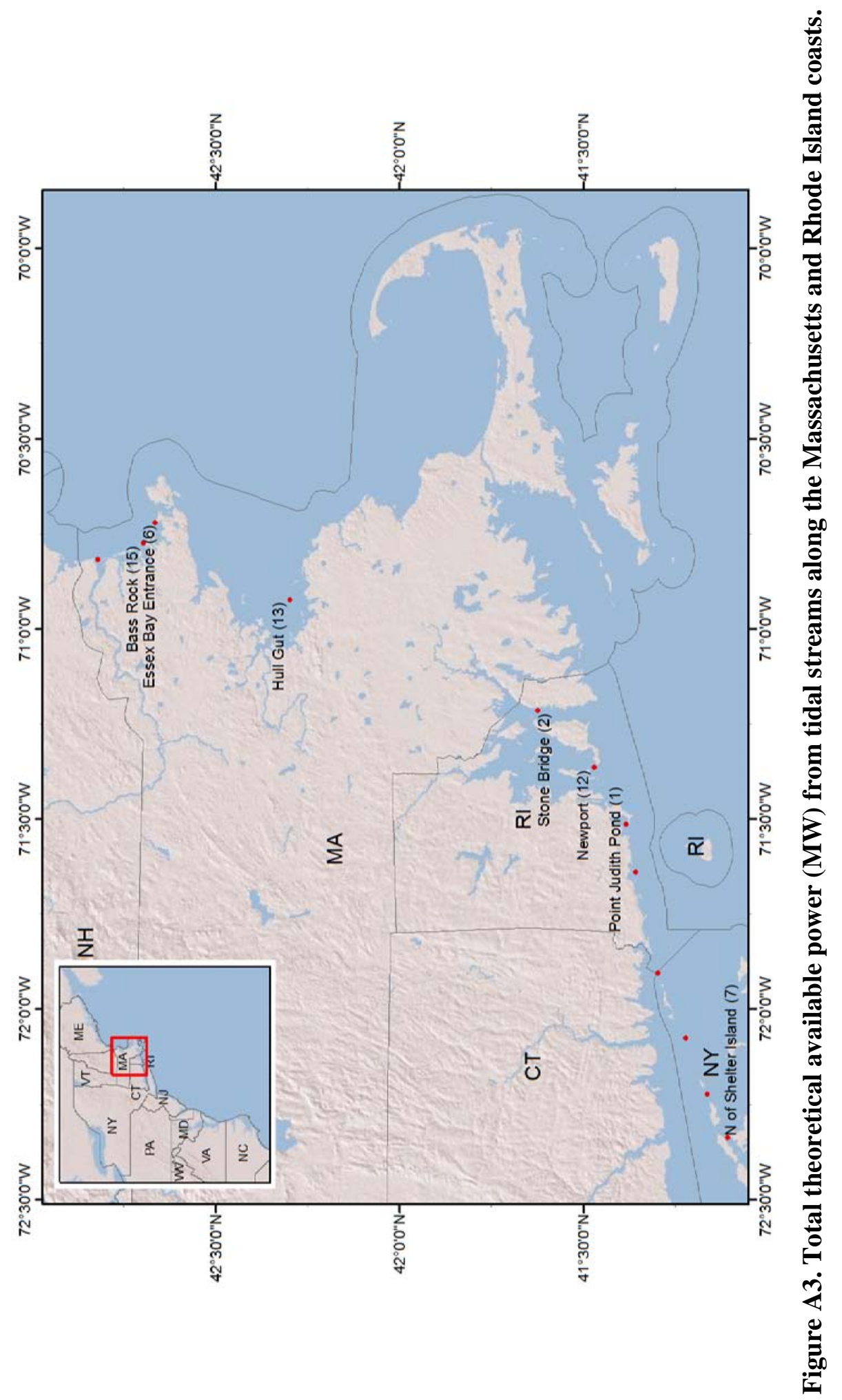




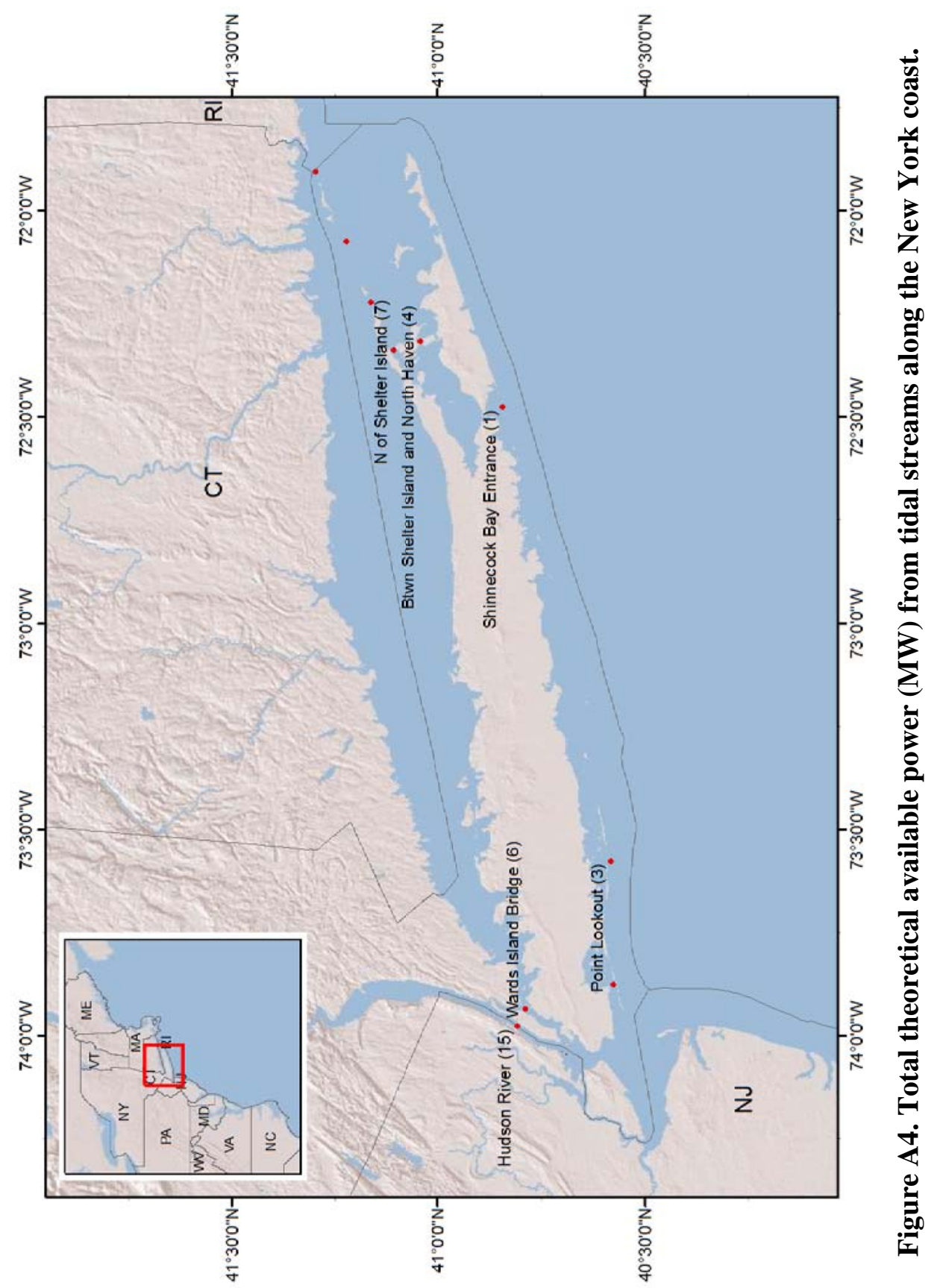




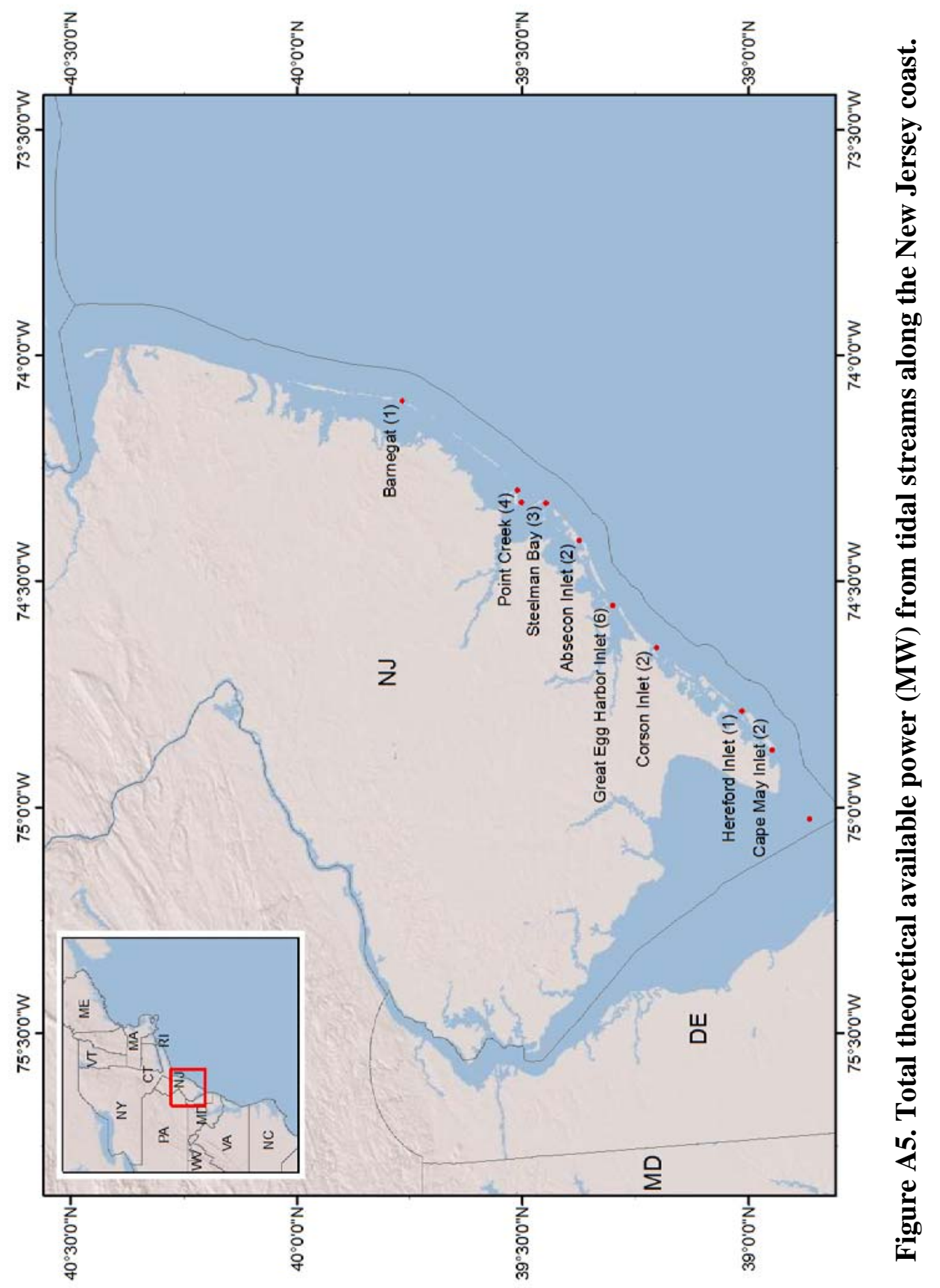




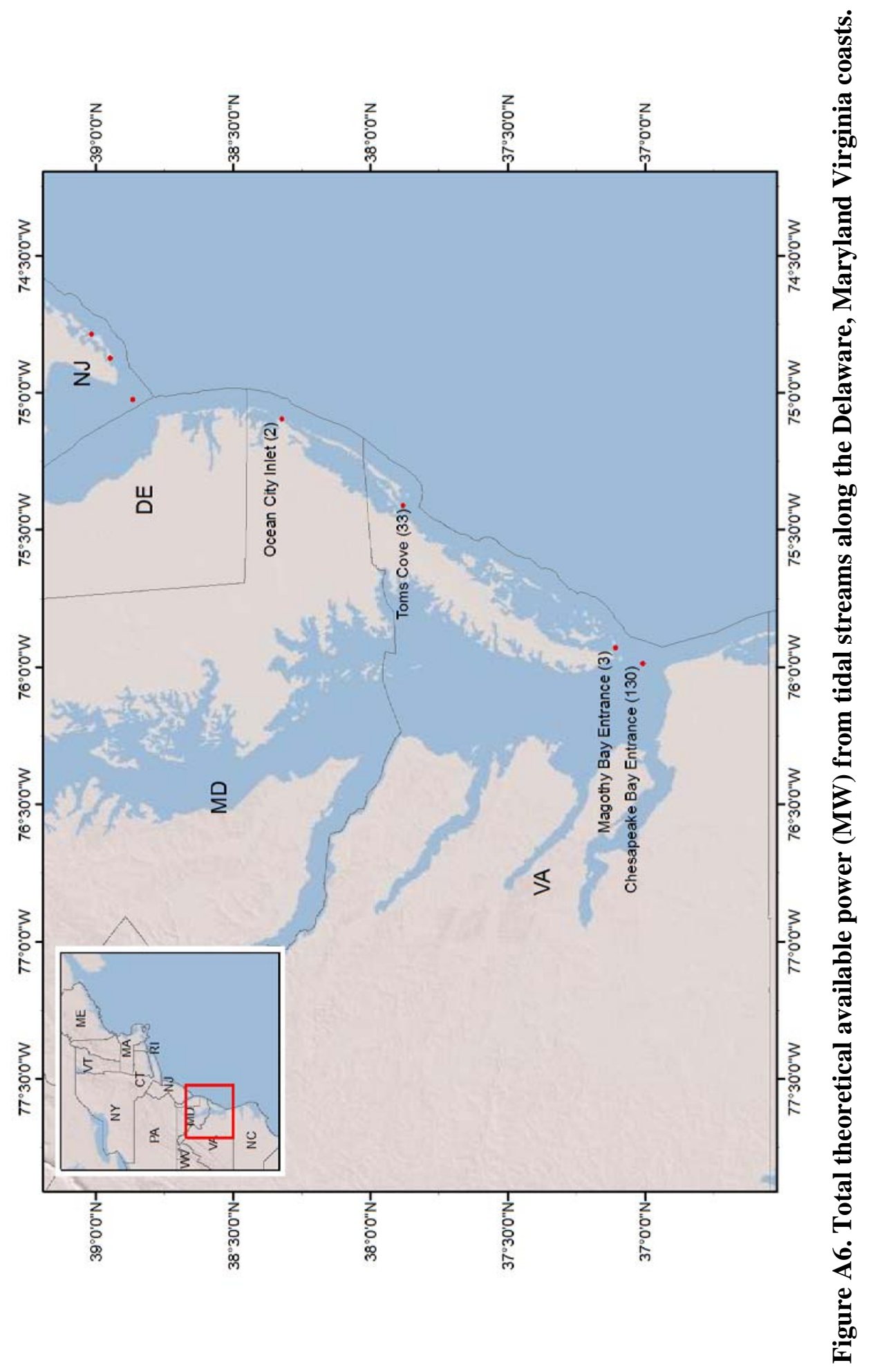




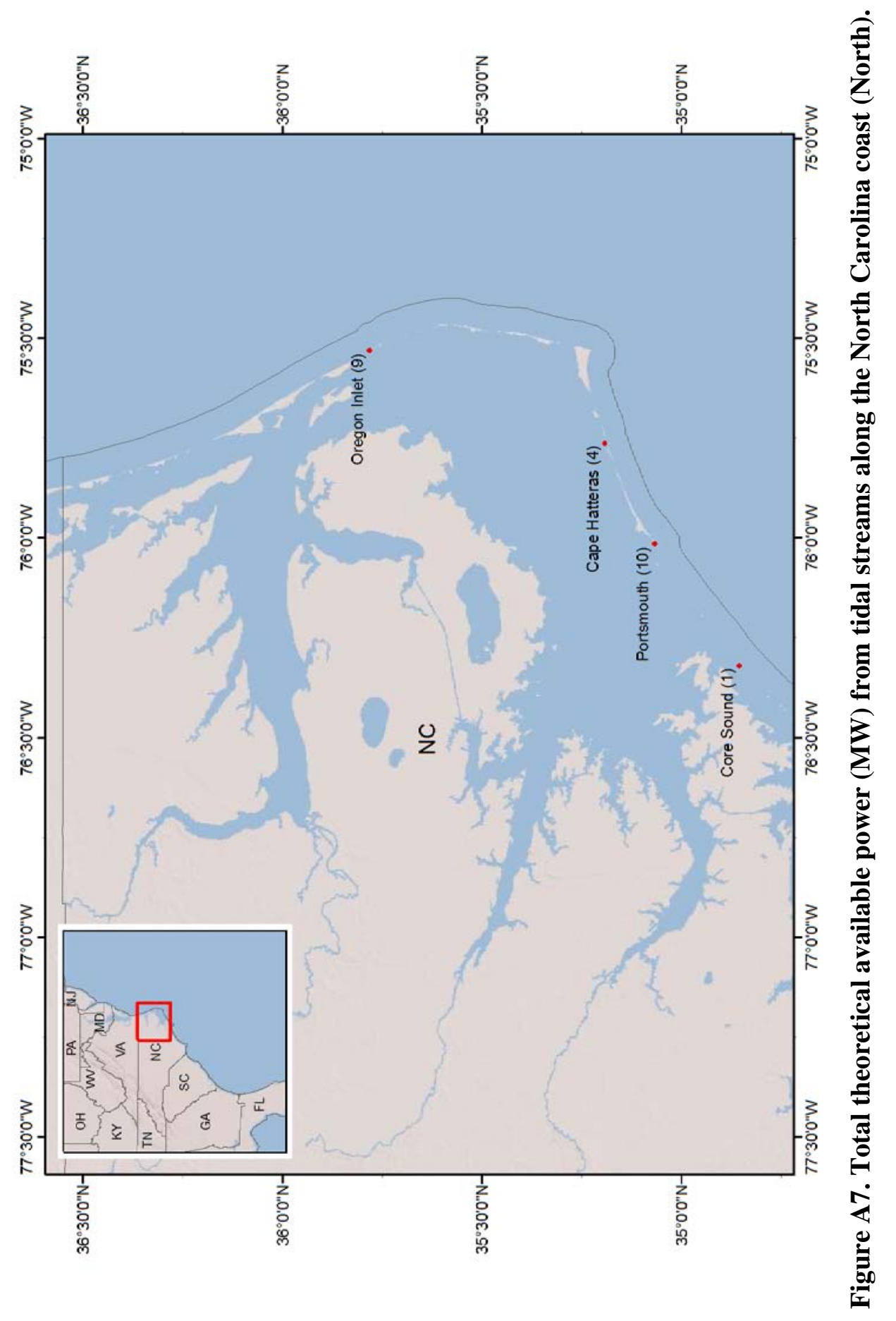




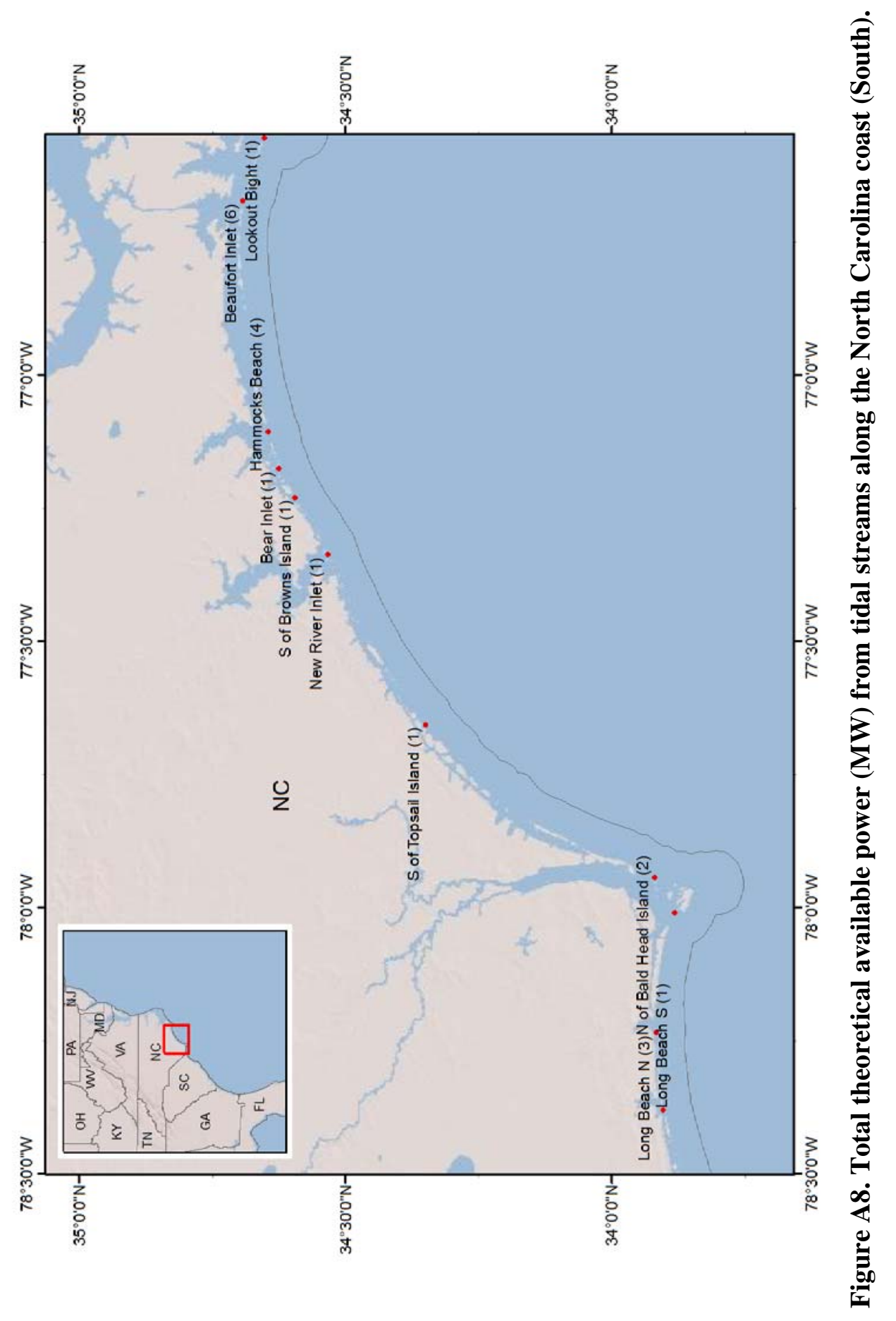




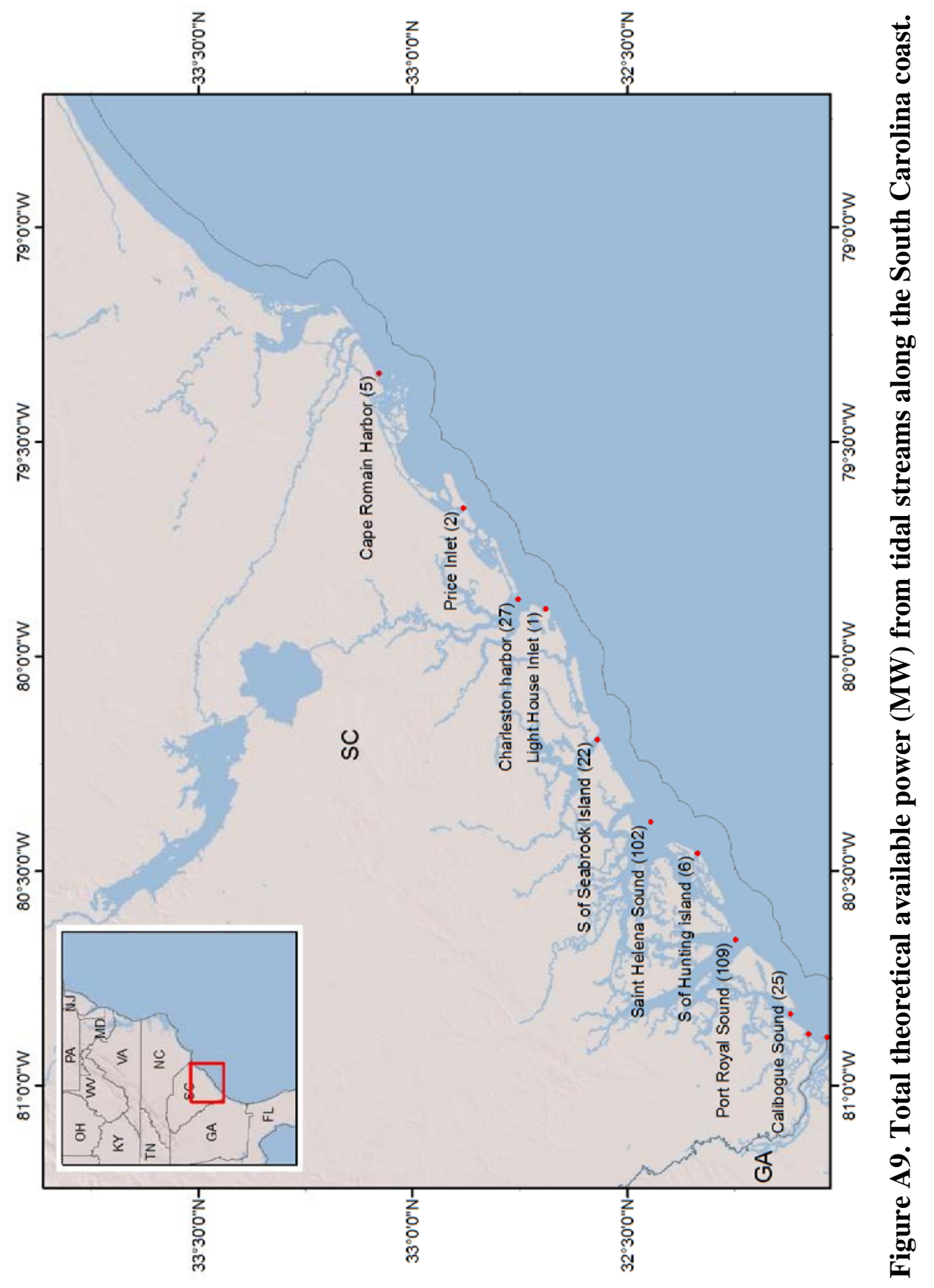




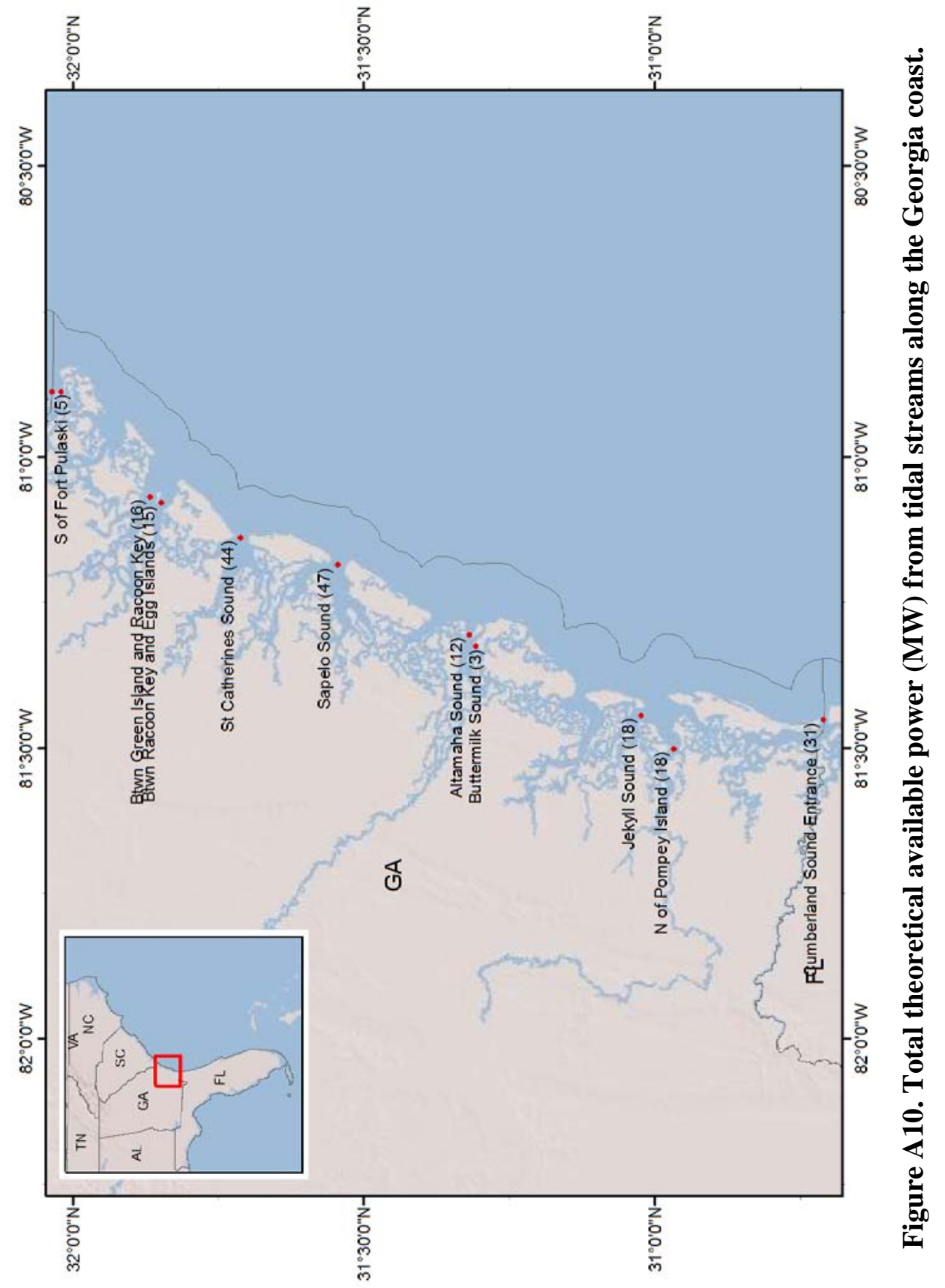




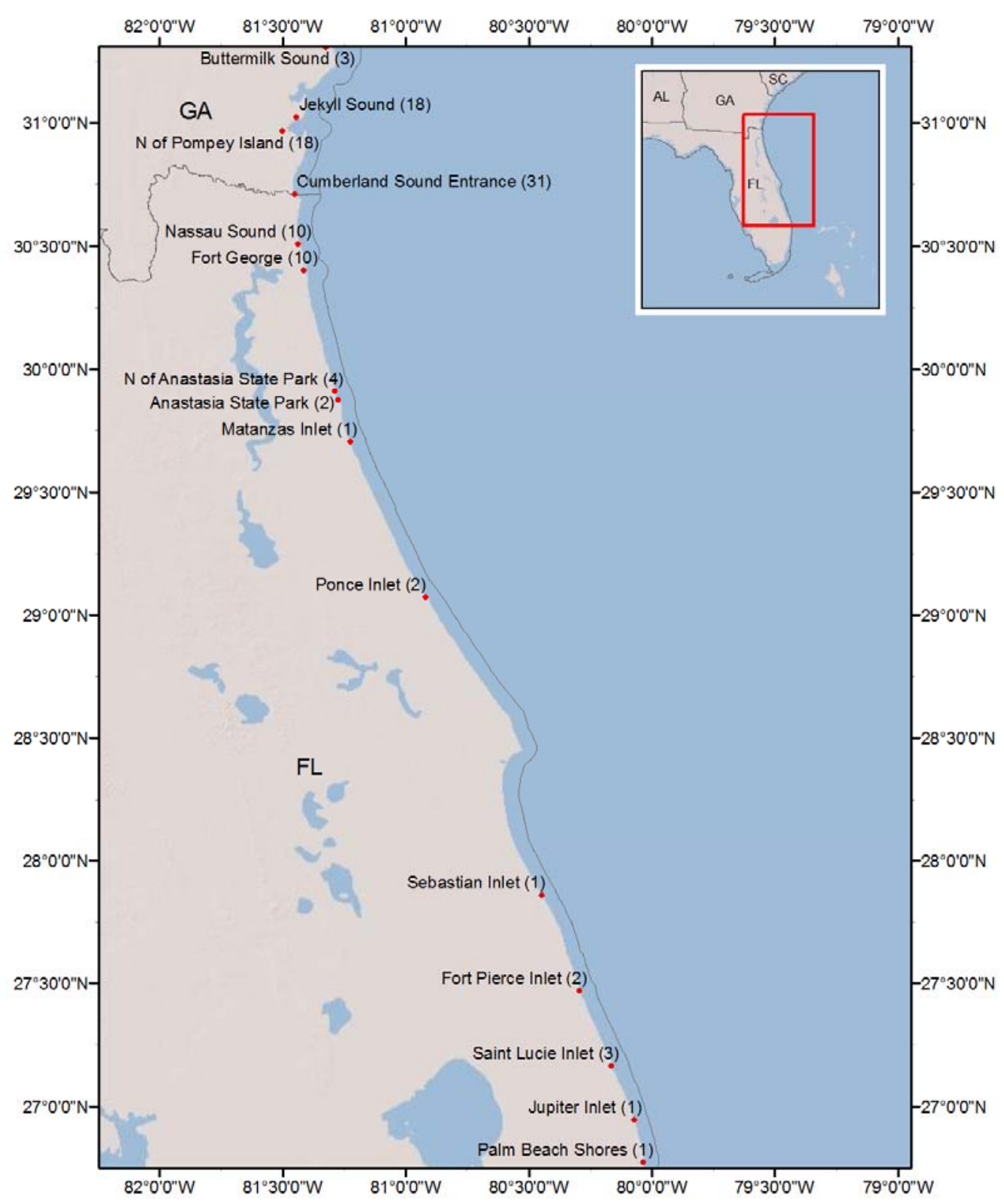

Figure A11. Total theoretical available power (MW) from tidal streams along the Florida coast (North East). 


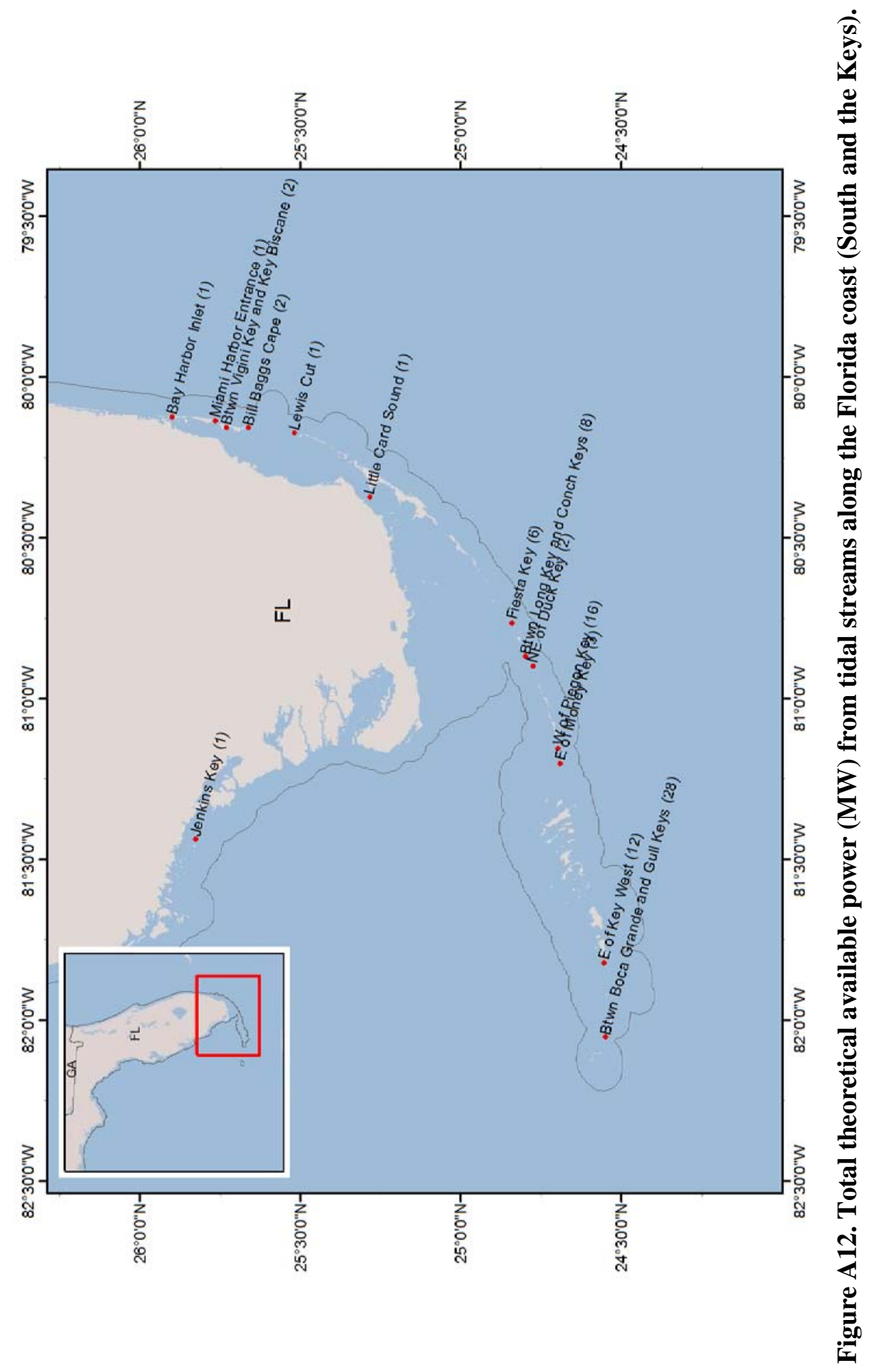




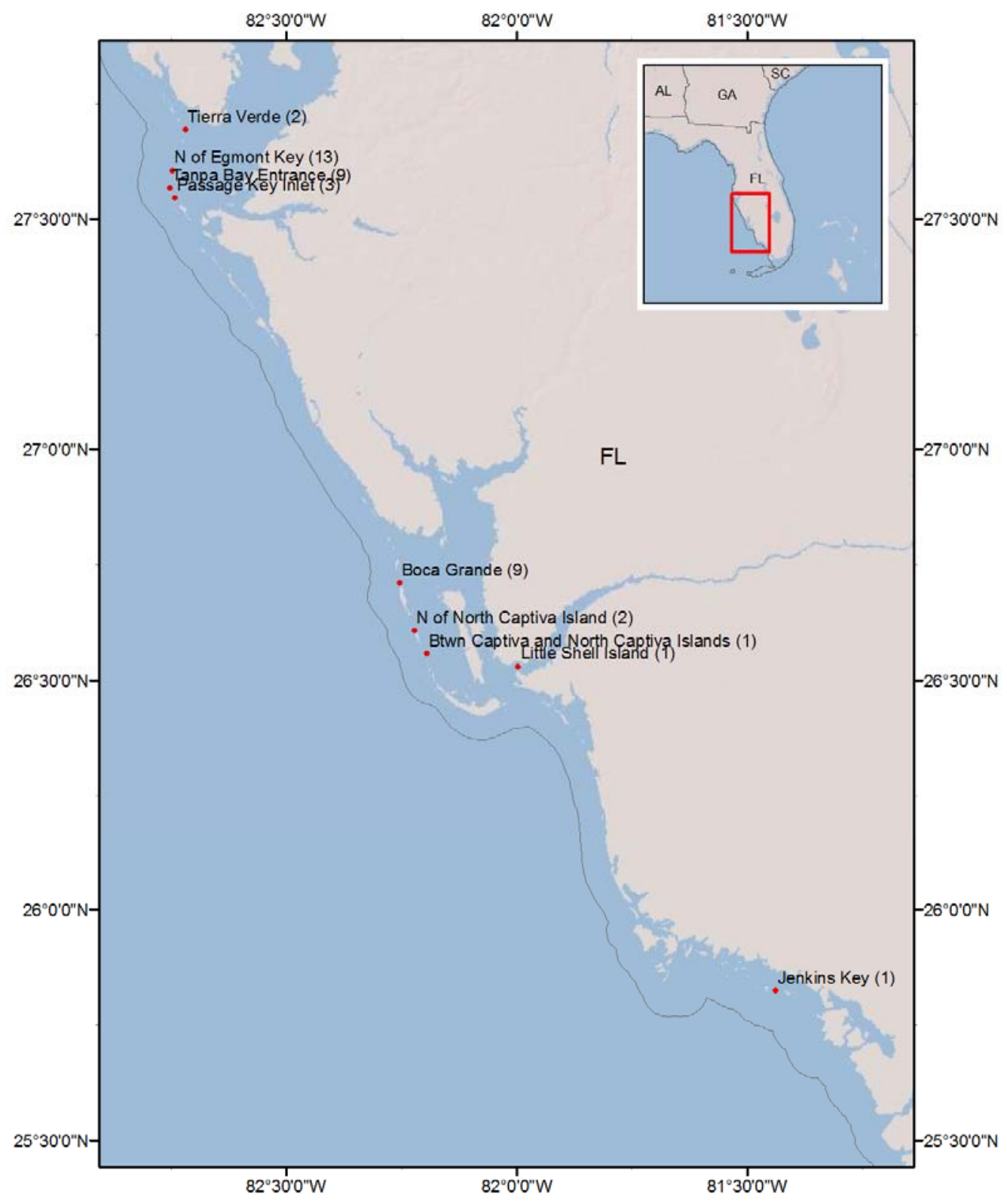

Figure A13. Total theoretical available power (MW) from tidal streams along the Florida coast (South East). 


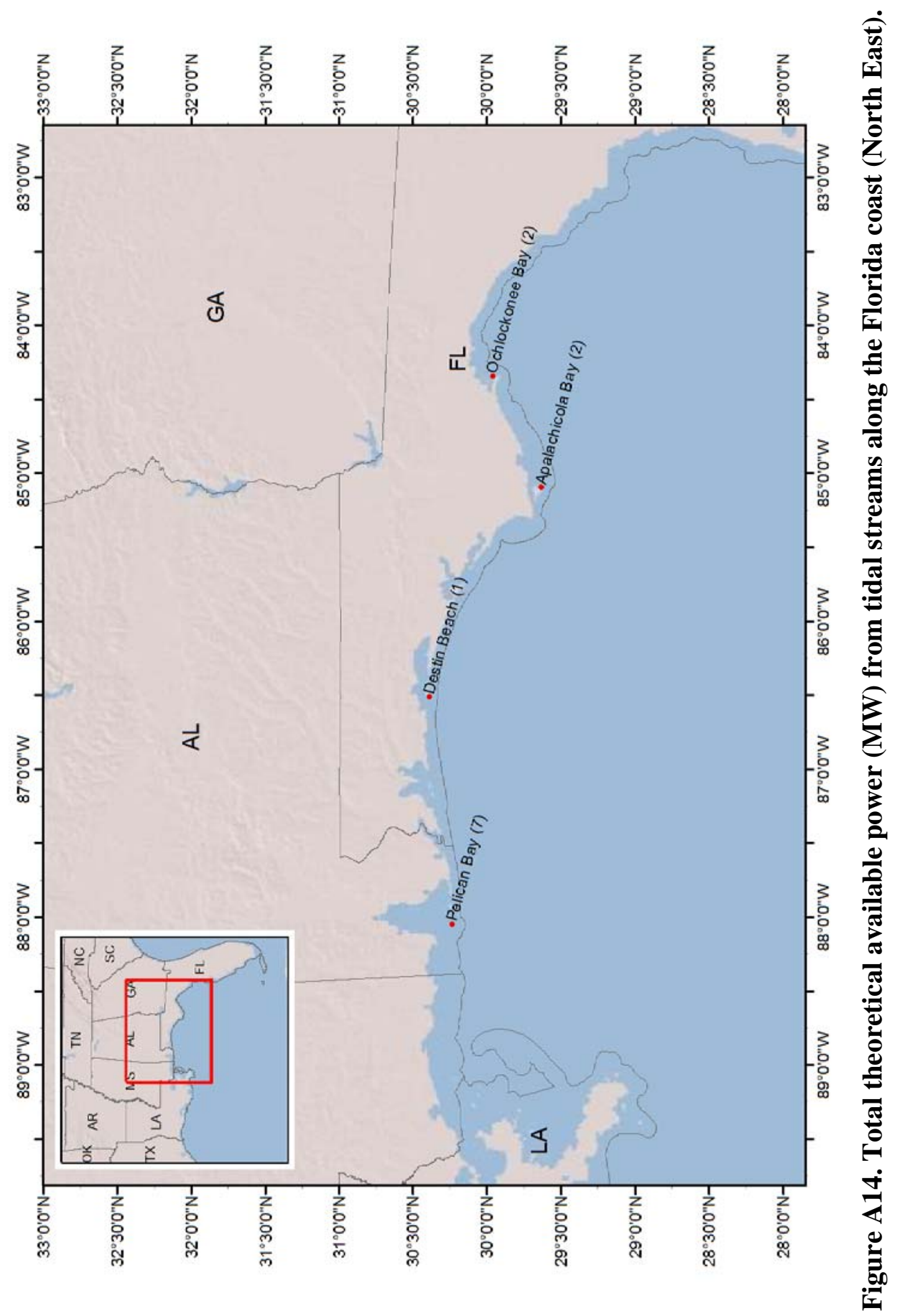




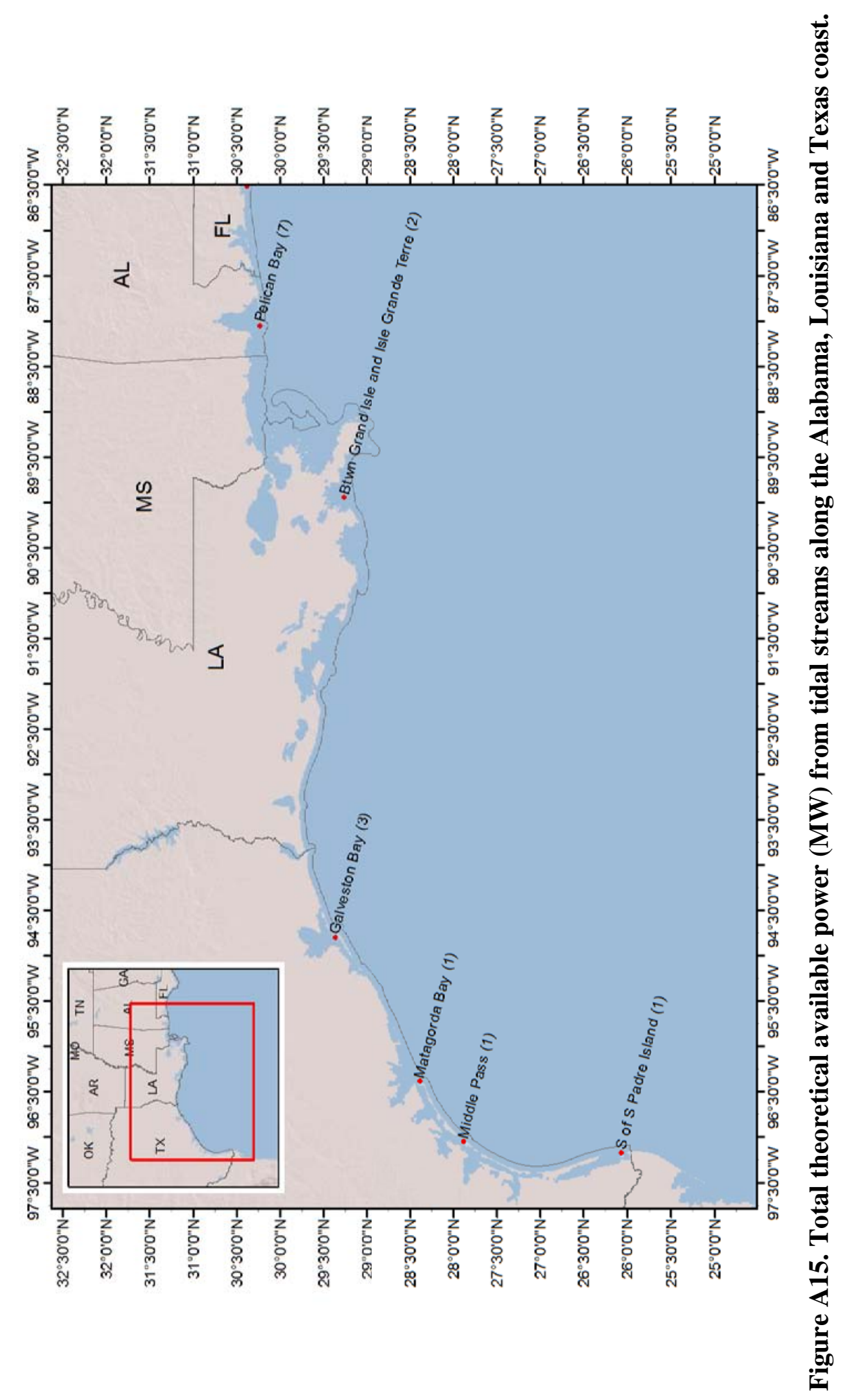




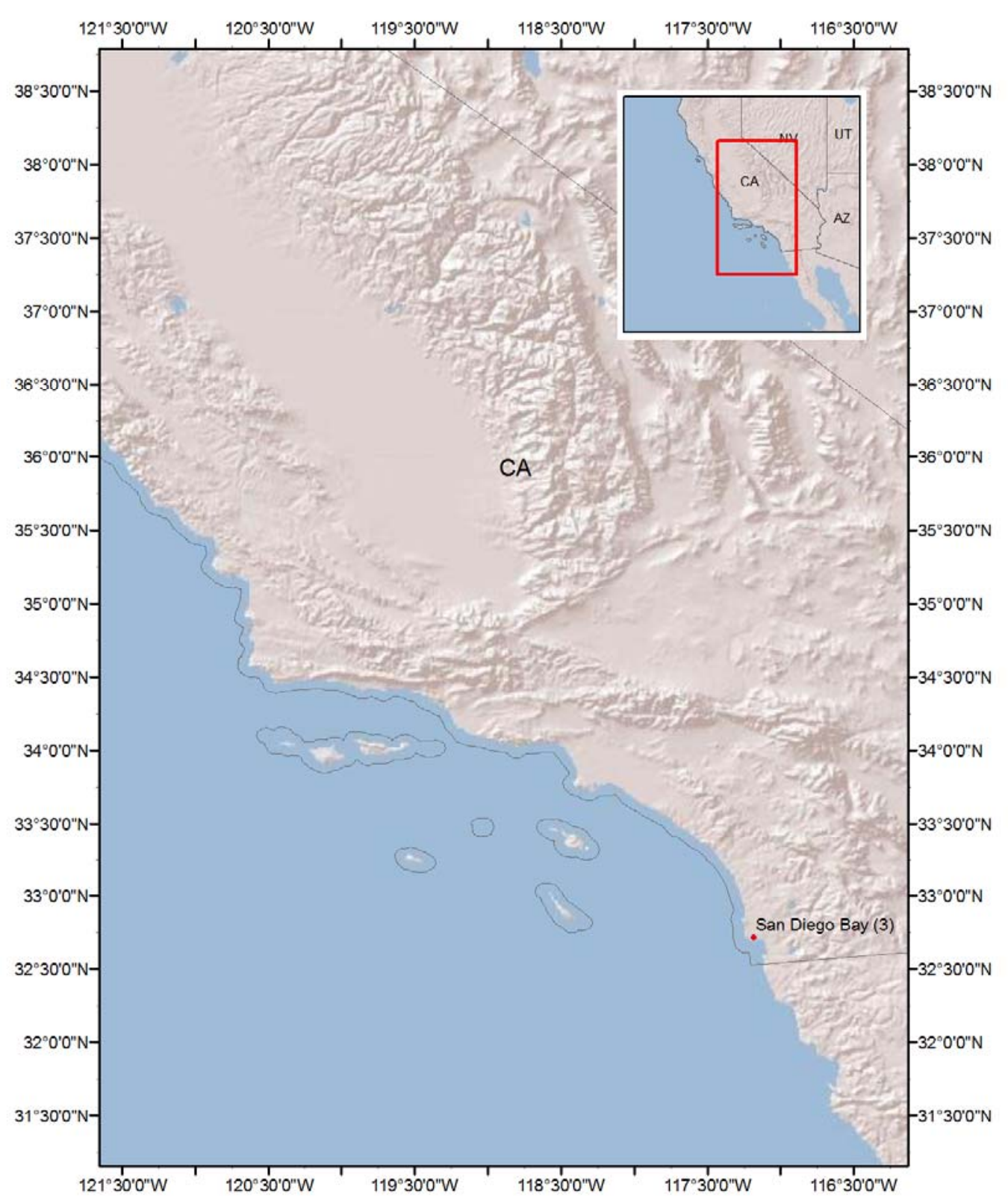

Figure A16. Total theoretical available power (MW) from tidal streams along the California coast (South). 


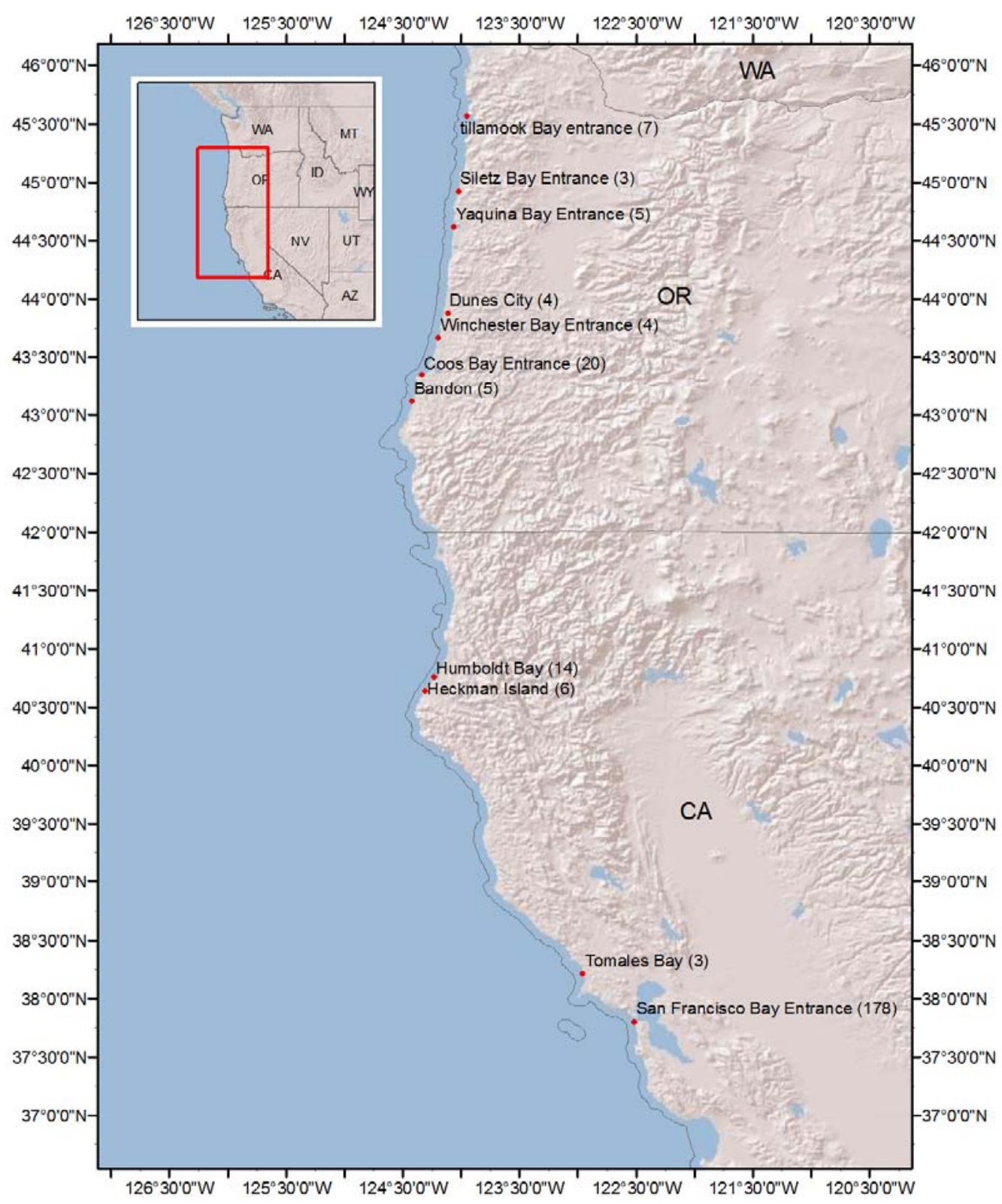

Figure A17. Total theoretical available power (MW) from tidal streams along the California (North) and Oregon coast. 


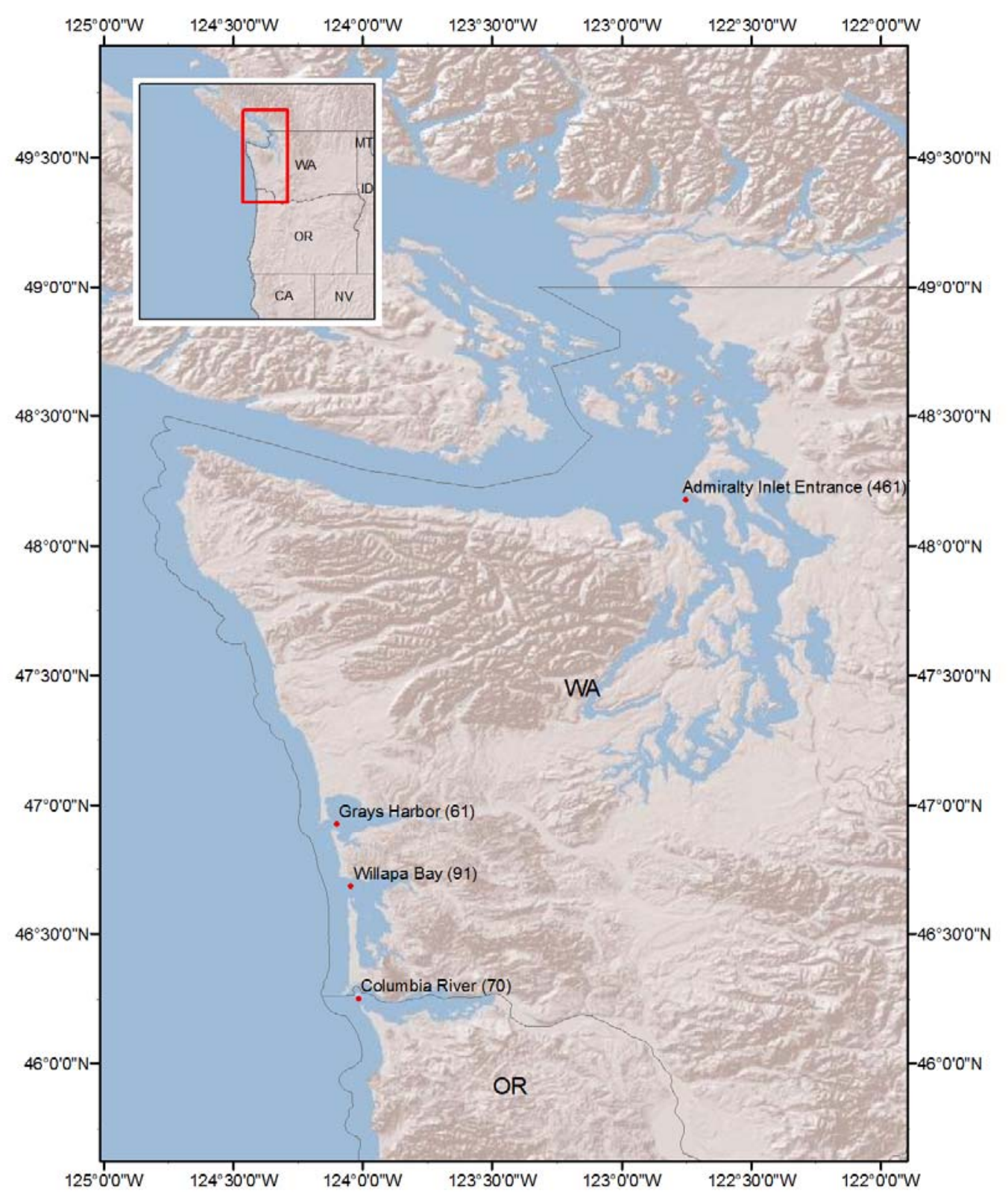

Figure A18. Total theoretical available power (MW) from tidal streams along the Washington coast. 


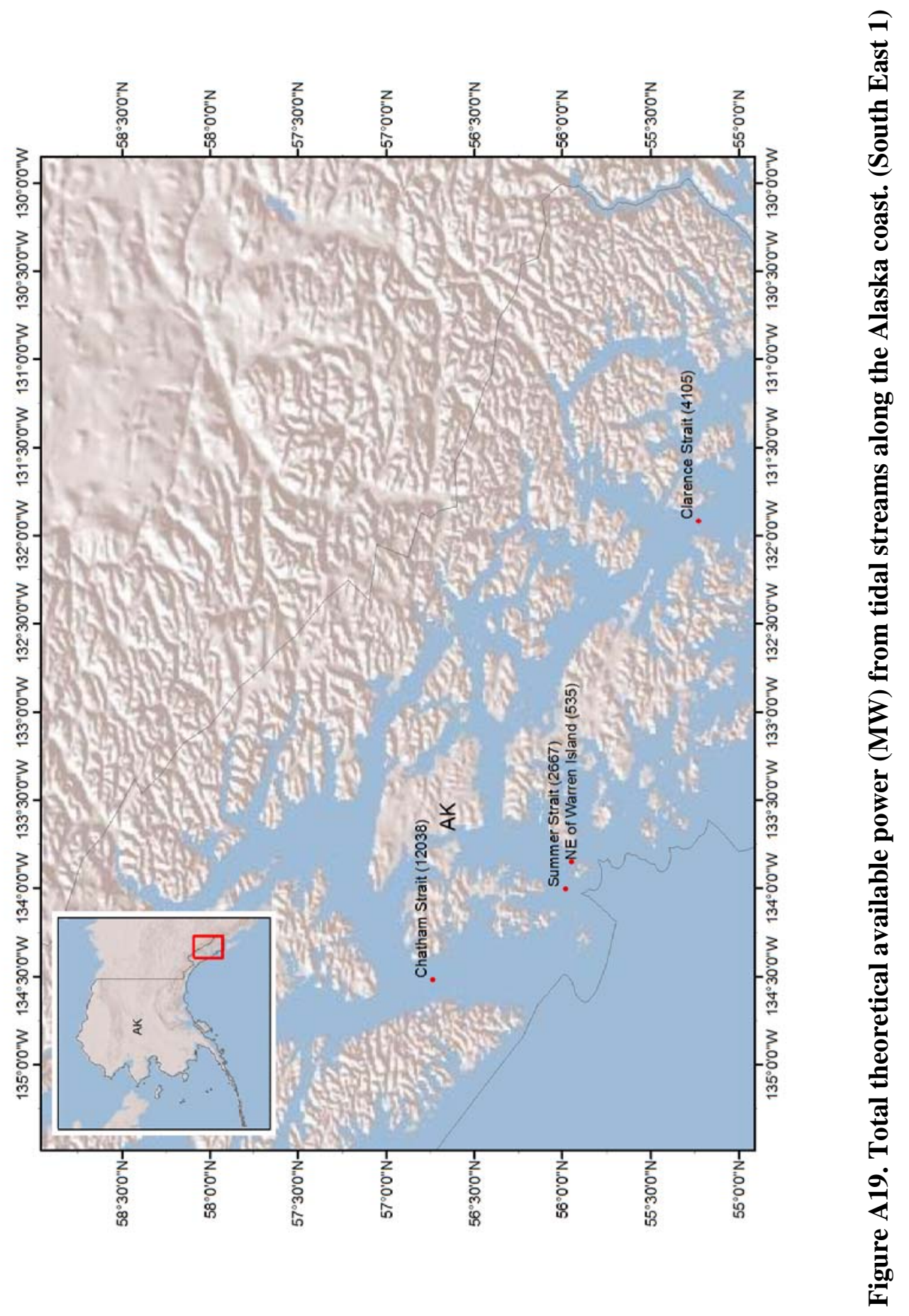




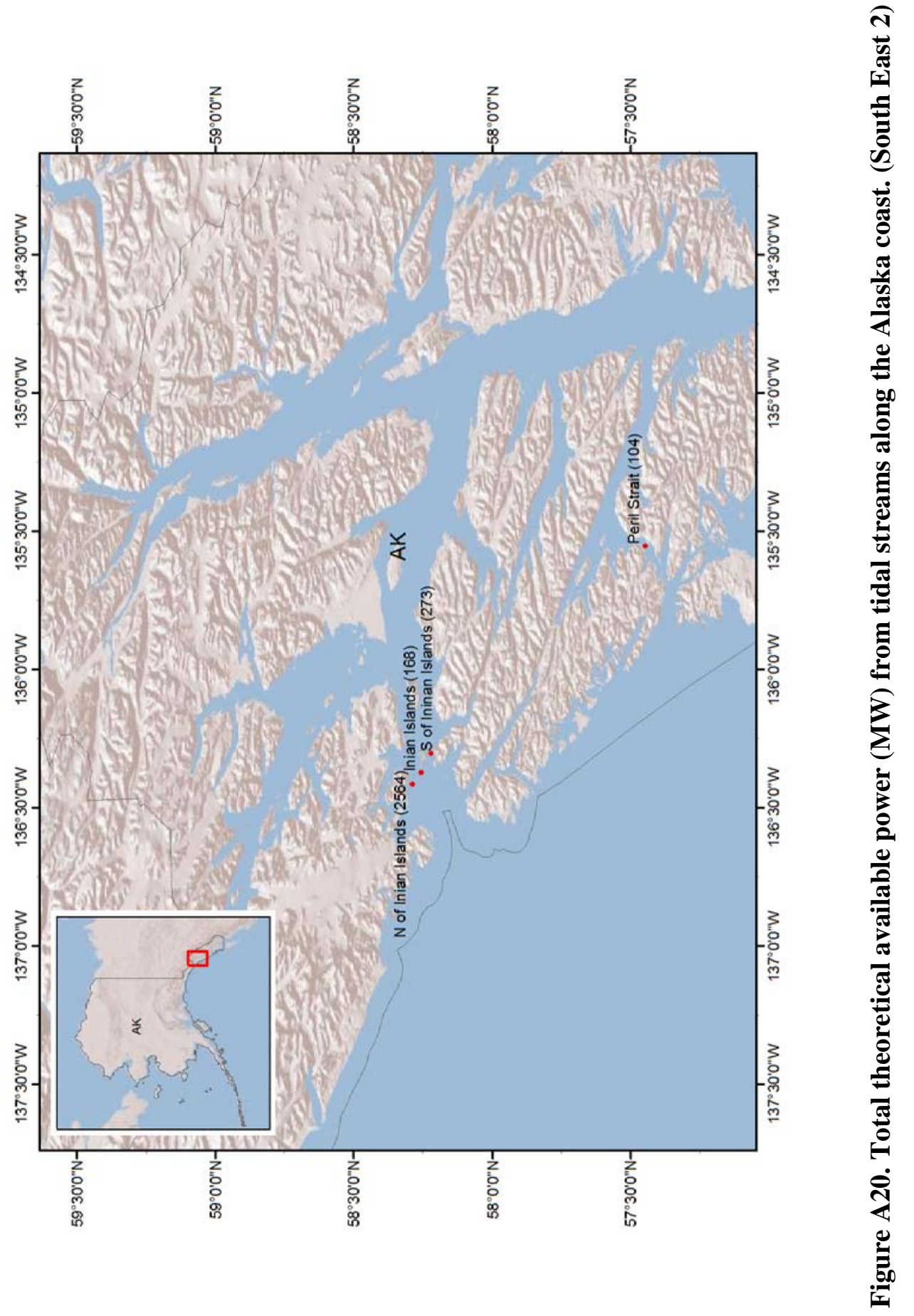




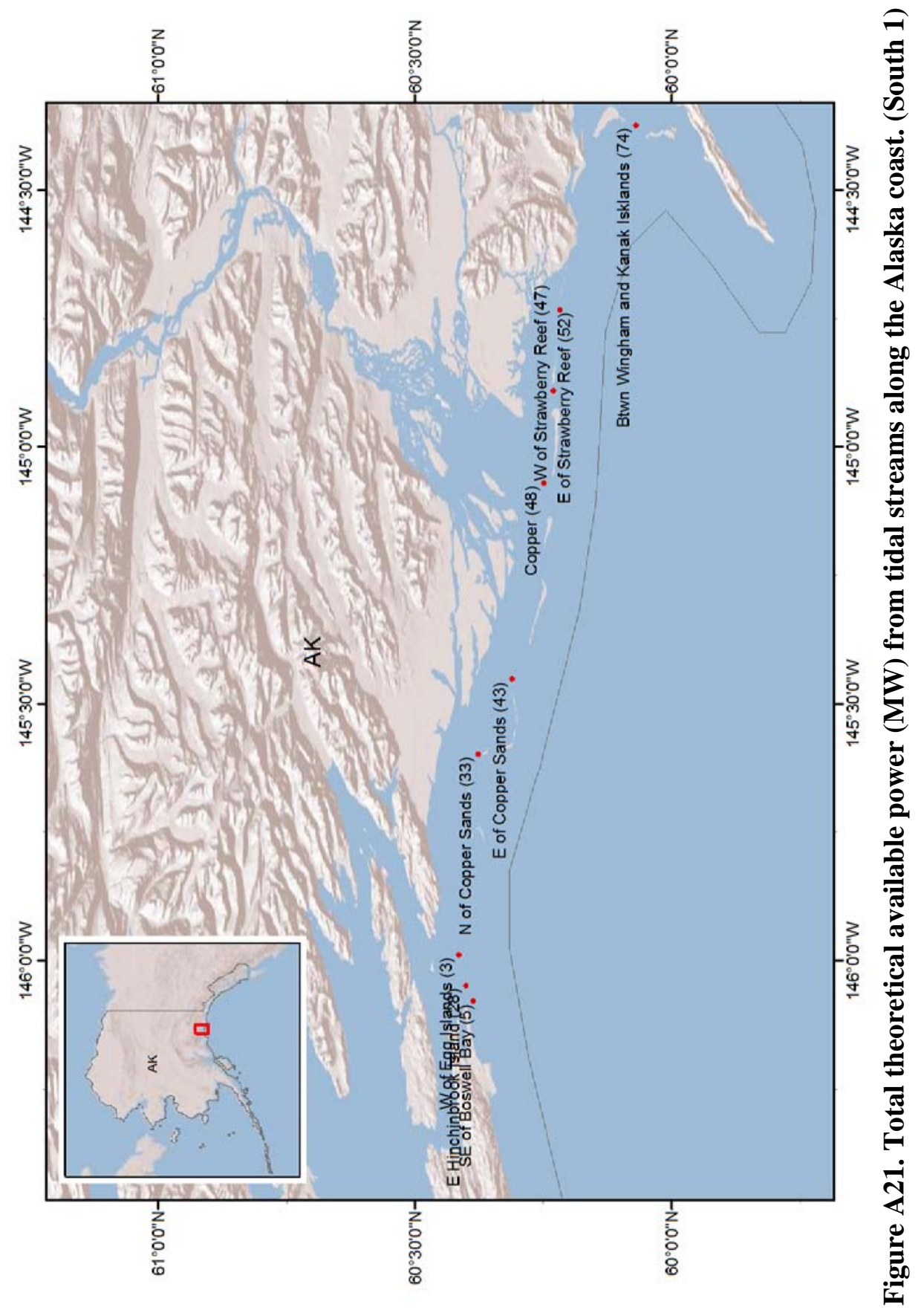




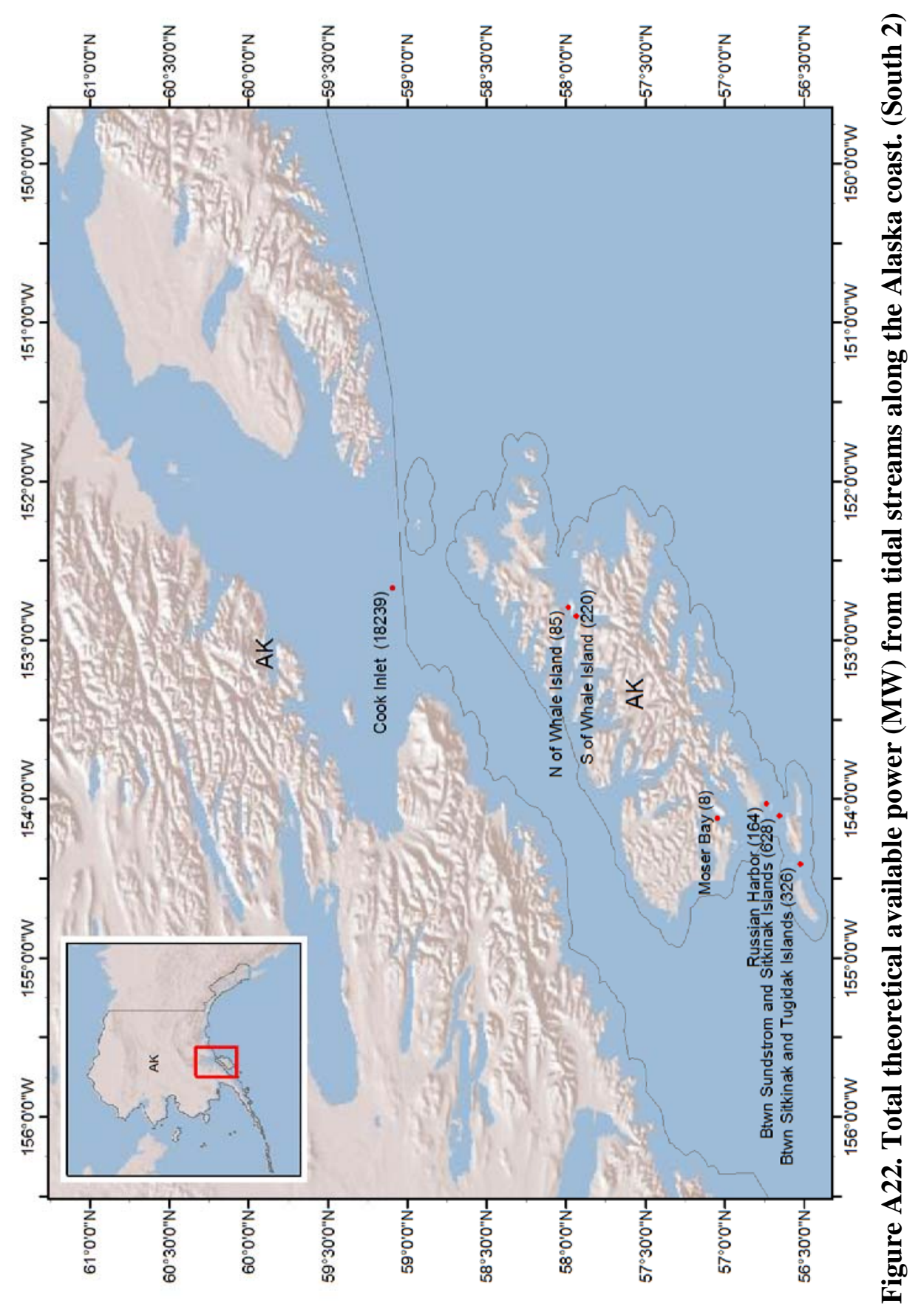




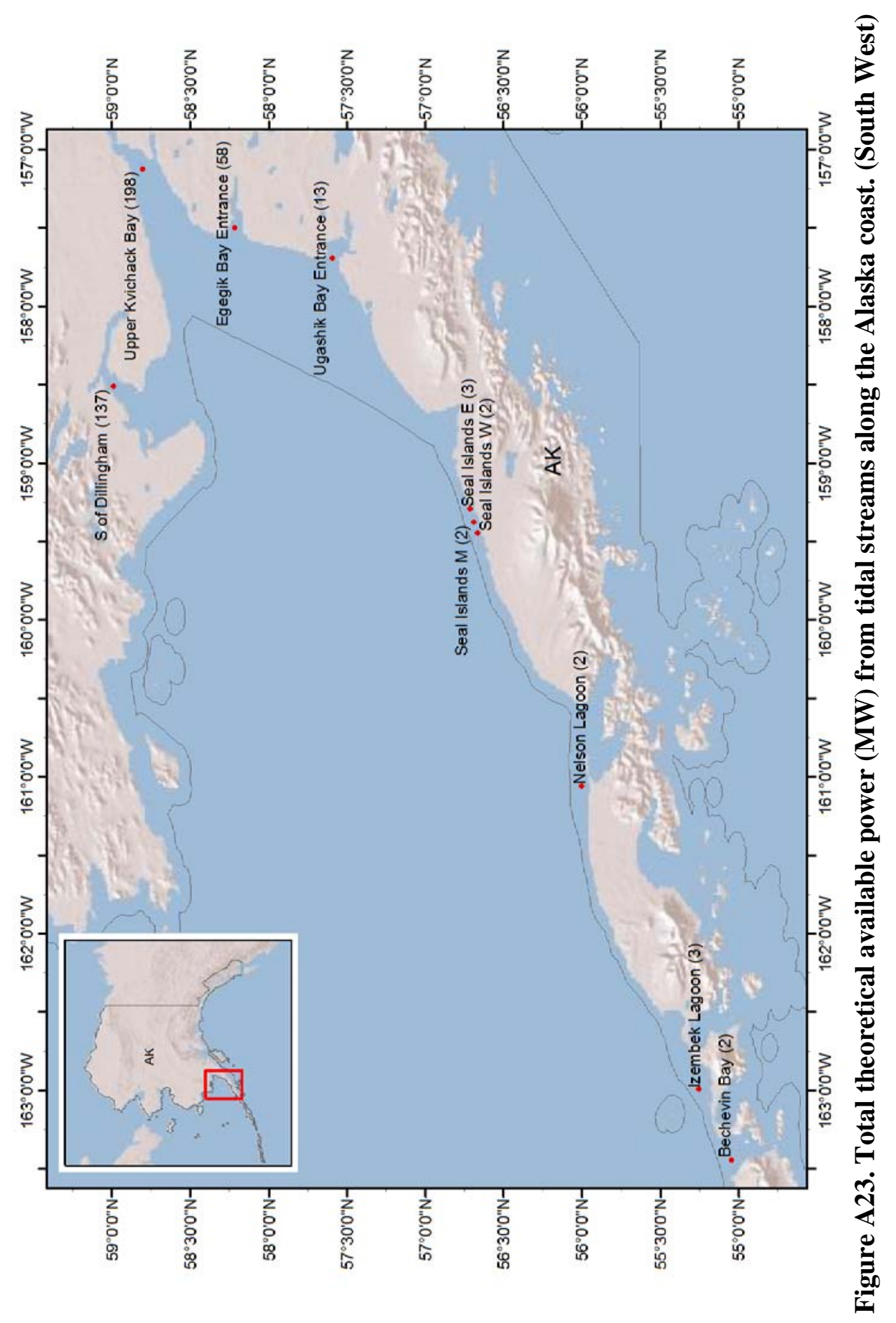




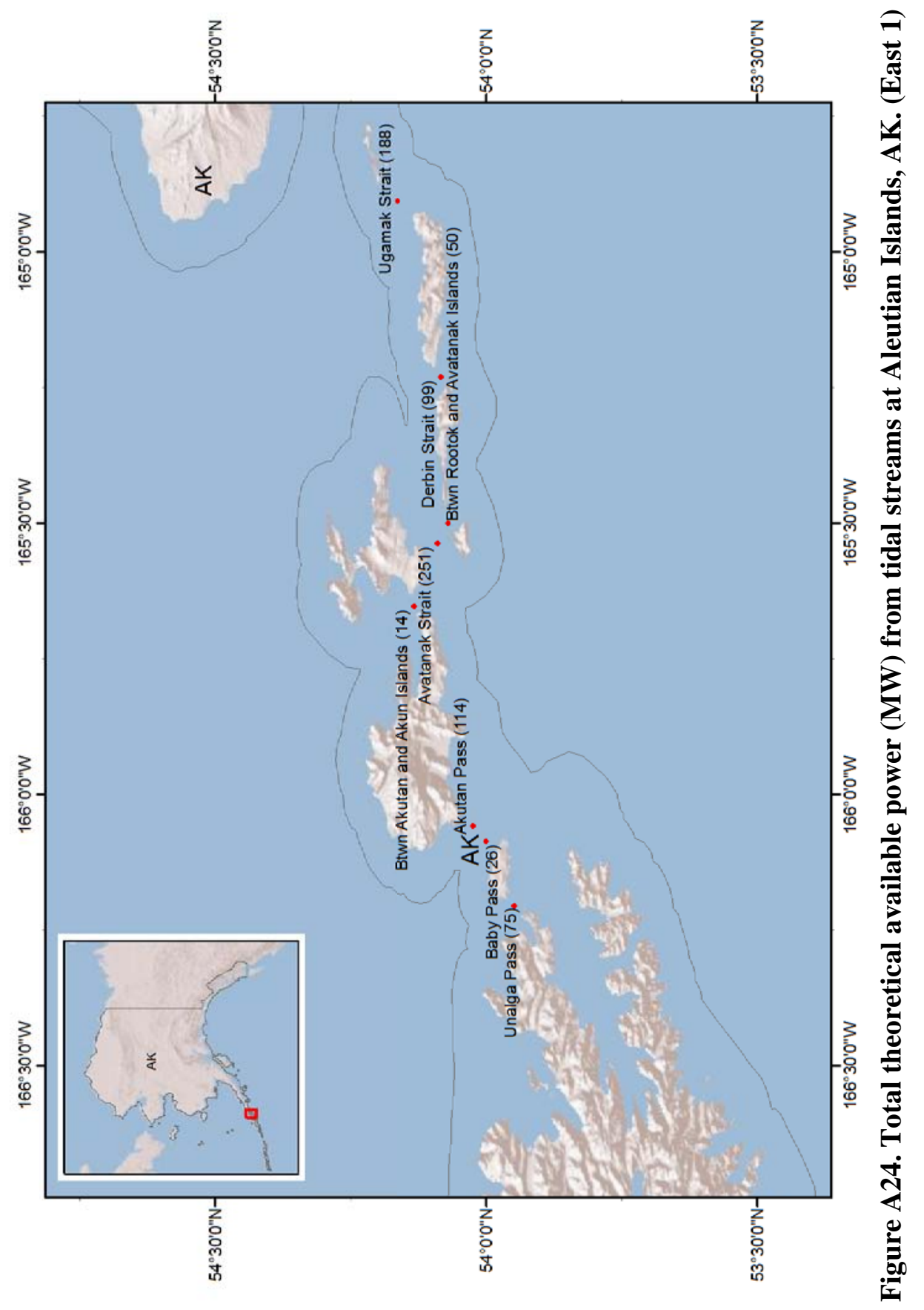




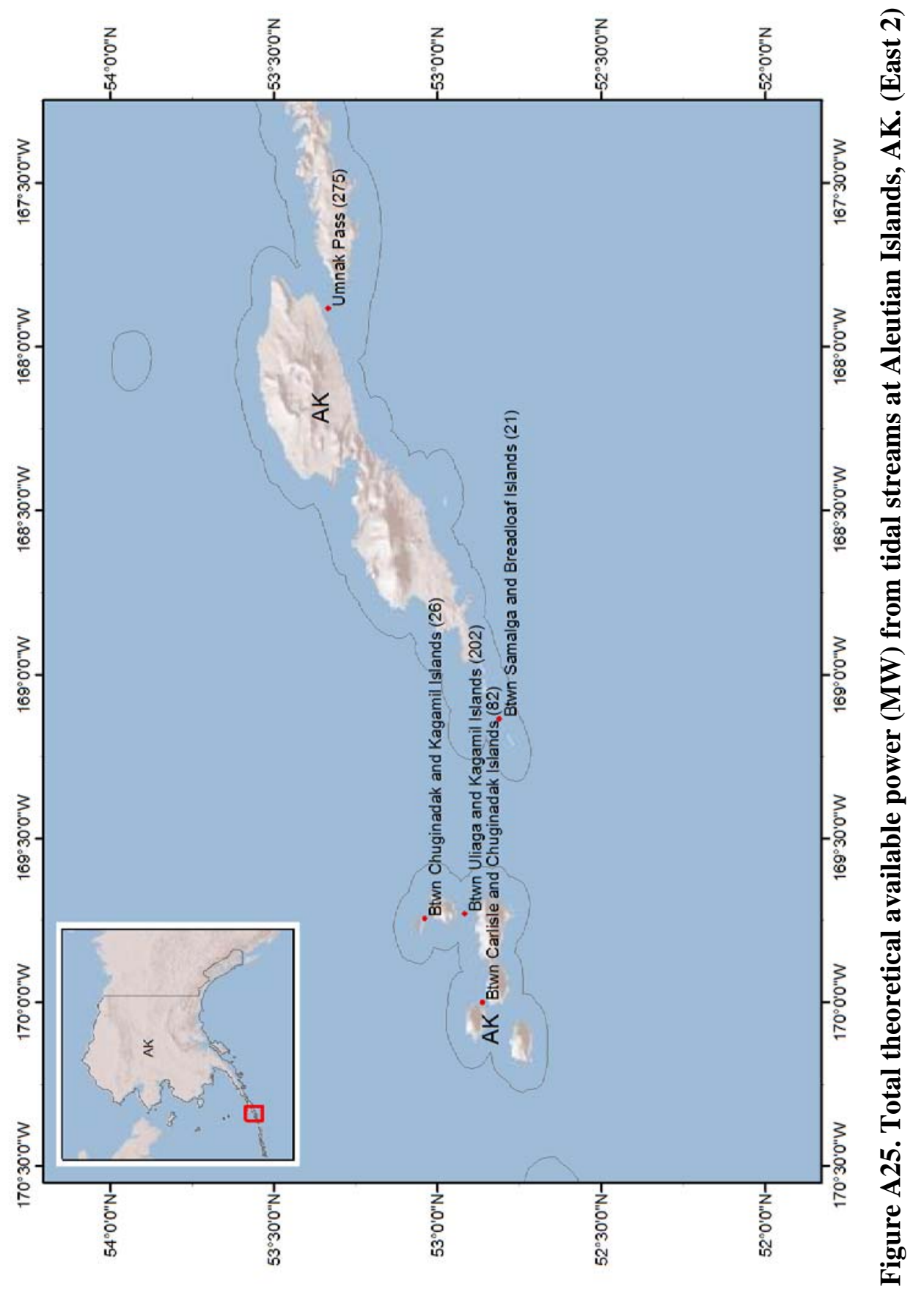




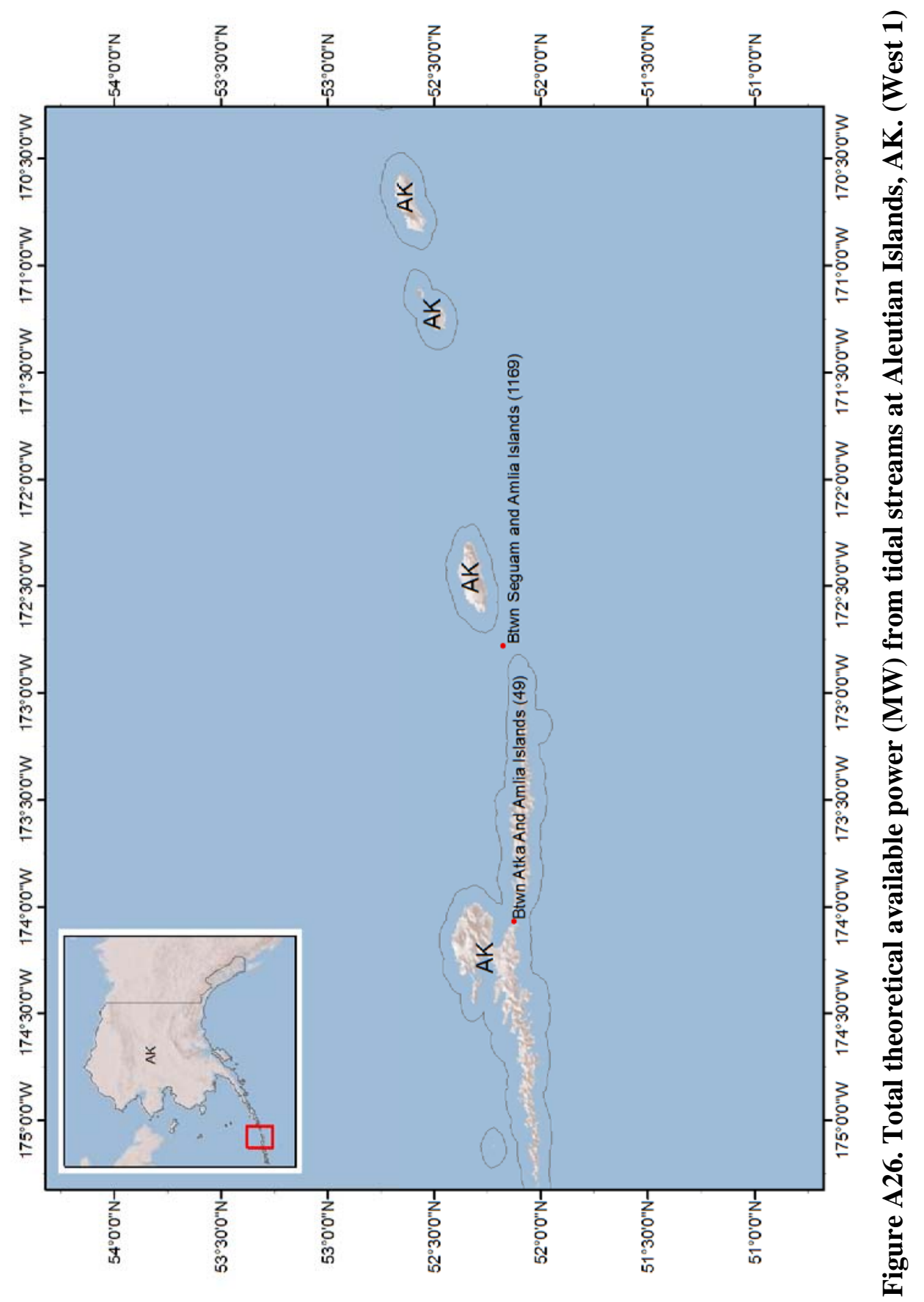




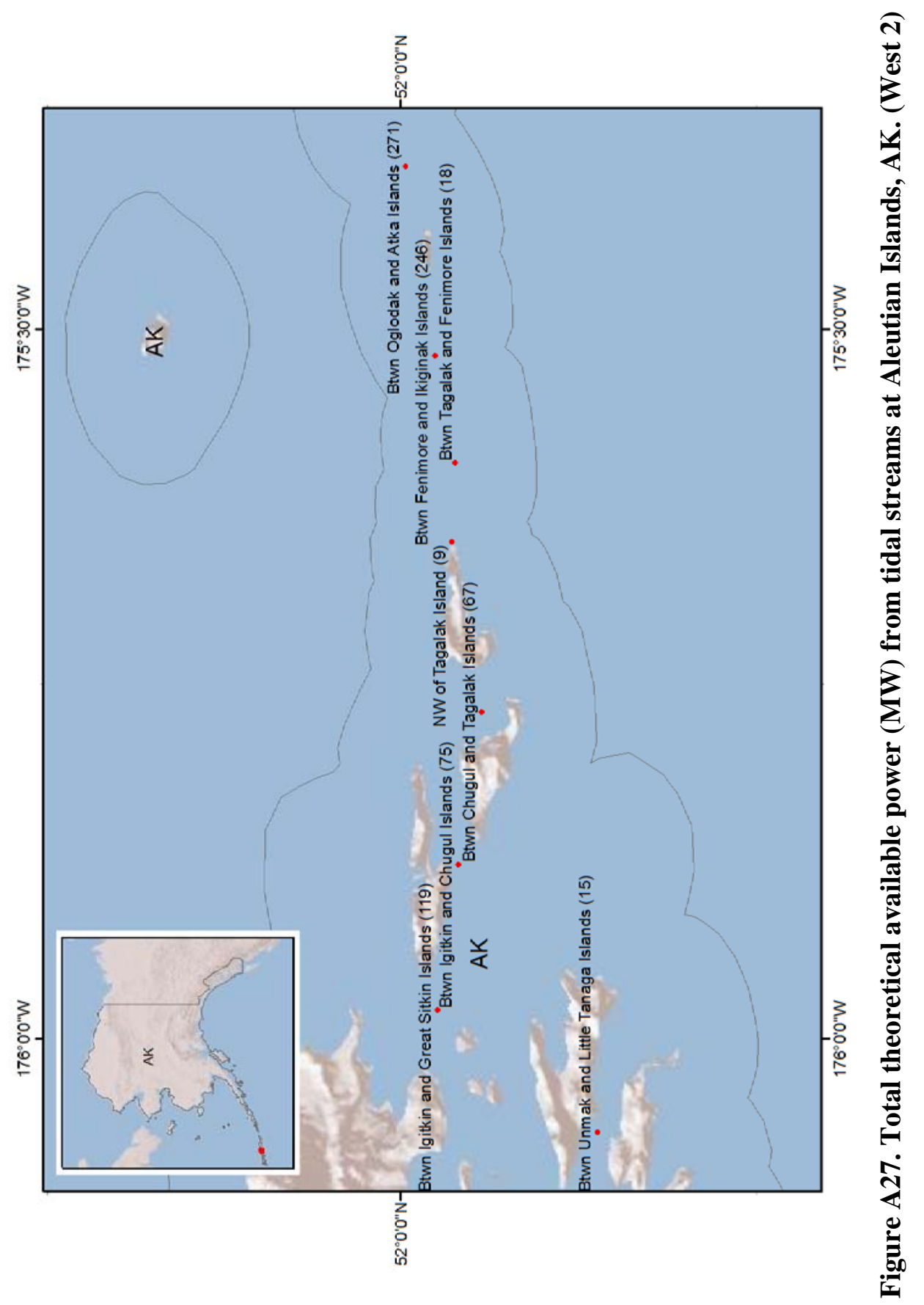




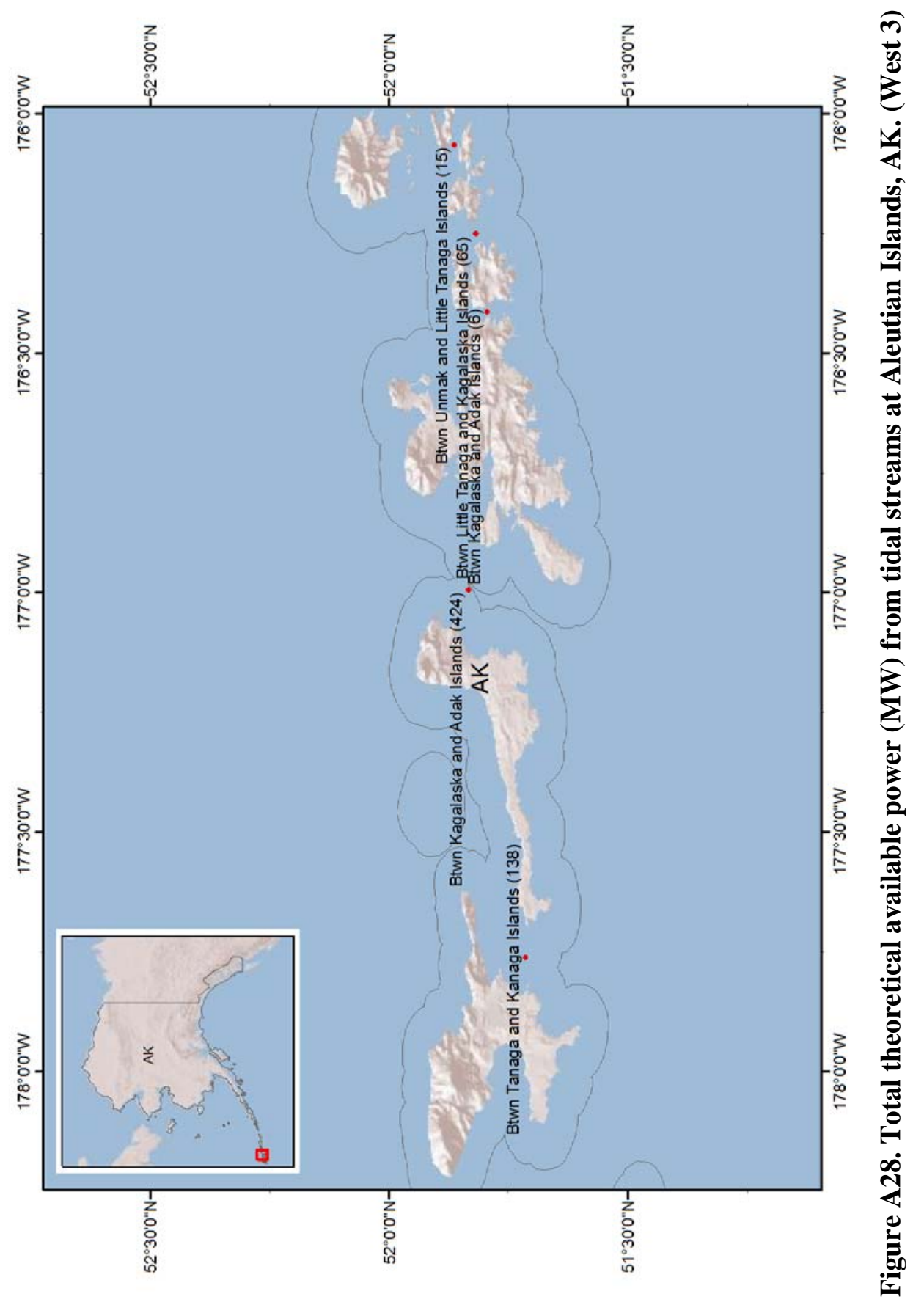




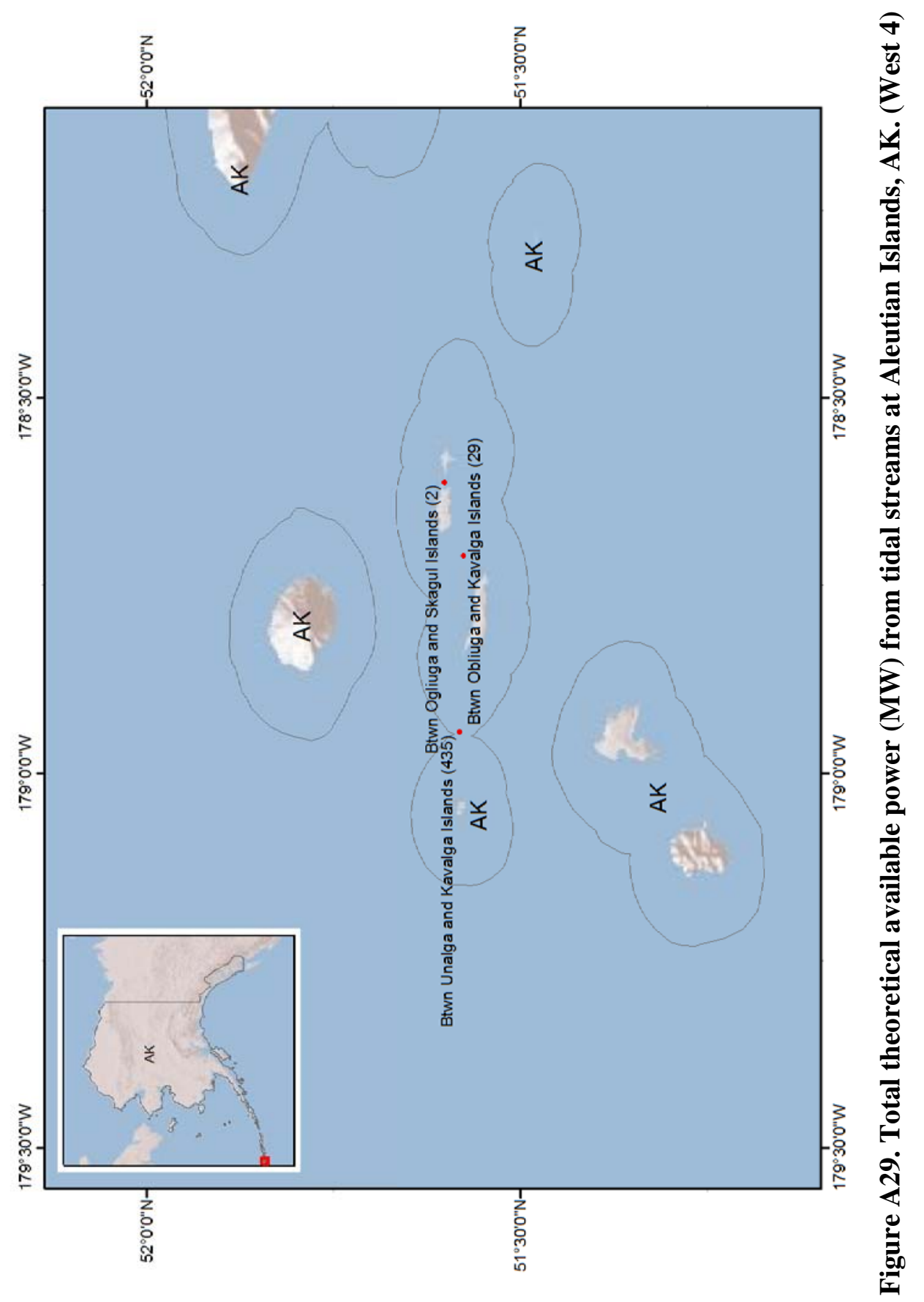




\section{APPENDIX B}

\section{REPRINTS OF PUBLISHED PAPERS}

This appendix includes reprints of the published journal and conference papers

Defne Z., Haas K. A., Fritz H. M. (2011) GIS based multi-criteria assessment of tidal stream power potential: A case study for Georgia, USA. Renewable and Sustainable Energy Reviews. Volume 15, Issue 5, June 2011, Pages 2310-2321.

Defne Z., Haas K. A., Fritz H. M. (2011) Numerical modeling of tidal currents and the effects of power extraction on estuarine hydrodynamics along the Georgia Coast, USA. Renewable Energy, in press.

Defne, Z., Haas, K. and Fritz, H. (2008) Assessment of Tidal Currents along the Atlantic Coast of the Southeast USA for Energy Conversion: Case Study for Georgia. 2nd International Conference on Ocean Energy, Brest, France. 


\title{
GIS based multi-criteria assessment of tidal stream power potential: A case study for Georgia, USA
}

\author{
Zafer Defne*, Kevin A. Haas, Hermann M. Fritz \\ Georgia Institute of Technology, 210 Technology Circle, Savannah, GA 31407, United States
}

\section{A R T I C L E I N F O}

\section{Article history:}

Received 19 October 2010

Accepted 28 January 2011

\section{Keywords:}

Site selection

In-stream converters

North Atlantic

\begin{abstract}
A B S T R A C T
A multi-criteria assessment methodology that accounts for the physical, environmental and socioeconomic constraints is proposed to assist in the selection of the most suitable locations for tidal stream power conversion projects. For this purpose, the tidal stream power resource data are incorporated into a Geographical Information System (GIS) database together with datasets that are related to different aspects of the site selection methodology. The proposed method is applied to the Georgia coast to find and rank the best locations for power conversion. The suitable areas are narrowed down to a subset of the high power density areas that satisfy the constraints of a tidal stream power conversion scheme. A demonstrative ranking procedure with equal weighting factors for all criteria shows that the Savannah, Ogeeche, Canoochee and Medway Rivers and the Cumberland Sound have the best locations for tidal power conversion on the coast of Georgia. This methodology is also applicable to other sites where sufficient geospatial data are available.
\end{abstract}

(C) 2011 Elsevier Ltd. All rights reserved.

\section{Contents}

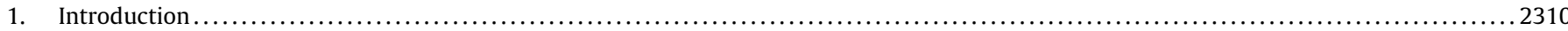

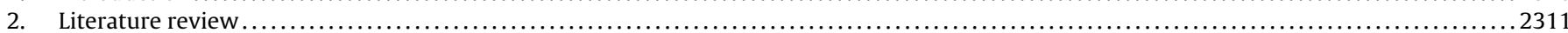

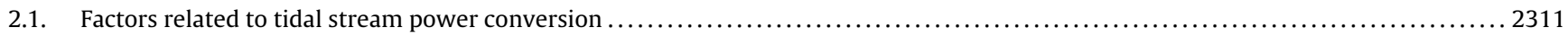

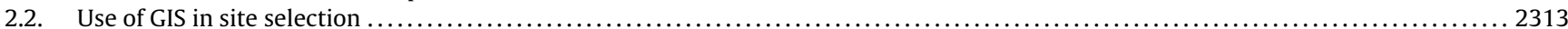

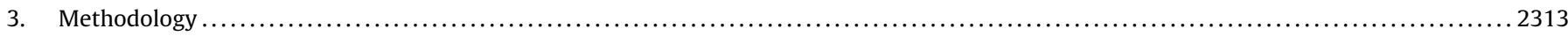

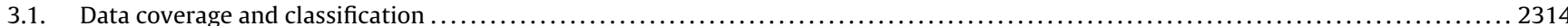

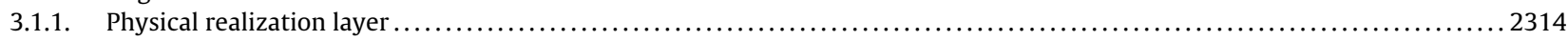

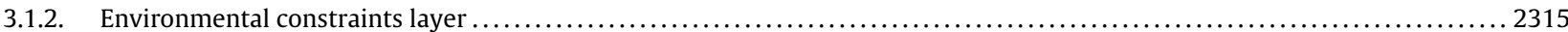

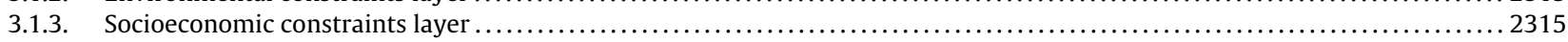

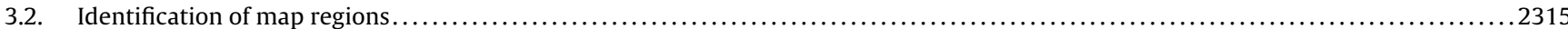

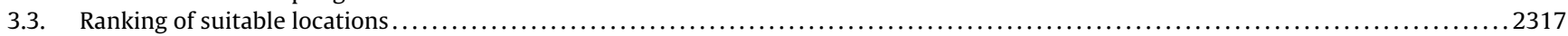

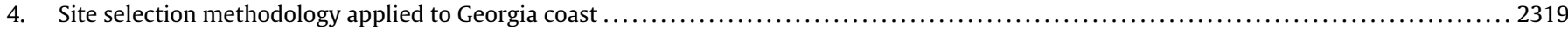

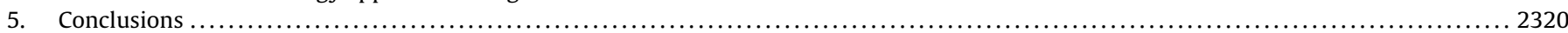

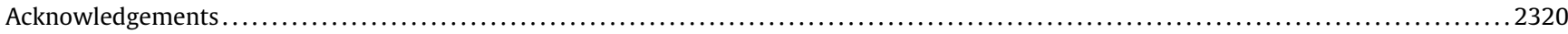

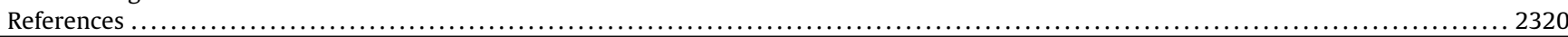

\section{Introduction}

Given the current and projected global energy demand and the associated impact on the environment, marine energy conversion projects offer viable alternatives with their clean and renewable applications. There are many projects and emerging technologies worldwide to convert the power from the vastly unexploited ocean

\footnotetext{
* Corresponding author. Tel.: +1912965 2393.

E-mail addresses: zafer.defne@gatech.edu (Z. Defne), khaas@gatech.edu (K.A. Haas), fritz@gatech.edu (H.M. Fritz).
}

tides and currents to electric power. Resource mapping is a fundamental step in development of such projects given the distributed nature of these resources. In order to provide this step for any possible future developments in the state of Georgia, the wave power potential and the tidal stream power resource in the region have been investigated [1,2]. The wave power was found to diminish significantly on the broad continental shelf with the regions of larger power being limited to the offshore portion of the shelf. The tidal stream power on the other hand was determined to be substantially amplified at some of the locations along the shoreline, at some specific parts of the Savannah, Canoochee, Ogeeche, Altamaha and Medway Rivers and the Intercoastal Waterway between the 

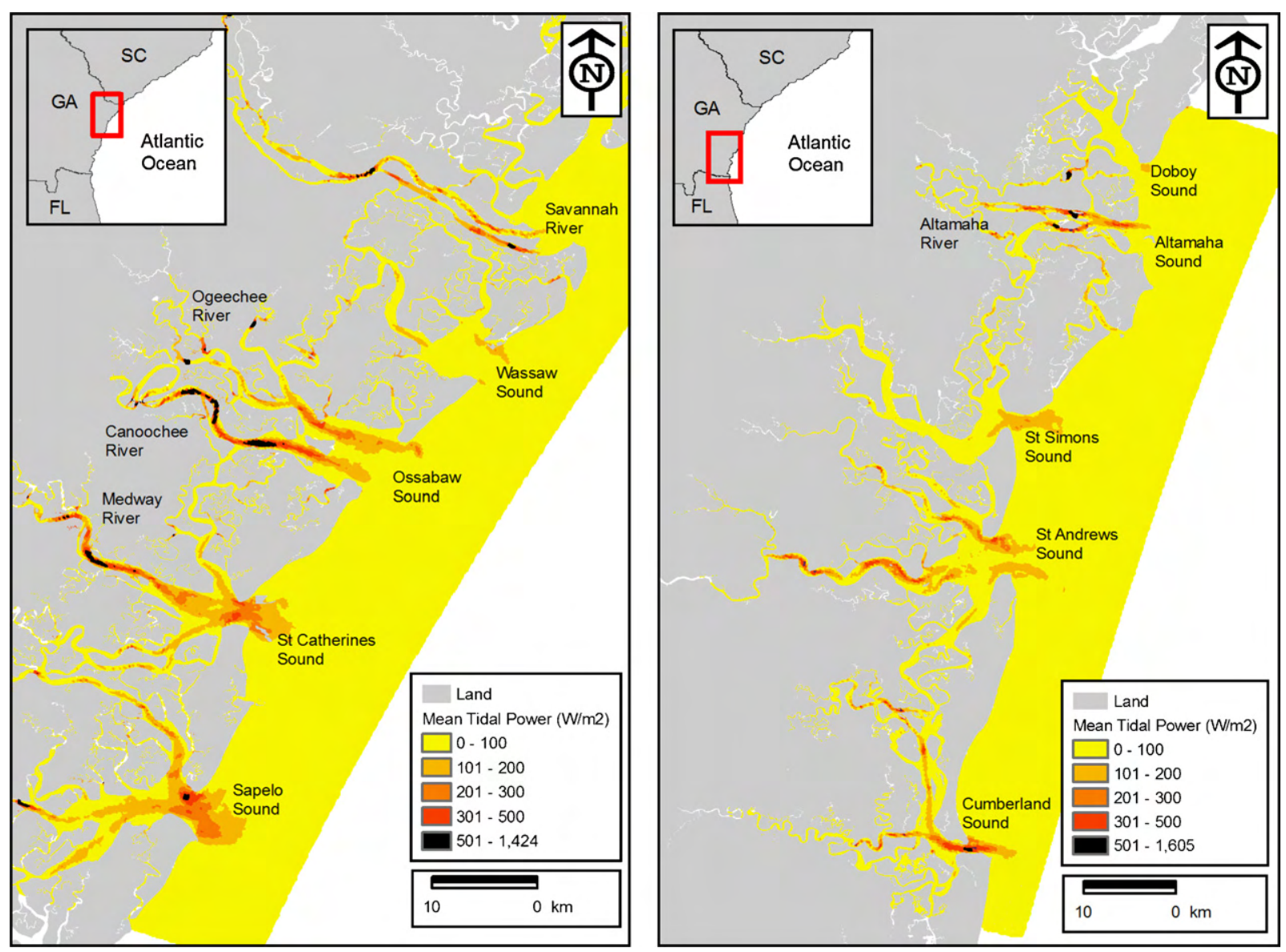

Fig. 1. Mean power density maps along (a) the northern and (b) the southern coasts of Georgia.

Altamaha and the Doboy Sounds as well as St. Catherines, Sapelo, St Andrews, and Cumberland Sounds (Fig. 1). Here, a comprehensive methodology to analyze the tidal stream power potential in the context of the physical, environmental and social constraints using GIS tools has been developed.

This paper is organized as follows: First the factors related to the tidal stream conversion projects are discussed along with the literature on use of GIS as a decision support tool for energy projects. Then, the data coverage, and the methodologies for identification and ranking of the suitable locations are presented in detail followed by the application to the Georgia coast to determine the most promising locations for tidal stream power conversion. Finally, the concluding remarks and suggestions for future work are presented.

\section{Literature review}

Recently, the International Electrotechnical Commission (IEC) has initiated international standards for marine power conversion systems, TC 114 Marine Energy-Wave and Tidal Energy Converters, which addresses the evaluation and mitigation of environmental impacts, resource assignment requirements, performance measurement of converters and other related issues [3]. Since there is no international standard available at the present, the current study relies upon the methodologies and experiences from other marine renewables and wind power conversion projects.

\subsection{Factors related to tidal stream power conversion}

The choice of location for a tidal stream power converter farm depends on assessment of a number of criteria including the avail- able power, site characteristics, and environmental, economic and social impacts of the planned project [4-10]. The available power and the site characteristics such as bathymetry, water depth and the geology of the seabed constitute the physical constraints of analysis, which are easier to assess quantitatively than the environmental, economic and social constraints with modeling and measurements.

The environmental impacts can be grouped as the physical impacts, such as changes in the flow patterns and water quality, and related ecological impacts on the aquatic and terrestrial life. The effect on water quality during installation mainly consists of disturbance to the sediment, which results in suspension of sediment and increased turbidity. This is of more concern if the bottom sediment has contamination. During operation, converters alter the tidal energy flow hence the sedimentation patterns and suspension as well as the vertical mixing. Scour and loss of soft sediments might occur near the structures.

In order to avoid the adverse impact on aquatic life, habitats for endangered, protected or sensitive species should be clearly identified and avoided if possible. Because suspension of fine sediment due to construction may have impacts on the immediate surroundings, fish spawning or nursery areas and sensitive benthic habitat should be avoided. While the effect of noise and vibration on aquatic life during operation is a research topic for the ongoing projects, noise and vibration during construction might be more critical especially during breeding, nesting and migration seasons. However, these can be minimized by careful site selection and timing for the project [7]. The mechanical and flow related injuries of the aquatic life from conventional hydropower facilities include impingement with screens and contact with the blades, 


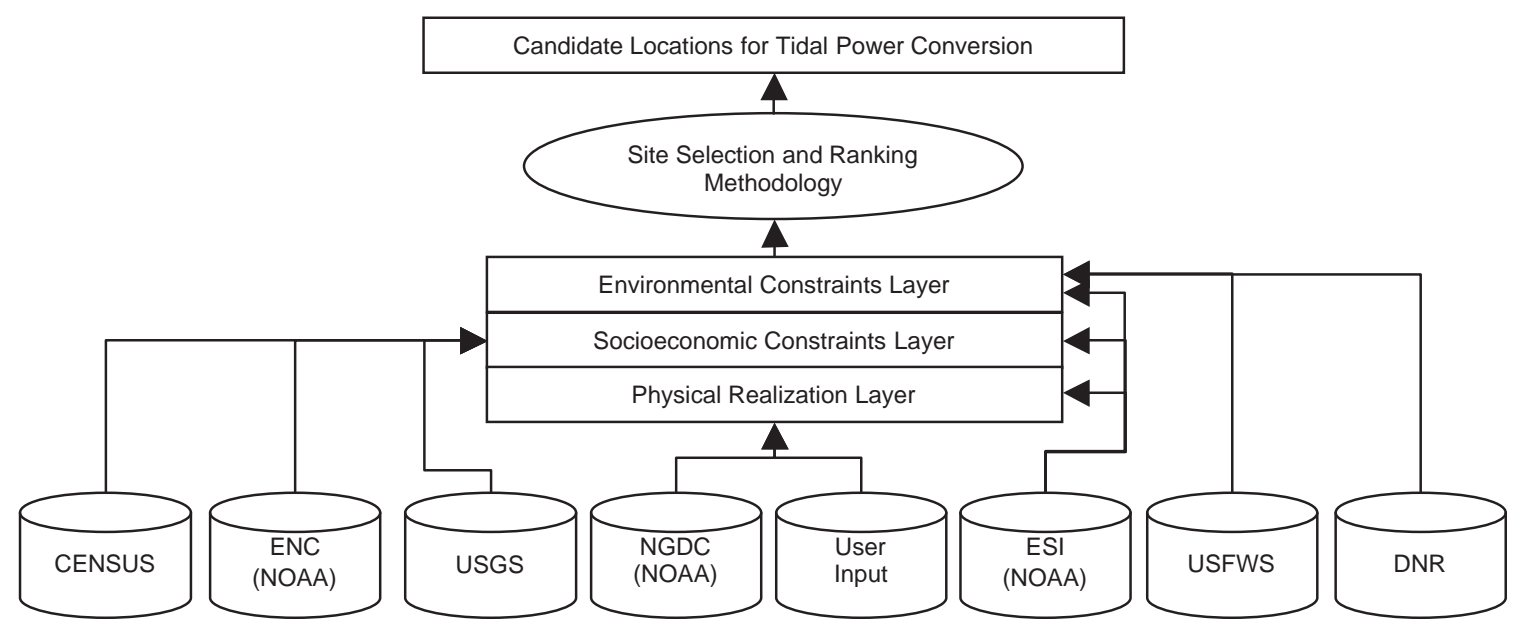

Fig. 2. Structure of geographically referenced information and the underlying data sources used for selecting candidate locations for tidal power conversion.

and abnormal changes in pressure gradients and water velocities. Although converters with unenclosed turbines look similar to boat propellers or hydroelectric power turbines, they operate at much lower speeds and much lower pressures than those traditional devices. The blades are usually slender and the percentage of area swept by the rotor is much smaller. This reduces the probability of fish passing through making contact with the blades. Injury from impingement, abrasion, pinching or grinding is prevented in the absence of a screen of a shroud. The installation stage may also require permanent removal of some terrestrial habitat to construct the shore station, access roads and right of way for the transmission lines [7]. The disturbance to the wetlands should be kept at minimum and temporary as much as possible and permanent changes to the hydrology of the wetlands should be investigated [11].

The economic and social impacts can be evaluated based on the increased energy supply for the region and alterations to the marine and land use. Commercial activities such as shipping and fishing usually share the sea space with recreational and touristic activities. However, during the installation of converters, most of land and marine activities in the vicinity of the project area need to be restricted. At the operation stage, fishing exclusion zones and restricted areas for recreational boats may need to be introduced. If navigation or commercial shipping cannot be avoided, enough safety clearance should be left between the rotor blade and the devices at lowest astronomic tides. The aesthetical concerns and the effects on the cultural and historic sites are additional aspects to be considered when evaluating the environmental effects [5].

Some positive environmental impact may be expected from the converters. Establishing fishing exclusion zones around converters may help increasing the amount of aquatic life by providing shelter for marine life. Project structures, such as transmission cables may serve as suitable structures for invertebrates

Table 1

List of layers, sources and themes and their roles. N.A. indicates the themes that are not assigned any roles.

\begin{tabular}{|c|c|c|c|}
\hline Layer & Source & Theme & Role \\
\hline \multirow[t]{4}{*}{ Physical realization } & NGDC, & Coastline & \multirow[t]{4}{*}{ Outlines and Filters } \\
\hline & ESI, & Bathymetry & \\
\hline & NOAA, & Hydrology layer & \\
\hline & User data & Tidal power map & \\
\hline \multirow[t]{6}{*}{ Environmental constraints } & ESI, & Fish (E) & \multirow[t]{6}{*}{ Critical Areas } \\
\hline & NOAA, & Invertebrates (E) & \\
\hline & USGS, & Reptiles (E) & \\
\hline & USFWS, & Birds (E) & \\
\hline & DNR & Mammals (E) & \\
\hline & & Plants and habitats (E) & \\
\hline \multirow[t]{20}{*}{ Socioeconomic constraints } & CENSUS, & Urbanized areas & \multirow[t]{4}{*}{ Favorable Areas } \\
\hline & USGS, & Transmission & \\
\hline & DOE, & Transportation & \\
\hline & DOT, & Built-up areas & \\
\hline & ENC, & Restricted areas & \multirow{14}{*}{ Restricted Areas } \\
\hline & NOAA & Fairways and shipping lines & \\
\hline & & Dumping sites & \\
\hline & & Cable areas & \\
\hline & & Pipeline areas & \\
\hline & & Shoreline constructions & \\
\hline & & Wreck points & \\
\hline & & Mooring and warping points & \\
\hline & & Recreation areas and access locations & \\
\hline & & (Boat ramps, diving sites, marinas) & \\
\hline & & Management areas & \\
\hline & & (Marine sanctuary, national parks, wildlife refuges, special management areas) & \\
\hline & & Cultural heritage sites & \\
\hline & & (Archeological sites, historical sites) & \\
\hline & & Resource extraction sites & \multirow[t]{2}{*}{ N.A. } \\
\hline & & (Aquaculture sites, commercial fisheries, recreational fishing) & \\
\hline
\end{tabular}




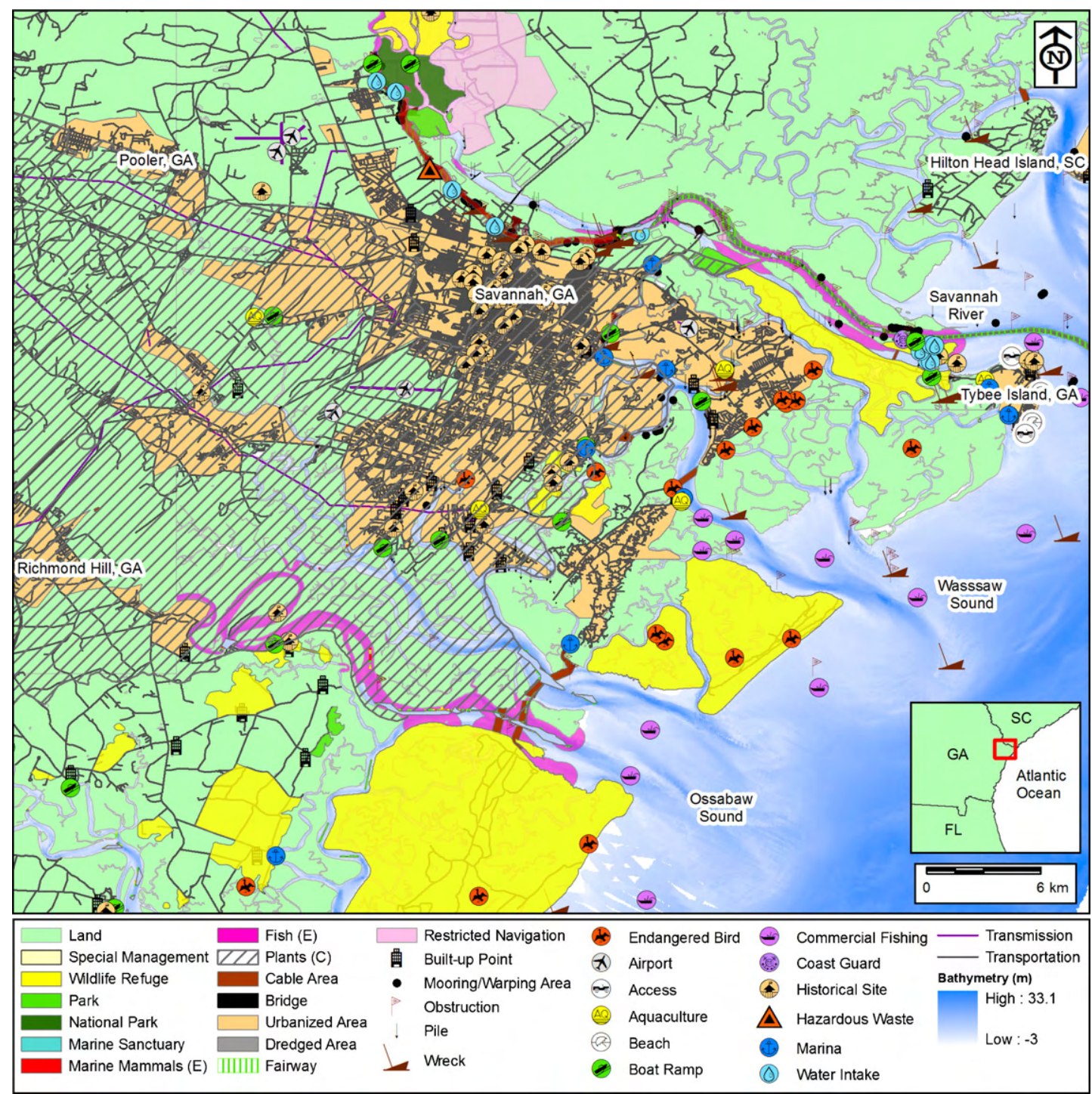

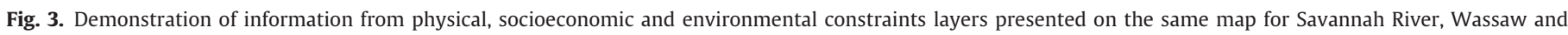
Ossabaw Sounds.

and macro algae developing an artificial reef for the aquatic community [5].

\subsection{Use of GIS in site selection}

Although it is not possible to quantify all of these criteria, their evaluation to minimize the consumption of material and energy requires integration of a significant amount of information, which makes utilizing GIS tools extremely beneficial [12]. For the last 20 years GIS applications have been successfully used to assess environmental and economic constraints, and to select suitable sites for energy projects [13-30]. The suitability of GIS to serve for this purpose was proposed earlier [12], while its performance and shortcomings having been evaluated more recently [31]. A decision support system to site wind power conversion projects was first defined in 1980 [23]. The system involved resource analysis, quantifying the proximities to areas of interest or special importance and excluding the restricted areas. The results were ranked and synthesized in a matrix in order to identify the most suitable locations. Through the years there has not been significant change in the methodology and in 2000, a GIS-based approach with a similar methodology was used to evaluate sites for wind farms in the
UK [15]. Although there are significant differences between them $[9,32,33]$, the essentials of wind power and tidal stream power conversion are close enough that a similar workflow can be created to assess the suitability of locations for tidal stream power conversion projects. Recently, more comprehensive approaches became available, such as the marine resource assessment of the UK [34] and the Ocean Special Area Management Plan in the state of Rhode Island [35], which can provide guidelines for future studies. There are no set rules on how to determine acceptable limits for changes to the currents and sediment transport climates caused by current energy extraction devices. Reports on assessing the tidal power potential of North America focusing on a few specific regions with high potential to identify the environmental impacts and economic constraints and assess the available technologies for suitability, and other related studies can be used as a guide for determining the related factors $[8,36,37]$.

\section{Methodology}

This section describes how the various data and constraints are incorporated into a decision making tool to assist in the site selection. First, the data from various sources are compiled in a GIS 


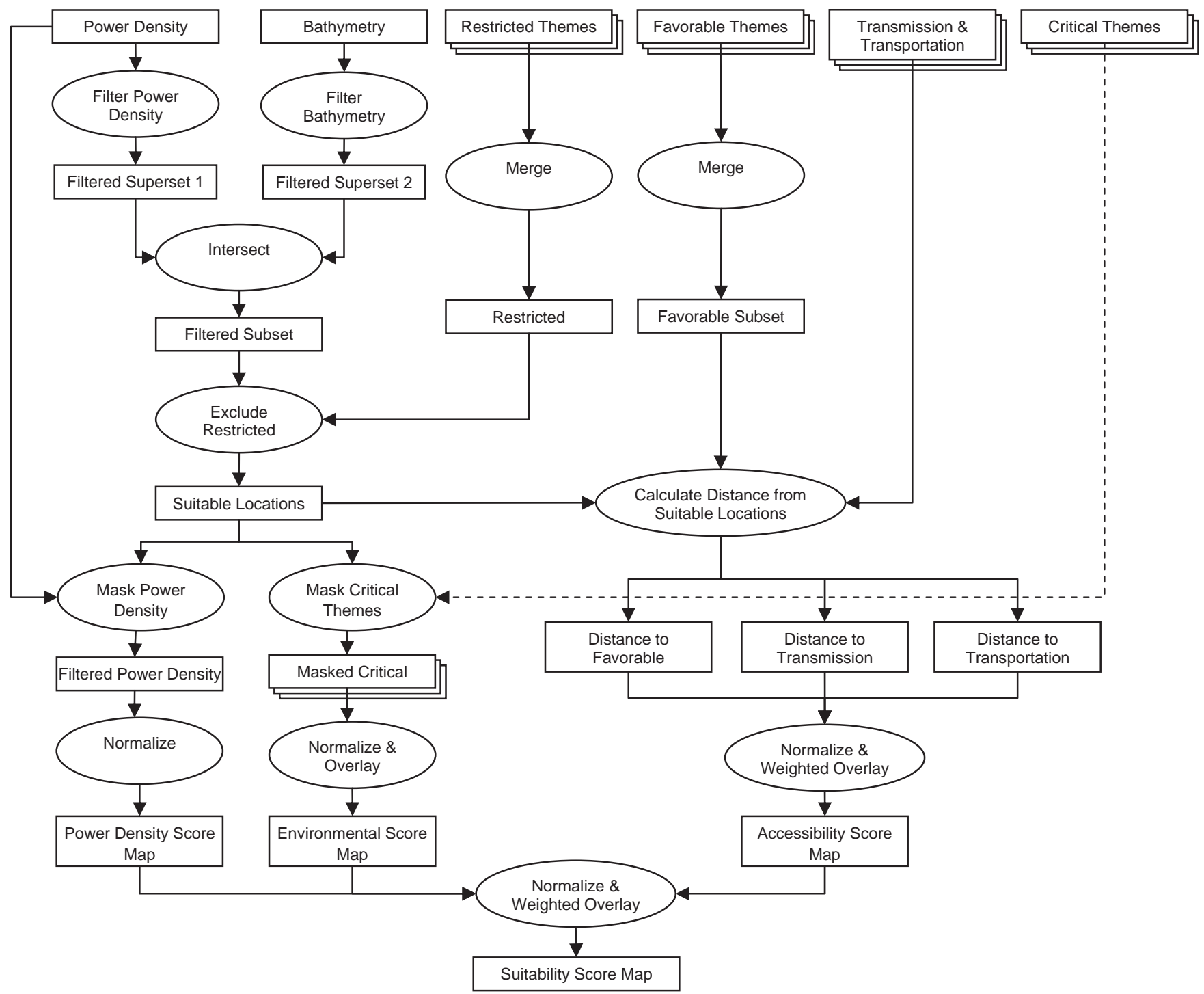

Fig. 4. Flow diagram of the site selection methodology for tidal power conversion. Ovals represent actions and rectangles represent objects.

environment and the themes in each dataset are classified into conceptual layers. Then, map regions are identified according to the role of each theme in tidal stream power conversion. Finally, the suitable locations are determined and the ranking algorithm is applied to calculate the score for each location and determine the best areas for tidal stream power project siting. The data coverage, definition of conceptual layers, and the details of the identification and ranking algorithms are discussed in details within this section.

\subsection{Data coverage and classification}

A large amount of GIS data is available online, scattered between governmental offices, science centers and the private sector, which requires significant amount of work to compile. The GIS portals such as the Georgia GIS Data Clearing House [38] and the Geodata [39] facilitate the retrieval of state wide and country wide geographic data, respectively. However, the data origins still vary, resulting in different datums, projections, scales and resolutions. Some of the data may be formatted to be used with specific software packages and on specific platforms. Hence, the attached metadata needs to be examined for compatibility and conversion between the datasets. After an extensive investigation of online resources, the number of related sources is reduced down to a set of major data providers according to their coverage of information, data quality and accessibility. These major sources include National Oceanic and Atmospheric Administration (NOAA) through Electronic Navigational Charts (ENC), National Geophysical Data Center (NGDC) and Environmental Sensitivity Index Maps (ESI); and United States Geological Survey (USGS), United States Census Bureau (CENSUS), and Environmental Protection Agency (EPA). State and local environmental information can also be accessed at Georgia Department of Natural Resources (DNR) and U.S. Fish \& Wildlife Service (USFWS).

The geospatial data gathered from various sources are categorized into three conceptual layers: The physical realization layer, the environmental constraints layer and the socioeconomic constraints layer (Fig. 2). These layers include the information on the basic geometry and physics of the problem, areas that are of environmental concern, and areas of social and economic concern, respectively.

\subsubsection{Physical realization layer}

The physical layer consists of the $1 / 70,000$ scale, medium resolution shoreline from NOAA, the digital sounding data from NGDC as the bathymetry and the tidal stream power density map. This layer, defining the physical boundaries and the amount of kinetic power per unit cross-sectional area, contains the most essential 


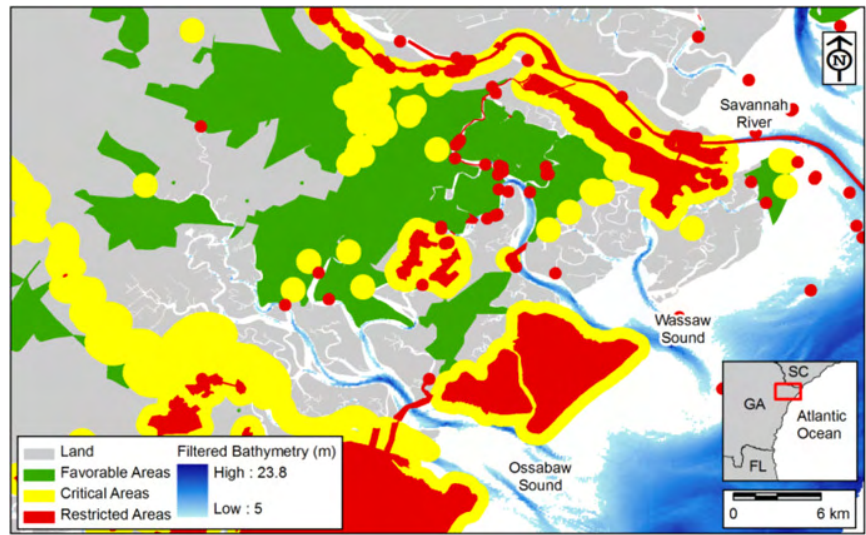

(a)

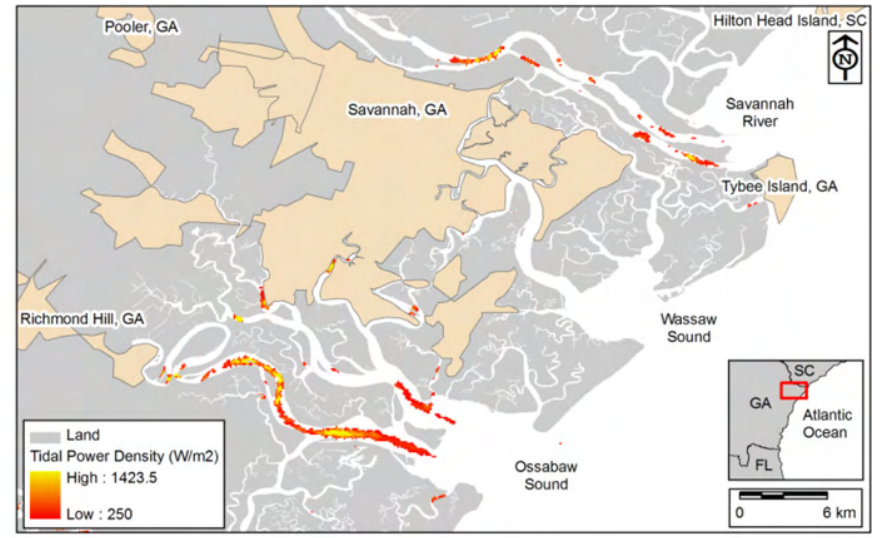

(b)

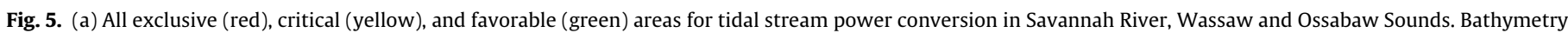

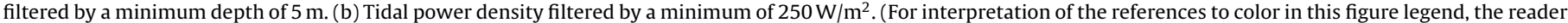
is referred to the web version of the article.)

data for the site selection scheme. One of the important factors is the depth of flow, which is used to verify the necessary vertical space to allocate the tidal power converters. Despite including the essential data, the physical layer itself alone is not sufficient to perform a rigorous multi-criteria assessment.

\subsubsection{Environmental constraints layer}

All plants, animals and microorganisms and the non-living physical factors of an environment is called the ecosystem of that area. Tidal stream power converters with their slow motion which may be avoided easily by fish and other sea animals [5] and low noise levels are expected to have low impact on the ecosystem of an area. Nevertheless, it is still necessary to evaluate their possible interference with the ecosystem further, especially where endangered species are present. This study does not attempt to answer these questions, but only use the related findings available in the literature. Environmental considerations require mapping of the endangered species habitats and avoiding these locations wherever possible. Although they are mainly prepared for oil and chemical spill response purposes, ESI maps provide some essential data such as sensitive biological resources and seabird colonies that can be used in the site selection methodology [40]. Detailed information on the threatened and endangered species in Georgia can also be obtained from USFWS Endangered Species and Georgia Ecological Services [41,42]. The GIS data from this source is merged with ESI data for the environmental constraints layer. Supplementary data are provided from Georgia Environmental Resources Digital Data Atlas, which is served by USGS Center for Spatial Analysis Technologies [43].

\subsubsection{Socioeconomic constraints layer}

The socioeconomic constraints layer contains the related human activities in the region. ENCs provided to the public by NOAA's Office of Coast Survey are vector-based digital files containing marine features suitable for marine navigation and GIS applications and usually used for route planning [44]. They carry information on the manmade structures and marine activities. The census data provides information about built-up areas classified by their surface area and the size of inhabiting population. Some of the supplemental data such as transportation and transmission lines can be found in Georgia Environmental Resources Digital Data Atlas. The location and orientation of transmission lines and the roads are some of the important factors for power conversion projects. ESI maps also provide some socioeconomic information which includes but not limited to location of boat ramps, historical sites, and aqua- culture and fishing sites. Sensitive human-use resources, such as water intakes, marinas, and swimming beaches are also marked in ESI maps.

\subsection{Identification of map regions}

The suitable areas are determined based on the level of power density, ease of accessibility and the number of environmental conflicts with the site selection methodology. For this purpose, each theme is tagged according to its role in the tidal stream power conversion. The list of themes, their roles, sources and the layers that they belong to are presented in Table 1 . The themes in the physical realization layers are used to set the physical constraints and boundaries of the problem and are tagged "outlines and filters". The themes with sensitive biological resources data are tagged as "critical", whereas the themes where it is socioeconomically more advantageous to have the power conversion projects closer are tagged as "favorable" and the themes where the placement of a tidal power converter would not be allowed or should be avoided are tagged as "restricted". An example of most of the data themes excluding the tidal power density data are shown on a coastline section that includes a part of Savannah River, Wassaw and Ossabaw Sounds in Fig. 3. The definition and classification of each theme is discussed in the following paragraphs.

The critical areas include the habitats of endangered species, which are at risk of becoming extinct. Endangered species are usually under legal protection and human activities in the proximity of their habitat are limited. Therefore, the list of the sensitive biological resources acquired from the GIS database is filtered to include only the species that are listed as endangered on the state or federal lists of endangered species. This is denoted by appending the theme name is appended with "(E)" in Fig. 3 and Table 1. The endangered marine mammals along the Georgia coast include whales and manatees. Given their size and offshore habitats, the whales are not as common as manatees in shallow estuaries and tidal creeks of the Georgia coast. High-use areas for the endangered West Indian Manatee species are Cumberland, St. Andrews, and St. Simons Sounds on the south and Savannah River on the north (Figs. 1 and 3). The official state marine mammal of Georgia, the Northern Right Whale, is known to prefer areas offshore of Cumberland, St. Andrews, and St. Simons Sounds for breeding. The second-largest living animal and an endangered species, the Fin Whale, can be found at offshore of Georgia (Gray's Reef National Marine Sanctuary) at certain times of year. Reptiles (E) and Fish (E) in Georgia include the Green Sea Turtle and the Shortnose Sturgeon, respectively. The Shortnose Sturgeon 


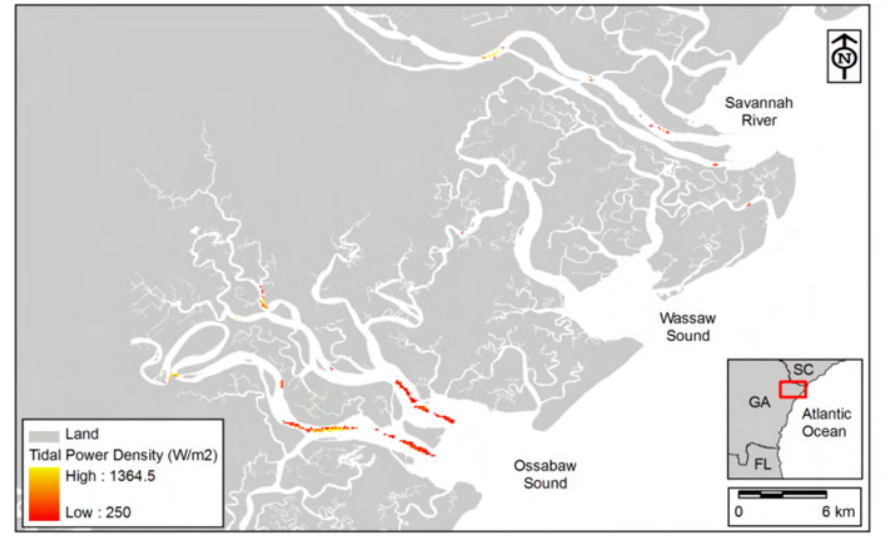

(a)

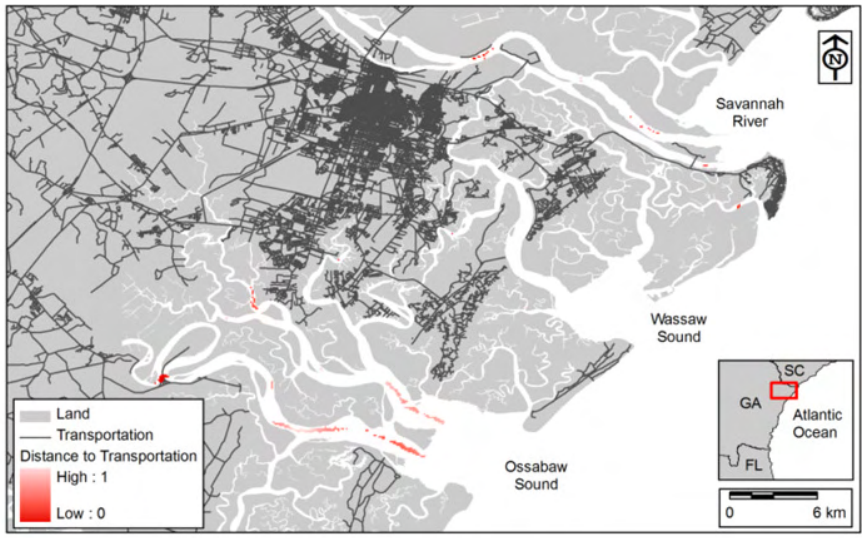

(b)

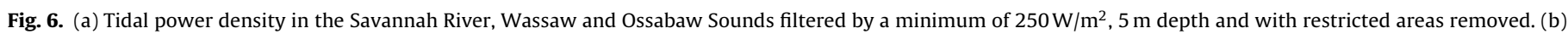
Normalized distance to transportation lines from the suitable locations for tidal stream power conversion.

inhabits Savannah, Canoochee, and Altamaha Rivers, whereas the Green Sea Turtle is observed mostly at Gray's Reef. The endangered bird species in the coastal Georgia are limited to Wood Stork, which have their nests scattered across the coastal zone (Fig. 3). Although Bald Eagles are listed as endangered in ESI maps, they were reclassified from endangered to threatened in 1995 by USFWS, and were removed from the USA federal government's list of endangered species in 2007 [45]. Threatened species such as Frost Flatwoods Salamander and Indigo Snake or the plants classified as Species of Concern $(C)$ such as Pondspice are not considered to be critical since they are not a part of endangered species [41].

Power from converters is anticipated to promote the local activities and developments in the coastal zone; therefore, socioeconomic considerations favor the locations that are closer to the socially developed areas, such as urbanized and built-up areas, where most of the demand is located. An urbanized area is defined as a densely settled territory that contains 50,000 or more people [46]. The extent of the urbanized areas is based on the CENSUS 2000 data (Fig. 3). Built-up locations are defined as a concentration of buildings supporting road or rail infrastructure [47]. Airports and U.S. Coast Guard facilities are considered as parts of built-up areas. Electric power transmission and all ground transportation are, respectively, indicated as transmission lines and transportation lines in Fig. 3. The right of way for the transmission lines and for the roads to access the selected area is another important decision factor. The right of way represents a big part of the cost of construction and it may also disturb the immediate nature and habitat [5]. It is desired to keep the right of way for the transmission and the access roads as short as possible. Therefore, the proximity of the power conversion projects to the main power grid for connection and to the transportation grid for easy access is also advantageous.

The restricted areas need to be excluded from tidal power conversion projects, due to their potential impact on the environment and on the existing use of sea space. The areas managed by the USFWS as National Wildlife Refuges or by Georgia DNR as State Wildlife Management Areas are shown as Wildlife Refuge in Fig. 3.
National parks include national parks, seashores and monuments managed by the National Park Service. Marine sanctuaries denote the areas managed by the NOAA Sanctuary and Reserves Division as National Marine Sanctuaries and as National Estuarine Research Services by NOAA and the state. These areas and together with areas designated by an appropriate authority within which navigation is restricted in accordance with certain specified conditions are marked as possible exclusive areas for tidal stream power conversion projects. Fairway is defined as a part of a river where the main navigable channel for vessels of larger size lies i.e. shipping channel, a mooring/warping facility is the structure used to secure a vessel, and a dumping site is a sea area where dredged material or other potentially more harmful material is deliberately deposited [47]. Pipeline areas consist of a string of interconnected submarine or overhead pipes used for transport of matter such as oil or gas. All fairways, dredged areas, mooring/warping facilities, dumping sites, historical sites and pipeline areas are considered as parts of the restricted areas. Recreation areas including boat ramps, diving sites and marinas are also considered as restricted.

General areas where commercial fishing activities take place are marked with specific symbols in Fig. 3. Recreational fishing is abundant along the Georgia coast, hence omitted. Locations for farming of freshwater and saltwater organisms are marked as aquaculture sites on the map. Some of these locations of interests such as aquaculture, commercial fishing, are not included in the site selection methodology at this stage. The benefits and the impact of tidal power conversion on these require special feasibility and design studies, and should include discussions and communications with all of the interested parties. Similarly, piles, obstructions, beaches, access locations and water intakes are not considered as factors for site selection.

A flow diagram that shows the steps in the implementation of the site selection methodology is provided in Fig. 4. Regardless of their design, most of the tidal stream power converters have a minimum depth requirement based on their dimensions. Additionally,

Table 2

Ranking results for tidal power conversion along the Georgia coast at selected locations shown in Figs. 7 and 8.

\begin{tabular}{|c|c|c|c|c|c|c|c|}
\hline Point & Lon & Lat & Power density score (P) & Environmental score (E) & Accessibility score (A) & Overall suitability score (S) & Rank \\
\hline A & -81.029 & 32.087 & 0.5 & 0.7 & 0.8 & 0.53 & 2 \\
\hline B & -81.127 & 31.857 & 0.6 & 0.3 & 0.5 & 0.30 & 5 \\
\hline C & -81.265 & 31.755 & 0.5 & 1.0 & 0.6 & 0.63 & 1 \\
\hline D & -81.182 & 31.539 & 0.2 & 1.0 & 0.5 & 0.36 & 4 \\
\hline $\mathrm{E}$ & -81.344 & 31.327 & 0.6 & 0.0 & 0.4 & 0.10 & 6 \\
\hline $\mathrm{F}$ & -81.448 & 30.708 & 0.4 & 0.7 & 0.8 & 0.50 & 3 \\
\hline
\end{tabular}




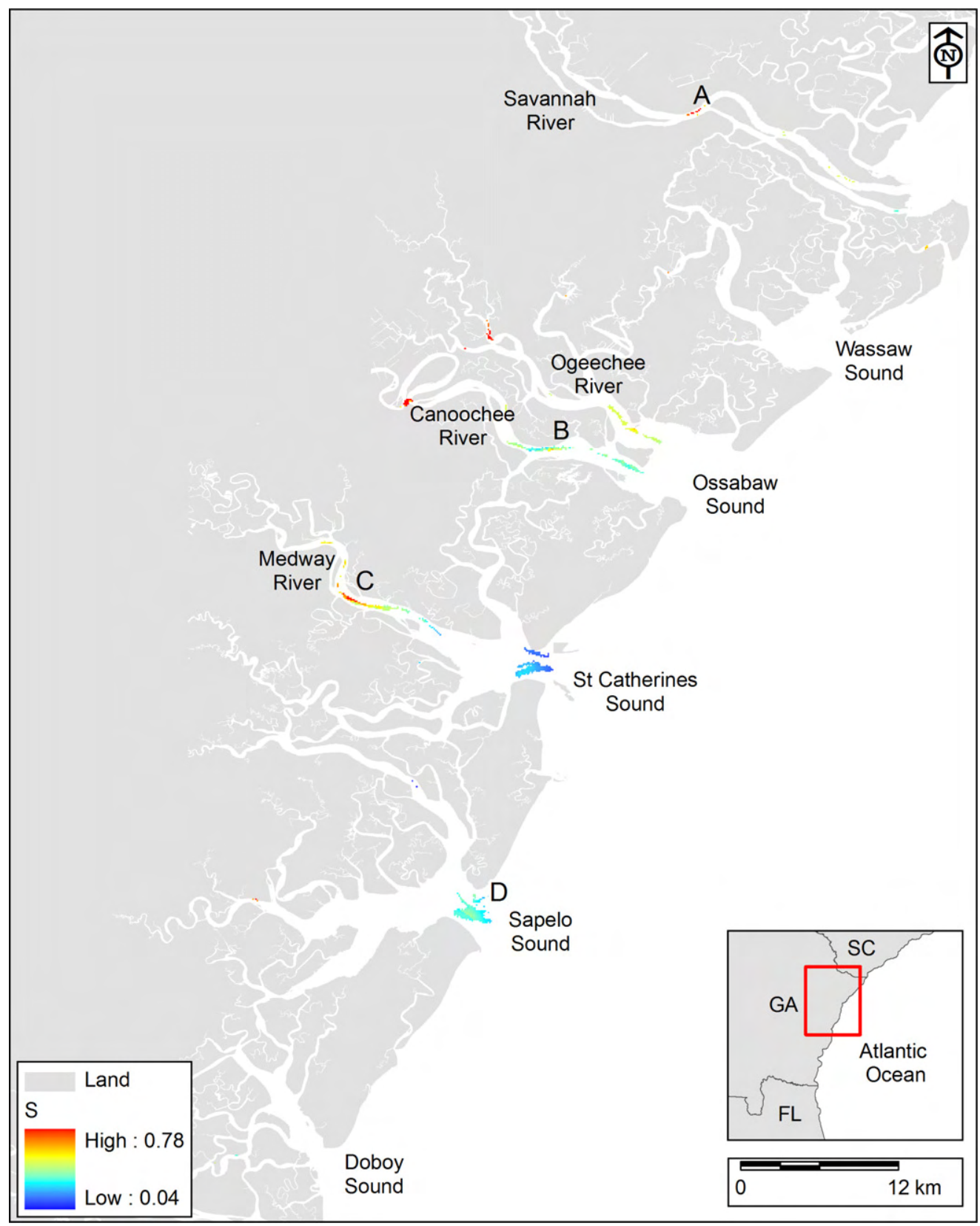

Fig. 7. Candidate locations with tidal power conversion potential on the northern Georgia coast that are determined by applying the site selection methodology.

there is usually a minimum flow speed (i.e. cut-in speed) that is required for the devices to start extracting power from the flow. The geospatial data for the power density and the bathymetry are filtered by minimum values to get the maps for filtered supersets (Fig. 4, top left). The intersection of these two supersets gives the filtered subset. The themes with restricted areas are merged into a single theme called restricted after applying certain buffer areas around the features (Fig. 4, top middle) and then excluded from filtered subset to determine the suitable locations. Similarly, the themes that contain the favorable locations are also merged into a single polygon. The habitats of endangered species are extracted from the GIS database and specific buffer zones are applied around them based on the federal and state regulations. The map of suitable locations is used to mask the power density and the critical areas maps, in order to calculate the scores for these locations. Likewise, the distances to favorable areas and transmission and transportation lines from the suitable locations are computed to facilitate the calculation of the accessibility scores. Finally, these scores are normalized and overlaid on the map to determine the candidate locations for tidal power density conversion. For normalizing each map, the maximum score in that map is used so that the data values range between 0 and 1,1 being the best score.

\subsection{Ranking of suitable locations}

The site selection methodology can serve as a useful preliminary analysis tool for decision makers before allocating resources for a more detailed evaluation. Consequently, the criteria for ranking the candidate sites can be simplified to three essential scores related to the level of power density, accessibility of the site, and the environmental challenges.

Normalized power density and the normalized environmental constraint are used to define two of the scores, whereas the normalized distances are combined into a single term to define the 


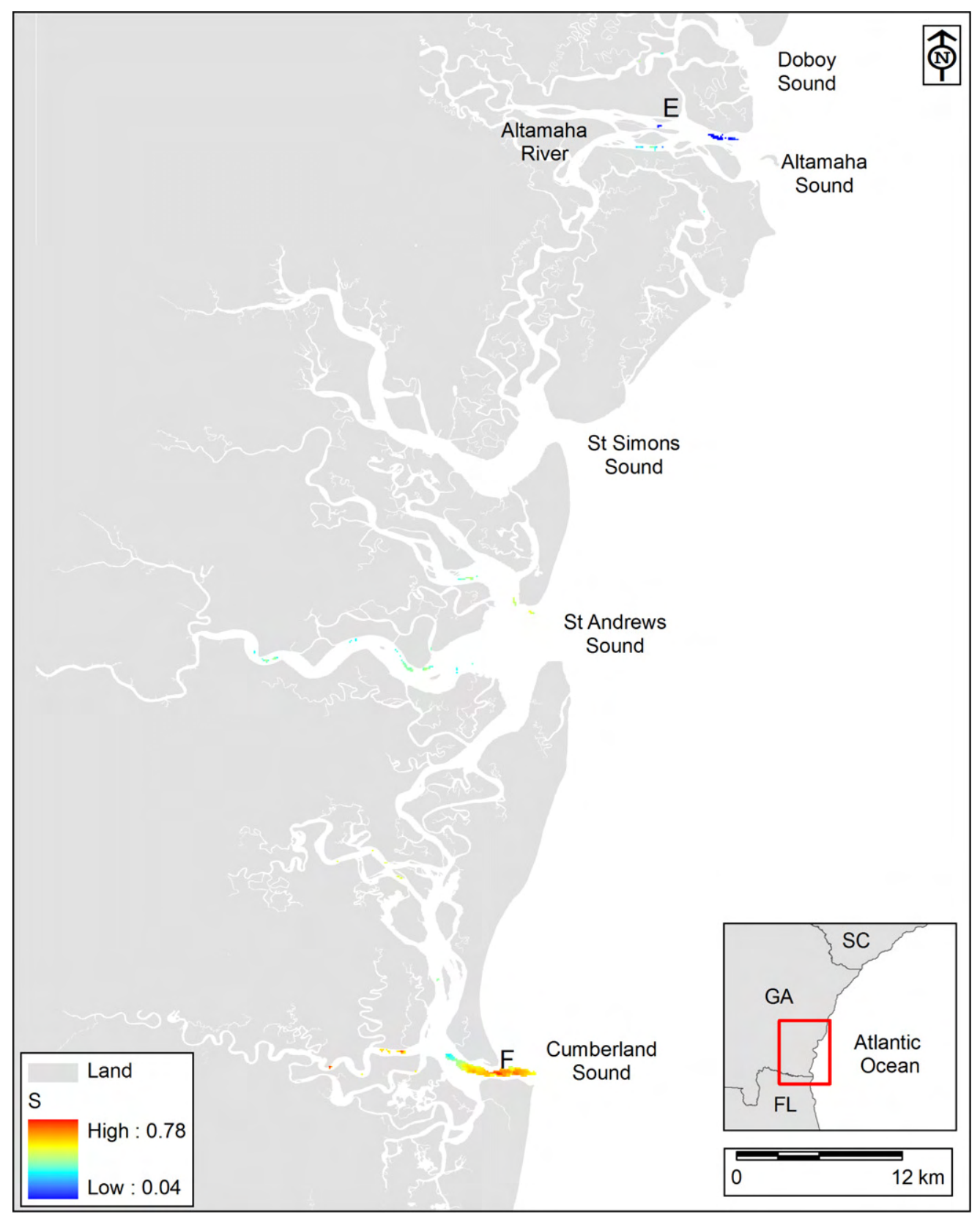

Fig. 8. Candidate locations with tidal power conversion potential on the southern Georgia coast that are determined by applying the site selection methodology.

accessibility score. It is important to note that the accessibility score is related to economics, but it is not used in the ranking algorithm here since an economic analysis is beyond the scope of this study.

The power density for every point is normalized with the maximum power density in the potential areas using

$P=\frac{P D}{P D_{\max }}$

where $P$ is the power density score, $P D$ is the power density at a point and $P D_{\max }$ is the maximum power density within the suitable areas (i.e. Filtered Power Density in Fig. 4), so that the point with the highest power density scores 1 .

Each distinct conflict with the environmentally sensitive locations on the filtered critical areas map is itemized and the values on the map are normalized with the total number of possible conflicts using

$E=1-\frac{N E}{N E_{\max }}$

where $E$ is the environmental score, $N E$ is the number of conflicts at a point and $N E_{\max }$ is the maximum number of conflicts. For example if the maximum possible number of conflicts is 4 , a point in the buffer zone for the endangered bird species gets 0.75 , whereas another point that lies on the intersection of the buffer zone of the endangered bird species and endangered fish gets 0.5 . The point that has all possible conflicts gets a score of 0 .

The distances to transportation and transmission lines and to favorable areas from every point on the suitable areas are computed and normalized so that the closest point to the transmission lines gets a score of 1 and the most distant location gets 0 . The normalized 


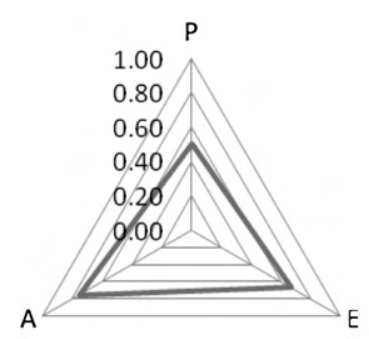

(a)

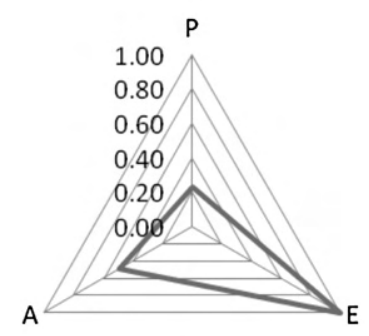

(d)

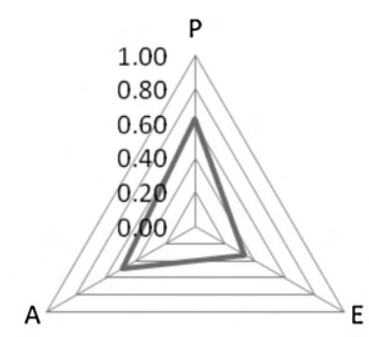

(b)

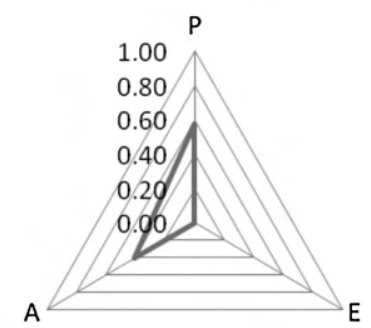

(e)

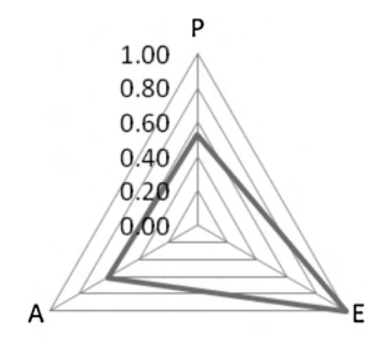

(c)

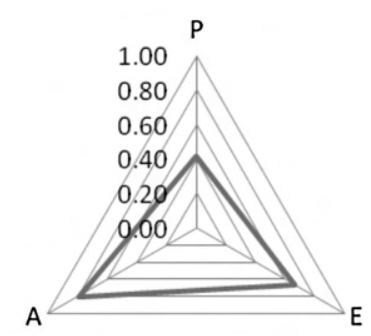

(f)

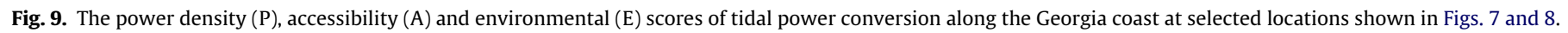

values are combined to get the accessibility score by

$$
\begin{aligned}
A= & 1-\left(\frac{k_{m}}{k_{m}+k_{p}+k_{f}} \cdot \frac{D T M}{D T M_{\max }}+\frac{k_{p}}{k_{m}+k_{p}+k_{f}} \cdot \frac{D T P}{D T P_{\max }}\right. \\
& \left.+\frac{k_{p}}{k_{m}+k_{p}+k_{f}} \cdot \frac{D T F}{D T F_{\max }}\right)
\end{aligned}
$$

where $A$ is the accessibility score, DTM, DTP and DTF are distances to transmission and transportation lines and favorable areas, respectively. The terms $k_{m}, k_{p}$ and $k_{f}$ are weighting coefficients, which are assumed to be equal in this study. Finally, the three scores are used to generate a triangular Kiviat diagram (radar chart). The quality of each location for tidal power conversion is computed from the area under the triangle using the formula

$S=\frac{k_{p} \cdot P \cdot k_{a} \cdot A+k_{p} \cdot P \cdot k_{e} \cdot E+k_{a} \cdot A \cdot k_{e} \cdot E}{k_{p} \cdot k_{a}+k_{p} \cdot k_{e}+k_{a} \cdot k_{e}}$

where $k_{p}, k_{a}$ and $k_{e}$ are the weighting coefficients for $P, A$ and $E$, respectively. $S$ is the overall suitability score nondimensionalized by the maximum possible area. A triangle with a larger area corresponds to a higher overall suitability score, hence a higher rank. In this study, power density, accessibility and environmental scores are assumed to have equal weights and the nondimensional suitability score is calculated by

$S=\frac{P \cdot A+P \cdot E+A \cdot E}{3}$

\section{Site selection methodology applied to Georgia coast}

The methodology is applied to the entire Georgia coast; however, intermediate steps are illustrated on a smaller section of the coastline, which consists of the Savannah River, Ossabaw and Wassaw Sounds (Figs. 5 and 6). All merged favorable, restricted and critical areas are shown in green, red and yellow, respectively, in Fig. 5a, where the circles with various sizes indicate the buffers created around the locations of interest. The size of the buffer is based on the related regulations whenever information is available, or a reasonable distance is determined based on the satellite imagery. All boat ramps, mooring/warping locations, marinas and coastguard are marked with a $400 \mathrm{~m}$ buffer. The locations indicated as hazardous in the original are applied $800 \mathrm{~m}$ buffer. Restricted navigation, pipelines, dumping ground, fairway, dredged area, cable locations and the special management areas are already defined as polygons in the original datasets and no buffer is required for these areas. Similarly, the urbanized area polygons are used as is, whereas all airports and built-up locations have a $100 \mathrm{~m}$ buffer. The spatial distribution of the endangered species other than the Wood Storks is provided as polygons in the original datasets and is used as is for the site selection methodology. Based on the environmental regulations the nest locations have a buffer zone of $800 \mathrm{~m}$ $[41,42]$. Correspondingly, the same distance is used for creating buffer zones around boundaries of the special management areas, such as wildlife refuges and national parks.

There is no standard for the size of power conversion devices, and most of the existing devices and prototypes are built to meet the requirements of a certain project with the dimensions of the devices changing from several meters to tens of meters $[48,49]$. Since the analysis in this study does not depend on a specific device and given the limited depth in Georgia coastal waters; the minimum depth is chosen to be $5 \mathrm{~m}$, large enough to accommodate a small size conversion device with the existing technology. The bathymetry filtered by $5 \mathrm{~m}$ for the Savannah River, Wassaw and Ossabaw Sounds is shown as an example in Fig. 5a. It is seen in this figure that the $5 \mathrm{~m}$ filter already removes a substantial amount of area from the whole domain, leaving only limited areas along the main rivers and part of the sound entrances.

The cut-in speeds for the tidal power conversion devices range from $0.5 \mathrm{~m} / \mathrm{s}$ to $1 \mathrm{~m} / \mathrm{s}$ depending on their design. Although some studies that simulate power extraction acknowledge cut-in speed values for the horizontal axis turbines as large as $1 \mathrm{~m} / \mathrm{s}[50,51]$, there are many examples with cut-in speeds around $0.7 \mathrm{~m} / \mathrm{s}$ and a vertical axis turbine with $0.5 \mathrm{~m} / \mathrm{s}[49,52,53]$. The minimum for the power density is selected as $250 \mathrm{~W} / \mathrm{m}^{2}$ which corresponds to a flow speed of $0.8 \mathrm{~m} / \mathrm{s}$. The example of the filtered power density for the pilot area is shown in Fig. 5b. The larger power density is constricted to the rivers and river mouths for this example. When the restricted areas are excluded from the subset of locations filtered for depth and the power density, the potential areas for tidal power conversion reduce drastically (Fig. 6a). The normalized distance to transportation lines from the suitable areas for the pilot region is 
shown in Fig. 6b as an example, demonstrating that a location with larger power may not have ease of access, which is likely to add up to the cost of a project.

The suitability score maps for the north and the south sections of the coast are shown in Figs. 7 and 8, respectively, after all normalized maps are overlaid on the entire Georgia coast. Based on the power density score map, St. Catherines, Sapelo and Cumberland Sound entrances and the Ogeechee, Canoochee and Altamaha River mouths are found to have large areas of candidate sites for power conversion, with the Cumberland Sound having the largest power density amongst all. The Canooche and Medway rivers have considerably higher power density over a substantially large area that meets the criteria, and there are few isolated patches of very small areas such as Savannah River and upstream Altamaha River. It is seen in Figs. 7 and 8 that some of the areas with large power density presented in Fig. 1 are eliminated, and a more useful subset of suitable areas is obtained when the methodology developed here is applied to the Georgia coast. The maximum suitability score is found to be 0.78 , which is less than 1 , meaning that none of the suitable locations is perfect in meeting all of the criteria. The locations with the highest suitability scores are discovered in the Savannah, Ogeechee, Canoochee, Medway Rivers and the Cumberland Sound considering equal weights for each criterion.

Six locations that have larger power density relative to their surrounding area are selected from the candidate areas to demonstrate the use of site selection methodology as a decision support tool. Labeled A to F from North to South, respectively, these locations are in the Savannah, Canoochee, and Medway Rivers, Sapelo Sound, Altamaha River and Cumberland Sound. The ranking scores for these locations are shown on Kiviat diagrams in Fig. 9 and the results are summarized in Table 2 . Based on the ranking algorithm, Location $\mathrm{E}$ is ranked the worst of the six locations, since it has a conflict with all possible critical areas, and has low accessibility. Location $B$ is also one of the environmentally disadvantageous locations, although it has a moderate power density. Location D and $F$ are more preferable than locations $B$ and $E$. Location $D$ has no environmental conflict, but considerably less power than all other locations while location $\mathrm{F}$ is more accessible and has a larger power density, but not as environmentally friendly as location D. Therefore, ranking between these two locations requires a more detailed analysis. On the other hand, location A has larger power density than location $\mathrm{D}$, and ranks better than $\mathrm{D}$ and $\mathrm{F}$. The accessibility of location $C$ is not the highest of all, which means the cost related to access roads and connection to the grid is expected to be higher. However, it has a substantial tidal power density and no environmental conflict. Therefore, location $\mathrm{C}$ gets the highest rank based on the implemented algorithm.

\section{Conclusions}

A set of parameters that are necessary to evaluate suitability and classify the favorability of a site for power conversion is established based on the analogy from site selection practices from other marine renewables, hydropower and wind energy projects. A methodology for selecting suitable sites for tidal power conversion is developed, and implemented using the available geospatial data and relevant GIS tools. It is applied to the Georgia coast to distinguish the areas with higher tidal power that meet the requirements of the multi-criteria selection methodology. The suitable sites for tidal power conversion are marked and evaluated for quality based on three essential criteria; the level of power density, the accessibility of the site and the number of environmental conflicts. There are relatively strong local currents within the complex network of tidal rivers and inlets between barrier islands along the Georgia coast [1]. It is shown that the depth constraints, human activates in the coastal zone and the sensitive biological resources limit the amount of suitable location for tidal power conversion once the site selection methodology is applied. Assuming equal weights on each criterion, it was found that parts of the Savannah, Ogeechee, Canoochee and Medway Rivers and the Cumberland Sound proved to be the most promising locations.

Field measurements that are long enough to extract the tidal constituents are still required to validate the tidal stream power density at the selected locations. The design of tidal power conversion devices is a developing research area and the suitability of the various available technologies should be investigated for extracting tidal power on the Georgia coast. Since the economic factors such as the cost and energy output depends on the type of the device it is not addressed in this study. Nevertheless, the developed methodology can be applied to other locations on the USA coast with small modifications. If there is sufficient geospatial data, it can also be extended for coastal zones on other parts of the world.

\section{Acknowledgements}

This study was supported by the National Science Foundation, Division of Industrial Innovation and Partnerships (IIP) under the Partnerships for Innovation Program Grant No. 0332613. Any opinions, findings, and conclusions or recommendations expressed herein are those of the author(s) and do not necessarily reflect the views of the National Science Foundation. Funding was also provided by the Strategic Energy Institute at Georgia Institute of Technology via a Creating Energy Options grant and the 104B Georgia Water Resources Institute Funding Program, and also by the Department of Energy, Wind and Hydropower Technologies Program award number DE-FG36-08G018174 and by the state of Georgia.

\section{References}

[1] Defne Z, Haas KA, Fritz HM. Numerical modeling of tidal currents and the effects of power extraction on estuarine hydrodynamics along the Georgia Coast, USA. Renewable Energy 2011, in press.

[2] Defne Z, Haas KA, Fritz HM. Wave power potential along the Atlantic Coast of the Southeastern USA. Renewable Energy 2009;34:2197-205.

[3] TC 114 - marine energy - wave, tidal and other water current converters. International Electrotechnical Commission. http://www.iec.ch/dyn/www/ $\mathrm{f}$ ? $\mathrm{p}=102: 17: 0::::$ FSP_SEARCH_TC:114 [accessed 2010]

[4] Young RM. Requirements for a tidal power demonstration scheme. Proceedings of the Institution of Mechanical Engineers Part A: Journal of Power and Energy 1995;209:215-20.

[5] Devine Tarbell \& Associates Inc. Tidal power in North America environmental and permitting issues. EPRI-TP-007-NA; 2006.

[6] Fraenkel PL. Tidal current energy technologies. Ibis 2006;148:145-51.

[7] Michel J, Dunagan H, Boring C, Healy E, Evans W, Dean JM, et al. Worldwide synthesis and analysis of existing information regarding environmental effects of alternative energy uses on the outer continental shelf. MMS OCS Report 2007038. U.S. Department of the Interior, Minerals Management Service; 2007.

[8] MMS. Technology white paper on ocean current energy potential on the U.S Outer Continental Shelf. Minerals Management Service Renewable Energy and Alternate Use Program, U.S. Department of the Interior; 2006.

[9] Pearce N. Worldwide tidal current energy developments and opportunities for Canada's Pacific coast. International Journal of Green Energy 2005;2:365-86.

[10] Triton Consultants Ltd. Green energy study for British Columbia. Phase 2: Mainland. Tidal current energy. Chapter 6: technology review. Prepared for BC Hydro, Engineering; 2002

[11] USEPA. Threats to wetlands. EPA 843-F-01-002d. Office of Wetlands, Oceans and Watersheds, United States Environmental Protection Agency; 2001.

[12] Yapa LS. Is GIS appropriate technology quest? International Journal of Geographical Information Science 1991;5:41-58.

[13] Ramachandra TV, Shruthi BV. Spatial mapping of renewable energy potential. Renewable and Sustainable Energy Reviews 2007;11:1460-80.

[14] Amador J, Domínguez J. Application of geographical information systems to rural electrification with renewable energy sources. Renewable Energy 2005;30:1897-912.

[15] Baban SMJ, Parry T. Developing and applying a GIS-assisted approach to locating wind farms in the UK. Renewable Energy 2001;24:59-71.

[16] Biberacher M. GIS-based modeling approach for energy systems. International Journal of Energy Sector Management 2008;2:368-84. 
[17] Brody SD, Grover H, Bernhardt S, Tang ZH, Whitaker B, Spence C. Identifying potential conflict associated with oil and gas exploration in Texas state coastal waters: A multicriteria spatial analysis. Environmental Management 2006;38:597-617.

[18] Cowen DJ, Jensen JR, Bresnahan PJ, Ehler GB, Graves D, Huang XQ et al. The design and implementation of an integrated geographic information-system for environmental applications. Photogrammetric Engineering and Remote Sensing 1995;61:1393-404.

[19] Kaijuka E. GIS and rural electricity planning in Uganda. Journal of Cleaner Production 2007;15:203-17.

[20] Larsen JK, Madsen J. Effects of wind turbines and other physical elements on field utilization by pink-footed geese (Anser brachyrhynchus): a landscape perspective. Landscape Ecol 2000;15:755-64.

[21] Moller B. Changing wind-power landscapes: regional assessment of visual impact on land use and population in Northern Jutland, Denmark. Applied Energy 2006;83:477-94.

[22] Muselli M, Notton G, Poggi P, Louche A. Computer-aided analysis of the integration of renewable-energy systems in remote areas using a geographicalinformation system. Applied Energy 1999;63:141-60.

[23] Otawa T. Wind energy planning: development and application of a site selection method for wind energy conversion systems (WECS). Energy Research 1980;4:283-306.

[24] Prest R, Daniell T, Ostendorf B. Using GIS to evaluate the impact of exclusion zones on the connection cost of wave energy to the electricity grid. Energy Policy 2007;35:4516-28.

[25] Ramirez-Rosado IJ, Garcia-Garridoa E, Fernandez-Jimenez LA, ZorzanoSantamaria PJ, Monteiro C, Miranda V. Promotion of new wind farms based on a decision support system. Renewable Energy 2008;33:558-66.

[26] Rodman LC, Meentemeyer RK. A geographic analysis of wind turbine placement in Northern California. Energy Policy 2006;34:2137-49.

[27] Voivontas D, Assimacopoulos D, Mourelatos A, Corominas J. Evaluation of renewable energy potential using a GIS decision support system. Renewable Energy 1998;13:333-44.

[28] Yue C-D, Yang GG-L. Decision support system for exploiting local renewable energy sources: a case study of the Chigu area of southwestern Taiwan. Energy Policy 2007;35:383-94.

[29] Yue CD, Wang SS. GIS-based evaluation of multifarious local renewable energy sources: a case study of the Chigu area of southwestern Taiwan. Energy Policy 2006;34:730-42.

[30] Arán Carrión J, Espín Estrella A, Aznar Dols F, Zamorano Toro M, Rodríguez M, Ramos Ridao A. Environmental decision-support systems for evaluating the carrying capacity of land areas: optimal site selection for grid-connected photovoltaic power plants. Renewable and Sustainable Energy Reviews 2008; $12: 2358-80$.

[31] Domínguez J, Amador J. Geographical information systems applied in the field of renewable energy sources. Computers \& Industrial Engineering 2007;52:322-6.

[32] Turner NE, Owen A. The development of a tidal turbine for deployment in areas with slow moving tidal flows. Aberdeen, Scotland, United Kingdom/Piscataway, NJ 08855-1331, United States: Institute of Electrical and Electronics Engineers Computer Society; 2007. p. 4302428.

[33] Herbert JGM, Iniyan S, Sreevalsan E, Rajapandian S. A review of wind energy technologies. Renewable and Sustainable Energy Reviews 2007;11:1117-45.
[34] MaRS (Marine Resource System). The Crown Estate. http://www. thecrownestate.co.uk/mars [accessed 2010].

[35] Spaulding ML, Grilli A, Damon C, Fugate G. Application of technology development index and principal component analysis and cluster methods to ocean renewable energy facility siting. Marine Technology Society Journal 2010;44:8-23.

[36] Schwartz SS.Proceedings of the hydrokinetic and wave energy technologies technical and environmental issues workshop. RESOLVE Inc.; 2006.

[37] Tidal In Stream Energy Conversion (TISEC) Project. Electric Power Research Institute. http://oceanenergy.epri.com/streamenergy.html [accessed 2008].

[38] Georgia GIS Clearing House. Georgia Spatial Data Infrastructure. http://data. georgiaspatial.org/login.asp [accessed 2010].

[39] Geodata U.S. Maps and Data. U.S. Geological Survey. http://gos2. geodata.gov/wps/portal/gos [accessed 2010].

[40] Environmental Sensitivity Index (ESI) Maps. Office of Response and Restoration, National Oceanic and Atmospheric Administration. http://response. restoration.noaa.gov/ [accessed 2008].

[41] Endangered Species Program. U.S. Fish \& Wildlife Service. http://www.fws.gov/Endangered/ [accessed 2009].

[42] Georgia Ecological Services Field Offices. U.S. Fish \& Wildlife Service [accessed 2009].

[43] Georgia Environmental Resources Digital Data Atlas. U.S. Geological Survey. http://csat.er.usgs.gov/statewide/downloads.html [accessed 2008].

[44] Electronic Navigational Charts (ENC). Office of Coast Survey, National Oceanic and Atmospheric Administration. http://nauticalcharts.noaa.gov/ mcd/enc/download.htm [accessed 2008].

[45] Bald Eagle Soars Off Endangered Species List. U.S. Department of the Interior. http://www.doi.gov/news/07_News_Releases/070628.html [accessed 2009].

[46] Decennial Management Division Glossar. U.S. Census Bureau. http://www.census.gov/dmd/www/glossary.html. [accessed 2009].

[47] ENC Information International Hydrographic Organization. http://www.ihoohi.net/english/about-encs/. [accessed 2009].

[48] Froberg E. Current power resource assessment. Uppsala: Uppsala University; 2006.

[49] Bedard R, Previsic M, Siddiqui O, Hagerman G, Robinson M. North American Tidal In Stream Energy Conversion Feasibility Demonstration Project. EPRI TP04-NA. Electric Power Research Institute; 2006.

[50] Myers L, Bahaj AS. Simulated electrical power potential harnessed by marine current turbine arrays in the Alderney Race. Renewable Energy 2005;30:1713-31.

[51] Lim YS, Koh SL. Analytical assessments on the potential of harnessing tidal currents for electricity generation in Malaysia. Renewable Energy 2010;35:1024-32.

[52] Fraenkel P. Marine current turbines: pioneering the development of marine kinetic energy converters. Proceedings of the Institution of Mechanical Engineers Part A: Journal of Power and Energy 2007;221: 159-69.

[53] Lee MQ Lu CN, Huang HS. Reliability and cost analyses of electricity collection systems of a marine current farm - a Taiwanese case study. Renewable and Sustainable Energy Reviews 2009;13:2012-21. 


\title{
Numerical modeling of tidal currents and the effects of power extraction on estuarine hydrodynamics along the Georgia coast, USA
}

\author{
Zafer Defne*, Kevin A. Haas, Hermann M. Fritz \\ Georgia Institute of Technology, 210 Technology Circle, Savannah, GA 31407, USA
}

\section{A R T I C L E I N F O}

\section{Article history:}

Received 30 June 2010

Accepted 18 May 2011

Available online $\mathrm{xxx}$

\section{Keywords:}

Tidal energy resource map

In-stream power conversion

North Atlantic

\begin{abstract}
A B S T R A C T
The tidal stream power potential along the coast of the state of Georgia is evaluated based on numerical modeling and validated with the available data. The Georgia coast consists of a complex network of tidal rivers and inlets between barrier islands that funnel and locally amplify the strength of the ambient tidal currents in the region. The number of existing tidal current prediction locations is not sufficient to resolve the temporal and spatial changes in the current speeds and patterns. Therefore, the currents are modeled with the Regional Ocean Modeling System (ROMS) to determine the locations with high tidal stream power potential and the results are validated against measurements. The wetlands and the topographical features are integrated in the computational model with wetting and drying of computational cells. The locations with the largest mean tidal stream power density are identified and their characteristics are provided. The effect of power extraction on estuarine hydrodynamics is simulated by implementing an additional retarding force in the governing momentum equations in ROMS. Two different power extraction schemes are simulated at the Canoochee River. The first scheme involves extracting $20 \%$ of the original kinetic power across the entire cross-section of the river, and is found to have substantially lower impact on the original flow than the second scheme with $45 \%$ extraction. The summation of removed and residual kinetic powers is found to be larger than the original kinetic power in the cross-section, which is attributed to the recovery in the flow momentum through reorganization of stream flow energy. In both of the cases the major impact on the currents is limited to a partial reach of the river. The change in the maximum and minimum water levels is observed to be on the order of centimeters.
\end{abstract}

(c) 2011 Elsevier Ltd. All rights reserved.

\section{Introduction}

Renewable marine power resources are strong candidates for alternative energy sources within coastal areas and mapping their availability is an important step towards development of power conversion projects. For this reason, the tidal stream power along the coast of Georgia is investigated with this study complementing an earlier study on the wave power potential along the Atlantic coast of the southeastern USA [1]. Additionally, the effect of tidal stream power extraction on the tidal regime is evaluated at an estuary scale. Modeling the effects of the tidal stream power extraction on the flow regime is important since the converters can alter the tidal regime, which may have consequences on the local ecosystem [2,3]. The hydrodynamics of the system should be

\footnotetext{
* Corresponding author. Fax: +1912 9652393.

E-mail addresses: zafer.defne@gatech.edu (Z. Defne), khaas@gatech.edu (K.A. Haas), fritz@gatech.edu (H.M. Fritz).
}

modeled at an estuary scale to investigate the far-field effects of the power extraction, for which three-dimensional full Navier-Stokes solvers are numerically too expensive currently. Therefore, simpler models are used with the energy extraction process introduced as a momentum sink in the governing momentum equations $[4,5]$ or an additional loss in the governing energy equation [6]. For onedimensional, simple channel models, the momentum sink or the energy loss is introduced uniformly across the channel [7], whereas for two-dimensional models it can be introduced within each desired computational cell. Although it is suggested to keep the level of energy extraction limited to $15 \%$ of the mean annual kinetic power by EPRI based on earlier studies [8], it has been proposed that even a $25-30 \%$ of energy extraction would have a small change in the flow speed, and may be environmentally acceptable for a tidal inlet that is energetic enough [8-11].

First, the numerical modeling of the tidal currents and the implementation of the tidal stream power extraction in the model are presented followed by validation of the model results. Then Tidal stream power density and annual average power estimates for 
the region are provided. The effect of power extraction on estuarine hydrodynamics is discussed with two different examples for power extraction in one of the estuaries with large tidal stream power density along the Georgia coast. Finally, the concluding remarks and recommendations are presented.

\section{Methodology}

Numerical modeling of tidal currents and the implementation of the power extraction in Regional Ocean Modeling System (ROMS) is discussed here briefly.

\subsection{Numerical modeling of tidal currents}

ROMS is a three-dimensional, free-surface, terrain-following, numerical model, which uses hydrostatic and Boussinesq approximations to solve the Reynolds-averaged Navier-Stokes equations. It has been used for various purposes in marine modeling systems across a variety of space and time scales as well as tidal simulations [12]. The tidal stream power is evaluated by computing the kinetic power density from the tidal current speeds using

$P=\frac{1}{2} \cdot \rho \cdot V^{3}$

where $P$ is the tidal stream power per unit area of flow, i.e. tidal stream power density, $\rho$ is the density of seawater and $V$ is the current speed.

Tidal constituents are periodic oscillations driven by the celestial forces computed with the mathematical approximation of the astronomical tides is given as

$H=a_{0}+\sum_{i=1}^{N} a_{i} \cdot \cos \left(\sigma_{i} \cdot t+\delta_{i}\right)$

where $H$ is the astronomical tide at time $t$ since the start of the tidal epoch, $a_{0}$ is the vertical offset, $a_{i}, \sigma_{i}, \delta_{i}$ are the amplitude, angular frequency and phase angle of the ith tidal constituent [13]. The tidal forcing is provided from the tidal database created based on the data from the Advanced Circulation Model For Oceanic,
Coastal and Estuarine Waters (ADCIRC) for the Western North Atlantic Ocean [14]. The constituents M2, S2, N2, K2, O1, K1, Q1, M4 and M6 for water levels and currents are extracted from the tidal database and applied at the open boundary of the computational grid.

The medium resolution shoreline $(1 / 70,000)$ data from National Oceanic and Atmospheric Administration (NOAA) and the digital sounding data from National Geophysical Data Center (NGDC) bathymetric maps are used as the coastline boundary and the bathymetry of the computational grids, respectively. The wetlands are included in the computational models with the wetting and drying of the computational cells. Wetlands are neither associated with high tidal currents nor suitable for power conversion, yet they might contribute to water volume that moves in and out with the tides affecting the tidal currents. The wetland boundaries are obtained from the National Wetlands Inventory of the U.S. Fish and Wildlife Service, and assigned elevations extracted from the U.S. Geological Survey Seamless server. The sea bathymetry and the wetland elevations are adjusted for the Mean Tidal Level (MTL) values reported by NOAA at local tidal stations. The friction coefficient for the wetlands is assumed to be the same with the rest of the domain.

The coast of Georgia is separated into three subdomains for modeling purposes (Fig. 1). The northern and southern grids (i.e. ga31, ga33) have negligible overlap at their boundaries, and the middle grid (ga32) overlaps sufficiently with both of neighboring grids to ensure full coverage. The computational cell sizes range from $180 \mathrm{~m}$ inland to $330 \mathrm{~m}$ offshore with an average of $230 \mathrm{~m}$. For each computational domain, the model is run to simulate 32 days, encompassing an entire lunar cycle starting from an arbitrarily selected date, November 1st, 2005. The constituents from the model are computed after neglecting the first 2 days to eliminate startup effects in the model.

A set of key validation parameters are defined to compare and validate the model results with the available data. Mean Current Magnitude Ratio of Maximum Currents $(C R)$ is defined as the average ratio of the maximum current magnitudes from the model to the magnitudes of the corresponding maximum current values from the validation data, given by
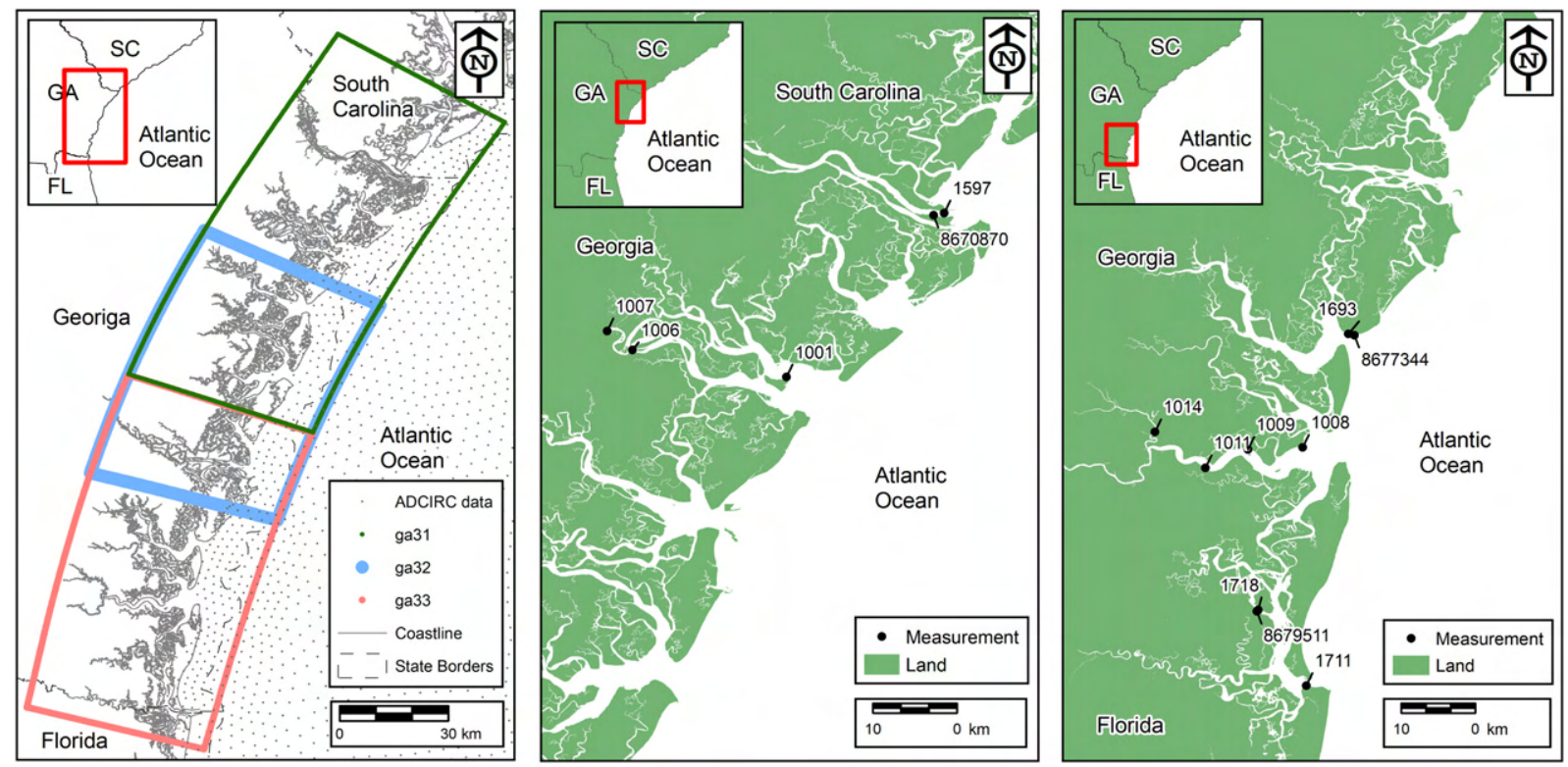

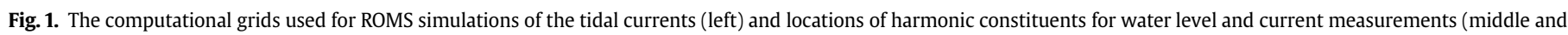
right) along the Georgia coast. 
$C R=\frac{\sum_{i=1}^{N} \frac{\mid\left(\text { cur }_{m}\right)_{i} \mid}{\mid\left(\text { cur }_{v}\right)_{i} \mid}}{N}$

where $\mathrm{cur}_{m}$ is the maximum current magnitude from the model and cur $_{v}$ is the maximum current value from the validation data. $i$ and $N$ are the $i$ th occurrence and total number of occurrences of maximum and minimum during the simulation duration, respectively. Root-Mean-Square Difference of Maximum Currents (CRMS) is the root-mean-square of the difference between the maximum current values output by the model and maximum current values from the data. It is an estimate for the error of the model prediction in terms of tidal current given by

CRMS $=\sqrt{\frac{\sum_{i=1}^{N}\left\{\left(\text { cur }_{m}\right)_{i}-\left(\text { cur }_{v}\right)_{i}\right\}^{2}}{N}}$

The mean phase difference for maximum currents and the mean phase difference for maximum flood and ebb currents are given by

$P D=\frac{\sum_{i=1}^{N}\left\{\left(t_{m}\right)_{i}-\left(t_{v}\right)_{i}\right\}}{N}$

$F P D=\frac{\sum_{i=1}^{N}\left\{\left(t_{m}^{f}\right)_{i}-\left(t_{v}^{f}\right)_{i}\right\}}{N}$

$E P D=\frac{\sum_{i=1}^{N}\left\{\left(t_{m}^{e}\right)_{i}-\left(t_{v}^{e}\right)_{i}\right\}}{N}$

where $t_{m}$ and $t_{v}$ are the times that correspond to the maximum tidal current occurrences in the model output and the validation data, respectively. The superscripts $f$ and $e$ denote flood and ebb. Current phase difference is an estimate to how much phase the model output lags $(P D, F P D, E P D>0)$ or precedes $(P D, F P D, E P D<0)$ the validation data.

\subsection{Numerical modeling of tidal stream power extraction}

Placing a group of power converters in a free stream flow will change the near-field and possibly the far-field flow patterns depending on the amount of power removed from the original flow. The extracted power and its effect on flow can be simulated by a retarding force collinear with the direction of the flow [5], and considering a computational cell with power extraction, can be given in the vectorial form as

$\vec{F}=-\frac{P_{\text {ext }}}{|\vec{V}|} \cdot \frac{\vec{V}}{|\vec{V}|}$
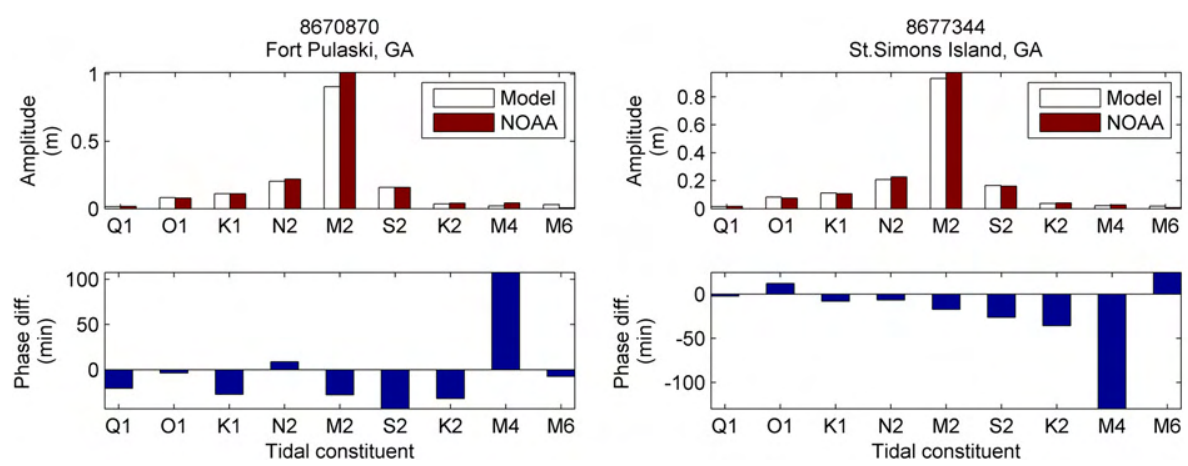

where $\vec{F}$ is the retarding force per unit area, $\vec{V}$ is the flow velocity, $|\vec{V}|$ is the magnitude of the velocity in that cell. $P_{\text {ext }}$ is the extracted power density given by

$P_{\text {ext }}=C_{\text {ext }} \cdot P^{\prime}$

where $C_{\text {ext }}$ is a free coefficient that denotes the amount of extraction and $P^{\prime}$ is the kinetic power density in the extraction cell at the time of extraction. The power extraction is implemented in the computational model by modifying the governing momentum equations at the computational cells that contain power converters. Combining Eq. (8) for the retarding force with Eq. (9) for the extracted power, results in the terms that need to be substituted in the general momentum equations in $\mathrm{x}$ and $\mathrm{y}$ directions, respectively as

$F_{u}=-C_{e x t} \cdot \frac{1}{2} \cdot \rho \cdot u \cdot|\vec{V}|$

$F_{v}=-C_{\text {ext }} \cdot \frac{1}{2} \cdot \rho \cdot v \cdot|\vec{V}|$

where $F_{u}$ and $F_{v}$ are the retarding force components per unit area, and $u$ and $v$ are the velocity components in $x$ and $y$ directions, respectively. These terms are implemented in ROMS as additional drag along the $x$ and $y$ axes of the computational cells with extraction. The retarding force is calculated based on the depth averaged velocity and a constant extraction coefficient, and applied at every depth layer. It is assumed that $C_{\text {ext }}$ is the same in both the $x$ and $y$ directions and its value is adjusted iteratively through successive model runs to meet the desired power removal from the flow. Consequently, the power extraction ratio presented in the results is with respect to the original kinetic power of the undisturbed flow.

\section{Assessment of the tidal stream resource}

First the model results are validated against the measurements, and then the annual tidal stream power estimates are provided for the locations with the largest tidal stream power density. This is followed by a discussion on the role of river streamflows in the region.

\subsection{Validation of model results}

The model results are validated at locations shown in Fig. 1, which include three NOAA tidal stations that provide harmonic constituents of tidal elevation, two locations where current meter measurements are available through NOAA's Currents Measurements for the Study of Tides (C-MIST) and several additional locations with tidal current measurements [15]. The harmonic

Fig. 2. Tidal constituents computed by the model and measured by NOAA at Fort Pulaski, St. Simons Island and Kings Bay stations. 
constituents of tidal elevation for station 8670870 show that the difference between the modeled and measured amplitudes is limited to a few centimeters (Fig. 2). The model underpredicts amplitude of the most energetic constituent M2 by $10 \%$, which corresponds to $0.1 \mathrm{~m}$. The difference between the computed and measured phases is below 50 min except M4. The M4 and M6, are overtides of M2 which are generated because of the nonlinearities [16]. They become important when tidal amplitude to bottom depth ratio gets larger and cause the maximum ebb and flood to shift closer to high or low water, distorting the M2 component. Their amplitudes in this case, however, are very small, hence their impact is minimal. The comparison of the model results to the data from stations 8677344 and 8679511 show that the model can successfully predict the tidal constituents for those locations that it can resolve (Fig. 2). The error in the amplitude of M2 is less than $0.05 \mathrm{~m}$, and on the order of a centimeter for other amplitudes at these stations. The phase difference is less than 20 min for M2 and below 50 min for all other constituents with the exception of M4 at station 8677344 . The overall effect of this on the predicted water levels is not a major issue since the amplitude for this constituent is on the order of a few centimeters. The amplitudes and phases predicted with the model are assumed to validate satisfactorily when the percent difference between the model and measurements is less than $15 \%$ and $60 \mathrm{~min}$, respectively. The amplitude and the phase of the major constituents (i.e. M2, N2, and S2) along with the other constituents used to force the model agree with the measurements and can be considered to validate with the measurements.
In order to validate the tidal currents, the constituents are calculated from a 30-day model simulation to generate the time series for the corresponding period of the measurements. The measured and modeled time series from three different locations along the Georgia coast are shown in Fig. 3 and the statistics for the complete set of locations are provided in Table 1 . The measurements show that the average of the maximum current magnitudes at location 1597 is on the order of $0.88 \mathrm{~m} / \mathrm{s}$. The model satisfactorily predicts the maximum tidal currents with a $10 \%$ relative difference $(C R=1.07)$ and a $0.2 \mathrm{~m} / \mathrm{s}$ absolute difference (CRMS $=0.19 \mathrm{~m} / \mathrm{s}$ ). A detailed look at the time series plot reveals that the model actually captures the flood dominated tides at this location, with the stronger flood and weaker ebb tides. However, there are time intervals where the ebb flow increases significantly and the flood decreases. This can only be explained by atmospheric or hydrologic events that might occur during the time of measurements. The phase for the flood matches better with the measured phases $(F P D<30 \mathrm{~min})$ than the phase for the ebb does with the measurements (EPD $>60 \mathrm{~min}$ ). However, when combined, the phase from the model precedes the measured phase within $30 \mathrm{~min}$. The model predicts a smaller difference between the magnitudes of neap tide currents and the spring tide currents than the given by the measurement at location 1693 , but are validated satisfactorily with $C R=1.08, C R M S=0.13 \mathrm{~m} / \mathrm{s}$, and $P D=19 \mathrm{~min}$. The current measurement data [17] at the entrance to Cumberland Sound (locations 1710 and 1711) are shorter than a day, but sufficient to display a good agreement between the model current predictions agree and the measurements with $C R=1.08$ and 1.00,

1597

Savannah River

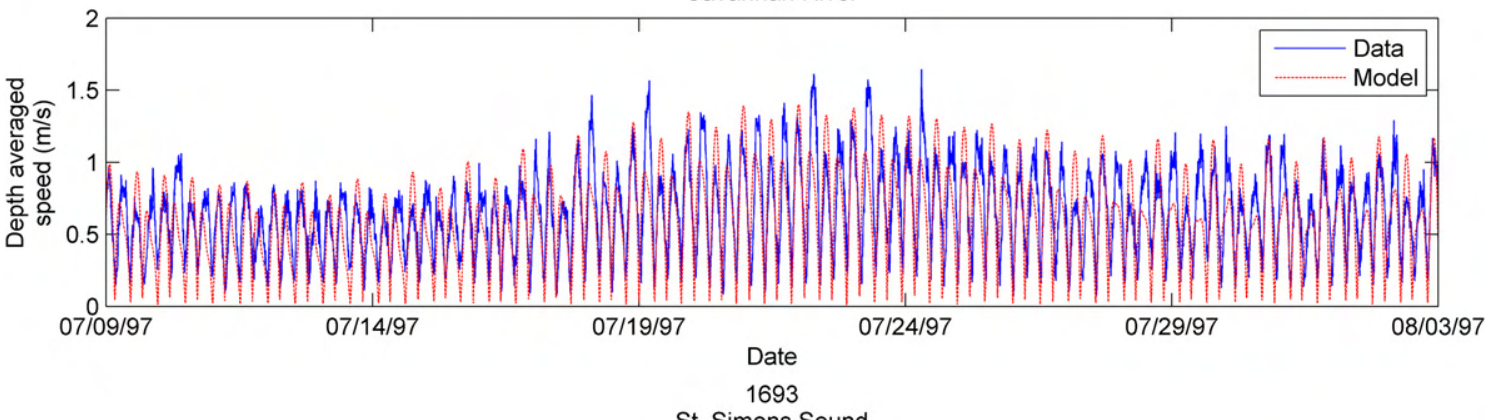

St. Simons Sound
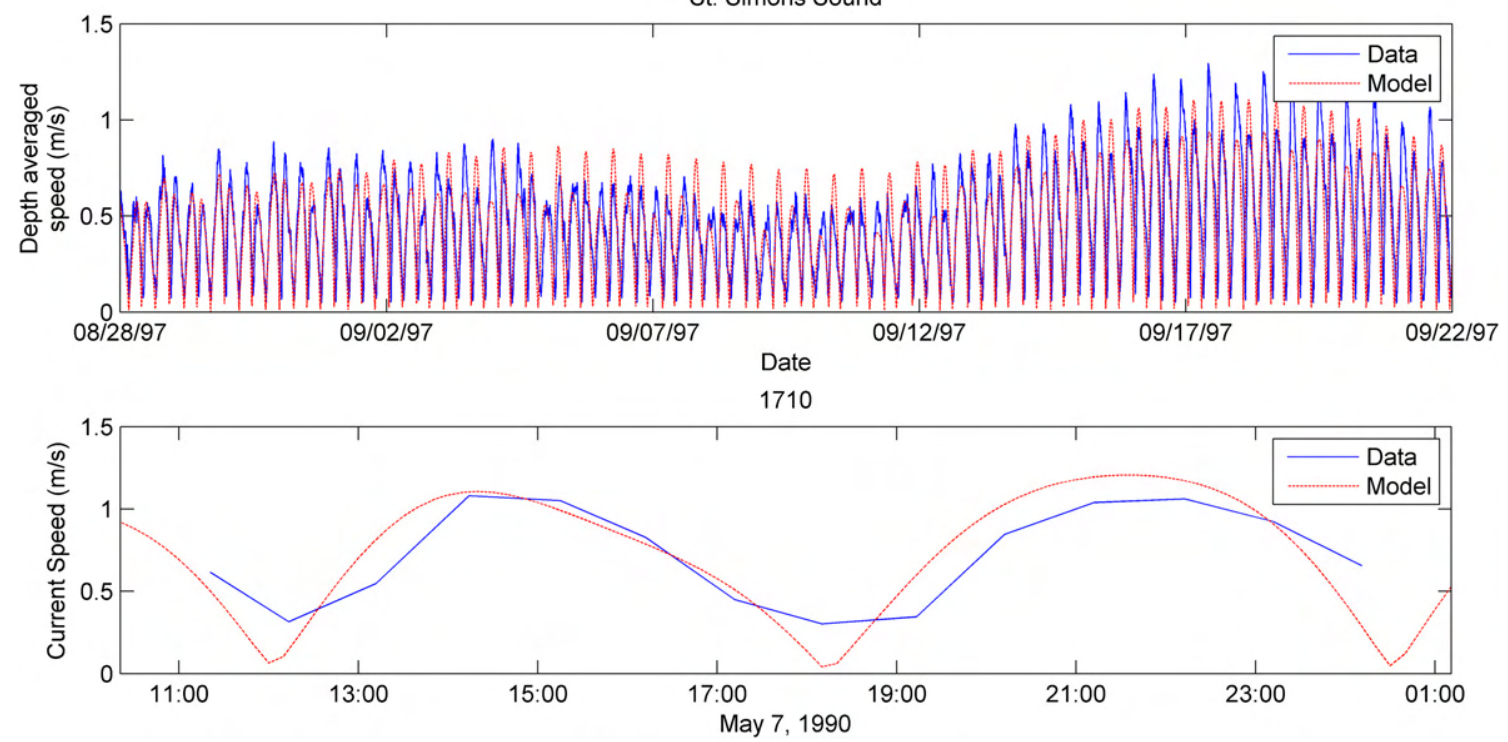

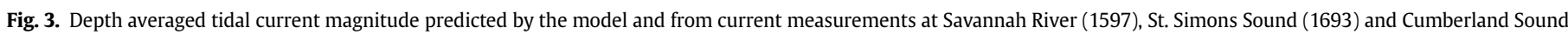
(1710), GA. 
Table 1

Validation parameters for maximum tidal currents at the measurement locations.

\begin{tabular}{lcllllrr}
\hline Location & $\begin{array}{l}\text { Depth } \\
(\mathrm{m})\end{array}$ & $\begin{array}{l}\text { Mean current } \\
\text { magnitude }(\mathrm{m} / \mathrm{s})\end{array}$ & CR $(-)$ & $\begin{array}{l}\text { CRMS } \\
(\mathrm{m} / \mathrm{s})\end{array}$ & $\begin{array}{l}\text { PD } \\
(\mathrm{min})\end{array}$ & $\begin{array}{l}\text { FPD } \\
(\mathrm{min})\end{array}$ & $\begin{array}{l}\text { EPD } \\
(\mathrm{min})\end{array}$ \\
\hline 1597 & 9.1 & 0.88 & 1.07 & 0.19 & -24 & 24 & -72 \\
1693 & 10.9 & 0.74 & 1.08 & 0.13 & -19 & -24 & -13 \\
1710 & 18.7 & 1.07 & 1.08 & 0.10 & -13 & 6 & -33 \\
1711 & 13.7 & 0.97 & 1.00 & 0.05 & -6 & 7 & -13 \\
1001 & 9.3 & 0.62 & 0.85 & 0.12 & -40 & -22 & -64 \\
1006 & 6.2 & 0.78 & 0.92 & 0.16 & 6 & 8 & 3 \\
1007 & 5.8 & 0.60 & 0.73 & 0.23 & -76 & -56 & -97 \\
1008 & 6.7 & 0.42 & 1.69 & 0.28 & -41 & -29 & -53 \\
1009 & 7.1 & 0.48 & 1.30 & 0.16 & -37 & 1 & -76 \\
1011 & 2.3 & 0.34 & 0.92 & 0.11 & -12 & 6 & -33 \\
1014 & 6.8 & 0.52 & 0.89 & 0.13 & -39 & -13 & -64 \\
\hline
\end{tabular}

CRMS $=0.1 \mathrm{~m} / \mathrm{s}$ and $0.05 \mathrm{~m} / \mathrm{s}, P D=-13$ and -6 min (Fig. 3 and Table 1).

The current measurements from several locations (1001-1014) on the Canoochee and Satilla Rivers [18-20] are used to validate the model predictions. The spring and neap tide pattern is seen to match the measurements at the Canoochee River, but the predictions are observed to deviate from the measurements moving towards inland where the river becomes narrower (e.g. 1007). The model predictions tend to be less reliable at the upstream reaches of rivers and creeks due to the model inability to resolve these features regarding its limited computational cell size. The current predictions are validated satisfactorily at 1001 and 1006 with

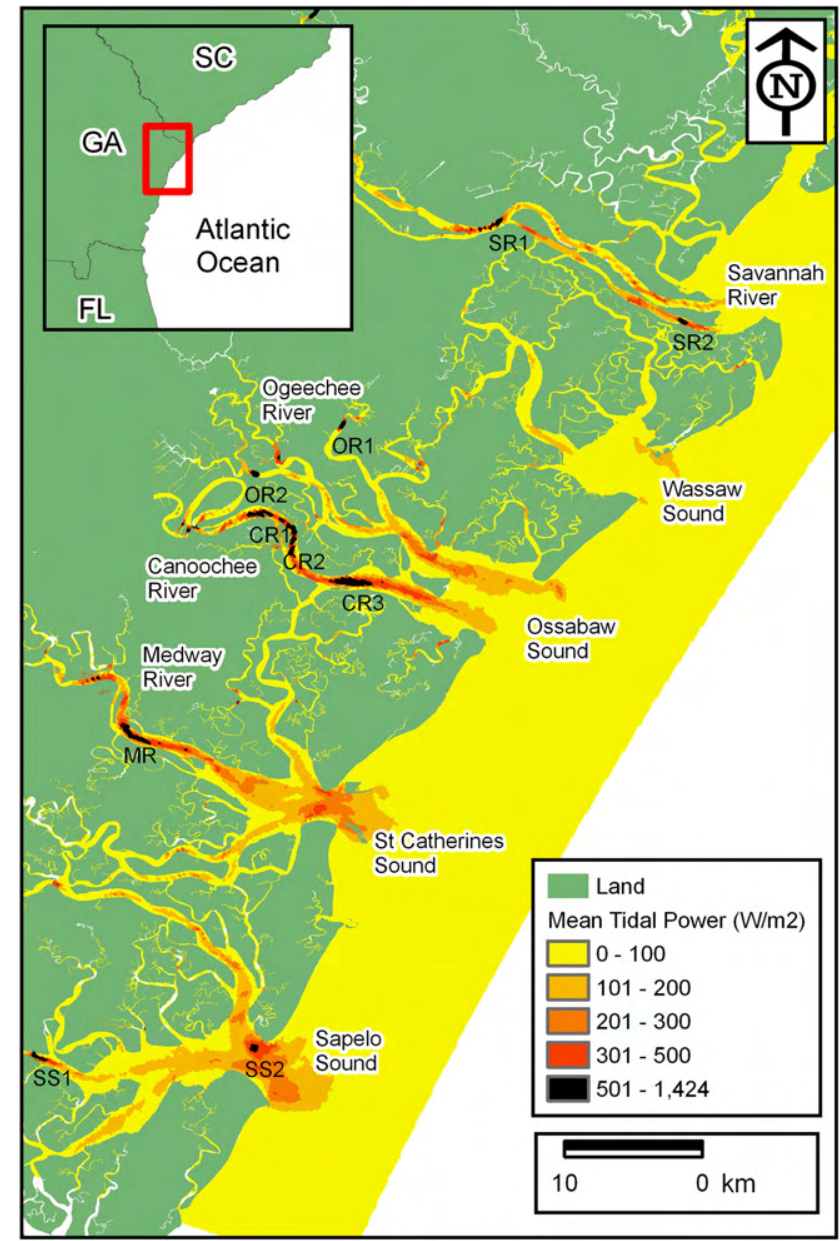

a
$C R=0.85$ and 0.92 and $C R M S=0.12$ and $0.16 \mathrm{~m} / \mathrm{s}$, respectively, but fall short in satisfying the measurements at 1007 with $C R=0.73$ and CRMS $=0.23 \mathrm{~m} / \mathrm{s}$ (Table 1). This holds true for the phase difference between the model predictions and the data, where 1001 and 1006 have phase differences less than 40 min whereas 1007 is more than 75 min. The measurements show that the magnitude of currents in Satilla River are too low for power conversion $(<0.5 \mathrm{~m} / \mathrm{s})$. The averages of the maximum current speeds are smaller than the other validation locations. This is one possible explanation to the fact that it is not possible to see a consistent trend when the predicted maximum current values are compared to the measurement data. The validations at these points are not superior, but since locations with very small tidal current magnitudes are not feasible for power conversion, they are of secondary importance. Overall, the model predictions agree well with the current measurements.

\subsection{Tidal stream power density and annual average power}

The average tidal stream power density computed by the model along the coast of Georgia is shown in Fig. 4. Regions with tidal stream power density larger than $500 \mathrm{~W} / \mathrm{m}^{2}$ and surface area larger than $0.10 \mathrm{~km}^{2}$ are represented in black on the map. Maximum/ average depth with respect to Mean Lower Low Water (MLLW), maximum width across the flow and surface area of these regions are given in Table 2 together with the largest mean power density

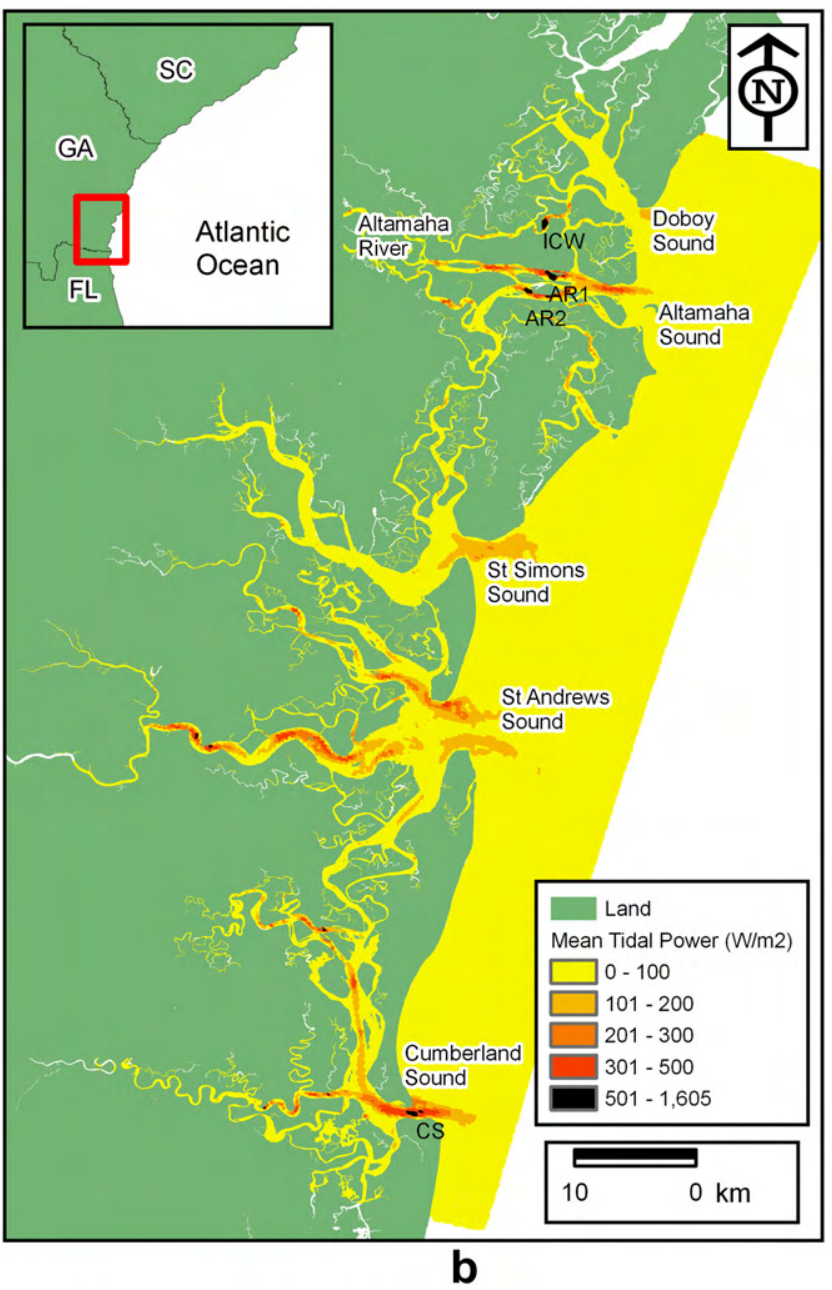

Fig. 4. Mean power density maps along (a) the northern and (b) the southern coasts of Georgia with labeled high tidal stream power density ( $>500 \mathrm{~W} / \mathrm{m}^{2}$ ) areas. 
Table 2

Characteristics of the higher energy locations shown in Fig. 4 along the Georgia coast.

\begin{tabular}{|c|c|c|c|c|c|}
\hline Location & Maximum depth (m) & Average depth (m) & Maximum width across the flow (km) & Surface area $\left(\mathrm{km}^{2}\right)$ & Largest mean power density $\left(\mathrm{W} / \mathrm{m}^{2}\right)$ \\
\hline R1 & 11.2 & 2.8 & 0.27 & 0.17 & 1420 \\
\hline SR2 & 2.9 & 2.3 & 0.34 & 0.13 & 760 \\
\hline OR1 & 4.8 & 2.8 & 0.25 & 0.13 & 1220 \\
\hline OR2 & 6.9 & 2.4 & 0.36 & 0.11 & 1360 \\
\hline CR1 & 3.7 & 1.1 & 0.23 & 0.14 & 790 \\
\hline CR2 & 5.9 & 2.7 & 0.27 & 0.11 & 1360 \\
\hline CR3 & 10.5 & 3.7 & 0.54 & 0.22 & 1020 \\
\hline MR & 9.6 & 3.9 & 0.42 & 0.21 & 730 \\
\hline SS1 & 4.0 & 2.6 & 0.26 & 0.11 & 580 \\
\hline SS2 & 8.1 & 3.5 & 0.46 & 0.14 & 580 \\
\hline ICW & 2.1 & 0.6 & 0.41 & 0.20 & 1600 \\
\hline AR1 & 10.2 & 1.5 & 0.37 & 0.24 & 790 \\
\hline AR2 & 4.3 & 2.6 & 0.24 & 0.11 & 900 \\
\hline CS & 19.4 & 15.2 & 0.31 & 0.17 & 590 \\
\hline
\end{tabular}

within each region. The surface area does not contribute to power density, but a larger area or a larger width across the currents is expected to accommodate more turbines than a smaller area. A larger depth allows for a larger size device that might lead to a larger power conversion. From north to south, there are two such regions along the Savannah River; upstream of the final bifurcation before the river reaches the ocean (SR1) and on the southern branch near Fort Pulaski (SR2). The mean tidal stream power density varies from 500 to $1420 \mathrm{~W} / \mathrm{m}^{2}$ at SR1 and to $760 \mathrm{~W} / \mathrm{m}^{2}$ at SR2. The width of these areas across the river is about $0.3 \mathrm{~km}$. Along the northern part of the coast, the Wassaw Sound has the lowest tidal current power with less than $200 \mathrm{~W} / \mathrm{m}^{2}$ at its entrance. Although the Ossabaw Sound entrance has low tidal stream power density, there is a relatively larger amount of tidal stream power density at the mouth of the Ogeechee River and Canoochee River that flows into the Ossabaw Sound. The regions of even larger tidal current power are isolated upstream of the branches that flow to the Ogeechee River (OR1, OR2), but there are considerably large areas along the Canoochee River (CR1-CR3). The model results indicate that the Canoochee River is the most energetic feature along the northern Georgia coast for tidal current power (Fig. 4.a). The mean tidal stream power density is found to be as large as $790 \mathrm{~W} / \mathrm{m}^{2}$ for some parts of CR 1 and up to 1020 and $1360 \mathrm{~W} / \mathrm{m}^{2}$ for parts of $\mathrm{C} 2$ and $\mathrm{C} 3$, respectively. The maximum width of these regions across the flow is more than $200 \mathrm{~m}$, with an exception for C3, which has a maximum width around $540 \mathrm{~m}$. St. Catherines Sound entrance has a moderate tidal current power density $\left(200-500 \mathrm{~W} / \mathrm{m}^{2}\right)$, but the mean tidal current power density in the Medway River that flows into it is relatively larger, up to $740 \mathrm{~W} / \mathrm{m}^{2}$ with a surface area of $0.2 \mathrm{~km}^{2}$ and maximum a width of $420 \mathrm{~m}$. Finally, the Sapelo River (SS1) and the Sapelo Sound entrance (SS2) contain locations with mean tidal stream power densities on the order of $580 \mathrm{~W} / \mathrm{m}^{2}$. The widths across these areas are $260 \mathrm{~m}$ and $460 \mathrm{~m}$ respectively.

The southern part of the Georgia coast is generally a more moderate source of tidal current power (Fig. 4.b). With mean tidal stream power densities less than 100 and $200 \mathrm{~W} / \mathrm{m}^{2}$ respectively, Doboy and St. Simons Sounds are the least energetic sounds along the southern coast. However, the largest tidal stream power density on the southern Georgia coast is observed in one of the channels along the Intercoastal Waterway between the Doboy and Altamaha Sounds. The mean tidal stream power varies from 500 to $1600 \mathrm{~W} / \mathrm{m}^{2}$ in an area of $0.20 \mathrm{~km}^{2}$. The tidal stream power density at the entrance of the Altamaha Sound is on the order of $300-600 \mathrm{~W} / \mathrm{m}^{2}$. It increases to $500 \mathrm{~W} / \mathrm{m}^{2}$ and up to $600-800 \mathrm{~W} / \mathrm{m}^{2}$ for an area of $0.37 \mathrm{~km}^{2}$ further upstream of the Altamaha River (AR1). Although tidal stream power density south of this location, along the branch that comes from the Buttermilk Sound is found to be as large as $800-1100 \mathrm{~W} / \mathrm{m}^{2}$, it is a narrowly confined area $\left(<0.15 \mathrm{~km}^{2}\right)$ not visible in the figure. The northern half of the St. Andrews Sound entrance, downstream of the Little Satilla River, has slightly larger power density than the southern half. However, the Satilla River itself has a larger area of larger tidal stream power density $\left(200-700 \mathrm{~W} / \mathrm{m}^{2}\right)$ than the sound and the Little Satilla River. A total area of $0.16 \mathrm{~km}^{2}$ with tidal stream power density larger than $500 \mathrm{~W} / \mathrm{m}^{2}$ is available, but it is split into two smaller areas along the upstream of the river. The Cumberland Sound entrance (including CS) has the largest contiguous area $\left(2.2 \mathrm{~km}^{2}\right)$ for a tidal stream power density level between 300 and $600 \mathrm{~W} / \mathrm{m}^{2}$. The largest tidal stream power density for this area $\left(\sim 600 \mathrm{~W} / \mathrm{m}^{2}\right)$ is observed right at the entrance to the Cumberland Sound. The extent of the total area with power density larger than $500 \mathrm{~W} / \mathrm{m}^{2}$ is about $0.31 \mathrm{~km}^{2}$. The width of this area across the entrance is roughly $\sim 300 \mathrm{~m}$.

The locations with higher power density and larger surface area are analyzed using histograms of the annual distribution of the mean tidal stream power density. One year of hourly data generated using constituents computed from the 30-day model runs are used to create a histogram of the velocity magnitude and the related power density. The annual histograms displaying the distribution of the number of hours per year for the range of power density at locations SR1, CR3, and AR1 using a bin size of $100 \mathrm{~W} / \mathrm{m}^{2}$ are shown in Fig. 5. The first bin that corresponds to $100 \mathrm{~W} / \mathrm{m}^{2}$ represents current magnitudes less than $\sim 0.75 \mathrm{~m} / \mathrm{s}$ and has the
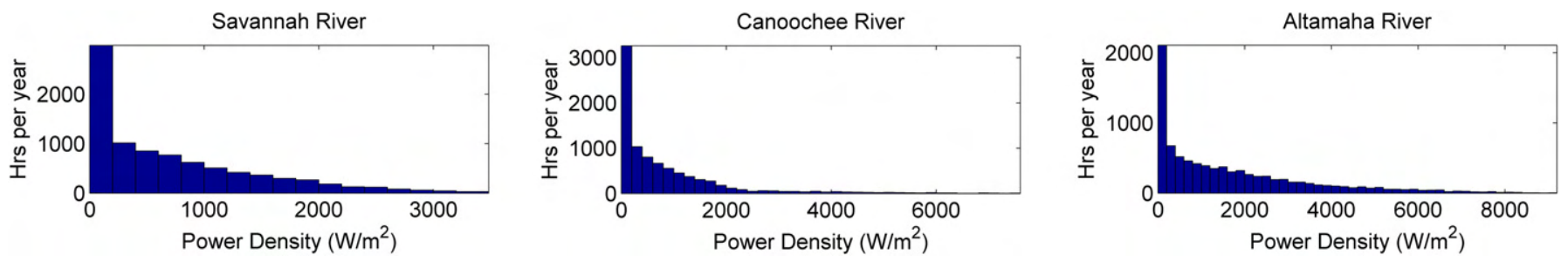

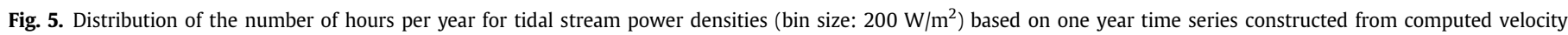
constituents at (a) Savannah River (SR1), (b) Canoochee River (CR3) and (c) Altamaha River (AR1). 


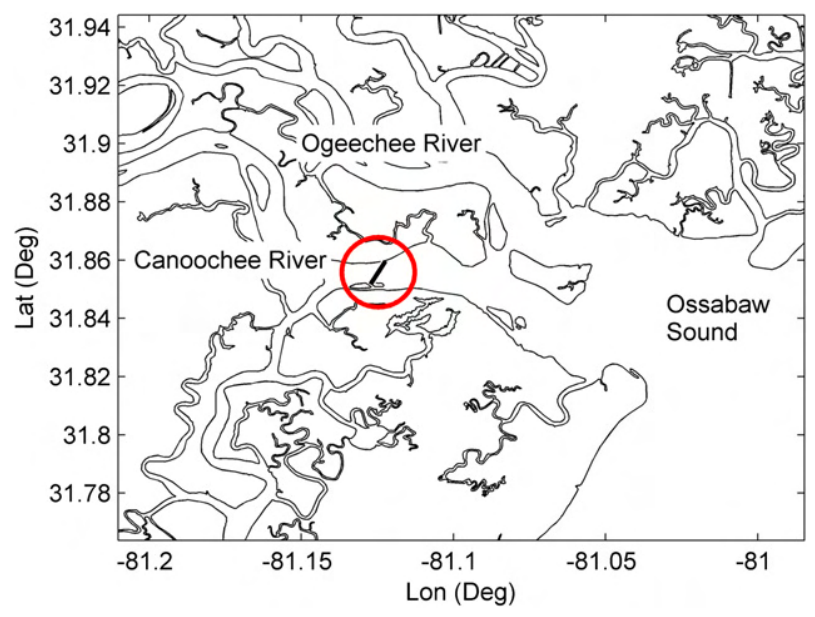

Fig. 6. Location of the modeled energy extraction in the Canoochee River, GA.

largest number of hours per year for the upstream of the Savannah River entrance. For more than $3000 \mathrm{~h}$ (125 days), the power density at this location is less than $200 \mathrm{~W} / \mathrm{m}^{2}$. The power density is less than $400 \mathrm{~W} / \mathrm{m}^{2}$ for $4153 \mathrm{~h}$ ( $\sim 173$ days) a year, and greater than or equal to $400 \mathrm{~W} / \mathrm{m}^{2}$ for $4584 \mathrm{~h}(\sim 191)$ days. The annual average for the tidal current magnitude and tidal stream power density upstream of the Savannah River entrance are computed as $0.93 \mathrm{~m} / \mathrm{s}$ and $745 \mathrm{~W} / \mathrm{m}^{2}$, respectively. The annual average kinetic power for the entire cross-section of the river at this location is $1.3 \mathrm{MW}$ which corresponds to a total kinetic energy of $112 \mathrm{GWh} /$ year. The annual maximum for the mean current magnitude in the Canoochee River can be as large as $3 \mathrm{~m} / \mathrm{s}$ whereas the average is $0.93 \mathrm{~m} / \mathrm{s}$, resulting in a large difference between the maximum and the mean of the tidal stream power. Here the tidal stream power density is larger than or equal to $400 \mathrm{~W} / \mathrm{m}^{2}$ for $4200 \mathrm{~h}$ ( $\sim 175$ days) a year. The tidal stream power density is less than $200 \mathrm{~W} / \mathrm{m}^{2}$ for about $3450 \mathrm{~h}$ ( $\sim 114$ days) a year. The annual average for the tidal stream power density in Canoochee River is computed to be $880 \mathrm{~W} / \mathrm{m}^{2}$, which translates to an annual average kinetic power of $3.0 \mathrm{MW}$ and a total kinetic energy of $258 \mathrm{GWh} /$ year. The annual mean tidal stream power density at the Altamaha River is less than $200 \mathrm{~W} / \mathrm{m}^{2} 2138 \mathrm{~h}(\sim 90$ days), and is more than $400 \mathrm{~W} / \mathrm{m}^{2}$ for $5905 \mathrm{~h}$ ( $\sim 245$ days). The annual average for the tidal current magnitude and tidal stream
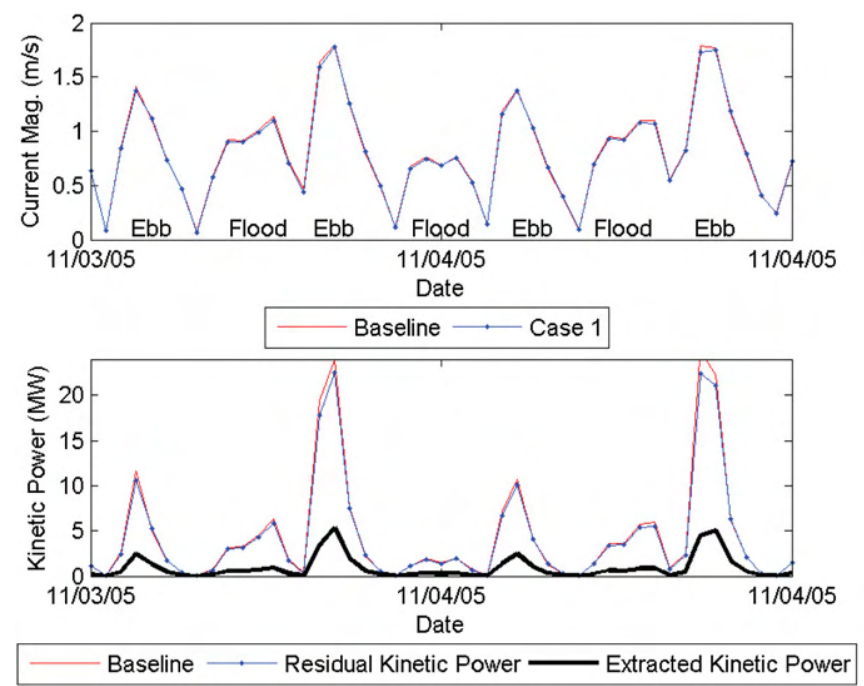

power density in Altamaha River are computed as $1.23 \mathrm{~m} / \mathrm{s}$ and $1735 \mathrm{~W} / \mathrm{m}^{2}$, respectively. The annual average kinetic power for Altamaha River is $1.9 \mathrm{MW}$ and the total kinetic energy is $162 \mathrm{GWh} /$ year.

\subsection{River streamflows}

Among the rivers along the Georgia coast, Savannah River has the largest discharge with the annual average ranging between 150 and $590 \mathrm{~m}^{3} / \mathrm{s}$, which corresponds to $5 \%-21 \%$ of the average tidal volume flux. In order to assess the role of streamflows, 30-day model results from the Savannah River obtained with purely tidal forcing without river flow are compared to those with a point source of $500 \mathrm{~m}^{3} / \mathrm{s}$ located at the river upstream boundary. The effect of the river inflow is observed as an increase in the power density in comparison to the case without the river flow. However, the maximum increase in power density is on the order of $50-100 \mathrm{~W} / \mathrm{m}^{2}$, and remains relatively small compared to the tidal current power at these locations (usually larger than $300 \mathrm{~W} / \mathrm{m}^{2}$ ). The increase is significantly smaller at the river mouth $\left(\sim 25 \mathrm{~W} / \mathrm{m}^{2}\right)$. Additionally, the effect on tidal constituents of water level and currents near the river mouth are determined to be negligible. These findings show that the rivers in the modeled area within Georgia have small discharges upstream of the intertidal zone compared to the tidal fluxes and with minimal effect on the tidal currents. They can be considered tidal rivers and applying only tidal forcing on the models can produce realistic results.

\section{Effect of power extraction on estuarine hydrodynamics}

The Canoochee and the Ogeechee rivers are interconnected with a natural channel a few kilometers upstream of the confluence with the Ossabaw Sound. This whole area provides regions of higher kinetic power density and with its geographical complexity constitutes a worthwhile region to study the effect of power extraction at an estuarine scale. For this purpose, power extraction is simulated across the Canoochee River at location CR3 (Fig. 6). Assuming an array of converters across the channel section, the power extraction is simulated at four cells across the river, where the depth ranges between 3.5 and $8.4 \mathrm{~m}$. Following the suggested significant impact factor in the literature the extraction of the kinetic energy flux is kept at $20 \%$ of the undisturbed kinetic energy
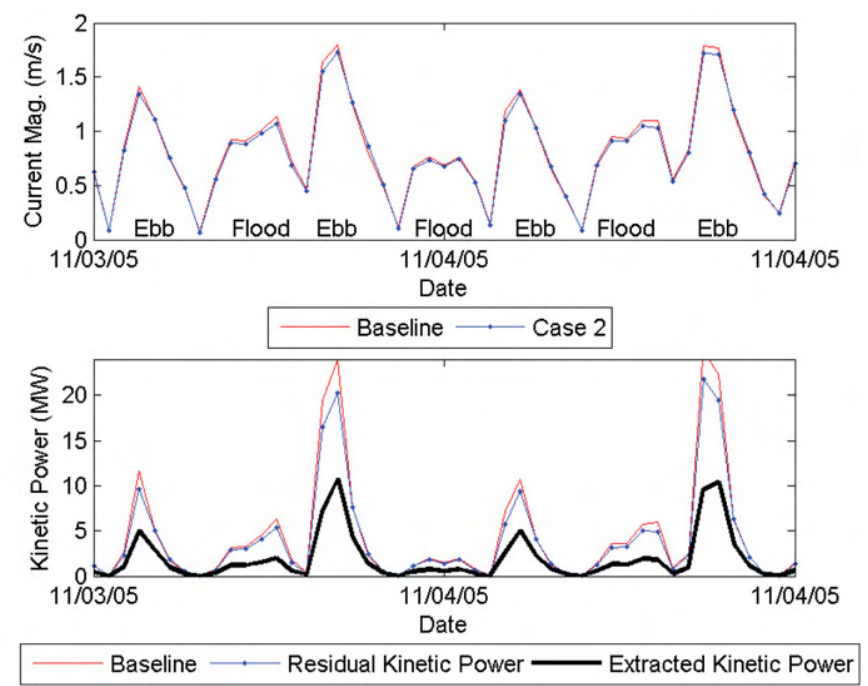

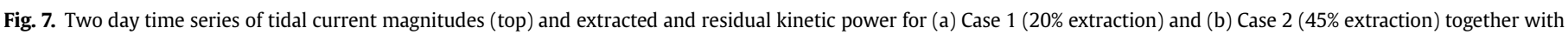
baseline tidal stream power (bottom). 


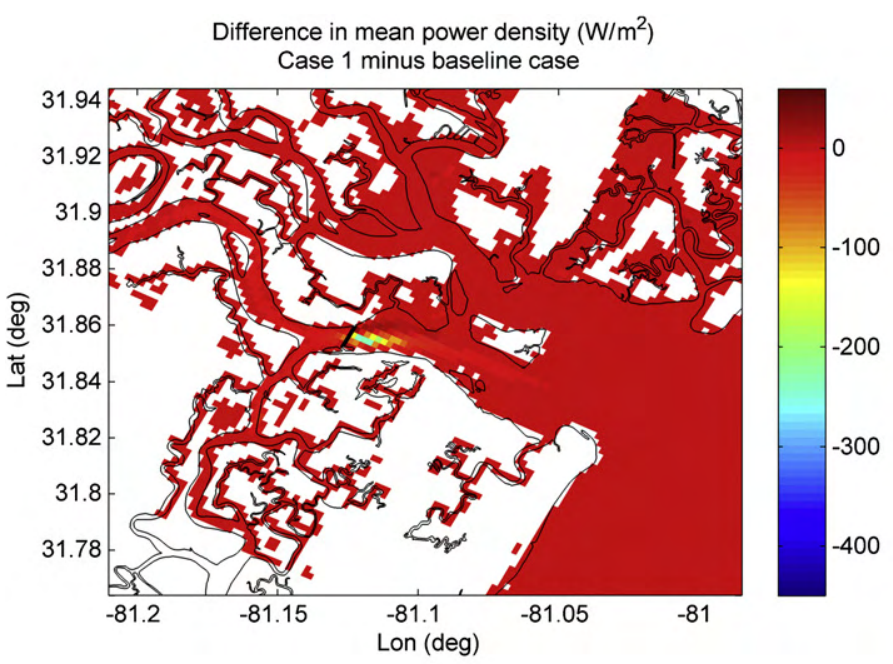

a

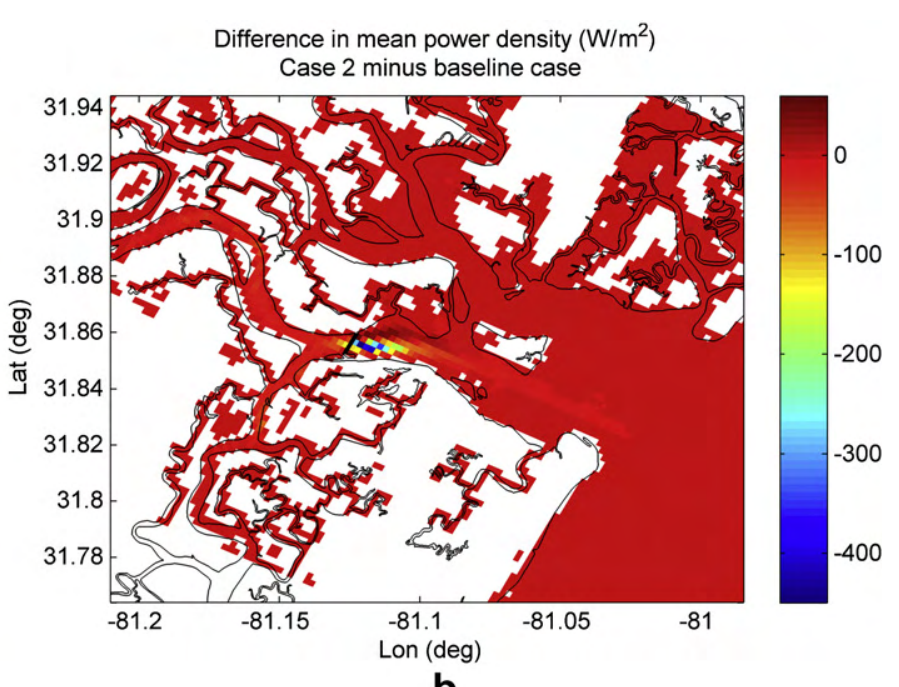

b

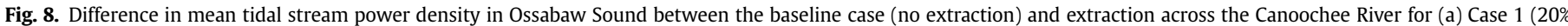
extraction) and (b) Case 2 (45\% extraction). For interpretation of the references to color in this figure legend, the reader is referred to the web version of the article.

flux for Case 1 . Then, the power dissipated is increased to $45 \%$ to analyze the possible amplified effects of power extraction on the far-field hydrodynamics in Case 2. The time series of the current magnitudes and kinetic power densities at the extraction location for two days of a one-month simulation are shown in Fig. 7 for both cases. The change in the current magnitude at the extraction location is unnoticeable in Case 1 and insignificantly small in Case 2 . The reduction in the power density however is more evident during larger current speeds since power density is a function of current speed cubed. Counter intuitively, the summation of the
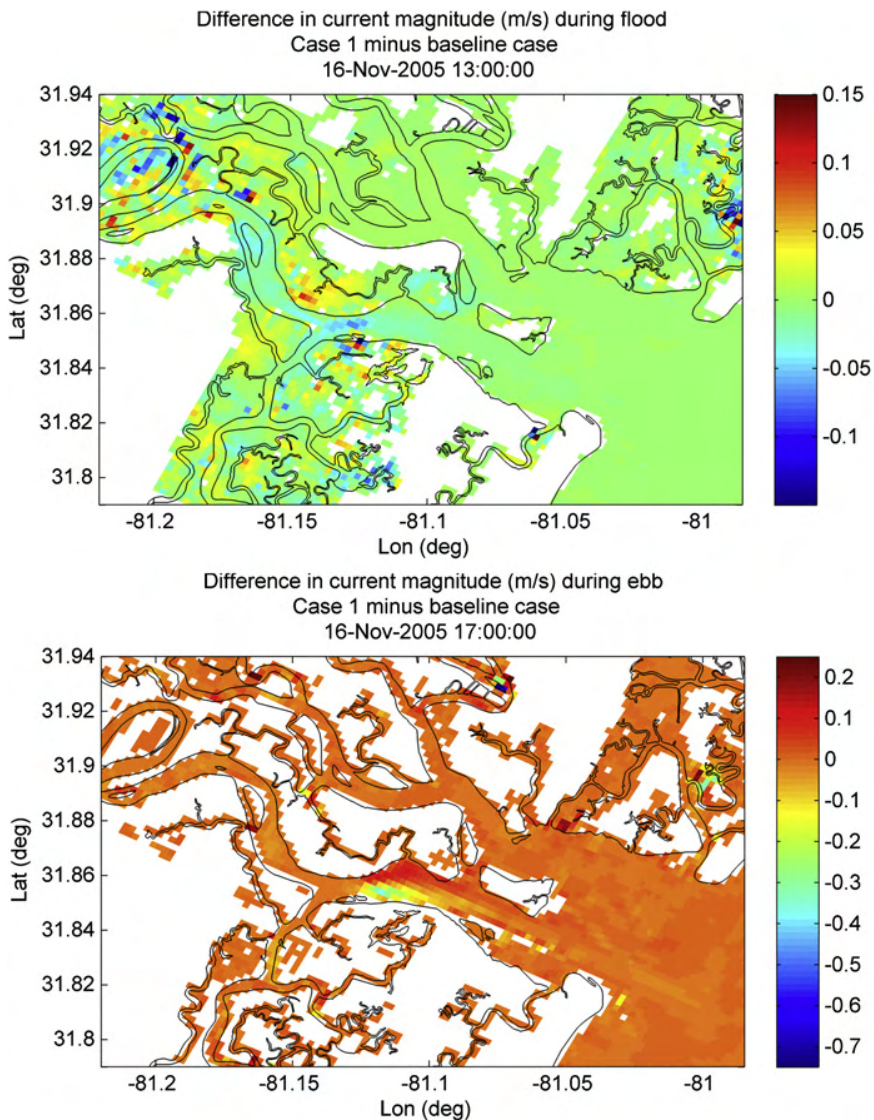

a
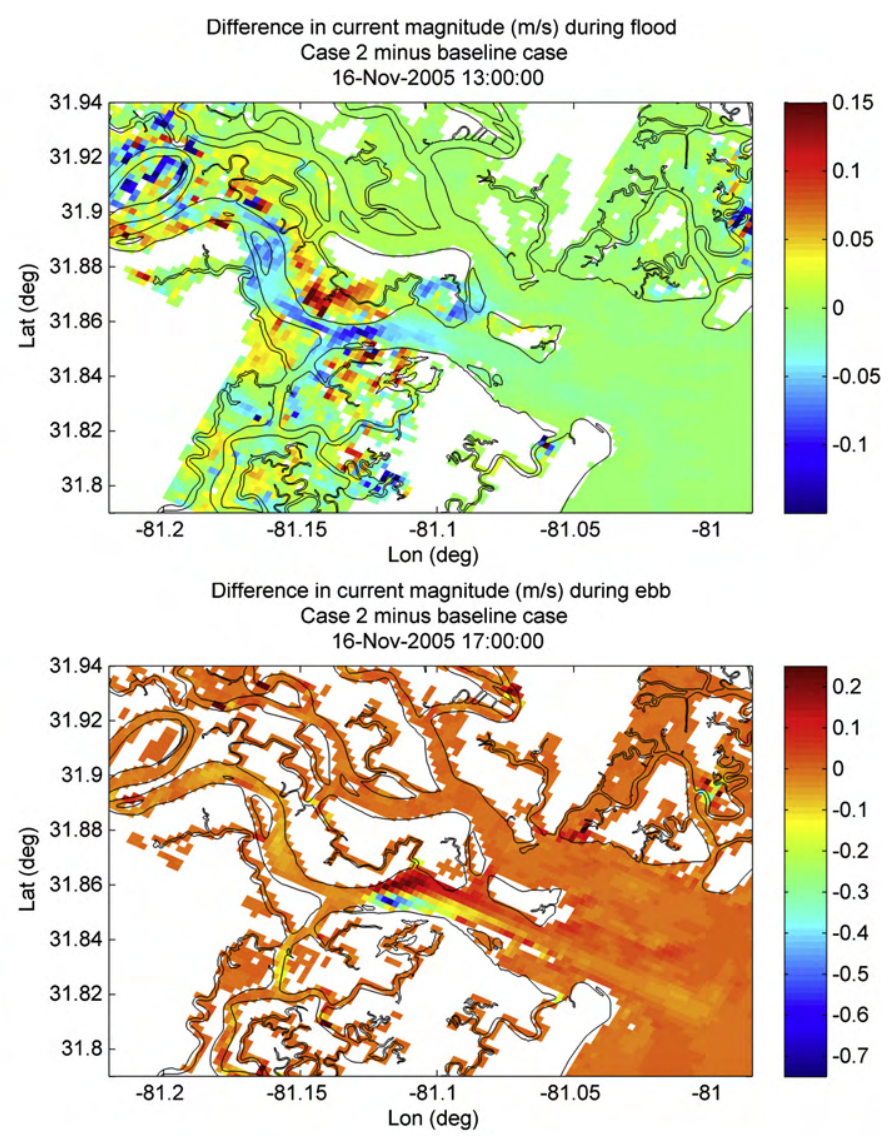

b

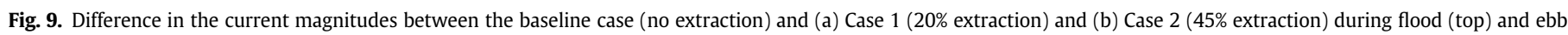
(bottom) tide. For interpretation of the references to color in this figure legend, the reader is referred to the web version of the article. 

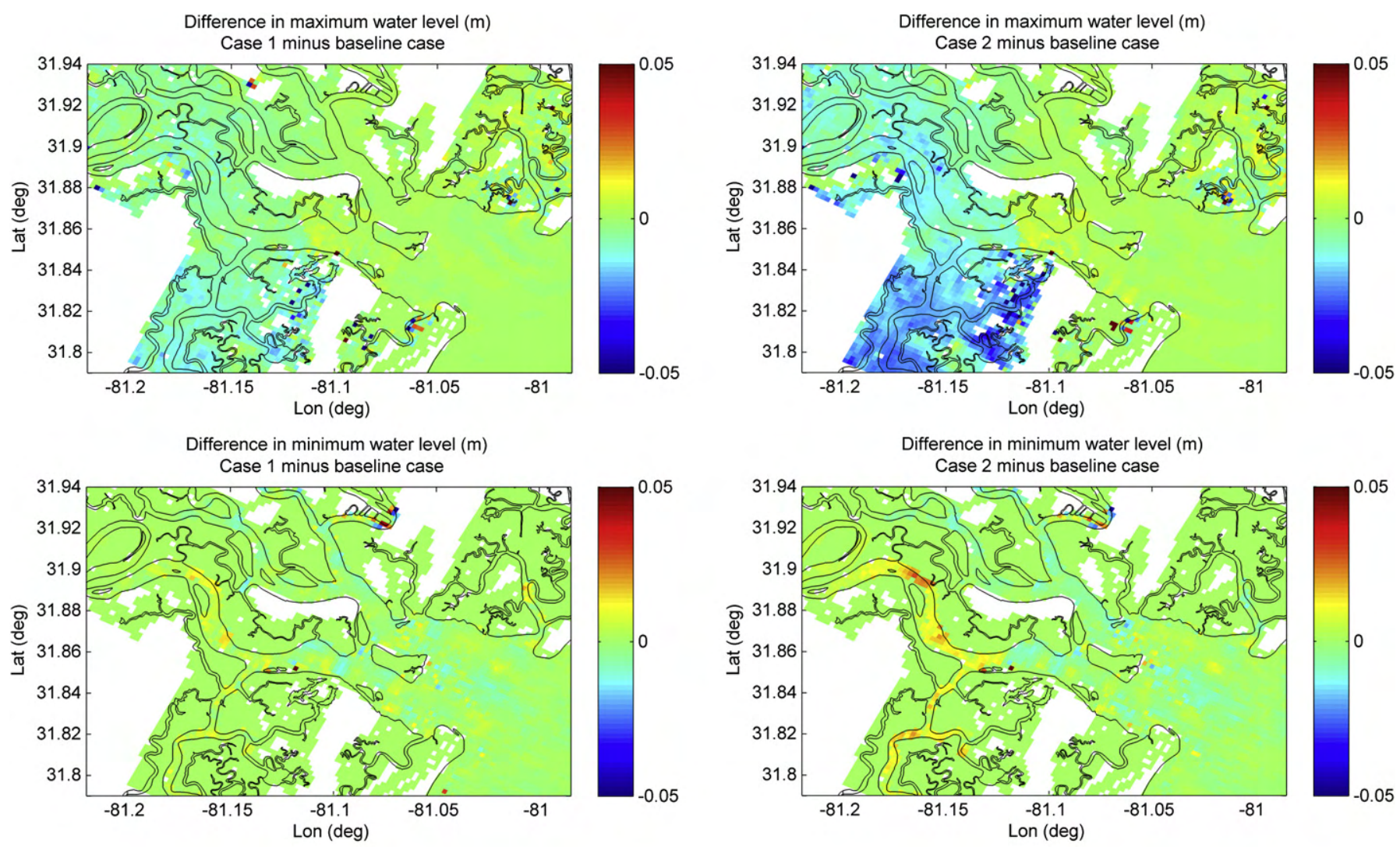

a

b

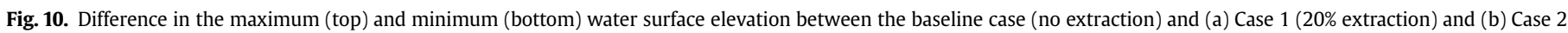
( $45 \%$ extraction). For interpretation of the references to color in this figure legend, the reader is referred to the web version of the article.

residual power and the extracted power during extraction is larger than the original available energy in the channel for the baseline case. This indicates a change in the flow regime and redistribution of the power through a transfer between the potential and kinetic power. This is an important finding, which suggest that the tidal stream power resource analysis of a location must be complemented with a simulation of the power extraction at that location to assess the real potential involved. The maximum extracted power in Case 1 is found to be $5.8 \mathrm{MW}$. The total extracted energy per month in this case is computed to be $403 \mathrm{MWh} /$ month, which corresponds to $20 \%$ of the $2.06 \mathrm{GWh} /$ month total kinetic energy in the baseline case prior to power extraction. In Case 2, 45\% of the undisturbed kinetic energy is dissipated, sustaining $854 \mathrm{MWh} /$ month and a maximum extracted power of $11.8 \mathrm{MW}$. The results from the two simulations are analyzed and compared to each other for their effect on the estuarine hydrodynamics i.e. alterations in the spatial distribution of the mean power density, tidal currents and water levels within the sound.

\subsection{Effect on mean tidal stream power density distribution}

The difference in mean tidal stream power density between the baseline case and the extraction cases based on a one-month simulation is shown in Fig. 8. In both cases, there is a noticeable impact in the vicinity of the extraction location, particularly significant downstream of the power extraction in the direction of ebb currents. The tidal currents are stronger during ebb than flood in the Canoochee River, and more power is extracted during ebb tides (Fig. 6). For this reason, the change in the mean power density is not symmetrically distributed around the line of extraction, but more seawards of it. The largest reduction in the mean kinetic power in the Canoochee River in Case 1 is less than $240 \mathrm{~W} / \mathrm{m}^{2}$ about a kilometer downstream in the ebb flow direction (Fig. 8.a). The overall decrease in the kinetic power density outside of this relatively highly impacted site within a $5 \mathrm{~km}$ diameter is well under $10 \%$, with an average of $5 \mathrm{~W} / \mathrm{m}^{2}$. There is also an increase in the mean power density observed on the northern edge of the extraction location on the order of $30 \mathrm{~W} / \mathrm{m}^{2}$, which can be attributed to the flow around the northern edge that could not be constricted. This prevails for less than $2 \mathrm{~km}$ in ebb direction. There is no noticeable effect of extraction at the entrance of the Ossabaw Sound or the Ogeechee River in this case. On the other hand, the power extraction in Case 2 results in a maximum drop of $443 \mathrm{~W} / \mathrm{m}^{2}$ within the highly impacted area, proportional to the increase in the extracted power (Fig. 8.b). Additionally, a 10\% drop in the kinetic power density is now observed in the southern branch and further upstream of the Canoochee River as well as the southern half of the Ossabaw Sound entrance. The increase in the kinetic power density in the non-constricted part of the Canoochee River reaches a maximum of $62 \mathrm{~W} / \mathrm{m}^{2}$, which stretches $3 \mathrm{~km}$ downstream in the ebb direction.

\subsection{Effect on tidal currents}

The difference in current magnitudes between Case 1 and the baseline case during ebb and flood tides is shown in Fig. 9.a. The current magnitude is decreased by $0.07 \mathrm{~m} / \mathrm{s}$ (which corresponds to a $\sim 15 \%$ reduction in the tidal stream power) at the river centerline immediately after the extraction location in the flood direction during flood tides. The reduction on the order of $0.02 \mathrm{~m} / \mathrm{s}$ in the 
river channel inland of the extraction location is partially compensated with increase in current magnitude of the flow outside the river channel. The strongest currents in the Canoochee River are observed during ebb currents allowing more power to be extracted resulting in a larger drop in the current magnitude. The maximum drop $(0.45 \mathrm{~m} / \mathrm{s})$ during the ebb tide shown in Fig. 9a. is several times larger than the drop during flood tide, but diminishes within a few kilometers. The increase in the flow speed on the northern half of the river channel is limited to $0.2 \mathrm{~m} / \mathrm{s}$ in this case. When the power removed from the system is increased up to $45 \%$ the current magnitudes are reduced by larger factors and the effects prevail in a larger area. The maximum drop in current magnitudes during the flood and ebb tide is $0.15 \mathrm{~m} / \mathrm{s}$ and $0.72 \mathrm{~m} / \mathrm{s}$, respectively (Fig. 9b.). During flood tide a substantial increase in the speed (up to $0.25 \mathrm{~m} / \mathrm{s}$ ) of the flow over the wetlands is observed in this case, especially over the northern bank. The increase in the current speed on the northern half of the channel during ebb tide is also determined to be limited to $0.25 \mathrm{~m} / \mathrm{s}$. Overall, no major difference in tidal currents between Case 1 and the baseline case during a flood tide is observed other than the modification in the current magnitudes close to the extraction location. The ebb currents are considerably larger than the flood currents in this domain and recent literature suggests that tidal asymmetry has a strong effect on sediment dynamics [21]. Therefore, although the power extraction in Case 1 has substantially less impact on the prevailing currents, the residual currents and their effect on transport of suspended sediments should be investigated for both cases.

\subsection{Effect on water level}

The minimum and maximum water levels for each case are determined by considering the highest and lowest water levels that occurred at each grid point during the entire duration of simulation. The change to the minimum and maximum water levels as a result of power extraction is shown in Fig. 10. In either case, there is no significant difference on the seaward side of the extraction location, which connects to the sound. However, a change in the minimum and maximum water level on the landward side of the extraction location is observed, especially during the larger power extraction in Case 2. While the change in the maximum water level is spread over the entire domain including the wetlands, the change in minimum water level is contained within the river channel only. Additionally, the high tide and low tide times are delayed. The maximum delay is bounded with $\sim 5 \mathrm{~min}$ in Case 1 and up to $\sim 10 \mathrm{~min}$ in Case 2 . The combined effect of these two factors may occur as a possible decrease in the maximum wet area. Nonetheless, the impact is very limited especially in Case 1 , where only $20 \%$ of the power is removed from the flow. The change in the minimum water level change in this case is insignificant. Despite the $45 \%$ power deficiency due to extraction, both the decrease in the maximum water level and the increase in the minimum water level are kept below $0.05 \mathrm{~m}$ in the majority of the affected area. Although Case 1 is anticipated to have substantially less impact on the intertidal ecosystem since both the water level difference and the lag are considerably smaller, the impact in Case 2 might still be acceptable depending on the ecological characteristics of the Canoochee River. This requires further examination, which is beyond the scope of this study.

\section{Conclusion}

The tidal stream power along the coastline of the state of Georgia is evaluated using the numerical modeling of tidal currents with ROMS. Validation of model results against the NOAA computed constituents shows that the error in the amplitude of the water level constituents is on the order of centimeters. The phase differences for the constituents are usually under $30 \mathrm{~min}$, except the overtide M4, which can be higher than 100 min. Comparisons with the measurements display current magnitude ratios within 1.0 and 1.1 with the phase differences on the order of $30 \mathrm{~min}$ for the currents. The standard deviation ratio of high/low tides computed by the model to the measurements is determined to be between 0.9 and 1 with the RMS differences on the order of $0.12-0.16 \mathrm{~m}$. The phase difference for the high/low tides between the model results and the measurements is also less than $30 \mathrm{~min}$. Validation of model results with the ADCP measurements at Ogeechee and Satilla Rivers is satisfactory at most of the measurement locations. However, the currents in these rivers are fairly low which causes the error in the current magnitude ratios to be larger.

Based on the model results, the Canoochee River $\left(1400 \mathrm{~W} / \mathrm{m}^{2}\right)$ and the Intercoastal Waterway between the Altamaha and Doboy Sounds $\left(1600 \mathrm{~W} / \mathrm{m}^{2}\right)$ have the largest mean tidal stream power densities along the Georgia coast. The areas with large power densities are the Savannah River (1100 and $\left.800 \mathrm{~W} / \mathrm{m}^{2}\right)$; Ossabaw Sound, Ogeechee and Canoochee Rivers $\left(800,1050\right.$ and $\left.1400 \mathrm{~W} / \mathrm{m}^{2}\right)$; St. Catherines Sound and Medway River $\left(800 \mathrm{~W} / \mathrm{m}^{2}\right)$; Sapelo Sound $\left(700 \mathrm{~W} / \mathrm{m}^{2}\right)$; Altamaha River $\left(800 \mathrm{~W} / \mathrm{m}^{2}\right)$; St Andrews Sound $\left(700 \mathrm{~W} / \mathrm{m}^{2}\right)$; and Cumberland Sound $\left(700 \mathrm{~W} / \mathrm{m}^{2}\right)$. Wassaw, Doboy and St Simons Sounds do not have significant amount of tidal stream power density. The largest river discharge along the Georgia coast comes from the Savannah River. Incorporating the annual average discharge of Savannah River in the model is found to increase the tidal stream power density at the river mouth by less than $3 \%$.

The effect of power extraction on estuarine hydrodynamics is simulated by implementing an additional retarding force in the governing momentum equations in the model and is evaluated in terms of the change in the original mean tidal stream power, tidal current magnitudes and water levels of the original flow. Two different cases of power extraction over the entire river crosssection are simulated in the Canoochee River. A reduction in current magnitudes is observed in both cases, more noticeable in the case with the $45 \%$ removal of the original kinetic energy in the entire river cross-section. A milder power extraction by removing $20 \%$ of the kinetic power in the cross-section allows for a better flow recovery and less impact on the currents. The effect of the extraction on the water levels is noticed as a delay in recession of the water levels during the ebb flow. The delay is more noticeable inland of the power extraction area in both cases, but it is negligibly small in the $20 \%$ extraction case. The high water elevation upstream of the extraction area is decreased and the low water elevation is increased more noticeably in the $45 \%$ extraction case. In both cases, the extracted and the residual kinetic power are observed to exceed the original kinetic power in the cross-section, suggesting that the replenishing of the flow due to changes in water level to restore some of the kinetic power removed from the flow. One possible conclusion is that the previously established guideline of limiting extraction to $15 \%$ of the undisturbed kinetic energy flux is probably a much too restrictive limit.

The overall effect of these changes on the intertidal ecosystem as well as the sedimentation patterns needs to be addressed in a future study. The methodology developed in this study can be applied to other locations with large tidal current power after validation with measurements. The model results can be merged with other important criteria for power conversion projects such as water depth allowance, sea space use, economical and environmental considerations to facilitate decision making [22].

\section{Acknowledgment}

This study was supported by the National Science Foundation, Division of Industrial Innovation and Partnerships (IIP) under the 
Partnerships for Innovation Program Grant IIP- 0332613. Any opinions, findings, and conclusions or recommendations expressed herein are those of the author(s) and do not necessarily reflect the views of the National Science Foundation. Funding was also provided by the Strategic Energy Institute at Georgia Institute of Technology via a Creating Energy Options grant and the 104B Georgia Water Resources Institute Funding Program, and also by the Department of Energy, Wind and Hydropower Technologies Program award number DE-FG36-08G018174 and by the state of Georgia. Zafer Defne would also like to thank to Dr. Lide Jiang for exchange of ideas during the analysis of the tidal data.

\section{References}

[1] Defne Z, Haas KA, Fritz HM. Wave power potential along the Atlantic coast of the southeastern USA. Renewable Energy 2009;34:2197-205.

[2] Pearce N. Worldwide tidal current energy developments and opportunities for Canada's Pacific coast. International Journal of Green Energy 2005;2:365-86.

[3] Scott BE. A renewable engineer's essential guide to marine ecology; 2007. 4302218.

[4] Bryden IG, Couch SJ. ME1-marine energy extraction: tidal resource analysis. Renewable Energy 2006;31:133-9.

[5] Garrett C, Cummins P. Generating power from tidal currents. Journal of Waterway Port Coastal and Ocean Engineering-Asce 2004;130:114-8.

[6] Couch SJ, Bryden IG. Large-scale physical response of the tidal system to energy extraction and its significance for informing environmental and ecological impact assessment. OCEANS 2007 Europe; 2007:1-5.

[7] Polagye B, Kawase M, Malte P. In-stream tidal energy potential of Puget sound Washington. Proceedings of the Institution of Mechanical Engineers, Part A. Journal of Power and Energy 2009;223:571-87.

[8] Hagerman G, Polagye B, Bedard R, Previsic M. Methodology for estimating tidal current energy resources and power Production by tidal in-stream energy conversion (TISEC) Devices. EPRI Tidal In Stream Energy Conversion Reports: Electric Power Research Institute; 2006.
[9] Bryden I, Melville G. Choosing and evaluating sites for tidal current development. Proceedings of the Institution of Mechanical Engineers, Part A. Journal of Power and Energy 2004;218:567-77.

[10] Couch SJ, Bryden IG. Tidal current energy extraction: hydrodynamic resource characteristics. Proceedings of the Institution of Mechanical Engineers, Part M. Journal of Engineering for the Maritime Environment 2006;220:185-94.

[11] Polagye B, Bedard R. Tidal in-stream energy resource assessment for Southeast Alaska. Electric Power Research Institute; 2006.

[12] Haidvogel DB, Arango H, Budgell WP, Cornuelle BD, Curchitser E, Di Lorenzo E et al. Ocean forecasting in terrain-following coordinates: Formulation and skill assessment of the Regional Ocean Modeling System. Journal of Computational Physics 2008;227:3595-624.

[13] Zevenbergen LW, Lagasse PF, Edge BL. Tidal Hydrology, Hydraulics, and Scour at Bridges. Ayres Associates; 2004.

[14] Mukai AY, Westerink JJ, Luettich RA. Guidelines for using Eastcoast 2001 database of tidal constituents within Western north Atlantic Ocean, Gulf of Mexico and Caribbean sea. US Army Corps of Engineers; 2002.

[15] Blanton JO, Seim H, Alexander C, Amft J, Kineke G. Transport of salt and suspended sediments in a curving channel of a coastal plain estuary: Satilla River, GA. Estuarine. Coastal and Shelf Science 2003;57:993-1006.

[16] Blanton JO, Lin G, Elston SA. Tidal current asymmetry in shallow estuaries and tidal creeks. Continental Shelf Research 2002;22:1731-43.

[17] Fagerburg T, Knowles S, Fisackerly G, Parman J, Benson H. Hydrodynamic data Collection in Cumberland sound, Georgia. Vicksburg: U.S. Army Engineer Waterways Experiment station. National Technical Information Service; 1992. Available from.

[18] Seim HE, Blanton JO, Gross T. Direct stress measurements in a shallow, sinuous estuary. Continental Shelf Research 2002;22:1565-78.

[19] Blanton J, Alexander C, Alber M, Kineke G. The mobilization and deposition of mud deposits in a coastal plain estuary. Limnologica - Ecology and Management of Inland Waters 1999;29:293-300.

[20] Seim HE, Blanton JO, Elston SA. The effect of secondary circulation on the salt distribution in a sinuous coastal plain estuary: Satilla River, GA, USA. Continental Shelf Research 2009;29:15-28.

[21] Neill SP, Litt EJ, Couch SJ, Davies AG. The impact of tidal stream turbines on large-scale sediment dynamics. Renewable Energy 2009;34:2803-12.

[22] Defne Z, Haas KA, Fritz HM. GIS based multi-criteria assessment of tidal stream power potential: a case study for Georgia, USA. Renewable and Sustainable Energy Reviews 2011;15:2310-21. 


\section{Assessment of Tidal Currents along the Atlantic Coast of the Southeast USA for Energy Conversion: Case Study for Georgia}

\author{
Zafer Defne \\ Georgia Institute of Technology \\ 210 Technology Circle, \\ Savannah, GA, 31407, USA \\ zafer.defne@gatech.edu
}

\author{
Kevin A. Haas \\ Georgia Institute of Technology \\ Hermann M. Fritz \\ Georgia Institute of Technology \\ M. Kemal Cambazoglu \\ Georgia Institute of Technology
}

\begin{abstract}
In this study an advanced method for assessing the tidal power potential with a three dimensional numerical model is developed and applied along the coast of the state of Georgia. This region has the largest tidal range for the southeast United States, with low to moderate average tidal currents along most of the coast, but with the possibility of very strong local currents within its complex network of tidal rivers and inlets between barrier islands. The preliminary investigation utilizes the tidal current predictions from 133 stations along the $160 \mathrm{~km}$ of coast. Tidal current predictions from these stations provide spatially scattered information about the tidal currents, whereas funneling effects due to the bathymetry may enhance the current speeds locally. In order to resolve the changes in magnitude and the flow pattern of the tidal flows the currents are modeled with the Regional Ocean Modeling System (ROMS). Digital sounding data from the National Ocean Service (NOS) Hydrographic Data Base is used for the bathymetry information. The tidal forcing for the model is acquired from the tidal elevations and constituents information from the ADCIRC tidal database. The model results are incorporated into a Geographical Information System (GIS) database to document local regions which might be used for energy conversion and distributed energy production in the future. Data from the tidal current stations and the modeling efforts show that there are locations with as much as five times larger tidal currents than the average for the region. The model simulations with ROMS resolve the spatial variability of the tidal currents better than the limited number of tidal stations, thereby providing a more comprehensive picture of locations with significant tidal stream energy potential.
\end{abstract}

\section{INTRODUCTION}

Tidal streams are high velocity sea currents created by periodic horizontal movement of the tides, often magnified by local topographical features such as headlands, inlets to inland lagoons, and straits. As tides ebb and flow, currents are often generated in coastal waters. In many places the shape of the seabed forces water to flow through narrow channels, or around headlands. Tidal stream energy extraction is derived from the kinetic energy of the moving flow; analogous to the way a wind turbine operates in air, and as such differs from tidal barrages, which relies on providing a head of water for energy extraction. A tidal stream energy converter extracts and converts the mechanical energy in the current into a transmittable energy form. A variety of conversion devices are currently being proposed or are under active development, from a water turbine similar to a scaled wind turbine, driving a generator via a gearbox, to an oscillating hydrofoil which drives a hydraulic motor [1].

Tidal energy is one of the fastest growing emerging technologies in the renewable sector and is set to make a major contribution to carbon free energy generation. Tidal energy can be harnessed wherever there is moving water in significant volumes. The key advantage of tidal streams is the deterministic and precise energy production forecast governed by astronomy. In addition, the predictable slack water facilitates deployment and maintenance. In 2005, EPRI was first to study representative sites within the United States (Knik Arm, AK; Tacoma Narrows, WA; Golden Gate, CA; Muskeget Channel, MA; Western Passage, ME) without mapping the resources [2]. Additional favorable sites exist in Puget Sound, WA; Cook Inlet and the Aleutian Islands, AK; Southeast Alaska, New York, and Connecticut among others. Besides large scale power production, tidal streams may serve as local and reliable energy source for remote and dispersed coastal communities and islands. The extractable resource is not completely known; assuming $15 \%$ level of extraction, EPRI has documented $16 \mathrm{TWh} / \mathrm{yr}$ in Alaska, 0.6 TWh/yr in Puget Sound, and 0.4 TWh/yr in CA, MA, and ME [3-7]. The selection of location for a tidal stream energy converter farm is made upon assessment of a number of criteria:

- Tidal current velocity: the speed and volume of water passing through the site in space and time. 
- Site characteristics: bathymetry, water depth, geology of the seabed and environmental impacts determine the deployment method needed and the cost of installation.

- Electrical grid connection: The seafloor cable distances from the proposed site to a grid access point help determine the viability of an installation.

In this study we are using state-of-the art modeling and mapping tools to assess the tidal energy potential along the coast of Georgia while satisfying some of these criteria. The Georgia coast stretches between the latitudes $30^{\circ} 42^{\prime}$ $\mathrm{N}$ and $32^{\circ} 3^{\prime} \mathrm{N}$ along the Atlantic Ocean. It is characterized with its complex network of tidal rivers and inlets between barrier islands. This complex geometry of the coast with many interconnecting channels is anticipated to create favorable conditions for strong local currents. Therefore, it is important to be able to create the full three-dimensional geometry of a region and run a numerical model that can accommodate the complete physics of the problem. This approach provides means to evaluate the water levels and water currents more comprehensively rather than depending on measurements or calculations limited to a number of specific points. Supporting modeling with advanced mapping tools makes it easier to include more criteria at the same time. For example, additional spatial criteria such as availability of enough space in the cross-section for energy conversion devices can be integrated by spatial filtering based on constraints using the bathymetry and the calculated water levels.

The information on the tidal current predictions and the details of numerical modeling is given in the next section. It is followed by the discussion of results, which includes the results of the tidal modeling, their verification with the measurements and integration of GIS tools. Finally, the conclusion is given in the last section.

\section{TIDAL CURRENT MODELING}

First the existing data and then the tidal modeling results are used to calculate the power from the tidal currents in the region. The tidal power per unit area or the power density is calculated using the equation

$$
P_{\text {tide }}=1 / 2 \cdot \rho \cdot V^{3}
$$

where $P_{\text {tide }}$ is the tidal power density, $\rho$ is the density of water and $V$ is the magnitude of the depth averaged velocity.

\subsection{Tidal Current Predictions}

Following the guidelines in the EPRI report for estimating tidal current energy resources [8], preliminary investigations of the tidal currents can be conducted based on the tidal current predictions provided by tidal current stations run by the Center for Operational Oceanographic Products and Services (CO-OPS) of the National Oceanic and Atmospheric Administration (NOAA). Only a limited number of these stations are categorized by CO-OPS as reference stations and full daily predictions are published for them. The remaining stations are categorized as subordinate stations. Specific differences are applied to the times and speeds of the predicted tidal currents at the specified reference stations to calculate the predictions for subordinate stations [9]. These predictions are based on harmonic analysis of previous measurements of various durations. Along the Georgia coast there are over 100 of these stations, which are sparsely distributed in inlets, rivers, channels and bays. The gauge stations are concentrated along navigation channels, harbors and rivers but widely lacking elsewhere along the coast. The information on maximum flood and ebb flow magnitudes and their directions are provided at these stations. The depth of measurement is also given at some of them. The maximum tidal power densities calculated using these data along the Georgia coast are shown in Figure 1(a)-(d).

As seen in Figure 1, the tidal currents can have significant spatial variability; therefore, measurements (or predictions) of currents at one location are generally a poor indicator of conditions at another location, even nearby. The majority of the data is available along the navigation channels, with sparse data within the rest of the tidal area. EPRI [8] suggests a methodology using continuity and the Bernoulli equation for determining the flow in different sections of a channel. This is a reasonable approach for flow along a geometrically simple channel, but is not applicable for the flow in the complex network of rivers and creeks along much of the Georgia coastline.

\subsection{Numerical Modeling}

The Regional Ocean Modeling System (ROMS) is a member of a general class of three-dimensional, free surface, terrain following numerical models that solve three dimensional Reynolds-averaged Navier-Stokes equations (RANS) using the hydrostatic and Boussinesq assumptions $[10,11]$. ROMS uses finite-difference approximations on a horizontal curvilinear Arakawa C grid [12] and vertical stretched terrain-following coordinates. Momentum and scalar advection and diffusive processes are solved using transport equations and an equation of state computes the density field that accounts for temperature, salinity, and suspendedsediment concentrations. The modeling system provides a flexible framework that allows multiple choices for many of the model components such as several options for advection schemes (second order, third order, fourth order, and positive definite), turbulence models, lateral boundary conditions, bottom- and surface-boundary layer submodels, air-sea fluxes, surface drifters, a nutrientphytoplankton-zooplankton model, and a fully developed adjoint model for computing model inverses and data assimilation. The code is written in Fortran90 and runs in serial mode or on multiple processors using either sharedor distributed-memory architectures (Open MultiProcessing or Message Passing Interface). 


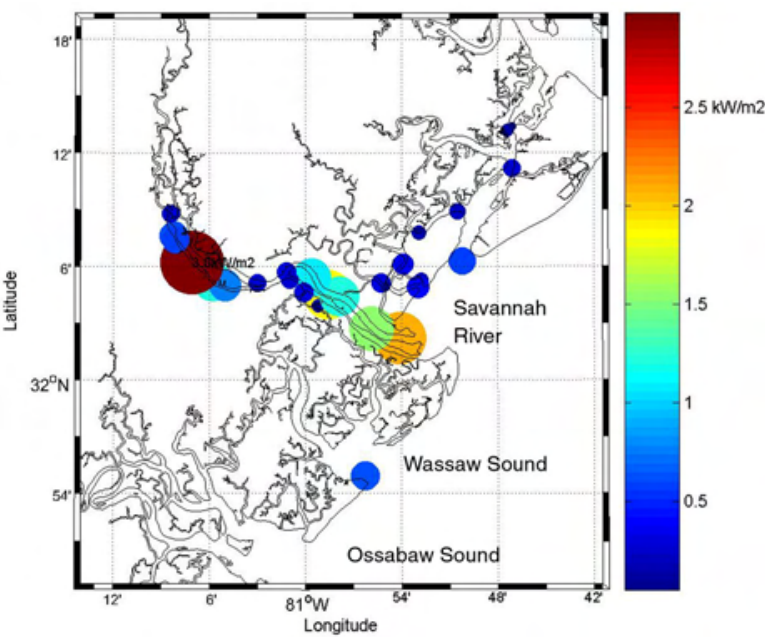

(a)

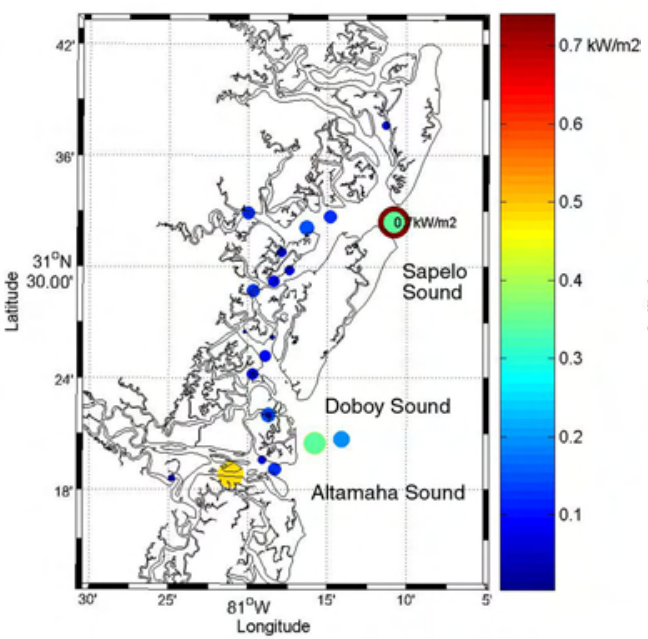

(c)

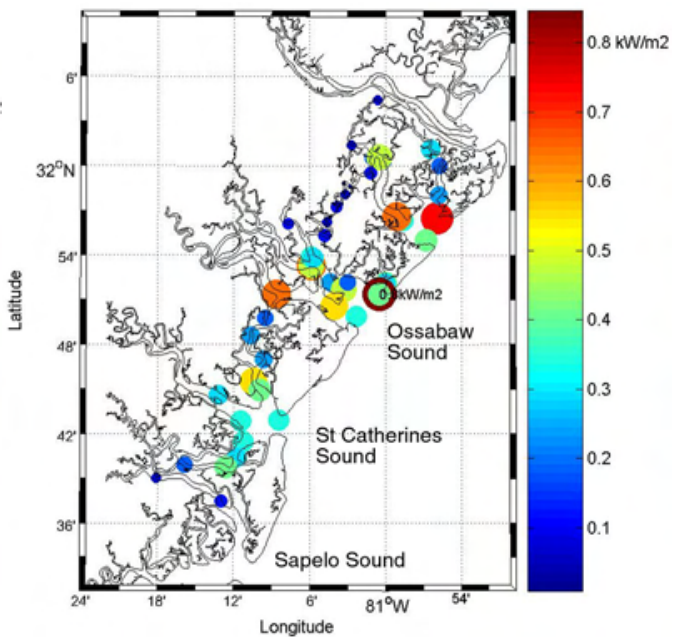

(b)

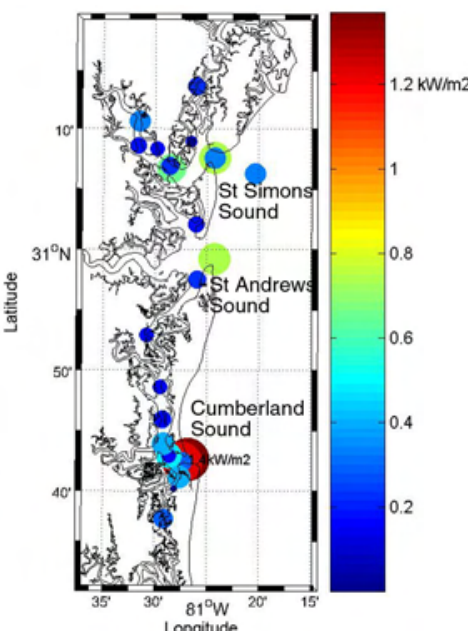

(d)

Figure 1. Maximum available power per unit area based on NOAA tidal current predictions along the Georgia coast.

To produce accurate simulations of tidal currents, the model requires detailed bathymetric data for the generation of the computational grid. The coastline and bathymetry information is obtained from the National Geophysical Data Center (NGDC). NOAA's Medium Resolution Shoreline $(1 / 70,000)$ dataset is used for the coastline information. The coastline dataset is extracted using the coastline extractor available at the NGDC website [13] and the bathymetry data downloaded through the ArcIMS [14] interface provided by NGDC, which is the official source for National Ocean Service (NOS) bathymetric maps. The vertical datum for the bathymetry data is adjusted using the Mean Lower-Low Water (MLLW) and Mean Tidal Level (MTL) values reported by local tidal stations [15].

The computational grid is generated using the SeaGrid orthogonal grid maker for Matlab [16]. The bathymetric data is used to generate depths for each grid point. Grid points within the computational domain which remain permanently "dry" are determined and marked by using a masking feature utilizing the coastline data. The grid is examined manually to ensure that all computational points are interconnected with at least two other points. Finally, the vertical datum for the grid is adjusted to the MTL. In order to simulate the tidal flows inside the estuaries, rivers, inlets and bays in more detail numerical grid resolution is kept to be as small as tens of meters. For this reason, to keep the computational domain to a manageable size, the coast is broken up into subgrids, each being used for separate simulations. The coast of Georgia has been separated into 4 different grids as shown in Figure 2. Wherever possible, natural barriers are selected as boundaries between the different grids; estuaries or bays are contained in their entirety within a single computational domain. The neighboring grids contain overlaps of several kilometers to ensure full coverage. 


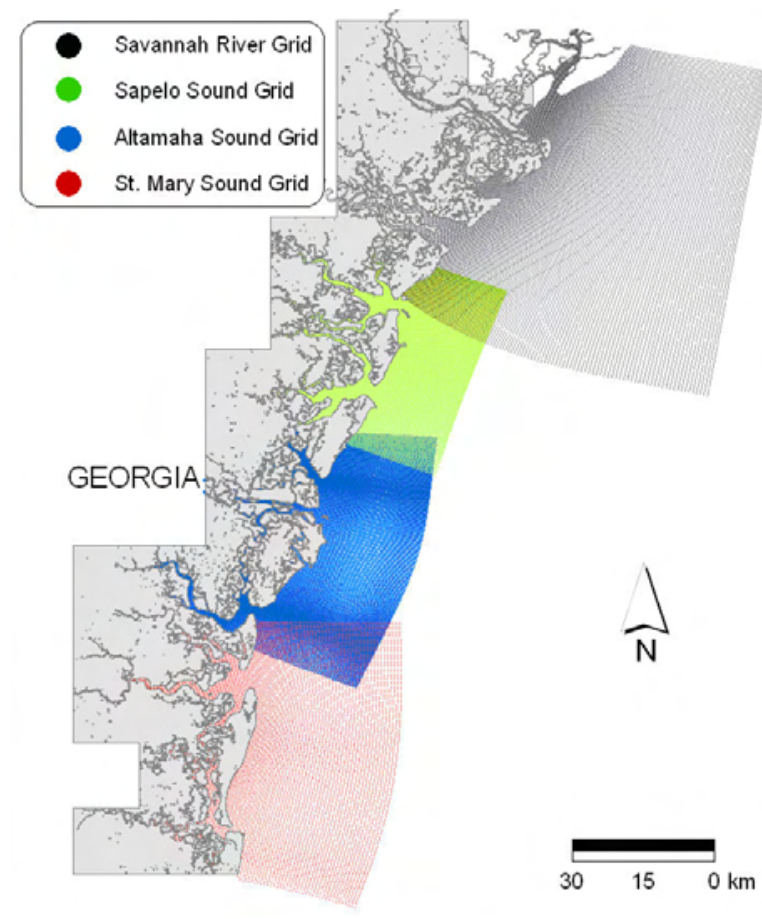

Figure 2. Map of the 4 computational grids used for ROMS simulations of the tidal currents along the Georgia coast.

In order to produce simulations of the tidal currents, the model requires tidal forcing along the boundaries of the computational domain. This forcing can be derived from a variety of sources including measurements, model simulations or the harmonic constituents provided by the NOAA CO-OPS. The tidal forcing comes from the ADCIRC tidal database created by the numerical model ADCIRC for the Western North Atlantic Ocean [17]. This database includes the M2, S2, N2, K2, O1, K1, P1, Q1, M4, M6 and STEADY tidal constituents, although the M4, M6 and STEADY components have not been verified and therefore are not used. The constituents are extracted from the tidal database and applied at the open boundary of the computational grids to force the ROMS simulations of the tidal currents.

The model is run to simulate 32 days, encompassing an entire lunar cycle, for each computational domain. Currents and water levels are retained at 1 hour intervals for all points within the domain to allow for harmonic analysis using the $T_{-}$Tide harmonic analysis toolbox for Matlab [18] of both the water levels and the velocities.

\section{DISCUSSION OF RESULTS}

\subsection{Verification of the tidal model results}

Starting from November 1, 2005, 32 days worth of tides were simulated with the model. The model results compared with available data for the water levels are shown in Figure 3. The water level data has been obtained from the CO-OPS website and run through the harmonic analysis toolbox to extract the same tidal constituents as used in driving the model. Differences between the model and measurements are evident in the first few tidal cycles as the model goes through its spin-up phase beginning from a cold start. After the initial startup, the model and measurements are quite similar, clearly demonstrating the ability of the model to reproduce the tidal water levels.

Six of the water level tidal constituents obtained from CO-OPS and computed from the model are shown in Table 1. The constituents from the model are computed while neglecting the first 48 hours to eliminate startup effects in the model. Even though the model is only using 30 days worth of data to compute the harmonics, the comparison with the measurements show that the computed amplitude and phase results are reasonably close to the measured values.

Table 1. Measured and modeled tidal constituents at the entrance to St. Simons Sound, GA.

\begin{tabular}{cccccc}
\hline Name & $\begin{array}{c}\text { Period } \\
(\mathrm{hrs})\end{array}$ & $\begin{array}{c}\text { Measured } \\
\text { Amplitude } \\
(\mathrm{m})\end{array}$ & $\begin{array}{c}\text { Model } \\
\text { Amplitude } \\
(\mathrm{m})\end{array}$ & $\begin{array}{c}\text { Measured } \\
\text { Phase } \\
(\mathrm{deg})\end{array}$ & $\begin{array}{c}\text { Model } \\
\text { Phase } \\
(\mathrm{deg})\end{array}$ \\
\hline M2 & 12.42 & 0.976 & 0.903 & 23.4 & 13.56 \\
$\mathrm{~S} 2$ & 12.00 & 0.160 & 0.149 & 51.1 & 19.4 \\
$\mathrm{~N} 2$ & 12.66 & 0.226 & 0.203 & 8.1 & 3.06 \\
O1 & 25.82 & 0.076 & 0.095 & 208.0 & 206.3 \\
K1 & 23.93 & 0.107 & 0.123 & 201.2 & 198.5 \\
Q1 & 26.87 & 0.017 & 0.017 & 201.6 & 195.3 \\
\hline
\end{tabular}

The accuracy of the velocities for the tidal currents is also evaluated by comparing the computed velocities with available data. A time series may be constructed utilizing information from the tidal current prediction gauges and compared directly to the model predictions of the magnitudes of the tidal currents. A comparison of the magnitude of the tidal currents from a station inside the entrance channel for St. Simons Sound in Georgia is shown in Figure 4. The reproduction of the tidal currents is quite good for this station. The time series constructed from the tide table assumed that the slack water velocity reaches $0 \mathrm{~m} / \mathrm{s}$ whereas the model, having 1 hour resolution for the velocity outputs may not resolve the precise slack water time. In addition, at many locations the tidal velocity may never entirely vanish, because the velocity actually follows an elliptical pattern as it turns from flood to ebb and not simply flop back and forth in a collinear pattern. This explains the apparent mismatch between the model and measurements for low current speeds. It is important to note that tide station measurements often include components from fresh water runoff or river flow and atmospheric effects, which are not included in the tidal model. 


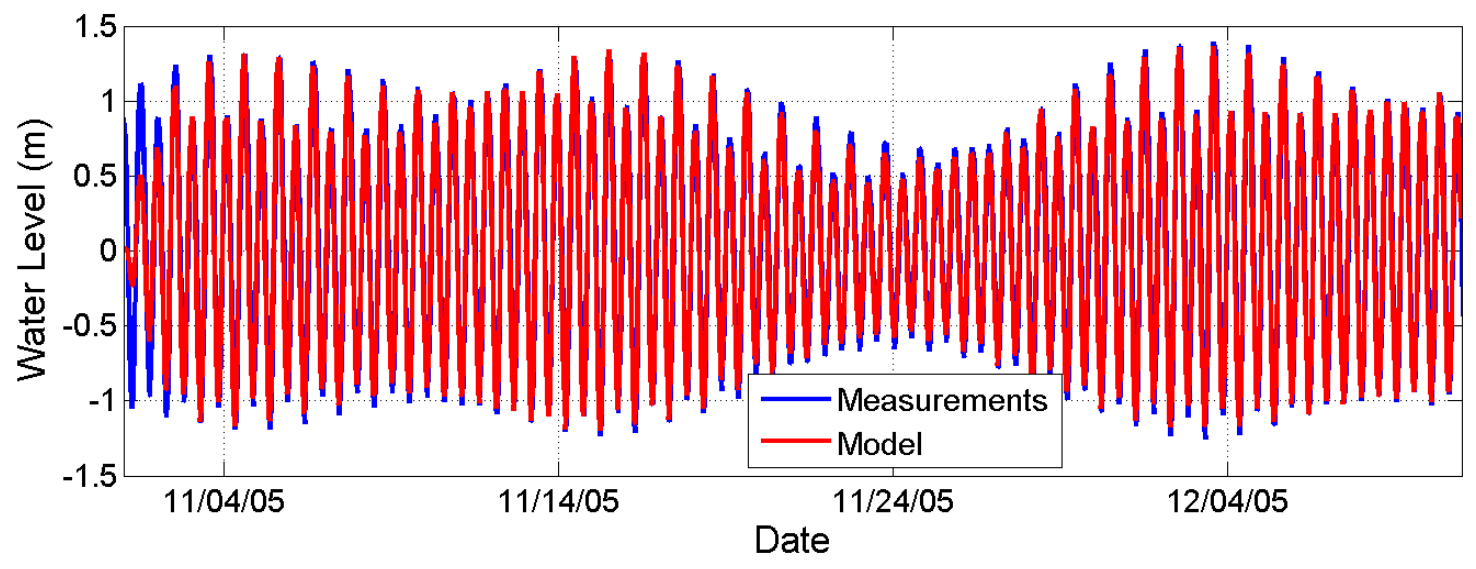

Figure 3. Water levels from model predictions and measurements in the entrance to St. Simons Sound, GA. The measurements have been filtered to only contain the same harmonic constituents used to force the model, thereby neglecting the atmospheric response.

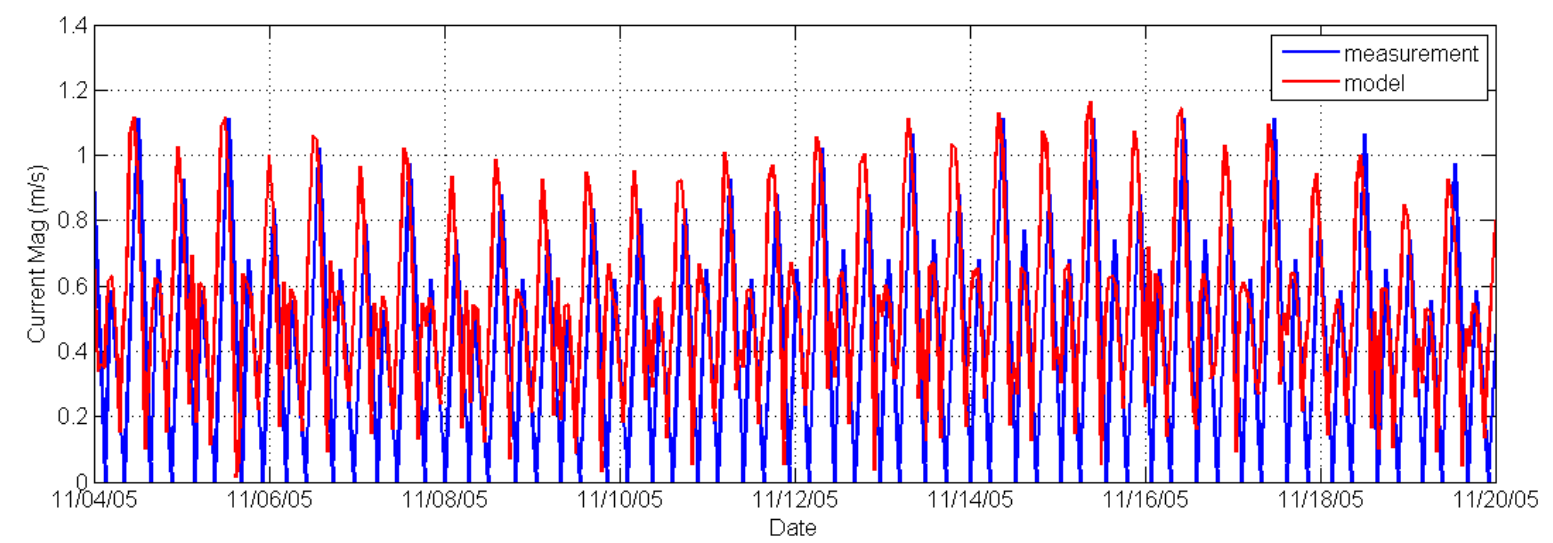

Figure 4. Magnitude of the tidal current from model predictions and NOAA predictions in the entrance to St. Simons Sound, GA.

\subsection{Velocity and Power Density Histograms}

The first 2 days of the 32 days are neglected for the computations of the tidal constituents, which are then used to create a new time series of the velocity for an entire year. Figure 5 shows an example of an original 30 day time series along with the 1 year time series computed from its constituents. This one year of hourly data can be used to create a probability histogram of the velocity magnitude. The histogram in the top panel of Figure 6 shows the distribution of the number of hours per year for the range of tidal current velocities at the entrance to Cumberland Sound computed from the one year time series in Figure 5.

The histograms of annual tidal current velocity are used to compute a histogram of total available power density. These histograms can be used to compute the annual average available power at all locations. For example, the histogram in the bottom panel of Figure 6 shows the distribution of the available power density based on the velocity histogram given in the top panel.

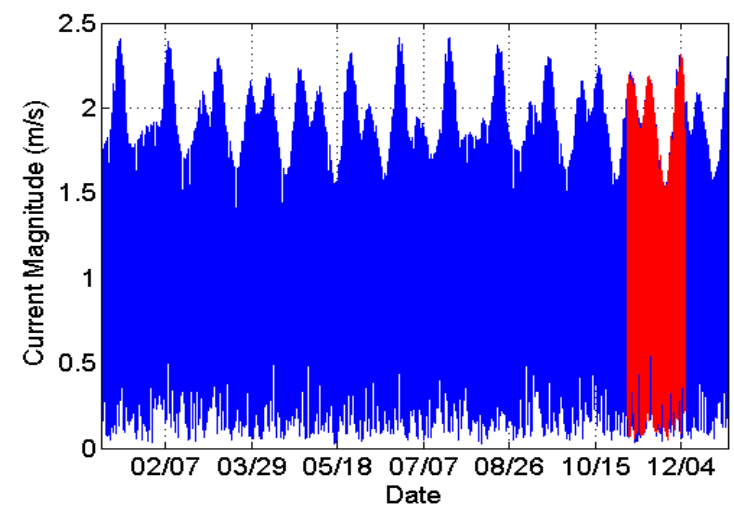

Figure 5. Time series for 30 days of the magnitude of the velocity from the numerical model (red) at the entrance of Cumberland Sound. Tidal velocity constituents are computed and used to construct a 1 year time series (blue) of the velocity magnitude. 

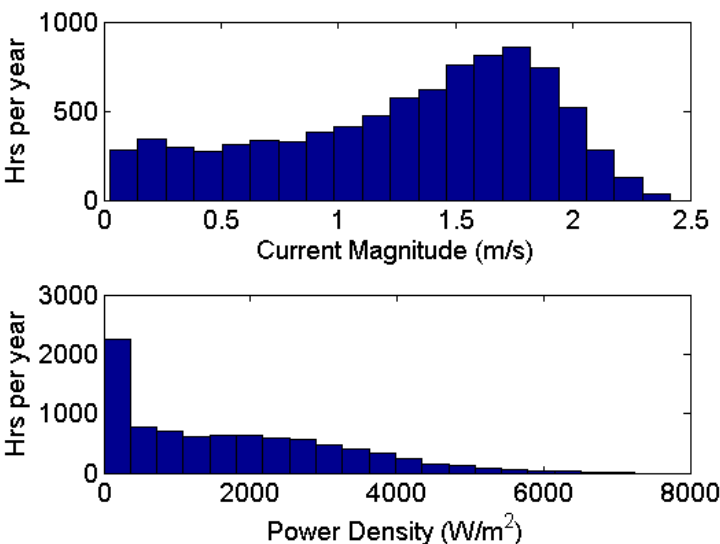

Figure 6. Histogram of the number of hours per year for the (top) range of tidal current magnitudes and

(bottom) total available power density from the entrance channel to Cumberland Sound taken from the one year time series in Figure 5.

The annual average power density for this case is computed to be $1700 \mathrm{~W} / \mathrm{m}^{2}$ and the maximum available power density is computed to be $7200 \mathrm{~W} / \mathrm{m}^{2}$. However, turbines are incapable of extracting all available power from the flow field. Since the efficiency is a function of the flow speed, an efficiency curve is frequently used for computing the expected turbine output power. An example of a typical efficiency curve is shown in Figure 7.

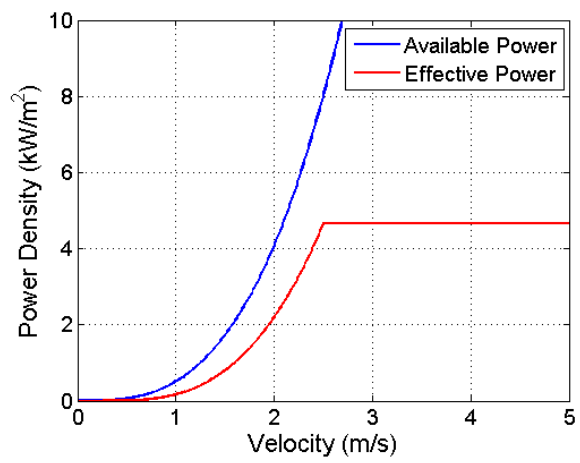

Figure 7. Example of an efficiency curve for tidal turbines $[8]$ and the ideal available power density.

Using an efficiency curve for calculating the power density results in a decrease in the output power but provides a more realistic estimate of the available power potential. After applying the efficiency curve at every computational grid point the annual mean effective power and the maximum effective power density reduce to 850 $\mathrm{W} / \mathrm{m}^{2}$ and $4200 \mathrm{~W} / \mathrm{m}^{2}$, respectively.

\subsection{Resource Mapping with GIS}

ESRI's ArcView [19] package with the Spatial Analyst extension has been used for resource mapping in this study. The spatial masking according to the minimum depth and minimum tidal power density using ArcView package is explained in details in the following subsections.

\subsubsection{Bathymetry Filter}

Tidal stream energy converters are currently limited in their variety and are primarily classified in vertical and horizontal axis devices with open or shrouded rotors. Independent of their design all the devices have depth requirement based on their dimensions. The first step for a site selection scheme for any of these energy converter projects is to determine which locations will meet the minimum depth requirements. The minimum depth is usually given as

$h_{\min }=h_{b}+h_{s}+d_{p}$

where $h_{\min }$ is the minimum depth, $h_{b}$ is minimum height of the prototype above the bed, $h_{s}$ is the minimum clearance of the prototype below the surface and $d_{p}$ is the device dimensions. As an example, if the minimum height above the bed was set at $2 \mathrm{~m}$, the minimum clearance below the MLLW was $2 \mathrm{~m}$ and the propeller diameter was $3 \mathrm{~m}$, the minimum depth becomes $7 \mathrm{~m}$. Figure $8(\mathrm{a})$ shows the raw bathymetry layer and Figure 8(b) shows the filtered bathymetry layers for the Georgia coast with $h_{\min }=7 \mathrm{~m}$ created in ArcView. All depths below the $h_{\text {min }}$ have been removed from this layer as evident by the white areas, leaving only the depths in the offshore region and within the channels in the nearshore region. This layer is used to mask the map for the available tidal power.

\subsubsection{Effective Power}

Figure 9 shows the annual average power for the southern coast of Georgia taken from the model simulations shown in Figure 2. Figure 9(a) is the total available power as computed from the model output. The annual mean effective power density is computed and is then filtered by the bathymetry threshold and also is filtered by a minimum required power $\left(>50 \mathrm{~W} / \mathrm{m}^{2}\right)$ in order to facilitate the identification of regions with useful tidal energy potential. An example of this product is shown in the right panel in Figure 9(b) for the southern coast of Georgia. The efficiency curve and the filters have reduced the data to just a few specific locations where there is significant tidal power available for extraction. The concentration of available power density is clearly located within the channels between the islands. In particular, the entrance to Cumberland Sound has extensive power density highlighting the importance of the tidal modeling for the entire coastline to identify potential sites. In Figure 9(b) it is seen that the effective power density in the Cumberland sound entrance can be as large as $1600 \mathrm{~W} / \mathrm{m}^{2}$, which is much larger than the average in the region. St. Andrews and Altamaha Sounds also have a few locations which qualify the minimum depth and minimum power density criteria. The tidal power densities in these areas are in the order of $100 \mathrm{~W} / \mathrm{m}^{2}$. It is also possible to see the surface area of the maximum effective tidal power density for each location in the same figure. According to this, about $1.5 \mathrm{~km}^{2}$ of the suitable area at the Cumberland Sound entrance has a power density between 990 and $1600 \mathrm{~W} / \mathrm{m}^{2}$. The total suitable area at Cumberland Sound is about $7.9 \mathrm{~km}^{2}$, with depths varying between 7 and $24 \mathrm{~m}$, and widths ranging from 0.9 to $1.6 \mathrm{~km}$ across the channel. 


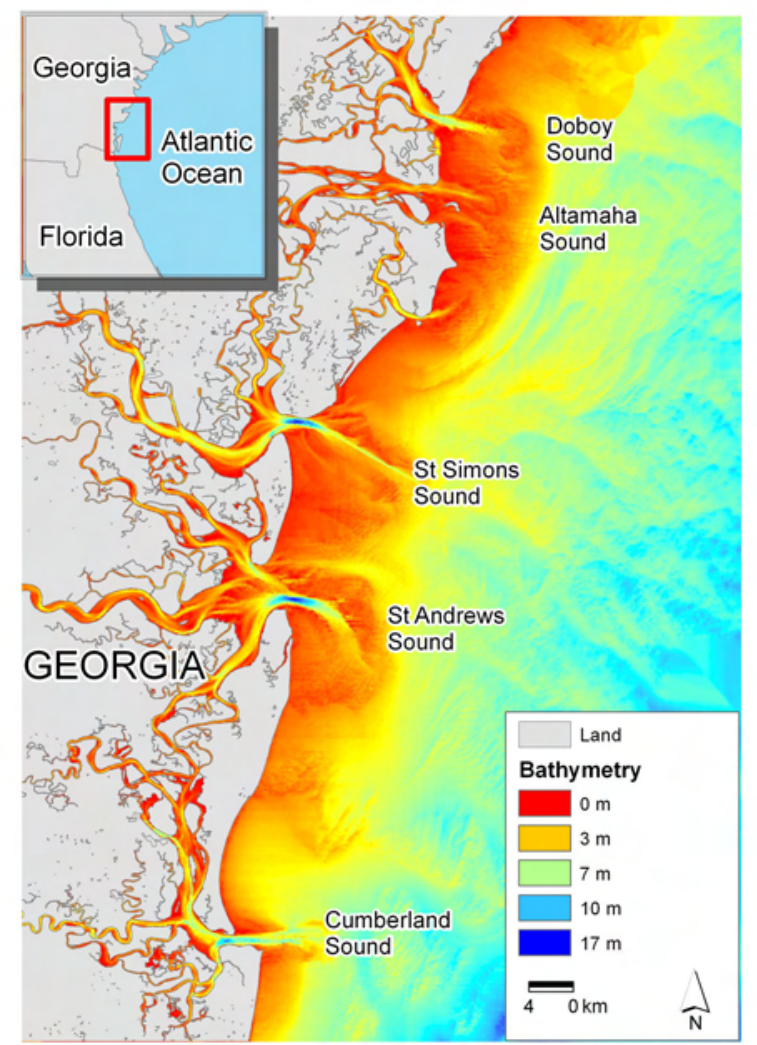

(a)

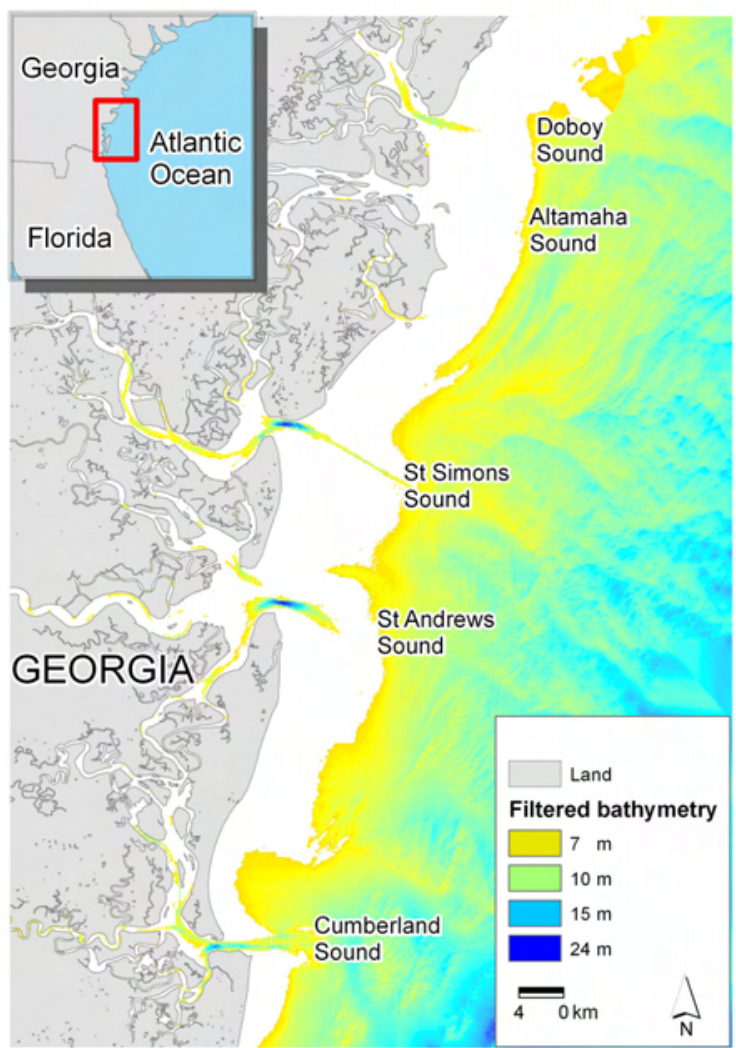

(b)

Figure 8. Images of the (a) raw bathymetry layer and (b) filtered bathymetry $\left(h_{\min }=7 \mathrm{~m}\right)$ layer for the southern Georgia coast.

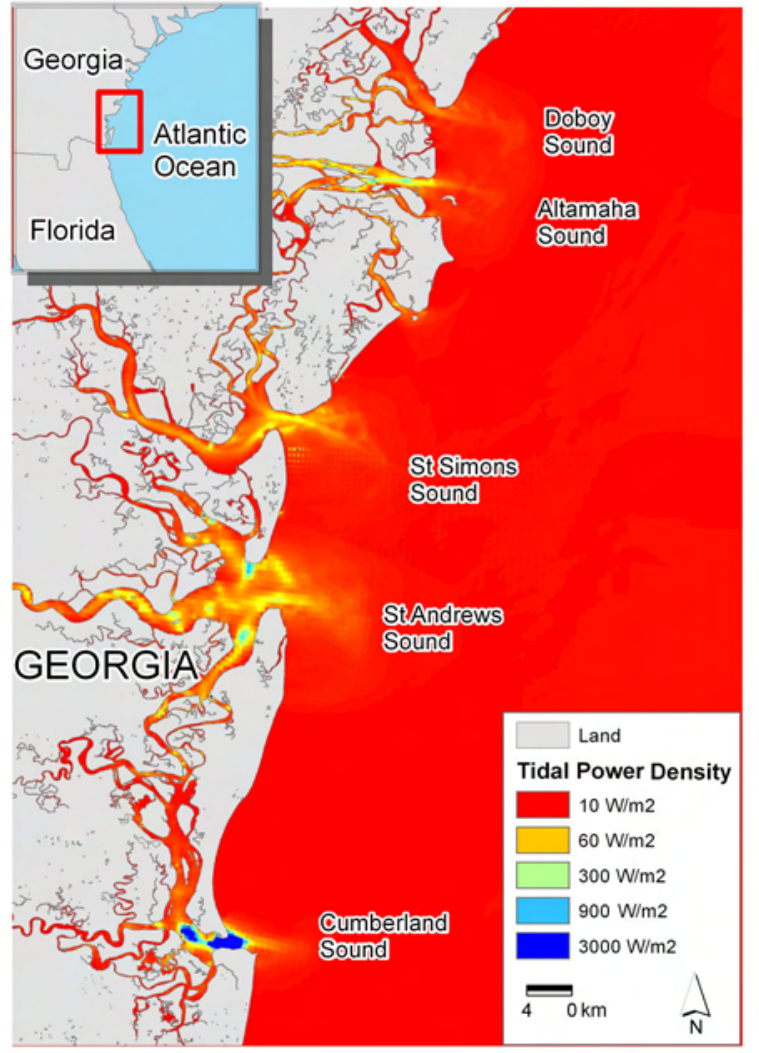

(a)

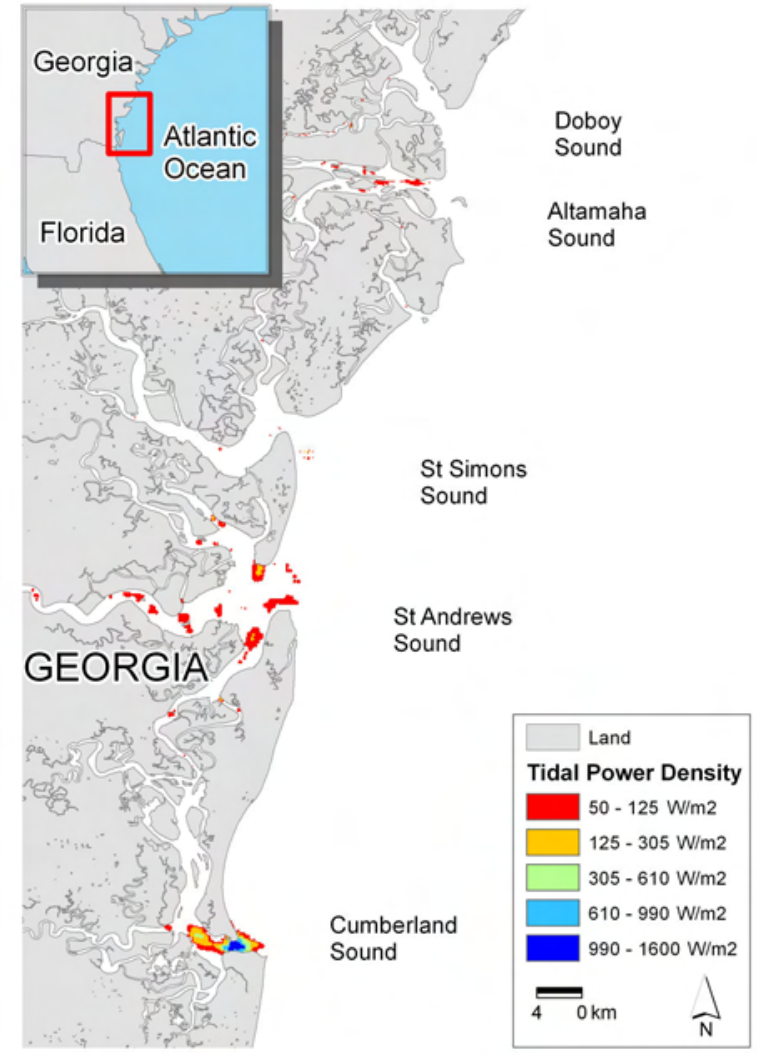

(b)

Figure 9. Images of the (a) total power density available and (b) effective power density using depth filter $\boldsymbol{h}_{\min }=7 \mathrm{~m}$, the efficiency curve in Figure 7 and a minimum power density of $50 \mathrm{~W} / \mathrm{m}^{2}$ for the southern Georgia coast. 
In Figure 10 the average effective tidal power density map for the northern part of the Georgia coast is given. Savannah River, Ossabaw and St Catherines Sounds have areas with more than $100 \mathrm{~W} / \mathrm{m}^{2}$ tidal power densities. Amongst these Ossabaw sound has the largest suitable area of $9.5 \mathrm{~km}^{2}$ with depths between 7 and $9 \mathrm{~m}$ for average tidal power densities higher than $50 \mathrm{~W} / \mathrm{m}^{2}$. The width of this suitable area changes from 0.3 to $1 \mathrm{~km}$ across the channel. At the Savannah River entrance and further inland of Ossabaw and St Catherines Sounds it is possible to find areas where effective tidal power density levels go up to $600 \sim 1000 \mathrm{~W} / \mathrm{m}^{2}$, but these are very small areas $\left(<0.3 \mathrm{~km}^{2}\right)$ when compared to the others.

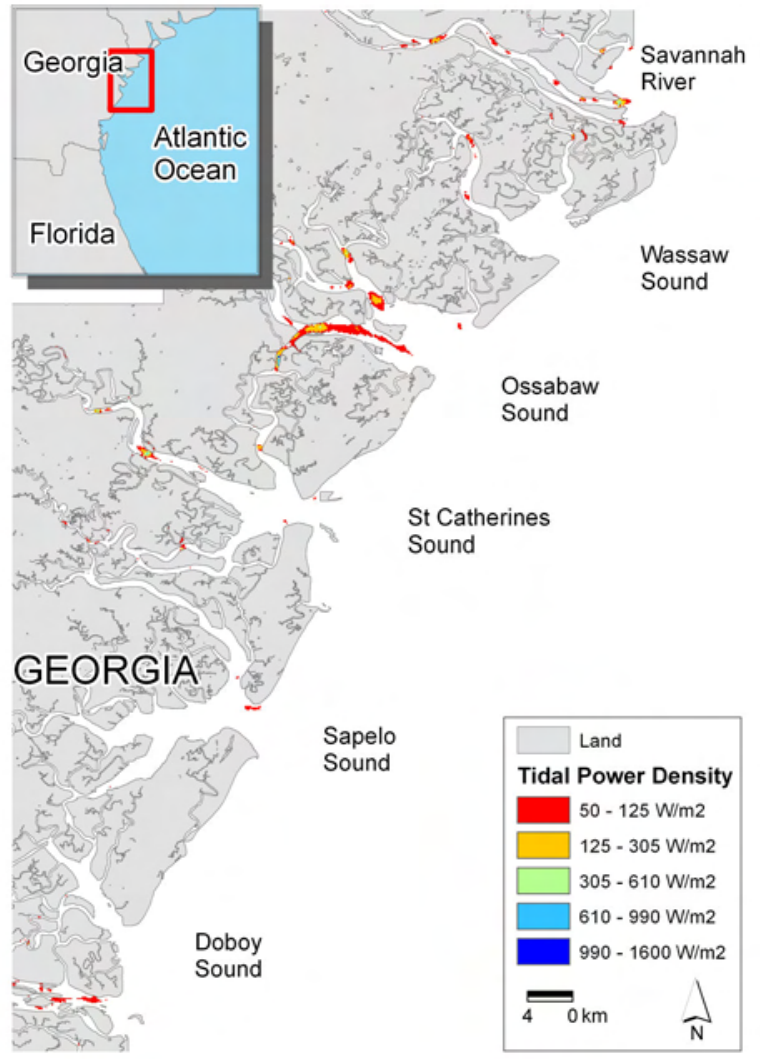

Figure 10. The effective power density using depth filter $h_{\min }=7 \mathrm{~m}$, the efficiency curve in Figure 7 and a minimum power density of $50 \mathrm{~W} / \mathrm{m}^{2}$ for the northern Georgia coast.

\section{CONCLUSION}

The Georgia coast of the USA has a complex geometry with many inlets between barriers. The 133 tidal current prediction stations in the region are not sufficient to resolve all of the flow patterns in this complex network of channels. Modeling results show that the largest tidal power density with a water column depth higher than $7 \mathrm{~m}$ is at the entrance of Cumberland Sound near the border to Florida. The average tidal power density at this location can be as large as $30000 \mathrm{~W} / \mathrm{m}^{2}$. However, the effective tidal power density is shown to be smaller than the available tidal power in regards to the efficiency of energy converters. Further, physical constraints such as the allowable space in the vertical for an energy converter limit the extent of areas that are available for energy conversion. St. Andrews, Altamaha, St. Catherines,
Ossbaw Sounds and Savannah River are the other locations that have patches of areas that satisfy the minimum depth $(>7 \mathrm{~m})$ and minimum tidal power density $\left(>50 \mathrm{~W} / \mathrm{m}^{2}\right)$ criteria. The effective tidal power density in these areas is in the level of $100 \mathrm{~W} / \mathrm{m}^{2}$ based on a typical efficiency curve shown in Figure 7. There are also very small areas at St Catherines Sound, Ossabaw Sound and at the entrance of Savannah River where the average effective tidal power density levels go up to $1000 \mathrm{~W} / \mathrm{m}^{2}$.

Although the modeling provides better spatial resolution, it needs to be verified with any available measurements to make sure that it represents the real physics of the problem. Modeling also provides means to integrate information from different sources such as bathymetry, efficiency of energy conversion devices and many others that have not been discussed here with the tidal modeling results. In the end the data set can be filtered to provide more elucidative findings.

\section{ACKNOWLEDGMENTS}

This research was a part of the InfinitEnergy partnership between colleges, universities, state and local governments, and commercial entities to promote the use of alternative energy technologies. This work was supported by the National Science Foundation, Division of Industrial Innovation and Partnerships (IIP) under the Partnerships for Innovation Program Grant No. 0332613. Funding was also provided by the Strategic Energy Institute at Georgia Tech via a Creating Energy Options grant and the 104B Georgia Water Resources Institute Funding Program, and also by the Department of Energy, Wind and Hydropower Technologies Program award number DE-FG36-08GO18174 and by the state of Georgia.

\section{REFERENCES}

[1] Charlier, R. H., (2003). A "sleeper" awakes: tidal current power. Renewable and Sustainable Energy Reviews, 7(6), 515-529.

[2] EPRI, (2006). North America Tidal In-Stream Energy Conversion Feasibility Study. EPRI-TP-008-NA

[3] EPRI, (2006). Tidal In-Stream Energy Resource Assessment for Southeast Alaska. EPRI-TP-003-AK

[4] EPRI, (2006). Maine Tidal In-Stream Energy Conversion (TISEC): Survey and Characterization of Potential Project Sites. EPRI-TP-003-ME

[5] EPRI, (2006). Massachusetts Tidal In-Stream Energy Conversion (TISEC): Survey and Characterization of Potential Project Sites. EPRI-TP-003-MA

[6] EPRI, (2006). New Brunswick Tidal In-Stream Energy Conversion (TISEC): Survey and Characterization of Potential Project Sites. EPRITP-003-NB

[7] EPRI, (2006). Nova Scotia Tidal In-Stream Energy Conversion (TISEC): Survey and Characterization of Potential Project Sites. EPRI-TP-003-NS

[8] EPRI, (2006). Methodology for Estimating Tidal Current Energy Resources and Power Production by Tidal In-Stream Energy (TISEC) Devices. EPRI-TP001-NA-Rev-3

[9] NOS, (2008). Tidal Current Predictions, http://tidesandcurrents.noaa.gov/curr pred.html 
$2^{\text {nd }}$ International Conference on Ocean Energy (ICOE 2008), $15^{\text {th }}-17^{\text {th }}$ October 2008, Brest, France

[10] Shchepetkin, A. F. and McWilliams, J. C., (2005). The Regional Ocean Modeling System (ROMS): A split-explicit, free-surface, topography-following coordinates ocean model. Ocean Modelling, 9, 347404.

[11] Haidvogel, D. B., Arango, H.G., Budgell, W. P., Cornuelle, B. D., Curchitser, E., Di Lorenzo, E., Fennel, K., Geyer, W. R., Hermann, A. J., Lanerolle, L., Levin, J., McWilliams, J. C., Miller, A. J., Moore, A. M., Powell, T. M., Shchepetkin, A. F., Sherwood, C. R., Signell, R. P., Warner, J. InfinitEC., Wilkin, J., (2008). "Regional Ocean Forecasting in Terrainfollowing Coordinates: Model Formulation and Skill Assessment." Journal of Computational Physics.

[12] Durran, Dale R., (1999). Numerical methods for wave equations in geophysical fluid dynamics, New York etc, Springer.

[13] NGDC, (2008). Coast Line Extractor, http://rimmer.ngdc.noaa.gov/coast/

[14] NOS, (2008). Office of Coast Survey US Bathymetric \& Fishing Maps, http://map.ngdc.noaa.gov/website/mgg/fishmap/

[15] NOAA, (2008). Tides and Currents, Tidal Datums, http://tidesandcurrents.noaa.gov/datum_options.html

[16] Denham, C. R., (2008). SeaGrid Orthogonal Grid Maker for Matlab,

http://woodshole.er.usgs.gov/staffpages/cdenham/pub $\underline{\text { lic html/seagrid/seagrid.html }}$

[17] Mukai, A. Y., Westerink, J. J., Luettich, R. A. and Mark, D., (2002). Eastcoast 2001, A Tidal Constituent Database for Western North Atlantic, Gulf of Mexico, and Caribbean Sea. ERDC/CHL TR02-24

[18] Pawlowicz, R., Beardsley B., and Lentz S., (2002). Classical tidal harmonic analysis including error estimates in MATLAB using T_TIDE, Computers and Geosciences 28, 929-937.

[19] ESRI, (2008), GIS Mapping and Software, ArcView. http://www.esri.com/software/arcgis/arcview/about/fe atures.html 